\title{
Mobilising investment in energy efficiency
}

Economic instruments
for low-energy buildings 
The International Energy Agency (IEA), an autonomous agency, was established in November 1974. Its primary mandate was - and is - two-fold: to promote energy security amongst its member countries through collective response to physical disruptions in oil supply, and provide authoritative research and analysis on ways to ensure reliable, affordable and clean energy for its 28 member countries and beyond. The IEA carries out a comprehensive programme of energy co-operation among its member countries, each of which is obliged to hold oil stocks equivalent to 90 days of its net imports. The Agency's aims include the following objectives:

- Secure member countries' access to reliable and ample supplies of all forms of energy; in particular, through maintaining effective emergency response capabilities in case of oil supply disruptions.

- Promote sustainable energy policies that spur economic growth and environmental protection in a global context - particularly in terms of reducing greenhouse-gas emissions that contribute to climate change.

- Improve transparency of international markets through collection and analysis of energy data.

Support global collaboration on energy technology to secure future energy supplies and mitigate their environmental impact, including through improved energy efficiency and development and deployment of low-carbon technologies.

Find solutions to global energy challenges through engagement and dialogue with non-member countries, industry, international organisations and other stakeholders.

IEA member countries:

\section{Austria}

Belgium

Canada

Czech Republic

\section{Denmark}

Finland

France

Germany

Greece

Hungary

Ireland

Italy

Japan

Korea (Republic of)

Luxembourg

Netherlands

New Zealand

Norway

Poland

Portugal

(c) OECD/IEA, 2012

\section{International Energy Agency}

9 rue de la Fédération

75739 Paris Cedex 15, France

www.iea.org

Please note that this publication

Slovak Republic

Spain

Sweden

Switzerland

Turkey

United Kingdom

United States

The European Commission

also participates in

the work of the IEA. 


\section{Table of Contents}

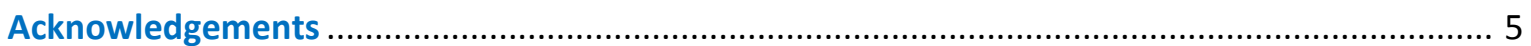

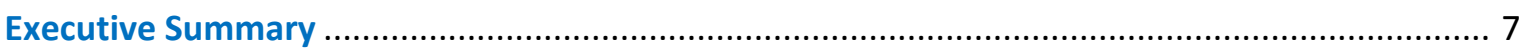

Economic instruments in energy efficiency policy ............................................................. 8

Economic instruments for low-energy buildings................................................................. 8

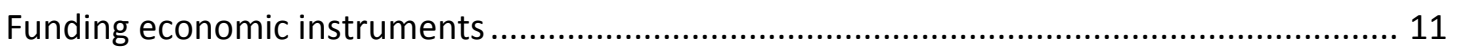

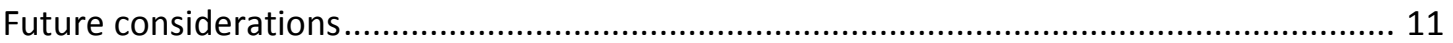

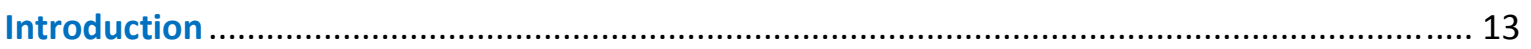

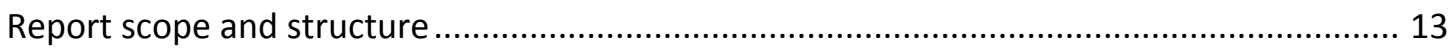

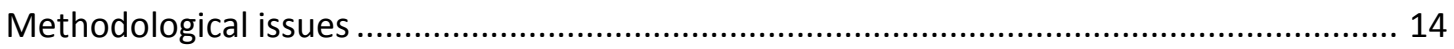

PART I: Economic instruments in energy efficiency policy ..................................................... 15

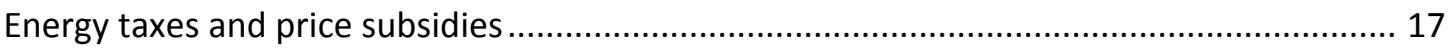

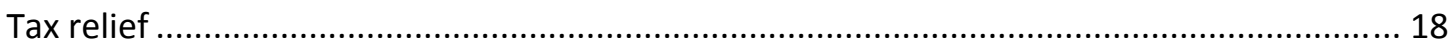

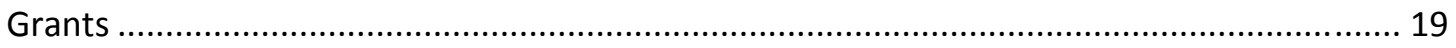

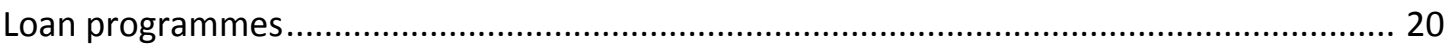

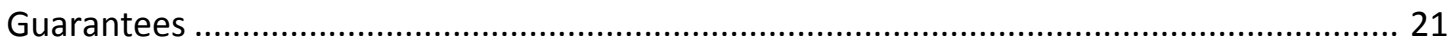

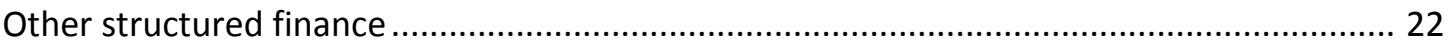

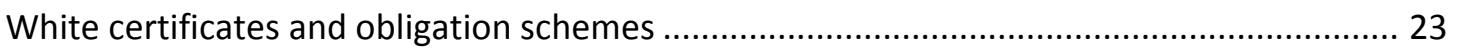

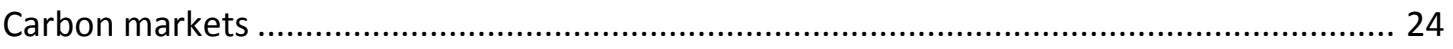

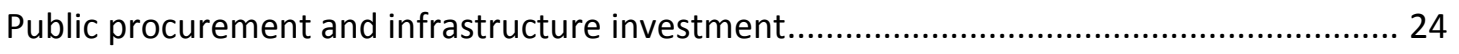

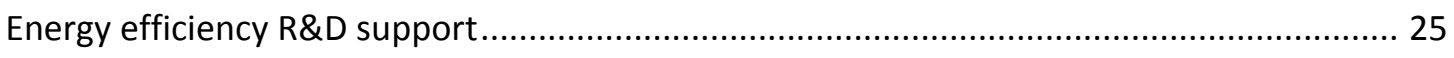

PART II: Economic instruments to mobilise investment in energy efficiency in buildings .......... 26

II.1 Introduction to the buildings sector and energy efficiency policy ................................... 26

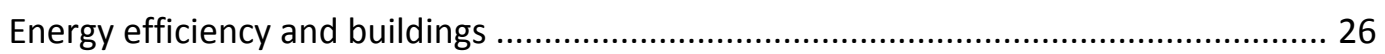

The role of governments to reduce energy consumption in buildings ........................... 28

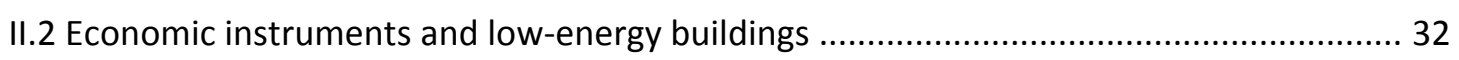

Energy taxes and price subsidies ............................................................................... 33

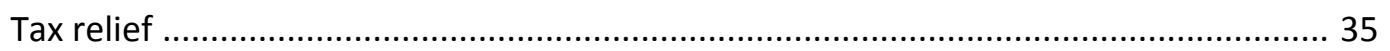

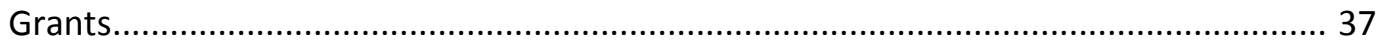

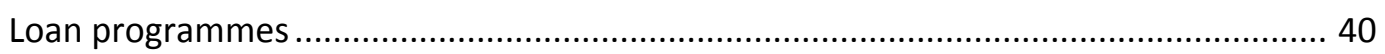

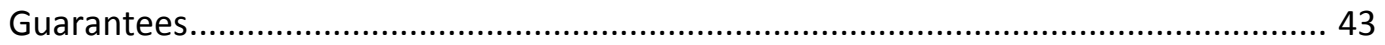

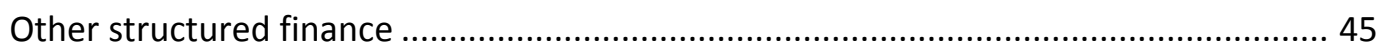

White certificate markets and obligation schemes ……............................................... 53

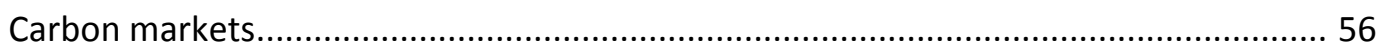

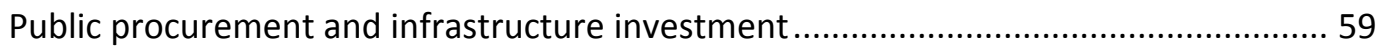

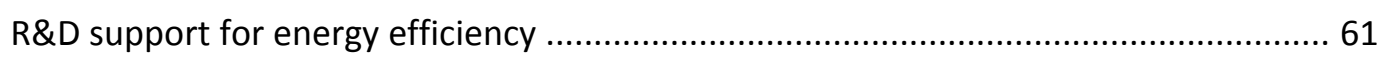

II.3 Discussion of current use of economic instruments for low-energy buildings ..................63 63

II.4 Moving towards deep retrofit - how can economic instruments help? ............................6 64

II.5 Selection and design of economic instruments for low-energy buildings ........................66 66 


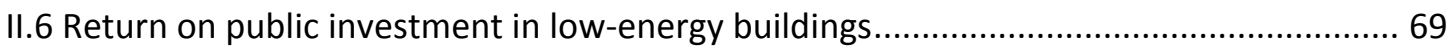

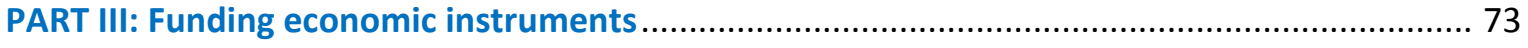

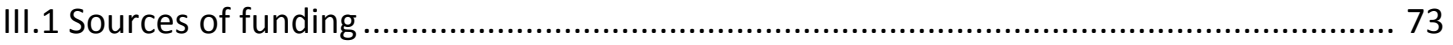

General budget allocations and earmarked tax revenues and charges ......................... 74

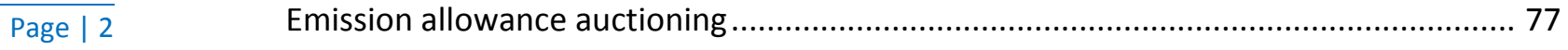

Institutional investing and private investment funds ................................................. 80

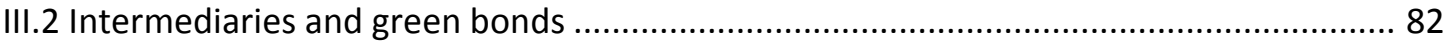

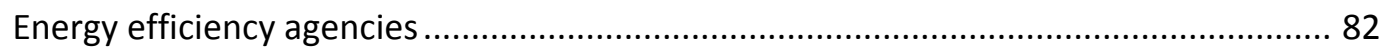

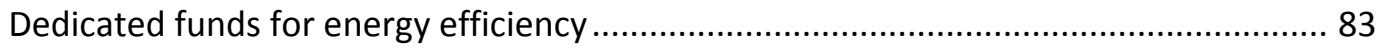

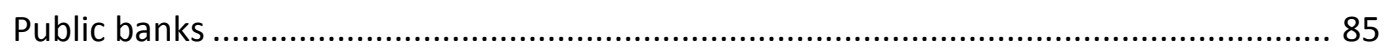

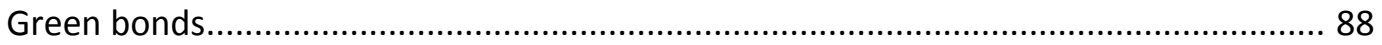

III.3 Discussion of funding for low-energy buildings ........................................................ 90

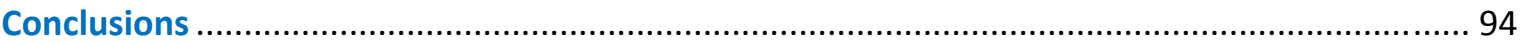

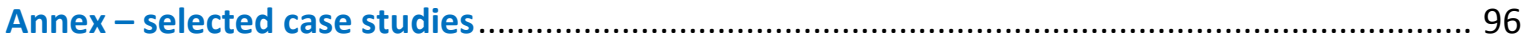

Canada: ecoENERGY Retrofit - Homes Program ................................................................... 97

France: Eco-PTZ green loan and tax incentives ............................................................... 103

Germany: KfW loans and grants for energy efficiency in residential buildings .................... 114

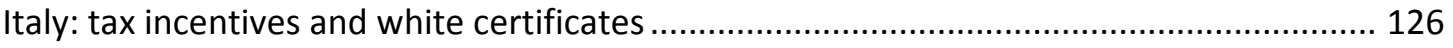

Ireland: Home Energy Saving Scheme grants .................................................................... 136

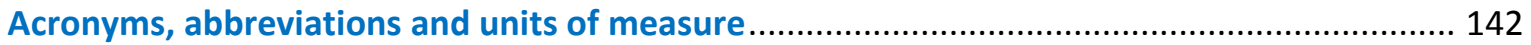

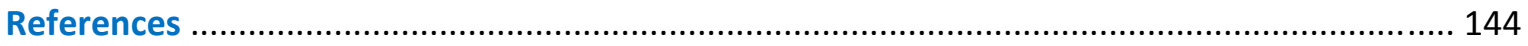

\section{List of Figures}

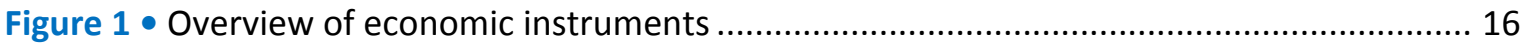

Figure 2 - RD\&D national public spending for EE in buildings, appliances and equipment ........... 62

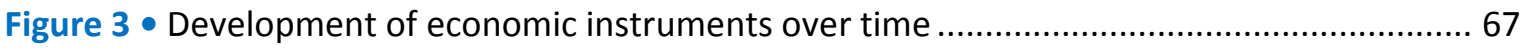

Figure 4 - Design options for government involvement in loans for low-energy buildings ............ 68

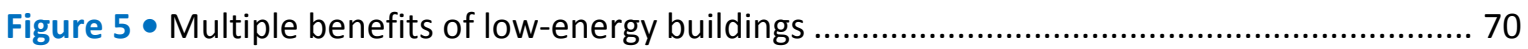

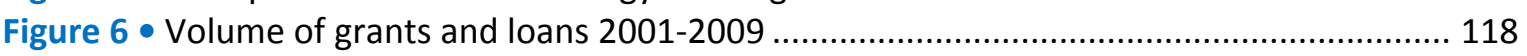

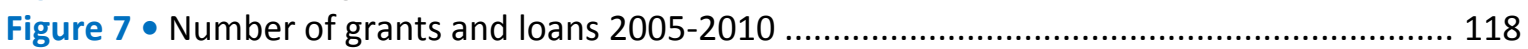

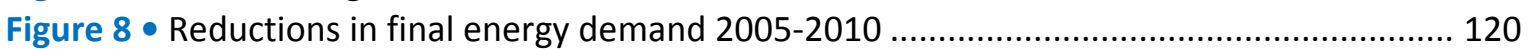

Figure 9 • Avoided CO2 equivalent emissions cumulated 2005-2010 ......................................... 121

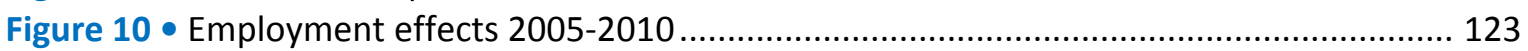

Figure 11 • Percentage effectiveness of energy efficiency measures ......................................... 134

\section{List of Tables}

Table 1 • IEA member countries with highest taxes on household energy in 2011........................ 33

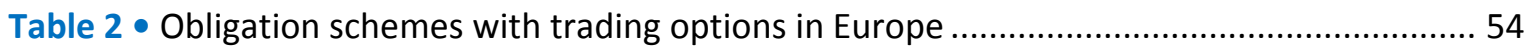

Table 3 • Comparison of economic instruments for low-energy buildings .................................... 71

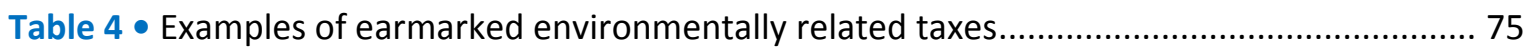

Table 5 • Comparing charges, earmarked taxes and general budget allocations ............................ 77

Table $6 \bullet$ Overview of existing emission trading schemes ............................................................ 78

Table 7 • Examples for Green Investment Schemes in Hungary, Latvia and Czech Republic.......... 80 
Table 8 - The market premium of green commercial buildings in the United States and Australia 81

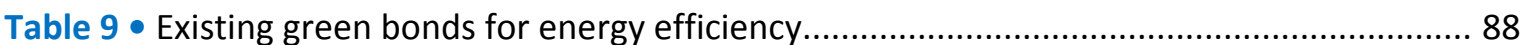

Table 10 - Summary of funding sources for economic instruments for energy efficiency ............. 92

Table $11 \bullet$ Residential Energy Use and Energy Savings per Household, Pre-1945 to 2000-2009 99

Table 12 • Summary of ecoENERGY retrofit - Homes programme April 2007-2012 _................... 102

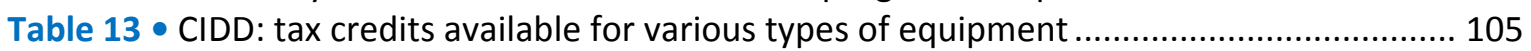

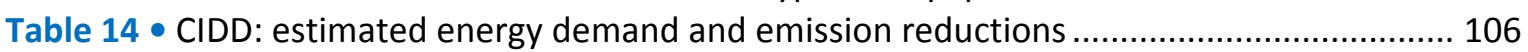

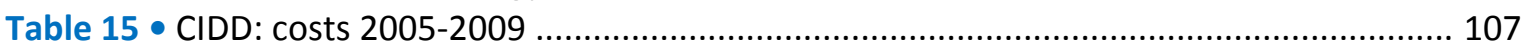

Table 16 • Eco-PTZ: eligible measures and maximum loan sizes and terms ................................ 109

Table 17 • Eco-PTZ: uptake and characteristics of loans ............................................................ 111

Table 18 • "CO2 refurbishment of buildings" and "Energy efficient refurbishment":

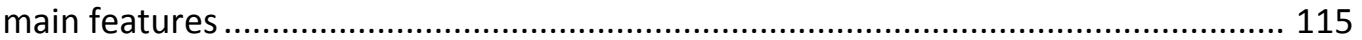

Table 19 • Measures undertaken in buildings participating in the programmes 2005-2010....... 119

Table 20 Estimated ratio of public costs to energy and emission savings ................................ 122

Table 21 Total impact in millions of Euros according to the two employment scenarios .......... 124

Table 22 Annual energy savings achieved in 2010 compared to targets for 2010 and $2016 \ldots 126$

Table 23 - Cumulative Targets for the Italian White Certificate System (Mtoe/year) ................. 129

Table 24 Energy savings achieved through White Certificates by 30 September 2010............. 130

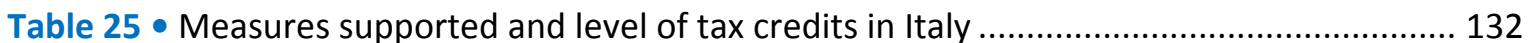

Table 26 • Claims and investment supported by the Italian tax credits, 2009............................. 132

Table 27 • Performance indicators of the 55\% tax deduction programme................................. 133

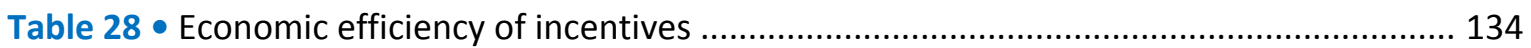

Table 29 Measures and grant amounts under the Home Energy Saving (HES) Scheme ........... 137

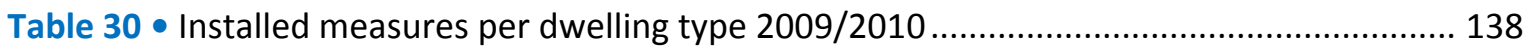

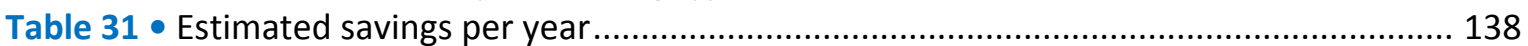

Table 32 • Value of awarded tax credits = government revenue foregone (Euros) ...................... 139

Table 33 • Overview of Cost-Benefit Analysis results (including sensitivity analysis) .................. 140

\section{List of Boxes}

Box $1 \bullet$ Definition of low-energy buildings and deep retrofit of buildings .................................... 28

Box 2 - Investment needed globally to reduce energy consumption of buildings by $2050 \ldots \ldots \ldots . . . .31$

Box 3 - Experiences with the use of household energy taxes in Denmark .................................... 35

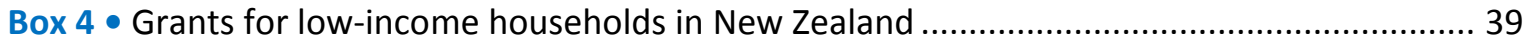

Box $5 \bullet$ Experiences with green loans from Australia.............................................................. 43

Box 6 - Experiences with risk-sharing facilities in Eastern and Central Europe for residential

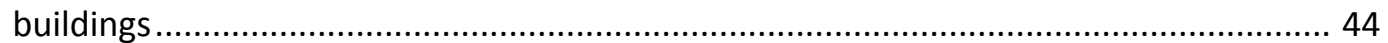

Box 7 Experiences with on-bill financing in the United States.................................................. 46

Box 8 - New on-bill financing initiative in the United Kingdom: the Green Deal........................... 47

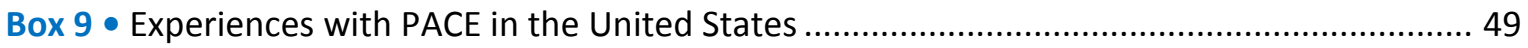

Box $10 \bullet$ ESCO market and performance contracting in the United States.................................... 52

Box $11 \bullet$ Emission trading for buildings: The Tokyo urban cap-and-trade programme ................. 57

Box 12 - CDM Programme of Activities for sustainable housing in Mexico .................................... 58

Box 13 - German experience in earmarking revenues from ETS allowance auctioning ................. 79

Box $14 \bullet$ Private investment funds and energy efficiency: The Climate Change Property Fund.... 81

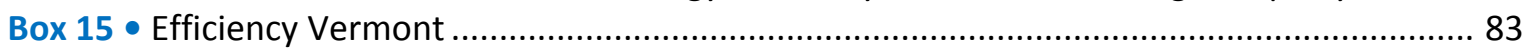


Box 16 European Union funds used for energy efficiency finance ........................................ 85

Box 17 Experience with public banks from Germany and United Kingdom ............................. 87

Box 18 - Qualified Energy Conservation Bonds in the United States ...........................................90

Box 19 - The role and functioning of the SGFGAS in France ................................................ 110

Box 20 - The German Energy Savings Ordinance (EnEV)................................................. 114

Page | 4

Box $21 \bullet$ Application procedures

Box 22 - ENEA: Italy's agency for new technologies, energy and sustainable economic development. 


\section{Acknowledgements}

The main authors of this report are Anuschka Hilke (previously of the IEA) and Lisa Ryan of the Energy Efficiency Unit in the Sustainable Technology Policy Directorate of the IEA. Charlotte Forbes and Ellina Levina made substantial contributions in the early conception of the project. In addition, Charlotte Forbes provided background research and compilation of information on economic instruments used in IEA countries to improve the energy efficiency of buildings. Ellina Levina authored the case study on Italy.

The authors are grateful for the guidance and support given by Robert Tromop, as head of the Energy Efficiency Unit, and Philippe Benoit, head of the Energy and Environment Division, and for their considered review of the work. Bo Diczfalusy, director of the Sustainable Technology and Policy Directorate provided leadership and overall encouragement.

We are also particularly grateful for the time taken to review this report by IEA colleagues: Grayson Heffner, Christina Hood, Marc Lafrance, Yamina Saheb, Cecilia Tam; and by OECD colleagues also: Nils-Axel Braathen, Christopher Kaminker, and Virginie Marchal.

The IEA would like to thank participants in the workshop hosted by the IEA on "The Future of Energy Efficiency Finance" in March 2012, which included presentations on the topics discussed here. ${ }^{1}$

Many of these participants also provided review comments on the final report as part of an extensive consultation and review process in developing this publication. We particularly thank the following people for their reviews and contributions to the workshop and document:

Bogdan Atanasiu, BPIE

Mélanie Barcet and Colas Paris, Ministère de l'Ecologie, du Développement Durable et de I'Energie, France

Catherine J. Bell, American Council for an Energy-Efficient Economy

Murray Birt, Deutsche Bank Group

Ben Caldecott, Climate Change Capital

Dean Cooper, United Nations Environment Programme, Division of Technology, Industry and Economics

Susanne Dyrboel, Rockwool International A/S

Alessandro Federici, ENEA

Agime Gerbeti, Gestore dei Servizi Energetici - GSE S.pp. a.,

Martin Gaudet, Debra Haltrecht, Victoria Ingram, Phil Jago, Ann Kowal, Renée Lazarowich, Claude Lefrançois, Laura Oleson, Siddiq McDoom, Kelly Smith, Natural Resources Canada

Ingrid Holmes, E3G

Bret Kadison, Rosebud Capital

Alexandra Langenheld and Paolo Bertoldi, Joint Research Centre, European Commission

Dilip R. Limaye, SRC Global Inc.

Vivien Lo, Gudrun Gumb, Rudolf Hennes, Martin Müller and Markus Schönborn, KfW Bank Maria Mendiluce and Philippe Fonta, World Business Council for Sustainable Development Murray Birt, Deutsche Bank Group

Robert Nuij and Roman Doubrava, DG Energy, European Commission

Karsten Neuhoff, DIW Berlin

Christine Patterson, Energy Efficiency and Conservation Authority, New Zealand

Robin Reid, World Economic Forum

\footnotetext{
${ }^{1}$ http://www.iea.org/newsroomandevents/workshops/workshop/name,14184,en.html
} 
Nick Robins, HSBC Bank Plc

Stephane de la Rue du Can, Laurence Berkeley National Laboratory

Jim Scheer and Josephine Maguire, Sustainable Energy Authority of Ireland

Thomas Schubert, European Commission, DG Research

Mikael Skou Andersen, European Environment Agency

Page | 6 Peter Sweatman, Climate Strategy and Partners

Matthew Wittenstein, Molly Lunn, Johanna Zetterberg and John Cabaniss, United States Department of Energy.

The resulting document is the IEA interpretation of these workshops, with additional information incorporated to provide a more complete picture, and does not necessarily represent the views of all the workshop participants and reviewers.

This publication has benefitted from the inputs of Angela Gosman, Marilyn Smith, Astrid Dumond, Muriel Custodio, Cheryl Haines, and Rebecca Gaghen in the IEA Communications and Information Office. Jenny Gell and Audrey Glynn formatted the report. 


\section{Executive Summary}

Taxes, loans and grants, trading schemes and white certificates, public procurement and investment in R\&D or infrastructure: known collectively as "economic instruments", these tools can be powerful means of mobilising the finances needed to achieve policy goals by implementing energy efficiency measures. The role of economic instruments is to kick-start the private financial markets and to motivate private investors to fund EE measures. They should reinforce and promote energy performance regulations.

This IEA analysis addresses the fact that, to date, relatively little effort has been directed toward evaluating how well economic instruments work. Using the buildings sector to illustrate how such measures can support energy efficiency, this paper can help policy makers better select and design economic instruments appropriate to their policy objectives and national contexts.

This report's three main aims are to:

- Examine how economic instruments are currently used in energy efficiency policy;

- Consider how economic instruments can be more effective and efficient in supporting low-energy buildings; and

- Assess how economic instruments should be funded, where public outlay is needed.

The purpose of economic instruments in energy efficiency policy is to provide financial incentives to invest in energy efficiency measures through price and investment signals. The signals may be in the form of incentives (e.g. via subsidies in the form of a grant, a concessional loan or some form of direct public investment) or disincentives (e.g. through price increases via taxes or the creation of a market for energy efficiency certificates). Economic instruments can also be used to increase the amount of finance available or to improve financing terms (e.g. through reduced interest rates, the unlocking of third-party finance or dedicated credit lines).

Economic instruments can be clustered into four categories, each of which has specific advantages in some contexts:

- Fiscal instruments:

○ taxes

- tax reliefs

- Financial measures:

○ loans

o grants

- Trading schemes:

- emissions trading schemes

○ white certificates

- Direct investment:

- public procurement

- public investment in R\&D

$\circ$ investment in public infrastructure.

This report is structured in three parts: (i) a taxonomy of economic instruments used in energy efficiency policy; (ii) the use of economic instruments to achieve low-energy buildings; and (iii) how these economic instruments are funded when public funds are needed. As a broad introduction, the first section describes and compares the main design features of each economic instrument. The second section investigates how economic instruments are used to improve the 
energy performance in the buildings sector, providing insights as to which is likely to be effective in different circumstances or to overcome specific barriers to energy efficiency. The final section explores how economic instruments in energy efficiency policy can be funded and/or raise revenue. The first and third sections are cross-sectoral, and relevant for improving energy efficiency in all sectors. The middle section provides lessons learned from implementing economic instruments specifically to support the finance of low-energy buildings. Many of the experiences in the buildings sector will surely be useful to policy makers seeking to improve energy efficiency in other sectors.

\section{Economic instruments in energy efficiency policy}

Economic instruments are used by all IEA country governments in energy efficiency policy to address barriers such as externalities, split incentives, perceived high investment risk, lacking access to finance, high transaction costs and behavioural issues.

Some general lessons can be drawn from experiences with economic instruments in energy efficiency policy to date.

- When part of a well-designed and coherent policy package, economic instruments have better potential to deliver maximum impact on the market and to be economically efficient. The policy package should also include minimum energy performance standards or regulations, information and awareness-raising measures, and capacity building.

- Barriers that need to be overcome to encourage investment should underpin the choice and design of economic instruments for energy efficiency. Other determining factors include the sector(s) to be addressed, national circumstances and other policies in place.

- As energy prices are drivers for investment in energy efficiency, the use of energy taxes and removal of energy price subsidies are prerequisites to putting in place any public financing programme or other subsidies.

- Tax relief and grants can act as "sweeteners" to encourage investment in energy efficiency that might otherwise not take place but are likely to leverage only smaller investments.

- Public funds and guarantees provide access to finance as the energy efficiency market develops and larger investments are encouraged or mandated. Finance may be combined with incentives to encourage uptake of the programme.

- Public-private financing instruments open up new ways of financing, enabling people to invest in energy efficiency measures that might not be eligible for regular bank loans.

To date, thorough evaluations of economic instruments have been rare, even though these instruments are widely used in IEA member countries. Most reporting on government programmes focuses only on outcomes in terms of related costs and programme participants; real-life impacts are rarely assessed and at best modelled. Diverging indicators and metrics used in the few available evaluations make it difficult to conduct a comparative analysis of impacts generated through government programmes. This paper aims to address gaps in knowledge, advance understanding and identify areas for future investigation.

\section{Economic instruments for low-energy buildings}

Making the buildings sector more energy-efficient is a global challenge of increasing urgency. The buildings sector represents $32 \%$ of global final energy consumption and recent trends show 
annual demand growth at almost $2 \%$. While many cost-effective measures to deliver energy savings have been identified for both new and existing buildings, implementation is hindered by a number of sector-specific barriers. Policy makers need to put in place a strong and enabling policy framework, comprising regulation, information and economic instruments, in order to mobilise the estimated USD 11.5 trillion needed on a global level up to 2050 to drastically reduce the energy consumption in buildings compared with business-as-usual.

Policy goals should be set to deliver nearly zero-energy new buildings and deep retrofit of existing buildings. As the rate of construction of new buildings is low in IEA countries, deep retrofits of the existing building stock will play the crucial part in reducing energy consumption from the buildings sector.

All IEA countries have at least one economic instrument in place to support energy-efficient buildings. ${ }^{2}$ Historically, energy taxes, grants and tax relief have been the schemes favoured by most governments.

Current targets and eligibility requirements attached to the economic instruments used for energy efficiency in buildings are, with few exceptions, not very ambitious. This analysis shows that there is a strong focus on low-cost and quick wins through the replacement of equipment (lighting and HVAC), rather than improvements in the building envelope or whole building energy performance. Subsidies have been mainly attached to requirements for eligible energy efficiency technologies and do not take a whole-building approach. It is difficult to find examples of economic instruments or subsidies that apply to ambitious levels of overall building performance improvements, although some do exist (e.g. the KfW loan scheme in Germany).

So far efficiency improvements of $10 \%$ to $30 \%$, rather than truly low-energy buildings, have been delivered through most programmes. On average, greater improvements in energy efficiency are likely to be needed across the buildings stock (amounts will vary for each building, depending on type, location and other factors). Achieving only $20 \%$, for example, can be expected to have a lock-in effect that results in unrealised energy savings potential over the next decades. Economic instruments are needed that enable and incentivise deeper energy retrofits, whether voluntary or mandated.

More ambitious and targeted deep cuts in energy consumption for retrofit of buildings should be the core element of energy efficiency policy. Governments should design economic instruments that:

(i) Provide greater access to finance for deep retrofit of buildings: policy makers need to replace or complement direct subsidies as incentives for individual energy efficiency measures and equipment with financing instruments that are tied to significant cuts in whole building energy performance.

(ii) Support private investment in low-energy buildings by:

- Setting up loan programmes directly through public banks or financial institutions, with preferential rate loans where needed;

- Assisting financial institutions with risk guarantees or credit lines until they have built up experience;

- Encouraging the private sector through changes to legal requirements that facilitate public procurement, energy performance contracting, on-bill financing or other third-party finance.

\footnotetext{
${ }^{2}$ Available at http://www.iea.org/policiesandmeasures/energyefficiency/
} 
In all cases, government support should be tied to ambitious energy performance improvements in line with a deep retrofitting strategy.

(iii) Focus on whole building energy performance: even when a step-by-step refurbishment approach is taken, an integrated assessment of efficiency potential for the whole building should be carried out so that early refurbishment steps do not impede later ones.

(iv) Address split incentives: the landlord-tenant problem is likely to be resolved only through mandatory retrofitting obligations. The issue of the full costs being recouped over the long term can be addressed through financing mechanisms that attach the loan to the property, rather than to the initial investor.

(v) Encourage higher renovation rates: incentives will play an important role in encouraging investors to undertake renovation and deep retrofit. Unless future regulatory requirements or significant energy price hikes are expected, it is unlikely, however, that any financial incentive on its own would be large enough to encourage the depth of retrofit needed in many buildings.

(vi) Time the economic instruments to match the development of mandatory standards and the market for low-energy buildings: at an early stage of awareness and implementation of low-energy buildings (i.e. before introducing ambitious energy codes for existing buildings), energy taxes and grants and/or tax relief can encourage early movers to invest. Any announcement of future stringent energy performance buildings regulations should be combined with straightforward access to finance with favourable terms, which might include some incentives. Once ambitious energy performance requirements are in place for renovation, subsidies should not be required; however, financial arrangements and guarantees are needed to encourage private sector investment in the market. Any public finance should be referenced to the building energy codes in force or planned, and should not establish alternative metrics in parallel.

Monitoring and evaluation are key to understanding the effectiveness and efficiency of economic instruments, and to making necessary adjustments to improve their impact. Monitoring and evaluation, including the definition of a baseline starting point and targets to be achieved, need to be part of the design of economic instruments. Close monitoring of real costs and uptake of the programme can give early indications of design flaws. Regular evaluations help to ensure the programme is meeting its targets and, eventually, to identify necessary changes.

Training and capacity building are needed at many levels to complement effective policy design. Financial institutions need greater capacity to assess risks and potentials attached to energy efficiency investments. Public institutions need training for the smooth implementation of programmes. Assessors need to be trained and certified to carry out building energy efficiency audits to a high standard in terms of accuracy so that audits are credible as a basis for programmes or loan applications.

Experience to date with innovative financial mechanisms should be useful in determining the instruments needed to develop long-term financing options for deep retrofits. Multiple innovative approaches have been developed in recent years, such as preferential rate loans, onbill and financing through initiatives such as the Property Assessed Clean Energy (PACE) programme in the United States. Detailed case studies in this report assess examples of economic instruments for energy efficiency in the buildings sector in Canada (grants), France (tax relief and loans), Germany (loans and grants), Ireland (grants) and Italy (white certificates and tax relief). 


\section{Funding economic instruments}

Some economic instruments require outlay of public budget. Grants, loans and tax relief require budgets, which can be made up of a mix of public and private funds. The funding may even be raised from other economic instruments such as taxes and emissions trading auction revenues.

A range of public funding sources can be used to fund economic instruments, including budget allocations, dedicated funds, public banks, earmarked taxes and charges, and revenues from emission allowance auctioning. Private sources of funds such as institutional investors and private investment funds can be blended with public resources to fund economic instruments. These options are equally valid for energy efficiency projects beyond the buildings sector.

Policy makers should consider several factors when deciding appropriate sources of funding streams for energy efficiency economic instruments, each of which is examined in more detail in the paper:

- stability and sustainability of the funding stream;

- least overall cost to society - including public and private costs;

- split between costs paid by public and private sectors;

- administrative simplicity;

- ability to leverage private funds; and

- public budget constraints.

The long-term goal should be to engage the private sector such that the energy efficiency market becomes self-sustaining. Financial institutions need to recognise energy efficiency investments as a source of valuable new clients and deals; yet to work in this market, they must have the capacity to evaluate the risk associated with different investments. Policy makers need to develop partnerships with financial institutions to build familiarity and trust in the business case for energy efficiency investments.

\section{Future considerations}

This report finds that investments in energy efficiency measures are low-risk and can provide high returns to investors and lenders. Financial instruments have the advantage of being less capital-intensive for the public budget, leveraging more private investments and providing more stable long-term financing opportunities. Governments could help motivate the financial sector to invest in low-energy buildings by building up evidence and good practices in three main areas:

- Accumulate proof that default rates of loans for low-energy buildings are low and present a low-risk investment opportunity;

- Monetise the multiple benefits attached to energy efficiency investments and standardise methodologies to complete cost-benefit assessments of investment; and

- Develop rating criteria for energy efficiency investments to increase attractiveness to large investors.

The lessons learned from this evaluation and the relevant case studies can be transferred and adapted to other sector and country contexts. While regulations will continue to play a key role in creating demand for ambitious energy efficiency, economic instruments and private finance will be crucial in meeting that demand. Without stringent energy performance requirements, economic instruments are unlikely to deliver enough of an incentive to mobilise the finance needed for dramatic reductions in energy consumption. 
Better evaluation and data related to the technical and financial requirements of low-energy buildings are needed to be able to assess properly the design of finance to meet longer term policy goals for low-energy buildings. Also the wider societal benefits associated with low-energy buildings should be estimated and internalised in interest rates for finance of energy efficiency measures in the buildings sector.

Page | 12 Public investments in energy efficiency yield more than energy savings alone. The return on public investment can include increased well-being, economic development, energy security, health, and other societal benefits well into the future. Policy makers should take a wide view and consider these benefits in designing and funding more ambitious policy instruments to improve energy efficiency. 


\section{Introduction}

The IEA project on economic instruments for the promotion of higher energy efficiency aims to identify effective ways of mobilising increased investment in energy efficiency, by evaluating the use of economic instruments across different sectors. This analysis should help policy makers from relevant institutions (such as energy, economy, finance or environment ministries) better understand, select and design appropriate economic instruments to improve energy efficiency in individual sectors. Future reports under this project will focus on the transport and industrial sectors.

This report focuses on the use of economic instruments to support energy efficiency, particularly in the buildings sector. The objectives of the report are to:

- Examine how economic instruments are currently used to improve energy efficiency, with a particular focus on improving the energy performance of buildings in IEA countries;

- Consider the most effective and efficient use of economic instruments to drive forward low-energy buildings; and

- Identify the sources of public funding of economic instruments, where subsidies are needed.

It should draw out insights for policy makers trying to identify and design the most applicable policies for their national circumstances to improve energy efficiency, not only in buildings, but also in other sectors where similar conditions exist.

\section{Report scope and structure}

This report examines the experience with economic instruments in energy efficiency policy. It is targeted at policy makers developing energy efficiency policy in the buildings and other sectors.

This first section presents economic instruments relevant to energy efficiency policy. It describes the range of economic instruments used in energy efficiency policy generally and outlines the main features of each. It should provide some background on economic instruments and their strengths and weaknesses.

The second section investigates how economic instruments are used to improve the energy performance of one sector in particular, the buildings sector. In this instance, the buildings sector serves to examine more closely the use of economic instruments in practice. This section provides a systematic overview of the effectiveness of existing economic policies in delivering low-energy buildings in IEA member countries. The focus is on policies for the energy efficiency (EE) refurbishment of existing buildings, and in particular deep retrofit, which is the priority in IEA countries, even though in some cases also policies for new buildings are covered.

The third section of the report provides an overview of possible funding sources and the relevant intermediaries for economic instruments where applicable to energy efficiency policy. Economic instruments are made up of revenue raisers, i.e. taxes, charges, and trading schemes; and subsidies. The public funding part of the report focuses on the source of funds for the subsidies part of economic instruments. The discussion of the different approaches to funding energy efficiency is enriched by a wide range of examples from experiences in IEA countries.

The first and third sections are cross-sectoral and relevant for improving energy efficiency in all sectors. The middle section provides lessons learned from implementation of economic instruments to improve the energy efficiency specifically in the buildings sector. It examines 
whether the current crop of economic instruments is delivering the deep cuts in energy consumption in buildings needed and how economic instruments should be adapted to mobilise the finance that will be required in the future.

\section{Methodological issues}

The initial information on existing economic instruments has been obtained mainly from the current IEA policies and measures (PaMs) database on energy efficiency. ${ }^{3}$ This database provides an overview of economic instruments currently in operation in IEA countries to support energyefficiency measures; these have been verified by corresponding with countries through the IEA Energy efficiency Working Party government delegates and cross-checked with the OECD economic instruments database. ${ }^{4}$ In some countries, the same instruments are used to promote renewable energy and the distinction has been made where possible.

The information was completed by a literature review of evaluations of economic instruments and funding mechanisms in the buildings sector. For selected countries (France, Germany, Ireland, and Italy), in-depth case studies of country experiences with different types of economic instruments and funding mechanisms were developed with input from policy makers in the respective countries. The case studies evaluate the effectiveness and efficiency of different policy instruments using an evaluation matrix developed by the authors. First results, as well as evaluation methods and case studies, were discussed during an expert workshop, which took place on 15 March 2012 in Paris, France. ${ }^{5}$

Very few thorough evaluations of economic instruments in energy efficiency policy are available that would facilitate benefit-cost ratio comparisons. The available sources do not allow general recommendations on which policies are most effective or efficient. In many cases, evaluations include more outcome-related indicators (e.g. public spending, number of programme participants) than impact-related indicators (reduction in energy demand, rebound effects, freeridership ${ }^{6}$ ) and where these are available, they are in many cases based on surveys of a small sample of programme participants and report the technical potentials of policies rather than reallife savings achieved. Additionally, the indicators used in available evaluations in different programmes are too different to allow a comparative analysis. ${ }^{7}$ Often baselines are not defined at the start of programs and then it is hard to evaluate what changes have occurred from the baseline as a result of this programme. Due to the lack of comparable data, the analysis remains qualitative and descriptive but should nevertheless provide insights for policy makers developing strategies to dramatically improve the energy performance in buildings and other sectors.

\footnotetext{
${ }^{3}$ Available at www.iea.org/policiesandmeasures/

${ }^{4}$ www.oecd.org/env/policies/database

${ }^{5}$ For documentation of the workshop see: www.iea.org/newsroomandevents/workshops/name,14184,en.html

${ }^{6}$ Rebound effect or "take-back" effect is when improvements in energy efficiency do not realise the expected energy savings due to either more intensive activity (the direct rebound effect) or reinvestment of the financial savings in other energyintensive activities or services. Free-ridership is the phenomenon of investors taking advantage of a subsidy even though they would have invested in the energy-efficient measure in the absence of the incentive. This means that the subsidy is granted to consumers who did not need it and that the programme is not creating any incentives for increased energy efficiency measures.

${ }^{7}$ Although some countries are developing standardised methods to evaluate energy savings data from energy efficiency policy (i.e. in the US see http://www1.eere.energy.gov/office_eere/de_umpp. html; in the EU see http://www.evaluate-energysavings.eu/emeees/en/publications/reports/EMEEES_WP61_report_090430.pdf
} 


\section{PART I: Economic instruments in energy efficiency policy}

Economic instruments in energy efficiency policy include all policy instruments that relate to fiscal, financial and other economic incentives and disincentives to deliver energy efficiency Page | 15 improvements across all sectors.

The term economic instruments is not well-defined in the context of energy efficiency policy. Often in energy efficiency policy the term financial instruments is used to describe policies that provide incentives for energy efficiency measures. However, the term economic instruments is broader and is used in the economics and environmental policy literature to describe price, incentives, finance, or trading schemes in policy. The term economic instruments more accurately encompasses the range of fiscal instruments and financial mechanisms used by policy makers in energy efficiency policy.

Economic instruments are used by all governments of IEA member countries to improve energy efficiency in different sectors. They can address barriers to energy efficiency such as:

- Market failures including externalities, where energy end-users do not pay the full cost to society of their energy consumption, and split incentives, which is when the economic benefits of an energy efficiency measure do not accrue to the financier of those measures;

- Uncertainty and risk associated with recoupment of the costs of energy efficiency investment in the future;

- Lack of access to finance for energy efficiency projects through unfamiliarity in financial institutions, lack of collateral, and difficulty in measuring energy savings associated with investments in energy efficiency;

- Relatively high transaction costs of small projects; and

- Behavioural issues in the form of inertia and bounded rationality. ${ }^{8}$

Figure 1 provides a schematic diagram for economic instruments. We categorise economic instruments under four headings - fiscal instruments, financial mechanisms, trading schemes, and direct investment. The classification of policy instruments can be a matter for some debate. We define fiscal instruments as those policy instruments that relate to the public treasury or government revenues and therefore include taxes, tax relief, and user charges in this category. Financial mechanisms relate to raising money and markets through the issuance of debt and/or equity. As with all definitions, there are some grey areas. Grants could be included in either the fiscal or financial categories. Here we have included them in the financial mechanisms category, as most governments provide grants with the goal of leveraging further private finance for energy efficiency. Direct investments by governments are often not included in descriptions of subsidies and incentives for energy efficiency but play an important role in influencing prices and markets for energy efficiency measures. The individual instruments are described in more detail in the next sections.

\footnotetext{
${ }^{8}$ Bounded rationality is when decision-makers do not make choices rationally, as generally assumed in classical economic theory.
} 


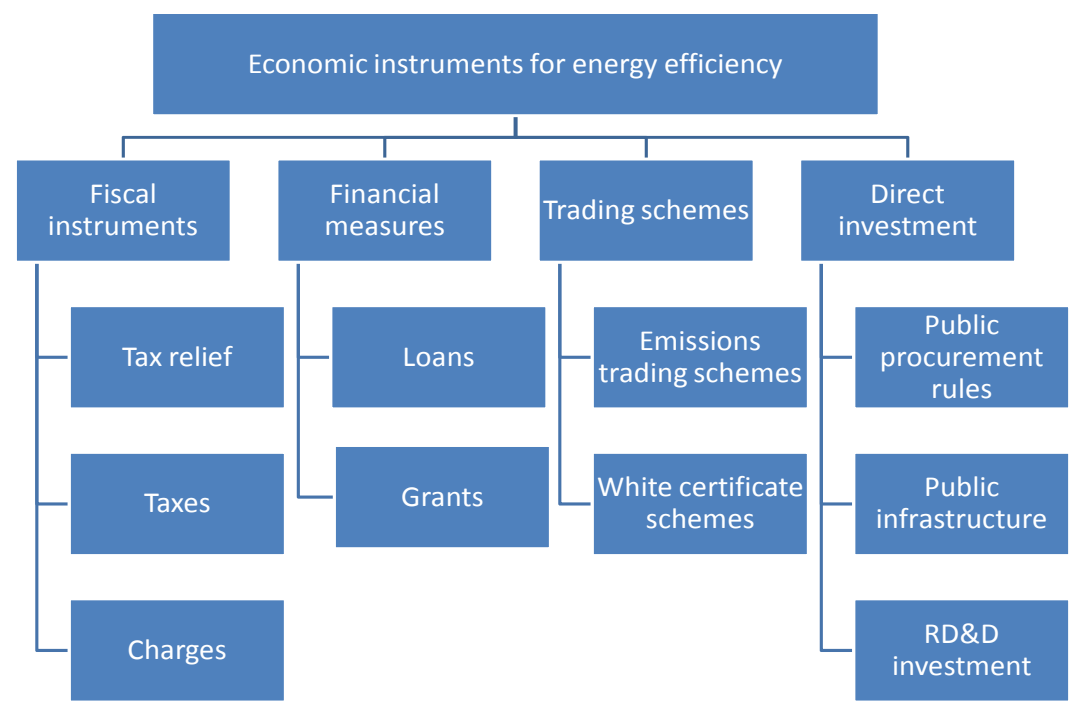

Source: IEA

Economic instruments can overcome the presence of externalities by adjusting the costs and benefits of an energy efficiency measure or by internalising the costs to society of polluting behaviour in order to reflect the effects on the public good associated with energy efficiency improvements on the one hand and pollution on the other hand. Split incentives can be addressed by ensuring that there are benefits to the agent investing in energy efficiency or that the investment costs can be passed on to the tenant or beneficiary of the reduced energy bills.

The second barrier of uncertainty or risk can also be addressed by sending a long-term price signal to the market that energy efficiency is important and reducing the costs associated with energy efficiency investments. Similarly, the proportionally high transaction costs triggered by the small size of energy efficiency projects can also be partially overcome through a realignment of incentives to invest in energy efficiency by economic instruments.

Finally, evidence that consumer decisions are not always perfectly rational is quite strong (Gillingham et al., 2009). Economic instruments can address this partly by, for example, overcoming inertia through giving a strong price signal, by bringing energy efficiency to the attention of boards of management in businesses or by simply giving consumers the feeling that they can make a good deal.

Tailoring to national circumstances and good design are important in the successful use of economic instruments in energy efficiency policy. Firstly, the appropriate choice of economic policy instrument to address a lack of investment in energy efficiency may differ in each country depending on national circumstances, such as economic situation, demographics, and energy prices, the barriers identified to improvements in energy efficiency, and the targeted sector. An analysis of these factors should be carried out in advance of the choice of instrument. For example, taxes, tax relief and grants are likely to be suitable tools to address externalities by readjusting the prices of energy and energy-using equipment to promote energy-efficient behaviour and investments. However, bigger energy efficiency projects in industry or in buildings may require additional economic instruments in the form of financial mechanisms, if the significant finance needed to fund these projects is not available from traditional sources due to 
the issues given above in the barrier on lack of access to capital. Countries may prioritise energy efficiency in one sector over another because of historical or projected energy use in that sector or perceived accessibility. It is important to know which economic instruments are likely to be more suitable to address energy efficiency in the priority sectors.

Secondly, good design of economic instruments is important and may have as strong an influence on the effectiveness and economic efficiency of the policy as the type of policy instrument chosen in some cases. Monitoring and evaluation of the economic instrument are important checks to determine if progress is made towards energy efficiency goals, as defined at the introduction of the economic instruments. Stability in the design and long-term funding (where necessary) of economic instruments is needed to give investors confidence in the viability of energy efficiency measures. Choosing the appropriate source of funds for such economic instruments is part of this process.

The goal of economic instruments is to ultimately kick-start the private financial markets and to motivate investors to fund energy efficiency measures. An important indicator of the effectiveness of economic instruments is the amount of private funds leveraged through the public funds spent, called the leverage ratio. The definition of leverage ratio varies between financial institutions and countries. From a government authority's perspective it can be approximately defined as the ratio between the total amount financed for an energy efficiency measure and the total amount of public funding provided. However, there can be different definitions used (as reviewed by Brown et al. 2011, CDCClimate 2012, Clapp et al. 2012, UN-AGF 2010) and therefore clear definitions are needed when discussing the leverage ratio. In this report, the term leverage ratio is used to mean the ratio of the public to private co-financing of an energy efficiency measure or project. ${ }^{9}$

The leverage ratio may not be the most important measure of effectiveness of public funds. For example, it is may be possible to find private finance more readily for lower cost measures than higher cost measures, resulting in a higher leverage ratio, although it may be in society's interest to use public funding for higher cost energy efficiency measures. More important may be which kinds of energy efficiency projects are being delivered as a result of the economic instrument, i.e. whether deeper cuts in energy consumption are achieved. Nevertheless, a high leverage ratio is a very important aspect as it maximises the impact of every unit of public money invested.

In all cases, economic instruments should be part of a policy package made up of regulatory, information and economic policies. Without a coherent, consistent policy framework, economic instruments are less effective and economically efficient. Economic instruments on their own will often not be enough to transform the market for energy efficiency products and services; longerterm regulations and frameworks are needed to provide forward-looking investors with direction and reassurance that energy efficiency is a long-term trend and requirement. Information and awareness raising measures are needed to support behavioural change and achieve real-world reductions in energy demand.

The next subsections describe the main features of economic instruments as they are used in energy efficiency policy.

\section{Energy taxes and price subsidies}

Energy taxes and price subsidies are economic instruments that directly affect the price of energy. They are the two main fiscal tools at governments' disposal to influence the price paid for

\footnotetext{
${ }^{9}$ This is similar to the definition used by climate funds such as the Global Environment Fund and the Clean Technology Fund (Brown et al. 2011).
} 
energy by consumers. High energy prices provide an incentive to invest in energy efficiency as they shorten payback periods and increase the net benefits of such investments. Conversely, low energy prices and direct energy subsidies encourage more wasteful consumption of energy and make investments in energy efficiency less attractive.

As a first step to encourage improved energy efficiency, it is important to remove energy price Page | 18 subsidies as far as possible. This is a precondition for the effective use of other economic instruments. Subsidising energy efficiency investments, while at the same time subsidising energy consumption, is a less efficient and effective use of public funds. The uptake of financing instruments that address the availability of financing for energy efficiency investments is also likely to be higher if energy prices are elevated.

Within OECD countries, directly subsidised energy prices remain the exception rather than the rule, even though a number of various indirect subsidies exist (e.g. subsidies for R\&D, public insurance for nuclear plants, military interventions to secure energy supply infrastructure, etc.). But indirect subsidies are very difficult to track. A preliminary OECD inventory of estimated budgetary support and tax expenditures for fossil fuels across 24 OECD countries, remarks that, within the OECD, the consumption of the majority of fuels is taxed to some degree. And even though between USD 45 billion and USD 75 billion in support for production and use of fossil fuels has been identified, these are mainly exemptions from some form of energy taxes. Not all of them can clearly be labelled as inefficient subsidies (OECD, 2011b). Where energy consumption subsidies exist and are deemed necessary, it should be ensured that these are well targeted to serve their original purposes and to avoid incentivising wasteful energy consumption.

Energy taxes are often set with the main purpose of raising revenue rather than influencing energy consumption. However, a large area of study is on the potential "double dividend" of raising energy or other environmental taxes. This literature focuses on estimating the potential double benefit of energy taxes through both a reduction in demand for energy consumption and increased revenue, facilitating the lowering of other taxes, for example on labour (Bovenberg, 1999).

The OECD/EEA database on instruments used for environmental policy and natural resource management defines environmentally-related taxes as "any compulsory, unrequited payment to general government levied on tax-bases deemed to be of particular environmental relevance. Taxes are unrequited in the sense that benefits provided by government to taxpayers are not normally in proportion to their payments" ${ }^{10}$ Environmentally-related taxes can be used to include costs in the price of energy that are not included by the market but which are paid by society, such as e.g. health costs due to environmental pollution. The revenues from energy taxes may flow into central government treasuries but in many countries a portion also may be earmarked for energy-related purposes such as energy efficiency and renewable energy.

\section{Tax relief}

Tax relief is an economic instrument that effectively reduces taxes on particular goods or for a certain part of the population to correct market failures and in this case overcome barriers to energy efficiency investment. It is referred to by the OECD as tax expenditures and defined as "provisions of tax law, regulation or practices that reduce or postpone revenue for a comparatively narrow population of taxpayers relative to a benchmark tax" (OECD, 2010a). In energy efficiency policy several types of tax relief are commonly used which reduce tax liability when investments to improve energy-efficiency are made:

\footnotetext{
${ }^{10}$ The database and definitions are available at www2.oecd.org/ecoinst/queries/version from 13.04.2012.
} 
- Tax deduction: eligible investment costs relating to energy efficiency measures can be deducted (fully or in part) from income or revenues liable to taxation. Eligible investment costs mostly cover purchase costs of materials or equipment improving energy efficiency, but may also include related services such as the installation costs of an energy efficiency measure;

- Tax credits: are similar to tax deductions but investment costs are deducted (fully or in part) from respective taxes due to be paid. Tax credits may also be refundable if tax credits are higher than taxes due, which is the case for example in Belgium. ${ }^{11}$

- Tax reductions and rebates: purchase taxes or sales taxes are reduced for qualifying equipment or services, e.g. reduced value added taxes for insulation material and installation services in the United Kingdom. ${ }^{12}$ This is either done directly at the point of sale (tax reductions) or applications for tax refund must be filed after the purchase (tax rebates);

- Accelerated depreciation allowances, which allow purchasers to write-off the cost of depreciation of qualifying equipment more rapidly than standard equipment, thus effectively reducing the after tax total cost of the equipment;

- Tax or customs duty exemptions which relieve purchasers from paying customs duties or import taxes on qualifying imported equipment or excise tax on consumption or purchase of specified products, e.g. highly efficient appliances.

The World Economic Forum notes that one advantage of tax incentives over grants, is that they are more likely to encourage greater scale of projects as they are usually granted over a longer time period and do not have a limited budget attached (WEF 2011, pp. 25).

\section{Grants}

Through grant schemes, an amount of money that covers all or part of the energy efficiency investment is provided to individuals or businesses. The award of a grant may be for specific pieces of energy-efficient equipment (on a technology list for example) or may be tied to energy performance, and may be set at a fixed amount or as a share of the investment made. Grants can be funded through energy efficiency agencies, dedicated funds or public banks.

Grants can be effective in encouraging people to undertake investment in energy efficiency measures that they might not otherwise do. But in order to actually influence investment decisions, they need to cover a significant share of the total investment costs. Therefore grants in energy efficiency programmes have tended to favour less ambitious measures where the investment costs are lower.

Grant schemes are costly to public budgets compared to other forms of finance such as lowinterest loans. From an administrative point of view, programme running costs can be lower for grants schemes, compared to loan schemes, because no payback needs to be administered.

Compared to tax incentives, grants might be equally costly in that the amounts subsidised may be the same. However, grants require outlay of the public budget, while tax incentives impact revenues. Costs for grants may, however, be easier to track and control as they will have a certain budget limit, whereas tax incentives are difficult to limit to a certain amount of revenue forgone and the amounts may only come to light at the end of the fiscal year. Tax incentives may be more suitable for larger investments, as the subsidy is likely to represent a smaller share of

\footnotetext{
${ }^{11}$ See for more information (in French): http://www.minfin.fgov.be/portail//fr/themes/dwelling/energysaving/index.htm

${ }^{12}$ See for more information: http://webarchive.nationalarchives.gov.uk/+/http://www.hmtreasury.gov.uk/budget/budget_2000/press_notices/bud_bud00_pressenergy.cfm
} 
the overall investment because it is limited to the tax rate normally paid. ${ }^{13}$

Free-riding, i.e. the share of people that would also have invested in the absence of the incentive, is an important issue for both grants and tax incentives. Therefore eligibility criteria for both economic instruments should be ambitious to ensure that the subsidy targets advanced products and real energy efficiency improvements.

Page | 20

\section{Loan programmes}

Finance may be needed to cover the upfront costs of measures to improve energy efficiency. For ambitious measures that significantly improve the energy performance of a building, industrial facility or other assets, the investment may be considerable and require debt financing. Debt financing, such as loans, seems to be particularly adapted to the characteristics of comprehensive energy efficiency investments, which can have high upfront costs and lead to monthly savings that may be used to service the debt.

Another advantage of loan financing is that it is a well-established way of financing upgrade or construction measures and that expenditures for energy efficiency investments may piggy-back on loan financing for other general investments. However there are several barriers to private debt finance for energy efficiency improvements, which means that public policy and funds are needed to intervene in the market.

From the investor's perspective, there may a number of reasons for reluctance to take on increased debt to finance energy efficiency measures. These may include a general aversion to debt, a lack of interest in undertaking investment in energy efficiency measures or a lack of confidence that investments will lead to the estimated savings. Another barrier is that a large investment in, for example, a deep retrofit, may require a substantial loan over a long period of time. However if the asset is sold in the short or medium-term, i.e. before maturity of that loan, the initial investor will be responsible for full repayment of the loan without any guarantee that the resale value of the property or business will reflect the energy efficiency investment.

From the lender's perspective, despite the slowly but surely increasing amount of information on the effectiveness of energy efficiency investments, private lenders still do not translate the lower risks and higher returns of green investments into lower interest rates (Kats et al., 2011 pp. 2021). Since the repayment is based on projected energy savings rather than assets to securitise the loan, financial institutions may perceive energy efficiency loans as higher risk. Additionally, industrial facilities or buildings often already have a primary loan attached for which the building is used as collateral. Acquiring a second loan for the same building or an extension to the first loan can be complicated, but may be possible especially when much of the original loan has already been repaid or when the upgrade positively affects the business or property value. Evidence on market premiums for energy efficiency investments are discussed in more detail in the section on institutional investing and private investment funds in the third part of the report.

Various forms of economic instruments are used in energy efficiency policy to support the debt finance or loans market for energy efficiency measures. Governments can support loans by intervening in the market, either directly with credit lines to financial institutions at concessional or market rates or providing loans directly to investors, or indirectly through policies that enable financing arrangements through third parties (described under "Other structured finance"). In both cases taking loans for energy efficiency becomes more attractive to potential investors as

\footnotetext{
${ }^{13}$ This depends on the rate of tax normally paid; for industry, corporate tax varies considerably between countries. In countries where corporate tax is low or there is tax relief on depreciation of equipment in any case, the subsidy for energyefficiency measures is likely to be a low share of the investment.
} 
well as to local financial institutions.

Close co-operation with private financial institutions with regard to programme implementation is very important for several reasons. Governments can use the existing, often highly decentralised, structures of private financial institutions to engage directly with potential investors. Also making use of their financial expertise and methods of client advice and assessment is very important. In order to familiarise financial institutions with the specifications of the loan programmes, including technical know-how on energy efficiency as well as eligibility criteria, specialised training and technical assistance is necessary. This is also important to enable the private financial sector in the long term to serve this market segment without further government engagement.

\section{Concessional loans}

Concessional loans are when subsidies are provided to reduce the cost of loans to investors in energy efficiency measures. There are several ways this can be done. Public funds may be used to fund the whole loan amount through credit lines to commercial financial institutions that are then on-lent at preferential to potential investors. Financial institutions can find this mechanism attractive, as they do not need to use their own funds, and it can encourage them to engage in new (energy efficiency) lending activities. This is especially attractive in times where liquidity is constrained, i.e. when it is difficult or expensive to get refinancing on the financial markets.

Alternatively, public funds can subsidise only the interest rates and/or can provide partial debt relief for energy efficiency loans. The remaining loan amount is provided by fully participating financial institutions or third parties. The interest rate subsidy may be passed on in full or only in part to the borrowers. Subsidised interest rates can be of great interest to potential investors, as they can significantly cut financing costs depending on how high is the subsidy. However, in contrast to credit lines, subsidised interest rates may not be enough to encourage financial institutions to actively seek customers for loans for energy efficiency measures, as there is still a risk involved with the loan that may be perceived as high compared to loans in areas the bank is more familiar.

\section{Guarantees}

Some of the barriers to energy efficiency finance relate not to a lack of availability of funds but rather to the perception of risk. Risk-sharing arrangements in the form of loan guarantees that reduce the perceived risks associated with the investment can increase the leverage of private debt finance and involve new actors in financing investments in energy efficiency.

Loan guarantees are when public funds provide default guarantees for loans to energy efficiency projects. The risk-sharing facility comprises a public partner that will guarantee all or some part of the risk, a local financial institution that provides loans and energy efficiency project developers in need of project finance (IEA, 2011a). Guarantees can be given for specific largescale projects with a risk sharing agreement adapted to the specific project design or to a portfolio of similar projects, i.e. all loans to a certain class of borrowers (portfolio guarantee). Alternatively, a loan loss reserve fund can be set up to pay (fully or partially) for loan defaults. Such a fund can also serve as a temporal buffer, when there is not the risk of a client's default, but payments are simply delayed (Rezessy and Bertoldi, 2010). Risk guarantee funds typically have a size of $2-10 \%$ of the overall loan portfolio (Kats et al., 2011 pp. 37).

Losses can be taken over fully or partially by the public institution. The risk remaining with the private bank will determine by how much the risk premium on the loan can be decreased. There 
exist a number of different ways to share the risk between the public institution and the private bank (IEA, 2011a):

- Equal risk sharing ("pari-passu"): each partner takes on an equal share of the loss.

- Pro-rata guarantee: the loss is shared according to a predefined percentage between the partners; a typical share of the public party can lie between $50 \%$ and $80 \%$.

- First-loss guarantee: all losses up to a predetermined maximum amount will be covered by the public institution, while the private bank pays for losses above this amount.

- Second-loss guarantee: all losses exceeding a predefined amount are paid for by the public institution. Potential losses of the private institution are thus capped and cannot exceed the determined amount. ${ }^{14}$

\section{Other structured finance}

Other financial instruments do not require public funds directly but enable financing arrangements to facilitate third party finance for project-based loans (loan enhancements). Governments can ensure that the legislative framework is in place to enable various loan repayment modes and new business models to finance energy efficiency measures.

This encourages private finance in the market for energy efficiency. We group several of these instruments together as:

- Energy provider on-bill financing (tariffs and loans)

- Property assessed clean energy (PACE)

- Energy performance contracting

On-bill finance arrangements through energy providers tie the repayments of loans to payment of existing utility bills. Policy is frequently required to enable energy providers to provide finance to customers and to develop the legal arrangements required to sort out seniority of payments, and liability for non-payment issues.

The investor avoids putting up the full amount of finance initially for the upfront costs of the energy efficiency measures but pays the costs as part of regular utility bill payments over time. The loan can, in some cases, be transferred with ownership of the business or property, thus enabling longer payback periods of up to 20 years.

On-bill finance can assist in overcoming the market failure, split incentives, that often occurs as a barrier to investment in more ambitious and/or costly energy efficiency measures over long periods because the investor may not recoup the benefit of his investment. Firstly, tying the amount of repayments to the energy saved gives a sense of security and a perceived avoidance of upfront costs. Secondly, attaching repayment of the loan to the asset rather than the initial investor means that there can be an incentive to undertake longer-term finance and therefore more ambitions measures, even if he wishes to sell the business or property before the loan is matured. Energy-providers are well-positioned to provide on-bill finance since they have a regular payment method in place. They also have a large and broad commercial and private customer base that can be targeted for energy efficiency improvements.

Property assessed clean energy (PACE) schemes represent a special kind of on-bill financing arrangement where the local government institutions that administer property taxes provide loans for energy efficiency investments. The local public institution provides a loan to the owner, which is repaid via an assessment (or surcharge) on the property tax. PACE can in principle be

\footnotetext{
${ }^{14}$ These are described in detail in another IEA report - Public-Private Partnerships for Energy efficiency Finance (IEA 2011).
} 
applied to the residential and the commercial sector, but only building owners can make use of it (Rezessy and Bertoldi, 2010 ppp. 38-39). The split incentive between owners and tenants can be overcome in cases where property tax payments are passed through to tenants, which is often possible for commercial or industrial tenants (Della Croce, Kaminker and Stewart, 2011 ppp. 4344).

Energy performance contracting (EPC) presents another way of organising energy efficiency finance. It involves an Energy Service Company (ESCO) which can provide a variety of services, including finance in some cases, but most importantly will guarantee energy savings of a certain amount. The remuneration of the ESCO depends on the achievement of the guaranteed savings. As the guarantor of the savings, the ESCO remains involved in measuring and verifying the savings during the debt repayment period. ESCOs may also provide other forms of contracting, such as "chauffage", "first-out", "Built-Own-Operate-Transfer" or leasing contracts (Bertoldi and Rezessy, 2005). ESCOs and energy performance contracting are mainly found in the public sector but also some examples exist in the industrial and commercial buildings sectors.

Many governments are interested in on-bill financing mechanisms and ESCO business models for their ability to address some of the key barriers to energy efficiency finance. However, they can be complex and costly to set up and there have been varying levels of success in their implementation to date.

\section{White certificates and obligation schemes}

A white certificate is a document issued by an authorised body certifying that a specified amount of energy savings has been achieved. Markets for white certificates can be set up as part of energy supplier obligation schemes. The certificates can be used by the company who has saved the energy for compliance with their energy saving targets or can be traded with other firms in the same obligation scheme.

Obligation schemes that require energy providers to engage in energy-saving activities are a growing phenomenon worldwide. Obligation schemes as such can be considered a regulatory instrument, as energy providers are obliged by law to engage in energy saving activities with regard to their clients (UNEP, 2007 ppp. 32-33).

Under obligation schemes, energy providers may achieve the required energy savings via a range of instruments implemented by themselves or through subcontractors, these may include: information, communication, advice and assistance as well as offering customers financial incentives, offering the replacement of equipment which may be acquired through bulk procurement or even the implementation of comprehensive measures (Heffner, DuPont and Rybka, 2012). The scope of energy providers included in the scheme differs by country - in some cases only electricity suppliers are obligated whereas in others, the scope is much wider and includes heating fuel and transport fuel providers.

Some obligation schemes enable energy providers to provide some form of energy efficiency finance and to eventually recover the related costs via the energy bills (on-bill finance as described above) or through specific user charges (public benefit charges). This may include the possibility for energy providers to take on debt. Through the obligation scheme, energy suppliers may be motivated to provide an important source of finance for investments in energy efficiency to customers or provide incentives to encourage private investment in energy efficiency.

Trading of white certificates encourages some flexibility in the market and economic efficiency so that energy-providers with lower cost options carry out more energy efficiency measures than those with higher costs. White certificate schemes can also enable other actors than the obliged parties to engage in energy efficiency investments as the white certificates provide a form of 
(additional) remuneration to these investors. This additional revenue can be an incentive to invest in the first place (as the pay-back period can be shortened to an acceptable level) or to make a greater investment (while keeping the pay-back period constant).

\section{Carbon markets}

Page | 24 Carbon markets can provide a source of funds for energy efficiency measures. The revenues from emissions trading schemes can be used to fund energy efficiency measures. Alternatively, greenhouse gas (GHG) emission reduction projects, i.e. energy efficiency measures, in need of funds can be matched with investors that are obliged to finance abatement activities under the UNFCCC Kyoto protocol. ${ }^{15}$ In this latter case, there is no lending or granting of funds involved; instead, emission reductions are purchased. Carbon markets thus present a way of leveraging private and public funds for energy efficiency measures for the purpose of reducing GHG emissions (Rezessy and Bertoldi, 2010).

Two general types of market mechanisms have been set upp. The first is GHG emissions trading schemes, both at the national or regional level, to fulfil local climate objectives, and internationally under the UNFCCC Kyoto Protocol. Companies covered by the emissions trading schemes are required to hold sufficient allowances for the GHG emissions they produce. These allowances can be traded with other companies in the scheme. Energy efficiency measures can be an important low-cost way for companies to reduce their emissions. If allowances are auctioned, the revenues are accrued by the treasury and can be ring-fenced for energy efficiency measures.

The second type of mechanism is crediting schemes, such as the Kyoto Protocol's Clean Development Mechanism (CDM) and Joint Implementation (JI). These allow obliged parties to finance GHG emission reduction activities outside their territories. Through a CDM project, an obliged party can finance abatement activities in developing countries, while through Jl projects, an obliged party can finance abatement activities in another country equally obliged under the Protocol. In both types of schemes GHG emissions reductions in industrial sectors and energy providers have mainly been targeted.

\section{Public procurement and infrastructure investment}

The public sector holds significant potential to improve energy efficiency by deploying advanced technologies and/or developing the market for improved energy efficiency. The small size of energy efficiency projects is a significant barrier facing energy efficiency measures. The public sector is an important market, representing between 10 and $20 \%$ of national GDP, that can assist in developing the market for energy efficiency products and services through its not insignificant purchasing power (Singh et al., 2010). In many countries facilities with a common function such as schools and hospitals offer opportunities to bundle energy efficiency projects, attracting larger-scale finance and new businesses to the energy efficiency market. The public sector can also play a leadership role in demonstrating the potential of energy efficiency to reduce energy consumption and showcasing new technologies and energy management. The large purchasing power of the public sector can be a catalyst for developing the energy efficiency market (Singh et al., 2010)

However, in many countries, barriers remain to public sector investment in energy efficiency. Rules governing the public procurement of energy savings performance contracts (ESPCs) and

\footnotetext{
${ }^{15}$ United Nations Framework Convention on Climate Change Kyoto Protocol available at http://unfccc.int/kyoto_protocol/mechanisms/items/1673.php
} 
energy-efficient equipment can overcome many of these barriers. Governments have used different approaches to encourage the procurement of energy efficiency services and products, including the creation of dedicated agencies to the procurement of energy efficiency-related services, establishing model contracts, creation of public energy service providers to avoid procurement-related issues (Singh et al., 2010; IEA, 2011a). Another way is to require that a given energy performance improvement is achieved by the public sector and ensure that there are no institutional or market barriers to implementing the requirement.

\section{Energy efficiency R\&D support}

Reducing energy consumption requires not only incremental improvements in technologies but also breakthrough developments. There are three well-documented steps in technological change - invention, innovation, and diffusion or adoption (Schumpeter, 1942). The economic instruments for energy efficiency described above focus on improving the price signal to support this third step by encouraging consumers and businesses to invest in energy efficiency. Governments also need to ensure sufficient long-term research and development (R\&D) to provide incentives for supply-driven technological change.

The justification for using public funds to invest in R\&D is explained by two market failures firstly, there are positive externalities, where the benefits of the R\&D are not recouped by the investor, in the form of a time lag between the moment of investment and the benefits from $R \& D$ to the company and the public. There are also spill-over effects where other companies benefit from the R\&D of the company who initially invested in a technology. Secondly, if energy prices are not high there is little demand for energy-efficient products and companies have little incentive to invest in R\&D to develop products to save energy.

Many countries in recent years have invested public funds in energy efficiency R\&D as part of economic stimulus programmes. Public investment in R\&D in the clean energy sector is often a feature of national green growth strategies. While the supply of low energy technologies is a goal of such investments, other objectives such as increasing employment in the clean energy sector and transforming industrial economies into knowledge-based or smart economies are also important political outcomes. 


\section{PART II: Economic instruments to mobilise investment in energy efficiency in buildings}

This section of the report illustrates how economic instruments are used in the buildings sector to improve energy efficiency. It examines how current and future economic instruments can deliver low-energy buildings in IEA countries including deep retrofit of existing buildings and also nearly zero energy new buildings.

The first subsection outlines the vision for low-energy buildings and why policies are needed. The second part outlines the current use of the economic instruments described in Part I to improve the energy efficiency of buildings. The third subsection discusses how economic instruments can be designed and employed to deliver low-energy buildings.

\section{II.1 Introduction to the buildings sector and energy efficiency policy}

This subsection begins with a description of the potential to improve energy efficiency of buildings and the types of measures needed. The role for government policies and how economic instruments fit in the policy package in reducing energy consumption in buildings are explained.

\section{Energy efficiency and buildings}

Energy demand from the buildings sector is significant and expected to grow rapidly on a global basis in the coming years. The buildings sector consumed $115 \mathrm{EJ}$ or $2750 \mathrm{Mtoe}$ in terms of final energy in 2009 globally, which represents about $32 \%$ of total global final energy consumption. Over the last decades, buildings energy consumption has been rising annually by $1.8 \%$, from just $58 \mathrm{EJ}$ (1385 Mtoe) globally in 1971. Total global energy demand in the building sector is expected to rise to 160 EJ by 2050 in the IEA Energy Technology Perspectives (ETP) 2012 4DS scenario, which assumes that all currently planned actions for addressing climate change and energy security concerns will be implemented (IEA, 2012a).

There are several reasons for the increasing energy consumption in the buildings sector, including pressure from population growth and increased personal wealth leading to increased consumer demand for appliances. Other contributing factors are falling occupancy rates per dwelling and increasing sizes of dwellings. While population growth is less of an issue in IEA member countries, the remaining reasons do apply.

Another parameter that plays an important role in the energy consumption in the buildings sector is the age of the buildings. Buildings constructed prior to the introduction of building energy codes are much less energy efficient compared with newer buildings.

Previous IEA work has identified the scale of energy savings potential in the buildings sector. The ETP 2DS scenario estimates the cost-optimal mix of technologies to halve GHG emissions from all sectors by 2050. In this scenario the average energy consumption for heating and cooling in residential buildings would be significantly reduced by 2050 - for heating in new buildings in cold climates to nearly zero, i.e. 15-30 kWh per $\mathrm{m}^{2}$ per year, and for existing buildings to on average $50 \mathrm{kWh}$ per $\mathrm{m} 2$ per year. In hot climates, energy needs for cooling in residential buildings would 
be reduced by one-third. ${ }^{16}$ Although this would still lead to a rise of $11 \%$ in energy consumption compared to 2009 levels, it allows for a projected 65\% increase in household units and a $72 \%$ increase in floor-area in the service sub-sector over the same period (IEA 2012a). Of the 25 IEA Energy Efficiency Policy Recommendations, five are dedicated to buildings (IEA 2011b).

In this report we use the term "low-energy buildings" to describe buildings that are nearly zero energy new buildings and deep retrofitted existing buildings (see Box 1).These energy efficiency improvements are within reach; but only when buildings are enhanced in a comprehensive way, incorporating improvements in the design, use and components of the building system.

The building envelope deserves particular attention, as the specification, and use of other components such as heating and cooling equipment, of the building are dependent on the energy performance of the building envelope. ${ }^{17}$ Additional energy savings can depend on achievements in reducing heating and cooling demand through building envelope measures, and the subsequent downsizing of heating and cooling equipment (IEA, 2012a).

Most buildings in IEA countries were constructed before 1970, and a significant percentage before 1945. This has significant implications, as requirements for the energy performance of buildings, i.e. building energy codes, were only introduced in most countries after 1970 as a reaction to the oil crises in 1973 . The average energy intensity of residential buildings in the EU is approximately $200 \mathrm{kWh}$ per $\mathrm{m}^{2}$ and $280 \mathrm{kWh}$ per $\mathrm{m}^{2}$ for non-residential buildings (all end-uses, in final energy) (BPIE, 2011) but there is wide variation in the energy intensity of buildings within each category dependent on the type and age of buildings, their location in terms of climate, as well as usage and behavioural issues.

In order to dramatically reduce the average energy consumption from the buildings sector in OECD countries, large-scale upgrade of the existing building stock is needed. As the economic life-span of a building envelope can be over 100 years, about $75 \%$ of the existing building stock in the OECD can be expected to still be standing in 2050. IEA analysis estimates that $60 \%$ of buildings in OECD countries need to be refurbished by 2050. Over the next decades, the refurbishment of existing buildings needs to be very ambitious in terms of: (i) the levels of energy performance reached; and (ii) the rate of refurbishment of buildings in OECD countries, if an average buildings energy intensity of $50 \mathrm{kWh}$ per $\mathrm{m}^{2}$ per year is to be achieved. About $70 \%$ of potential savings come from the residential sector (IEA, 2012a).

Given the long lifespan of buildings, the long-term goals for lowenergy buildings and the slow rate of renovation in OECD countries, the buildings community now recommends that as far as possible each building should undergo deep retrofit whenever it is being renovated. There may not be an additional opportunity for another 30 years and during that time opportunities are missed to save energy. ${ }^{18}$

In developing countries, the rate of new construction is much higher than in OECD countries, and therefore the focus should be on mainstreaming the construction of nearly zero energy new buildings. ${ }^{19}$ However, the scope of this report focuses on IEA countries and there the emphasis is on economic instruments to support the deep retrofit of existing buildings.

\footnotetext{
${ }^{16}$ THE IEA ETP models a scenario where the temperature rise through climate change is limited to 2 degrees Celsius (2DS) and estimates the cost-optimised mix of technologies needed to achieve this goal.

${ }^{17}$ The building envelope or shell means the outer structure of a building, including the foundation, walls, roof, doors and windows..

${ }^{18}$ We refer to these missed energy savings as energy savings that are "locked-in".

${ }^{19}$ The number of households in non-OECD countries is estimated to grow by $82 \%$ between 2009 and 2050 (IEA 2012a).
} 


\section{Box 1 - Definition of low-energy buildings and deep retrofit of buildings}

The term "low-energy buildings" is used in this report to describe buildings that are near zero energy new buildings and deep retrofitted existing buildings. It is used as a general policy target whereby the energy consumption of buildings is cut drastically.

The concept of "deep retrofit" in the context of energy efficiency in buildings is the term used in the buildings policy community to denote the refurbishment of an existing building that improves the overall energy performance of a building by a significant amount, achieving a low level of energy consumption. The degree of improvement in energy efficiency is determined by implementing the energy efficiency measures in buildings that do not lock-in the future energy savings potential of the building. These should incorporate at least the cost-optimum energy performance of the building but may go further.

Establishing what is economically-efficient or cost-optimal is very dependent on the time frame over which it is calculated. The EU Energy Performance in Buildings Directive (EPBD) defines the costoptimal as: "the energy performance level which leads to the lowest cost during the estimated economic lifecycle". ${ }^{20}$ Increasingly, policymakers use thirty years as the economic life cycle of a building over which investments in buildings should be assessed. ${ }^{21}$

Additionally, cost-effectiveness depends heavily on current and future energy prices as paid by the consumer (i.e. including taxes and charges).

In this report, the definition of deep retrofit includes energy efficiency measures which fit this concept. This means a reduction in energy consumption leading e.g. to an average building stock energy intensity of $50 \mathrm{kWh}$ per $\mathrm{m}^{2}$ per year for heating and cooling in cold climates, in accordance with the IEA ETP 2DS modelling scenario. Given the current buildings energy intensity in OECD countries, this would generally mean an improvement of approximately 50-80\% (or factor four) for total final energy consumption per building.

\section{The role of governments to reduce energy consumption in buildings}

Policy intervention is needed to improve energy efficiency in buildings to overcome market barriers and/or failures that hinder investment in buildings energy performance to achieve lowenergy targets, even when cost-effective in the longer-term. These market failures and/or barriers have been highlighted by many others and can be summarised as: ${ }^{22}$

- Low prioritisation of energy efficiency: Energy efficiency investments are of low priority in comparison to competing investments as energy costs represent in many cases a small share of overall occupancy costs, even though rising energy prices can increase the attention paid to energy costs. ${ }^{23}$

- Investment risks and uncertainty: the uncertain future of energy prices means that it is difficult to predict the value of the return on investment.

- Information failures: basic information for potential investors on the energy performance of individual buildings and the building stock is sometimes unavailable, even though a lot

\footnotetext{
${ }^{20}$ See the EPBD, art. 2.14 at http://eur-lex.europa.eu/LexUriServ/LexUriServ.do?uri=OJ:L:2010:153:0013:0035:EN:PDF

${ }^{21}$ For example, the EU recommends a framework for calculating cost-optimal levels of minimum energy performance requirements for buildings and building elements using a 30 year time period. See http://eurlex.europa.eu/LexUriServ/LexUriServ.do?uri=OJ:L:2012:081:0018:01:EN:HTML

${ }^{22}$ See for example: Ryan et al. 2011; Sweatman and Managan, 2010

${ }^{23}$ The price elasticity of energy demand is low in the short term but higher in the long term, as building owners factor in the potential rise in energy prices when they next renovate a building. See the section on energy taxes for more discussion.
} 
of progress has been made, notably in the EU through the introduction of energy performance certificates. ${ }^{24}$

- Split incentives: in the case of rented properties, owners are likely to be unwilling to undertake investments if the returns, in form of reduced energy bills, accrue to the tenant. Likewise, tenants are likely to be unwilling to undertake long-term investments in EE if they do not plan to stay very long in a particular property.

- Transaction costs: higher in the building sector because of the large number of building refurbishments and the relatively low value of each investment.

- Knowledge and awareness: lacking with regard to energy efficiency as a potential investment opportunity at all levels, including building designers, occupants, assessors, staff in financial institutions, etc.

- Positive externalities: these arise when the long-term societal benefits from deep retrofit do not accrue to the initial investor but to wider society through public benefits such as public health savings, increased employment, economic activity etc., or to future generations.

- The buildings sector is fragmented and complex with a range of owners and users. ${ }^{25}$

A strong policy framework is needed to increase renovation rates of buildings and the level of energy performance whenever renovation works are undertaken. Governments have a range of policy instruments at their disposal. Historically in the buildings sector, regulations, such as building energy codes, were the main form of energy efficiency policy used. Yet so far these have not been very successful in limiting the rising energy demand from the sector, despite some successes with regard to the energy performance of new buildings.

Even though building energy codes exist in all OECD countries, they are mandatory only in European Union countries and Australia and they are not well implemented and enforced in many countries. Most of them target only new buildings or extensions to existing buildings. Future building codes will need to be mandatory for existing buildings and demand high levels of energy performance. In order to improve their effectiveness, IEA has developed guidelines on implementing and enforcing building codes for policy makers which will be published in $2012 .^{26}$ The other main categories of policy instruments are information measures such as buildings certification schemes, awareness raising and training and capacity-building, and economic policy instruments such as taxes, incentives, and financial mechanisms. Information is available on policies for energy-efficient buildings in IEA member countries and India, China, Russia, South Africa and Tunisia on the IEA Buildings Energy Efficiency Policies (BEEP) database. ${ }^{27}$

Many countries use a combination of policy instruments to improve energy efficiency in buildings, but all too frequently these policies are not aligned and fail to mutually reinforce each other. For example, the energy requirements for buildings eligible for subsidies in many countries are not aligned, even in terms of the metrics used, with the energy requirements demanded by building codes in force, which makes it difficult for investors to understand the improvement or not of the building compared with the current or future building code.

Analysis from the World Economic Forum shows that a combination of mandatory disclosure processes and asset efficiency ratings with regulation and some form of incentives, can lead to more developed retrofit markets (WEF, 2011). A survey done by the World Energy Council

\footnotetext{
${ }^{24}$ See: http://www.epbd-ca.eu/

${ }^{25}$ See, for example, WBCSD, 2007

${ }^{26}$ IEA Policy Pathway on building energy codes (forthcoming)

${ }^{27}$ www.sustainablebuildingscentre.org
} 
revealed that energy industry executives see mandatory standards and financial incentives as the most effective policy instruments (WEC, 2011 pp. 42). Also the World Business Council on Sustainable Development rated a combination of measures to be most effective and costeffective - standards and labelling approaches, energy supplier obligation schemes and demand side management, as well as fiscal instruments and incentives (WBCSD, 2007 pp. 23). Although financial incentives may not seem necessary if building energy codes are in place, they can encourage investment in more ambitious energy performance than required and also assist in providing finance to meet building energy code requirements.

How best to combine different policy instruments to deliver low-energy buildings is answered differently in different regulatory contexts and cultures. There is also likely to be a temporal dimension to how policy instruments can best be combined. ${ }^{28}$ Building energy policies should be considered within a long-term strategic framework. Once a government has set out a long-term target for energy consumption from buildings, policy makers can devise a technology and regulatory roadmap to achieve this target. This may mean introducing a package of policy measures such as:

- Increasingly stringent energy requirements in building codes for new and existing buildings over time;

- Mandatory refurbishment;

- Energy certification of buildings;

- Economic instruments to encourage investors to invest in low energy buildings.

\section{The role of economic instruments in the policy package}

Economic instruments play an important role in the policy package outlined above to encourage investment in low-energy buildings. As has been outlined in the previous section in more general terms, economic instruments can act either through disincentives for inefficient energy use (taxes and prices) or incentives for energy efficiency (in the form of subsidies such as grants, tax relief, financial mechanisms and trading). Placing a monetary value on improved energy performance through carefully designed subsidies and higher energy prices can increase the appeal of energy efficiency investment as payback times are shortened.

Ultimately, the goal is to scale-up private investment in low-energy buildings to realise the full, economically-efficient energy saving potential as soon as possible. However, even though there seems to be consensus on the wide ranging cost-effectiveness of energy efficiency measures for buildings, the share of low-energy new and existing buildings remains very small. Refurbishment rates still stay far below the identified necessary levels (IEA, 2012a). Taking Europe as an example, renovation rates estimated by industry are currently around 1.2\% per year and energy efficiency measures are not always part of general renovation works. ${ }^{29}$

Economic instruments serve several purposes at different points in the scaling up of investment in low energy buildings, if based on stringent building codes and energy labels, to improve the business case for investment in buildings:

(i) As incentives (or "sweeteners") to encourage potential investors to take action in improving energy performance by reducing the costs of the carrying out energyefficient actions, i.e. subsidies such as grants, tax incentives and preferential rate

\footnotetext{
${ }^{28}$ Makes reference to the presentation by Ingrid Holmes (E3G) given at the IEA expert workshop: www.iea.org/media/workshops/2012/energyefficiencyfinance/2bHolmes.pdf

${ }^{29}$ See http://www.euroace.org/Resources/Projects/RenovateEurope.aspx
} 
loans;

(ii) As deterrents to energy inefficient activity by increasing the cost of doing nothing through the reduction of consumption subsidies and/or the increase of consumption taxes;

(iii) As enablers of ambitious regulation by providing or facilitating access to finance to invest in energy efficiency, such as concessional loans, risk guarantees, on-bill finance.

The upfront costs of deep retrofitting a building are relatively high; they are also greatly dependent on the energy performance of the building before renovation and the type and age of the building. A German study on additional costs for deep retrofit analysing 250 buildings found a cost range of EUR $80-90 / \mathrm{m}^{2}$ in order to reach performance levels of about $85 \mathrm{kWh} / \mathrm{m}^{2}$ primary energy demand per year (current regulation for new buildings) and up to EUR $240 / \mathrm{m}^{2}$ to reach performance levels of $40 \mathrm{kWh} / \mathrm{m}^{2}$ primary energy demand. ${ }^{30} \mathrm{New}$ buildings, on the other hand, that consume very low or nearly zero energy buildings may not be significantly more costly to construct than less efficient buildings, since the building design and orientation can already deliver better energy performance even before investment is made in more advanced components and equipment.

Box 2 - Investment needed globally to reduce energy consumption of buildings by 2050

Under the IEA low carbon (2DS) scenario, the IEA estimates the additional investment needs for the buildings sector to be USD 11.5 trillion globally on top of the USD 16.3 trillion needed under a business-as-usual scenario (leading potentially to a global temperature increase of $6^{\circ} \mathrm{C}$ ). About twothirds of the additional investments (USD 7.5 trillion) are needed for the residential sub-sector. The additional investment would be used to "ensure new buildings meet more stringent building codes, to refurbish around $60 \%$ of the OECD building stock still standing in 2050 to a low-energy standard, and for additional investments in heat pumps, solar systems, CHP systems, lighting systems and appliances" (IEA, 2012a). Improvements in buildings' shells alone will require $40 \%$ of total additional investments.

Expected fuel savings as well as savings through lower electricity costs that can be realised through the additional investments are outweighing the overall investment costs and undiscounted net savings are estimated to amount to USD 7 trillion in the building sector alone.

The years until 2020 will be a crucial phase for the building sector as half of the additional investments needed until 2050 (i.e. USD 6 trillion) should already be made during these early years. Measures need to be a mixture of quick wins with short payback periods and low, or even negative, abatement costs, and longer term investments such as deep renovation. Longer term investments must be part of early action as sometimes energy efficiency renovation measures are cost-effective only if they are done as part of the regular renovation cycles of a building. ${ }^{31} \mathrm{~A}$ missed opportunity locks-in inefficient technologies for another 30 years or so.

The level of investment required to improve the energy efficiency of a building, even if costoptimal over 30 years, may not appear to provide a good return on investment for the initial investor. For many investors, 30 years is much longer than they are willing to wait to see a return

30 See study in German: www.dena.de/fileadmin/user_upload/Publikationen/Gebaeude/Dokumente/denaSanierungsstudie_Teil_1_MFH.pdf

${ }^{31}$ The World Business Council for Sustainable Development emphasizes that the cost-effectiveness of retrofitting can be improved when carried out as part of general refurbishment (WBCSD, 2007) 
on their investment. Policy intervention is needed to drive investments in deep retrofits of buildings at cost-optimal levels and not only in single "cherry-picking" measures that provide higher returns on investment. Regulation, through more stringent requirements for buildings energy performance, and easily understandable energy certification of buildings can push demand for investment.

Page | 32 Different economic instruments are appropriate at different stages of development of the market for low-energy buildings. Energy taxes and prices are needed all the way through the process to provide a disincentive to consume energy in both efficient and inefficient buildings. The IEA recommends that all countries implement stringent mandatory building energy codes. At an early stage in the development of the market, when very stringent building codes are being phased in, economic instruments in the form of subsidies such as tax incentives or grants or access to preferential rate loans can be offered as incentives to encourage early adopters to invest in deep retrofits. As awareness is raised and it becomes clear that tight energy codes will be enforced in the not-so-faraway future, more people should begin to invest in deep retrofits and government subsidies can be reduced and access to finance encouraged. Finally, with the introduction of stringent building energy codes covering both new and existing buildings, easy access to finance is needed to enable the last adopters to invest in deep retrofits.

Energy efficiency markets in IEA member countries have sufficiently developed to require tight building energy codes. The use of economic instruments should be adapted accordingly. Economic instruments that facilitate access to finance for large numbers of investors become important as markets for low-energy buildings develop and investment is scaled up over time. Some compensatory mechanisms may also be required for low income groups to offset any regressive effects of stringent building codes. Debt finance should be straightforward and designed to facilitate larger investments that benefit not just the initial investor alone but also future occupiers in terms of lower energy bills. Innovative financing mechanisms are needed at this stage to tie debt to the property rather than the initial investor, to enable third parties to invest and collect repayments, and to ensure that the private sector is financing the bulk of the investments.

The next sections examine how economic instruments have been used by governments to date to encourage individuals and businesses to invest in low-energy buildings. Interest from governments in innovative public financing mechanisms that also leverage private finance in energy-efficient buildings is growing and so the experiences available to date in this area have also been investigated to see whether any lessons have been learned so far.

\section{II.2 Economic instruments and low-energy buildings}

This subsection describes the current use of economic instruments to improve energy efficiency in the buildings sector. It follows the taxonomy of economic instruments outlined in Part I.

Many IEA countries have implemented economic instruments to support implementation of energy-efficient buildings and these experiences are examined in the following subsection. The emphasis is on examining whether economic instruments to date have supported significant improvements in energy performance in buildings, i.e. the delivery of low-energy buildings, rather than incremental improvements in energy efficiency, and how they should be used in the future to achieve long-term deep cuts in energy-use in buildings. Economic instruments cannot overcome all the barriers to investment in low-energy buildings on their own, but should rather be seen as an essential part of a policy package comprising regulatory and information measures as well. 


\section{Energy taxes and price subsidies}

Energy taxes paid by households and businesses, act as economic instruments to support investment in energy efficiency in buildings. Higher energy prices make the business case more persuasive for investment in energy efficiency in buildings, as they reduce the time to pay back the initial cost through energy savings. They also raise revenue which can be earmarked for spending on energy efficiency in buildings.

According to IEA statistics, the taxes paid on different energy sources by households differ considerably between member countries as well as tax bases. Table 1 shows countries with the highest taxes on energy paid by households in 2011 (adjusted for relative purchasing power) and, in the last column, those with the lowest in each category of energy. However, there are many confounding factors that influence the use of energy by buildings users such as climate, population density, types of fuel, and buildings energy policies that make a simple comparison of energy prices with average buildings energy use in different countries difficult.

Table 1 - IEA member countries with highest taxes on household energy in 2011

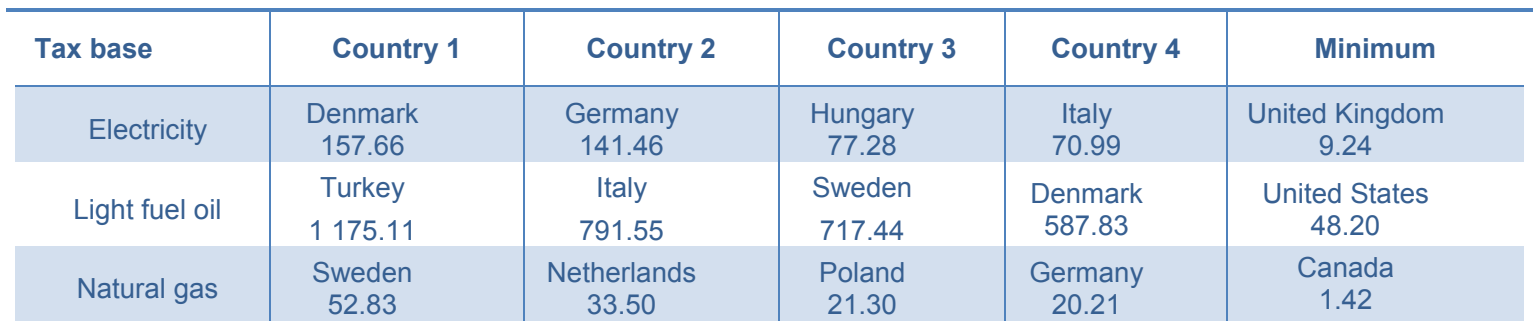

Note: total taxes in USD per unit of energy adjusted for purchasing power, USD PPP/unit

Sources: IEA database on energy prices and taxes

Higher energy prices (including energy taxes) increase the profitability of energy efficiency investments. However, studies in several countries have shown that the consumer response in the buildings sector to higher energy prices is relatively inelastic in the short term, i.e. it is less than 1 - a $1 \%$ increase in household energy prices would lead to a decrease in energy demand of between $0.1 \%$ and $0.4 \%$ (various authors, cited in UNEP 2007, pp. 36). ${ }^{32}$ This illustrates the fact other market barriers exist in the buildings sector apart from externalities, e.g. split incentives or lacking access to finance, and therefore energy prices alone will not be enough to encourage lowenergy buildings. It is also due to the lack of immediate substitution options available to endusers.

In the longer term, the price elasticity of energy demand is higher (converging at around 0.7, i.e. a $1 \%$ energy price rise leads to a $0.7 \%$ reduction in energy demand over 3-5 years) because behaviour and equipment can change in the long run. Even though households may only be able to change their energy consumption to a small extent in the short term (i.e. through behavioural changes), the next time they plan to invest in equipment or undertake buildings refurbishment, they are more likely to take the energy performance into consideration when making their purchasing decision (UNEP 2007, pp. 35-36). Therefore rising energy prices are important as a medium- and long-term strategy to signal to householders and businesses that reducing energy consumption is something they have to care about. Energy taxation and prices can also play an important role in reducing the rebound effect, so that the gains through energy-efficient

\footnotetext{
${ }^{32}$ The consumer response to prices is considered inelastic when the ratio of the change (reduction) in demand for energy relative to the increase in energy price is less than one. This value is called the energy price elasticity of demand.
} 
technology are not lost through increased use of energy and ensure that energy efficiency measures actually reduce energy consumption. Research shows that a mix of instruments is needed to address the rebound effect, but that instruments that ensure high prices must be part of the policy package (EC, 2011b, pp. 16-17).

Energy taxes represent an important source of revenue for governments as discussed in the chapter on sources of funds later. The optimal tax rate may differ depending on the goal pursued by the tax (e.g. revenue raising, carbon pricing, promoting energy efficiency or slowing rebound effects). The objective of environmental taxation must be clear and may depend on the country context. Special consideration should also be given to low-income or vulnerable groups as energy prices rise, as regressivity may be an issue. Targeting and prioritisation of these groups through deep retrofits can help shield groups of all income levels from price rises.

Box 3 provides more information on how Denmark has used household energy taxes as a long term strategy to reduce energy consumption.

Energy taxation and prices can also play an important role in reducing the rebound effect, so that the gains through energy-efficient technology are not lost through increased use of energy and ensure that energy efficiency measures actually reduce energy consumption. ${ }^{33}$ Research shows that a mix of instruments is needed to address the rebound effect, but that instruments that ensure high prices must be part of the policy package (EC, 2011b, pp. 16-17).

Energy taxes represent an important source of revenue for governments as discussed in the chapter on sources of funds later. The optimal tax rate may differ depending on the goal pursued by the tax (e.g. revenue raising, carbon pricing, promoting energy efficiency or slowing rebound effects). The objective of environmental taxation must be clear and may depend on the country context. Special consideration should also be given to low-income or vulnerable groups as energy prices rise, as regressivity may be an issue. ${ }^{34}$ Targeting and prioritisation of these groups through deep retrofits can help shield groups of all income levels from price rises.

\section{Main points:}

- Energy taxes are one of the few economic instruments for energy efficiency in buildings that do not need public funding, but which present a source of revenue for public budget.

- Some form of energy taxes on household energy consumption is levied in almost all IEA member countries but tax rates vary widely between countries and between energy sources.

- Rising energy prices through progressively introduced taxes give a strong long term incentive to invest in energy efficiency and can also address the risk of rebound effects, whereas energy consumption subsidies provide a clear disincentive to undertaking such investments.

- Energy taxes can shorten pay-back periods and increase rates of return of energy efficiency investments, but do not help to address other more structural barriers, such as split incentives or the lack of access to finance.

- Low-income and vulnerable groups need special consideration when energy prices rise due to their potential regressive impact. Special measures may need to be taken to assist these groups in investing in low-energy retrofit measures to reduce the burden of rising energy costs.

\footnotetext{
${ }^{33}$ The rebound effect describes the idea that energy savings may not be realized as planned despite efficiency gains due to increased consumption resulting from e.g. increased room temperatures or the purchase of additional energy consuming appliances (Ryan and Campbell, 2012).

${ }^{34}$ Regressivity or regressive impact is when imposing taxes on energy or other goods would impose a heavier burden on lowincome households than on high-income households, since the former spend a larger share of their income on these goods.
} 


\section{Box 3 • Experiences with the use of household energy taxes in Denmark}

In Denmark, the government first introduced energy taxes on households in 1977. In 1986, these were considerably increased to keep energy prices for households on a high level, just at the moment were these were going down again after the second oil crisis. By using the prevailing situation as a window of opportunity, resistance from consumers was greatly reduced ${ }^{35}$. In 1992, Denmark started phasing-in a $\mathrm{CO}_{2}$ tax on households. Both taxes were extended to cover also the business sector in 1996. Between 1995 and 1999, about 2\% of all taxes were shifted from distortive taxes on labour towards a taxation of pollution and resource use. The highest taxes are paid by the household and the public sector, followed by the transport sector and space heating, which together account for $64 \%$ of energy taxes paid in Denmark. In 2009, households and the public sector paid electricity taxes of EUR 0.09 per kWh. In 2009, a general tax reform was adopted by the Danish parliament which included a number of changes for energy taxes. Energy taxes, with the exception of petrol and diesel taxes, were raised by $15 \%$, new taxes were introduced, such as a tax on air conditioning, and thresholds to the $\mathrm{CO}_{2}$ tax were lowered among other changes.

An evaluation from 2008 has estimated that without energy taxes energy consumption in Denmark would be at least $10 \%$ higher. Other researchers estimated that energy taxes in Denmark between 1977 and 1991 reduced energy consumption of the residential sector by $15 \%$.

An important feature of the Danish energy taxes is also that taxes are indexed on inflation since 2008, which prevents an annual decline of the real value of taxes through inflation. The Danish energy tax system differentiates between energy used for space heating and energy used for productive processes and energy taxes are set according to the relative energy content of different fuels.

Denmark also combines energy taxes with a range of other instruments to achieve its national targets set in 2008 for energy efficiency (annual reductions of total final consumption by $1.5 \%)^{36}$, these include emission trading, energy supplier obligations, labelling for buildings and appliances, stringent building energy codes, voluntary agreements with industry, regulation aimed at the public sector and information and awareness raising.

Source: Togeby et al., 2009 and Danish Ministry of Taxation, 2009

\section{Tax relief}

Various tax reliefs exist for energy efficient equipment and material or related services in a number of countries. Australia, Belgium, France, Italy, Japan, Portugal, the United Kingdom and the US have one or more forms of tax relief with regard to energy efficiency in buildings or efficient appliances. Tax relief relating to the energy performance of buildings has tended to focus on the installation of energy-efficient equipment, such as boilers, heating, ventilation and cooling (HVAC) systems, insulation, energy audits, renovation of buildings, and new construction of low energy buildings rather than deep retrofits aimed at improving the energy performance of the whole building.

Tax relief for energy efficiency measures in the buildings sector can be useful in elevating attention on investment in energy efficiency measures to the level of chief financial officers and other decision-makers in a company. This may raise the profile of energy efficiency investments and overcome the split incentives between production managers that are concerned about the running costs of commercial buildings and equipment and the financial officers that are more

\footnotetext{
${ }^{35}$ Refers to the presentation by Mikael Skou Andersen (EEA) given at the IEA expert workshop: www.iea.org/work/2012/energy_efficiency_finance/2c3SkouAndersen.pdf

${ }^{36}$ The latest energy agreement of March 2012 included initiatives that shall lead to a reduction of $7 \%$ reduction of final energy consumption (excluding transport) between 2010 and 2020: www.kemin.dk/Documents/Presse/2012/Energiaftale/FAKTA\%20UK\%201.pdf
} 
interested in reducing upfront investment (capital) costs.

However, financial institutions may be reluctant to take into account available tax relief for energy efficiency investments in their risk assessment if they are not familiar with the process related to claiming the tax relief. This may be especially the case where eligibility requirements are complicated to understand and/or to fulfil. This may be the case where the relief can only be claimed after the purchase or investment, as in the case of a partial tax refund, and even more so where the exact amount saved depends on other factors. But the uptake of new types of tax relief for commercial buildings should increase over time as experience is gained and the perceived risk accordingly can be downgraded (WEF 2011, pp. 25).

An interesting feature of tax relief for energy-efficient buildings is that they often achieve a very high level of uptake in the residential sector. Since 2007 Italy has provided tax relief for energy efficiency improvements to existing buildings including the installation of double-glazed windows, thermal insulation, high-efficiency boilers and the installation of solar panels. In 2009, building owners submitted 240,000 tax credit applications. As the programme was originally expected to be terminated in 2010, the number of applications in 2010 exceeded the previous year by around $71 \%$. In France about 4.2 million households have benefitted from similar tax incentives between 2005 and 2008 which equals about 13\% of the residential building stock, (see case studies in the annex for more information on tax incentives in France and Italy).

Tax relief for low energy buildings thus has the potential to transform markets in a relatively short period of time. Through tax credits for energy-efficient new homes in the US, the market share of eligible homes ${ }^{37}$ rose from 1\% in 2006 to $10 \%$ in 2009 (ACEEE 2011a, pp. 3-4). Another example can be found in US tax credits for non-business energy improvements put in place 2006 and extended several times until 2010. The most impressive effects of the US programme are found for Energy Star windows: the national market share rose from 49\% in 2005 to $93 \%$ in 2010. Even though the incentive was cut back sharply in 2011 (from originally $\$ 1500$ to $\$ 200$ ), the market share stayed high at 89\% in 2011 (ACEEE 2011a, pp. 6).

While these results seem to be impressive, it seems certain that tax relief schemes have not achieved deep retrofit in buildings to date. It is very difficult to assess how ambitious are performance requirements for the different schemes. Because every scheme uses different technical characteristics and benchmarks a comparison of different schemes is impossible. This in turn makes it very difficult to assess the overall effectiveness and efficiency of such schemes. But it is clear that all of the tax relief schemes for energy efficiency in buildings examined have been for the purchase of individual pieces of equipment rather than improvements in whole building energy performance and therefore would not have been suitable on their own in their design to achieve deep retrofit of buildings.

Additionally, there is a serious issue about free-ridership, i.e. the share of people that would have invested anyway even in the absence tax relief. The goal is to encourage the uptake of energyefficient technologies in buildings and increase the numbers and scope of refurbishment that would otherwise not take place. Therefore it is important that tax relief be targeted at new and innovative technologies with little market access and high upfront costs (Geller 2006, pp. 571). Surveys of free-riders for various former US tax incentive programmes in the buildings sector have indicated possible rates between $53 \%$ and $94 \%$. The number of free riders clearly depends on the design of each programme and in order to address the issue, the US federal government is now targeting incentives at only the most efficient measures and appliances with a market share below 5\% (Neuhoff et al., 2011 pp. 12).

\footnotetext{
${ }^{37}$ built according to the 2004 supplement to the International Energy Conservation Code - ICEE
} 
Tax relief has a negative impact on public budget revenues, which is not easy to control. The uptake of programmes depends on many factors and there is no way to limit the overall uptake in order to limit the impact on public budgets. In France the level of the tax relief was reduced several times in order to reduce the costs of the scheme (see case study in the annex). At the same time there exists no clear threshold for tax relief in order to mobilise sufficient uptake of energy efficiency measures (UNEP 2007, pp. 37).

Another issue is the administrative burden related to the application process can not only weigh heavily on the programme costs but will also impede potential participation and thus reduce impact. Cited in this regard is tax relief for commercial buildings in the United States with multiple conditions attached (WEF 2011, pp. 25) or complex application processes, i.e. where software to automatically generate reference buildings was not available in time, which meant that applicants had to generate their own reference building manually (Gold and Nadel, 2011, pp. 2). Before introducing new tax relief schemes, sufficient preparation time should be given so that guidance can be provided to potential participants and implementing authorities are prepared to administer the programme smoothly (Gold and Nadel, 2011, pp. 3).

Tax relief for low-energy residential buildings is more likely to be attractive to individuals paying higher income taxes, and therefore will not be useful in encouraging low-income groups to improve the energy performance of buildings.

\section{Main points:}

- Tax relief is less frequently used for energy efficiency investments in the buildings sector compared to grants or loans but is not uncommon.

- Tax relief for energy efficiency measures in buildings can achieve high levels of uptake and may potentially transform markets rapidly but serious doubts exist if tax exemptions use potential public revenues in an efficient way.

- Tax relief needs to be targeted at highly efficient equipment or materials with very small market shares (e.g. less than 5\%) in order to limit free-ridershipp. It has not been used to incentivise whole building deep retrofits.

- Tax relief is not the right instrument to target low-income households.

- The negative impact of tax relief on government revenues can become significant and is difficult to administer.

More in depth information on experience with tax relief in the building sector can be found in the case studies on France and Italy in the annex.

\section{Grants}

Grants schemes are probably the best-known economic instrument supporting energy efficiency measures in the buildings sector. Grant schemes are the most frequent form of incentives provided for the building sector according to the IEA policies and measures database, which counts 17 countries with such grant schemes. ${ }^{38}$ Most grant schemes target residential buildings rather than commercial or public buildings. However, there are also examples for the latter case; e.g. Australia, Canada, and Japan have grant schemes for commercial buildings and Austria, Portugal and Germany have grant schemes for public buildings. Often several parallel schemes

\footnotetext{
${ }^{38}$ Namely: Australia, Austria, Finland, Greece, Hungary, Ireland, Italy, Japan, Luxembourg, New Zealand, Spain, Sweden, Switzerland, United States, United Kingdom
} 
exist in one country for different target groups.

Many countries, e.g. France, Germany, Ireland, New Zealand, the United Kingdom and the United States, have special grant programmes for the refurbishment of residential buildings with lowincome families (see Box 4 for New Zealand). Despite the existence of plenty of examples, few thorough evaluations are available.

Grant schemes have generally targeted investments in buildings with high returns at the lower end of the cost curve in order to keep overall programme costs low. Overall, it appears that grants have mainly been used to date to subsidise the sale of energy-efficient equipment in buildings, such as boilers, heating, ventilation and lighting systems, as well as renewable energy systems. In a few countries they have also been used for insulation measures e.g. in Canada, Germany, Ireland and New Zealand. Grants have not been used to promote comprehensive retrofit of buildings through multiple measures. However, an exception is Germany which attaches high efficiency criteria to the components financed under their grant programme, with a view of enabling a step-by-step approach towards deep retrofit (see case study on Germany).

Due to the scale of investment needed for buildings deep retrofit and tight public budgets, it seems unrealistic that deep retrofitting can be achieved on a broad scale through grant schemes. In Canada over 640000 building owners have received grants between 2007 and 2012 (about $5 \%$ of the low-rise building stock). In Ireland around 160000 homes, (representing $9.4 \%$ of the total occupied dwelling stock), have been upgraded through the grant scheme between 2008 and 2011. Both in Canada and in Ireland, grant schemes have led to savings of on average $20 \%$ in buildings in the schemes.

Grant schemes for energy efficiency in buildings can be useful for raising awareness of energy efficiency in buildings. They deliver a message to the public that investment in energy efficiency improvements is valuable and are usually a simple-to-understand subsidy mechanism for energyefficient equipment for consumers.

However, similar to tax relief schemes, policymakers should recognise that even with high uptake, grant schemes have not and are not likely to achieve neither the scale nor depth of retrofit required for buildings (in the range of 50-80 \% improvement in energy performance). Instead, there is a risk of creating a lock-in effect for another 30 years. In order to avoid the lock in effect, one option might be to ensure that single measures financed through grants are part of a longer-term approach to deep-retrofit the whole over time. This might be achieved by requiring that measures financed through grants are part of a package proposed by a whole-house energy assessment. Thereby a step-by-step refurbishment plan could be enabled, delivering widespread deep retrofitting of buildings.

Grant schemes are most appropriate when the market for energy efficiency in buildings is at an early stage and the goal is to encourage early movers to invest in energy efficiency and equipment suppliers and installers to provide and install more energy-efficient models. They should be time-limited and replaced with economic instruments enabling finance of deep retrofit measures as the market becomes more developed. Grants are also appropriate to address fuel poverty in low-income households and may be used to enable low-income households to invest in energy efficiency in order to counter rising energy prices. 
The "Warm up New Zealand: Heat Smart" programme ${ }^{39}$ provides grants for the refurbishment of homes built before the year 2000 and the replacement of inefficiency heating systems. The programme has two levels of grants: one for low-income earners (i.e. those that hold Community Service Cards), and one for other income groups. Low-income homeowners or landlords with low-income tenants can recover $60 \%$ of costs for insulation works through grants, whereas the grant size for other home-owners is limited to 33\%. Grants for efficient heating are limited to NZD 1200 for low-income home-owners and NZD 500 for homeowners with low-income tenants as well as all other home-owners. In the years 2009/2010 and 2010/2011 slightly more low-income households have benefitted from the programme compared to other households, i.e. 52000 retrofits of buildings of low-income households against 48000 other buildings and 13000 heating replacements in low-income households against 11000 heating replacements in other households. Total programme costs for the two years amounted to NZD 186.5 million of which less than $8 \%$ were administrative costs.

The programme evaluation has looked at energy saving impacts as well as health impacts. For this programme, health impacts have dominated the overall impacts clearly and were significantly larger in low-income households. Energy savings are estimated at NZD 17 million whereas health benefits amount to over NZD 1200 million (using a 4\% discount rate), compared to overall programme costs of NZD 332 million. The insulation component was the main driver to achieve these significant health effects, much more so than the heating component. This could be an indication that the participating homes were not sufficiently heated before the refurbishment. Some part of the potential energy savings have thus been "taken-back" through an increase of average indoor temperatures. Net benefits of the programme are, however, positive even when applying an $8 \%$ discount rate. In order to decrease freeriding, householders have to contribute to the cost of the work. However, this cost can be further reduced as third-party finance is provided by a range of groups, including charities to low-income groups.

Source: Grimes et al., 2011

Free-ridership is a significant issue with grant schemes and surveys of the Canadian eco-ENERGY programme indicated that as much as $70 \%$ of participants might be free-riders. In order to limit the potentially great risk of free-riding, grant schemes can be limited in time and/or to only specific technologies with little market shares so that only early movers and advanced technologies are targeted (UNEP, 2007). Grants should no longer be awarded to energy-efficient equipment models that have reached widespread market penetration.

\section{Main points:}

- Grants are currently mainly used to encourage energy efficiency investment in residential buildings and to promote single measures, such as installation of individual pieces of energyefficient equipment or in some cases for insulation measures.

- The amounts awarded by grant programmes are limited by the budgets accorded to the respective programmes, which are renegotiated for each budget cycle. This reduces the predictability of future investment costs in the construction sector.

- In countries with grant schemes for energy efficiency in buildings there has been a high rate of take-up; however there is strong evidence of high numbers of free-riders.

\footnotetext{
${ }^{39}$ The New Zealand programme was presented by Christine Patterson and discussed during the IEA expert workshop in March 2012 and further details can be found at: www.iea.org/work/workshopdetail.asp?WS_ID=552, evaluations are available at: www.healthyhousing.org.nz/research/current-research/evaluation-of-warm-up-new-zealand-heat-smart/
} 
- Grant programmes can be useful in preparing the market (construction sector and the public) for deeper retrofit programmes when familiarity with energy efficiency measures in buildings is low. However, sufficient technologies are already available in IEA countries and therefore other policy instruments are now required to move on to widespread deep retrofit. Achieving deep retrofitting on a broad scale is unlikely to be achieved via grant programmes alone.

- Grants can be used to target energy efficiency measures in low-income households. Such programmes are likely to produce less environmental benefits (compared to programmes targeting the highest technical potential) but instead other benefits, such as health benefits may be significant.

More in-depth information on experiences with grant programmes can be found in the case studies on Germany and Ireland in the annex.

\section{Loan programmes}

Debt finance in the form of loans is needed to finance the upfront costs of energy-efficient buildings. However, private individuals or businesses may be reluctant to take on personal loans to finance energy-efficient buildings and may also have difficulty accessing finance even if willing to do so. Access to conventional bank loans to finance energy efficiency measures in buildings still poses a major problem in many cases; even though investment costs can be recovered by energy savings over time.

Governments can make funds available for specialised loan programmes that support investment in low-energy buildings. This subsection discusses more traditional concessional loan schemes whereby the government provides capital directly to subsidise loans to investors in low-energy buildings. The following subsections on "Guarantees" and "Other structured finance" discuss several financial and legal provisions involving other actors, which can be used to further enhance the attractiveness of loans for investment in energy efficiency in buildings in order to address additional financing barriers in the buildings sector.

\section{Concessional loans}

There is growing interest in loan support mechanisms as policy makers acknowledge the scale of investment needed to move to low-energy buildings. Countries with concessional loan programmes are France, Germany, Hungary, Japan, Korean, Luxemburg, Norway, Poland, Slovak Republic, Spain and the United States (and previously Australia).

Concessional loans are when loans are provided at either preferential interest rates or with debt relief for investment in low-energy buildings. Public funds are used generally to provide either credit lines from government to financial institutions, which are on-lent to investors, or a special fund that is lent directly to investors in energy efficiency measures in buildings.

The provision of funds for financial institutions to on-lend to investors in low energy buildings can provide financial institutions with access to new customers without any commitment of their own funds. Financial institutions can gain familiarity with investments in low energy buildings and build up expertise in this area.

Public subsidies used for interest rate relief can generate interest in investment in low-energy buildings. In France where regular market interest rates tend to be around $8 \%$, the French EcoPTZ programme offers a $0 \%$ interest rate. ${ }^{40}$ The German KfW loan scheme provides lower-than-

\footnotetext{
${ }^{40}$ See: http://www.developpement-durable.gouv.fr/L-eco-pret-a-taux-zero-en-13.html
} 
market interest rates that vary, depending on the current subsidy available to the programme, but at the time of writing were at $1 \%{ }^{41}$

Both the French and German schemes have had significant rates of uptake, yet compared to the overall residential building stock their impact remains marginal. Between 2005 and 2010 the German KfW loan programme awarded about 250000 loans leading to the refurbishment of $1.4 \%$ of the national residential building stock. The French Eco-PTZ programme awarded almost 200000 loans between 2009 and 2011 reaching $0.6 \%$ of the residential building stock.

There is a trade-off between stricter requirements for packages of measures leading to deep retrofits and higher uptake of the programmes. Both the French and German schemes have targeted multiple energy efficiency measures, leading to larger reductions in energy demand per building $(30-50 \%)$ compared with any other economic instruments used in the buildings sector to date (see Annex case studies for details). However, since the KfW scheme allowed single measures to become eligible for loans in 2009, the volume of loans and grants has increased but the average reduction in energy demand per building fell from $48 \%$ to approximately $30 \%$.

Other concessional loan programmes that provide reduced interest rates, such as the Connecticut Home Energy Solutions programme and the New York Residential Loan Fund in the US, report that this approach can still be very costly (Hayes et al. 2011). Alternative approaches to reduce interest rates are discussed in the sub-section below on risk-sharing facilities.

Partial debt relief has in theory a similar effect as a grant, but as it is tied to a loan, it can be used to leverage investments of a greater size compared with grants or tax relief for investments in single measures in buildings. Also, debt relief conditions can specify that partial relief will be granted only once the remaining debt under the loan has been repaid, and thus create an incentive to fully repay the loan on time. The German KfW loan programme provides partial debt relief to encourage deeper retrofitting. It is granted only for retrofits that outperform the thermal standards for new buildings and increase with the level of performance reached.

Setting ambitious, easily understandable and aggregated criteria (such as overall reduction in final energy consumption or emissions of a building) for buildings energy performance is important to ensure that loans are provided for deep retrofitting rather than superficial measures. Using overall building energy performance improvement as a criterion provides flexibility to reach these targets in the most cost-effective and suitable way for the individual building. It also makes the programmes easier to evaluate and monitor, and facilitates the comparison of results.

It can be equally important for communication and awareness-raising purposes to link loan programmes to building codes and buildings energy certificates. Again, a good example is seen in the German KfW loan programme, where loan conditions are set relative to equal or better energy performance than required by the building energy codes (EnEV), and are now widely known and viewed as a "label" for high performance buildings. The fact that houses comply with $\mathrm{KfW}$ energy performance requirements is now being used as a selling point in advertisements when selling properties.

Another critical issue when designing a programme is a requirement to provide an independent ex-ante energy assessment of the building. Several problems were reported in the Australian programme in this area, where self-declared experts essentially proposed measures that their

\footnotetext{
${ }^{41}$ At 25.07.2012, source https://energiesparen.kfw.de/inter-lt-eneffbausan$\mathrm{war} / \mathrm{html} /$ finanzierungsangebote/energieeffizient-sanieren-151/konditionen/
} 
own business would be able to implement. ${ }^{42}$ As these were often equipment suppliers, recommendations seldom included insulation measures and other more complete building measures for deeper retrofit. Germany, on the other hand, has had good experience in this area, mainly through the requirement to use certified and accredited energy experts. ${ }^{43}$

Other lessons learned from Australia were that a greater level of detail in the energy assessment, including more targeted recommendations, proposals for their implementation and related cost estimates, especially for low-income households, would have made the assessments of more use for loan applications. An ex ante energy assessment carried out by a certified expert can also help the banks to do better risk assessment. A credible estimation of savings associated with the measures to be undertaken can decrease the risk premium attached to the loan. In many cases the risk assessment is done by local banks. Banks are unlikely to be able to carry out either the audit or verify the technical requirements, as it is not part of their core business and they lack the needed skills. It is therefore of importance that the technical assessment is done by a credible institution or a certified assessor.

In some cases, ex-ante assessments can allow the use of e-loans, where a high degree of automation is achieved in the application process through the use of an online portal. Examples with automated loan application procedures can be found in the US, where it is applied to the PACE programmes. Yet, these kinds of automated processes may only be applicable for aggregated purchases of specific technologies and may be too costly to put in place for more customised retrofit projects (Kats et al., 2011, pp. 38). Australia had planned to use an online application procedure for its Green Loan programme, but due to a lack of lead time was not able to set up a working system in time for the launch. The responsible institution concluded that a more streamlined approach to obtain the loan would have encouraged a higher loan uptake and led to the programme having a much greater impact (see Box 5).

Loan programmes clearly enable access to energy efficiency finance, but in order to see sufficient uptake and achieve real improvement in energy performance of buildings, need to be accompanied by intense information campaigns and awareness-raising activities. Loan programmes for low-energy buildings can also be combined with other economic instruments such as grants or tax incentives.

\section{Main points:}

- Loan programmes provide liquidity to financial markets for low-energy buildings and reduce the cost of financing energy efficiency investments to home owners. They are a crucial part of the policy package needed to scale up investment in low-energy buildings.

- Using the thermal performance improvement for the whole building as an eligibility criterion has many benefits compared to the use of technical criteria for each eligible measure.

- Ex ante energy assessments are important for the success of loan schemes if they are done by credible and competent experts.

- Engaging local financial institutions in such schemes from the start and providing them with technical assistance to build up in-house competences is important.

- As concessional loan programmes do not address many of the other barriers to increasing investment in energy efficient-buildings they need to be part of a policy package.

More in depth information on experiences with loan programmes in the buildings sector can be

\footnotetext{
${ }^{42}$ See expert workshop report: $w w w$.iea.org/work/workshopdetail.asp?WS_ID=552

${ }^{43}$ See case study on Germany
} 
found in the case studies on France and Germany in the Annex.

\section{Box 5 - Experiences with green loans from Australia}

The Green Loans programme was an Australian Government initiative which commenced on 1 July 2009 to promote and assist energy efficiency initiatives in Australian homes by providing free home sustainability assessments to home owners or tenants (HSAs) with an annual taxable income of maximum AUD 250 000. The assessments were voluntary and provided householders with valuable information and advice on the actions they could take around their home to save energy and water. In the early phase of the programme, there was a loan component where householders could borrow from participating banks up to AUD 10000 over 4 years without paying interest to implement recommendations. The government funded the interest forgone to the banks as well as a fixed administration fee of AUD 200 per loan. The key objectives for the programme were to encourage wide-scale improvement of energy and water efficiency in existing homes; provide sound advice to households on the most appropriate actions to reduce the environmental impact of operating their home; and reduce greenhouse gas emissions. The loan component was phased-out in March 2010 but HSAs carried on until the programme close on 28 February 2011.

The Green Loans programme experienced an unexpected demand for participation from assessors as well as from households. The administration of the programme faced a number of difficulties to respond adequately to the demand due to the fact that it was launched with preparation time that was too short to set up the needed procedures and support mechanisms and to train assessors adequately. It also coincided with the introduction of a number of other environmental programmes (some as part of stimulus funds) and there was a lack of experienced personnel in the implementing institution. In February 2010 it was announced that the loan part of the Green Loan Programme would be phased out.

Over 670,000 home assessments were conducted during the course of the Green Loans Programme. Of the households assessed, $1.5 \%$ received a Green Loan for implementing one or more of the assessments' recommendations. The low uptake of loans was mainly due to the administration being overwhelmed which resulted in long lead times between the assessment and the household's reception of the assessment report. Loans were mainly invested in solar panels $(78 \%)$, efficient hot water services $(25.2 \%)$, heating or cooling devices $(10.6 \%)$, window treatments $(9.9 \%)$, water storage $(8.7 \%)$ and insulation (8.3\%). However, over half $(55 \%)$ of the people surveyed who did not receive a Green Loan still implemented some of the recommendations as a result of the HSA.

An independent survey of programme participants (comprising about 1200 telephone interviews) found that it was successful in developing an improved understanding of how to achieve a sustainable and more efficient household. Further, it provided householders with access to financial assistance to invest in energy and water efficient technologies that they were unlikely to implement otherwise. Approximately $93 \%$ of householders that received a Green Loan reported that their energy bills had decreased. Additionally, $82 \%$ of loan recipients declared to have changed their behaviour, compared to only $15.6 \%$ of respondents that had only received the HSA.

Source: AECOM, 2011 and ANAO, 2010

\section{Guarantees}

Loan guarantees are joint public-private approaches with the primary purpose to reduce the cost of capital for investment in low-energy buildings by limiting the risk faced by financial institutions. As energy efficiency measures in buildings are still perceived by private financial institutions as a risky investment, risk premiums in terms of higher interest rates are frequently attached to energy efficiency loans. This is the case even though first experiences with energy efficiency loans have shown that their default rate is actually lower than those for traditional loans in the buildings sector. Loans that were part of energy efficiency programmes in the United States have shown default rates of only $0-3 \%$ in spite of the housing market crisis (Hayes et al., 
2011 p. 6).

Public risk guarantees can be used as a transitional instrument to familiarise the local banking sector as well as banking regulators with the energy efficiency market segment, creating first experiences and to allow building up specialised knowledge and procedures with regard to energy efficiency investments (IEA, 2011a). They can be used alternatively or in combination with Page | 44 interest subsidies, as discussed in the section on concessional loans above.

Portfolio guarantees and loan loss reserve funds are especially adapted to the buildings sector which comprises a multitude of small-scale projects in need of finance and setting up a guarantee for each project would be far too costly (see Box 6. Risk-sharing facilities are also used to support the development of an ESCO market (IEA, 2011a).

\section{Box 6 • Experiences with risk-sharing facilities in Eastern and Central Europe for residential buildings}

The Commercialising Energy Efficiency Finance (CEEF) programme was jointly set up by the International Finance Corporation (IFC) and the Global Environment Facility (GEF). It was running between 2003 and 2008 with 14 participating banks and 41 project developers and ESCOs from Czech Republic, Slovakia, Hungary, Latvia, Lithuania and Estonia. Through the programme, 700 projects were financed; a large majority of which concerned multi-family residential buildings built in the Soviet era. Overall project investment amounted to USD 208 million and guarantees were given covering almost $25 \%$ of overall investment. While the GEF set up a first loss reserve, the IFC provided a pari-passu guarantee to participating banks. Yet none of the guarantees had to be called. Costs for programme administration, monitoring and evaluation and technical assistance amounted to USD 3.65 million and were paid for by the GEF. The projects financed led to an estimated reduction of 846 TJ per year in energy demand and 145700 tonnes per year in $\mathrm{CO}_{2}$ emission reduction. The evaluations assumed a 10 year lifetime for investments and calculated the GEF funds invested per tonne of avoided $\mathrm{CO}_{2}$ to be USD 2.5 .

It was estimated that the programme has also initiated further project activities through participating banks and ESCOs that did not make use of the guarantees with an additional investment amounting to USD 80 million.

A number of participating banks have continued serving this marked after the end of the programme, notably in Hungary and the Czech Republic.

Source: IEA, 2011a

Preconditions for effective risk-sharing facilities are the existence of a well-functioning banking sector and with enough liquidity to serve the new market share (Rezessy and Bertoldi, 2010). There can be relatively low costs associated with the approach, as shown in the example in Box 6, however this is dependent on whether the guarantees are called. In the CEEF programme for residential buildings in Box 6, the guarantees were not called and all of the funds invested were provided by private financial institutions. The barriers addressed with this instrument are the high perceived risks associated with energy efficiency investments in the buildings sector and the lack of methods and reference cases in the banking sector.

Technical assistance, in order to build up the necessary skills and procedures to process loans for low-energy buildings in the participating private financial institutions, is an important key to success. Government intervention should be restricted to a transitional phase, as the banking sector should not need to attach higher risk premiums to energy efficiency investments in lowenergy buildings as soon as enough experiences and adapted procedures have been built up (IEA, 2011a).

The IEA has published a Policy Pathway report that provides guidelines to policy makers for setting up risk-sharing facilities (IEA, 2011a). 
Main points:

- Risk-sharing facilities are a transitional measure to reduce the high risk perception of banks that are not yet familiar with financing energy efficiency measures in buildings.

- They can be an alternative to interest rate subsidies or a complementary measure to incentivise commercial banks to explore this new market segment.

- In order to have a lasting effect, technical assistance to banks to build up internal competencies on procedures and technical requirements for investments in low-energy buildings.

- They are unlikely to be very costly to the public budget but only address one specific barrier, i.e. the high risk perception of banks with regard to energy efficiency investments in buildings.

\section{Other structured finance}

Increasingly, governments are seeking ways to involve private and semi-state partners in investing in low-energy buildings. This may require new financial and legal frameworks to enable third parties to provide finance and take over the performance risk associated with the investments made in low-energy buildings. Experiences with these mechanisms to date are grouped as the following in the next subsections:

- Energy-provider on-bill finance;

- Property Assessed Clean Energy (PACE) schemes;

- Energy Performance Contracting (EPC).

Policy and capital to facilitate third party finance for energy efficiency measures is a recent phenomenon in some countries, however it is a trend set to continue with further programmes planned in several countries. These provisions can also be combined.

\section{Energy provider on-bill finance (tariffs and loans)}

On-bill financing presents a way of providing the needed upfront investment by energy providers or a third party, which is paid back by the client via the regular energy bill. While some general features of on-bill financing can be described, each programme is specific.

Most experiences with on-bill financing have been in the United States with 31 programmes in 2011 and target small commercial and industrial customers as well as home owners (especially the on-bill loans), see also Box 7. But recent developments have seen programmes extended to multifamily households (Bell, Nadel and Hayes, 2011 pp. 6). In Europe on-bill schemes are less well-known. However, the United Kingdom is about to launch an on-bill financing programme (see Box 8). 


\section{On-bill finance programme: Electric Cooperatives of South Carolina Rural Energy Savings Programme}

South Carolina passed on-bill financing legislation in 2010 which allows utilities to lend to their customers. The objective of this programme is to apply 225000 retrofit measures across the building stock by 2020, impacting 185000 - 195000 homes. The Electric Cooperatives of South Carolina (ECSC) and Central Electric Power Cooperative (Central) run the on-bill finance programme, which is financed by USDA's Rural Economic Loans and Grants Program (REDLG). The federal loans are made to Central, which on-lends to a NGO, KW, that works with individual cooperatives to administer the programme. The cooperatives collect repayments and the collected funds are sent back to Central. While all electricity customers in South Carolina are eligible, billing history is used to identify potential clients with high energy consumption for the programme. Audits are undertaken before and after the retrofit to measure the expected as well as the achieved energy savings. Although this programme is an on-bill loan programme, the loan is tied to the building energy meter and so is passed on from one owner to the next. The state hopes to lend USD 750 million through the programme and will avoid the costs that would have arisen through the construction of new power plants in South Carolina as a result of the projected energy savings of about $2700 \mathrm{GWh}$ of electricity.

\section{On-bill tariff programme: Midwest Energy Kansas How\$mart}

Midwest Energy launched an on-bill tariff programme for its residential customers in 2007. Currently, commercial and industrial financing is also provided. Until the end of 2011, approximately 650 projects had been completed through the programme, totalling USD 3.7 million of utility project investment and customers have added USD 1 million to this. Several public sources of funding Kansas Housing Resources Corporation, Efficiency Kansas - have been used to supplement utility funding and buy down the project costs and interest rates. Repayments for customers are set at $90 \%$ of estimated monthly energy savings. This mechanism helped alleviate initial concerns that customers would be cut off in the case of non-repayment. Residential projects are repaid over 15 years and so far there is a participation rate among customers of $1.3 \%$, which is considered to be relatively high for a loan programme (Hayes et al., 2011). Electricity savings are estimated to amount to around 2000 kWh per year per project and around $7600 \mathrm{kWh}$ for natural gas projects.

Source: Bell, Nadel and Hayes, 2011

On-bill financing has a number of advantages. It builds on the existing billing infrastructure and customer relationship between the energy provider and the client. Oftentimes the payments are structured in a way that the savings are equal or higher than the monthly payments (Bell, Nadel and Hayes, 2011 pp. 1-2). In this way, no additional costs are born at any time by the client with the exception of an eventual loan application fee (WEF, $2011 \mathrm{pp}$. 30). The energy provider usually has a payment record of the client at its disposal which may serve as a proof of creditworthiness of the client. Customers tend to prioritise energy bill payments, as in many countries services can be quickly interrupted in case of non-payment. Thus, providing finance for on-bill finance appears to be a low-risk investment (Bell, Nadel and Hayes, 2011 pp. 1-2). Yet some risk remains that customers with financial problems might decide to pay only the part of the bill related to the energy consumption and not the loan repayment, leading to legal ambiguity. In this case, the energy provider might decide to cover its own costs instead of reimbursing third-party lender (Capital-E, 2011 pp. 23). 
Through its Energy Act 2011, the United Kingdom set up an on-bill tariff mechanism, the "Green Deal" that is planned to come into effect towards the end of 2012. While many details are still to be sorted out, it shall be available to residential (home owners as well as tenants) and small commercial clients, be attached to the meter and repaid via energy bills. The sources of finance are to date only loosely defined as "Green Deal Providers" which may include any interested third-party finance providers. Energy suppliers will also act as finance providers, targeting specifically vulnerable clients (such as low-income households), as the scheme will be combined with energy supplier obligation legislation. ${ }^{44}$

There are in principle two kinds of on-bill financing: on-bill loans and on-bill tariffs. In both cases, the energy provider pays the upfront costs of the energy efficiency upgrade and the customer repays the costs as an additional charge on their monthly energy bill. The difference between onbill loans and tariffs lies in the timing and obligation to repay the credit for the upgrade.

Under on-bill tariffs, the loan or credit is attached to the building's meter rather than the customer of the energy provider at the time of the improvement. In the case of a change of building tenant or owner, the repayment obligations stays with the meter, so that the new tenant or owner takes over the repayments. This has the advantage of facilitating longer repayment periods and thus bigger investments; it also allows the targeting of rented homes (Bell, Nadel and Hayes, 2011 pp. 1-2). Sometimes the on-bill tariff is viewed legally as part of the energy bill rather than a loan, in which case it can be a way to finance energy efficiency improvements without taking on new debt (off-balance sheet finance). In order to structure onbill financing through tariffs, regulatory reforms might be necessary, which can become a complicated process (Capital-E, 2011 pp. 23).

In the case of on-bill loans, the repayment obligation is held by the property owner or tenant. The energy-provider may act as a broker to facilitate a loan between its customers and a financial provider and collect the payment from customers and repay the lender. It is highly unlikely that a tenant is willing to undertake such an investment, as they will not see the long-term benefits particularly if they are not planning to stay for a long time. If the property is sold, the loan must be repaid in full by the property owner at the time of the sale.

In both situations, the fact that loan payments can be made via the energy bill seems to be more attractive than taking on a usual loan and enhances participation in such schemes (Capital-E, $2011 \mathrm{pp}$. 23). As with regular debt finance, the loan conditions can be structured in a way that deeper retrofitting is encouraged (Capital-E, 2011 pp. 23). Energy providers can also make available attractive discounts on equipment through the aggregated procurement of certain products and thus further increase the cost efficiency of measures (WEF, $2011 \mathrm{pp} .30$ ).

Providing sufficient funds over the longer term remains a challenge. Often energy providers lack own resources to provide enough funding for large-scale programmes of this kind. Public benefit funds or energy provider funds which are sourced by charges play an important role as a source of funding, though these are often limited in size and may not be sufficient to scale-up the programmes. Energy providers may also act as a broker between potential third-party funding providers and clients. For this service, some energy providers take a fee (WEF 2011, pp. 30-34).

44 www.decc.gov.uk/en/content/cms/legislation/energy_act2011/energy_act2011.aspx, accessed on 07/07/2012 and http://www.decc.gov.uk/assets/decc/11/consultation/green-deal/5533-final-stage-impact-assessment-for-the-green-deala.pdf, accessed October 2012 
Yet, third-party funding for these programs is limited despite on-bill loans being cost-effective and having a low risk. They have remained so far less attractive to private investors as they offer only low returns and repayment periods can be long if deeper retrofit is the aim (Bell, Nadel and Hayes, 2011 pp. 3).

In any case, energy providers very likely need to make changes in their billing system, which can be complicated and costly for them and presents a barrier for engaging in such a system. This can be especially the case where providers of third-party funding will have specific requirements with regard to the billing administration (Capital-E, 2011 pp. 23).

While energy-providers run such programmes, they are usually enabled or mandated through state legislation. Initial capital to start a number of such initiatives in the US was provided through the American Recovery and Reinvestment Act (ARRA) of 2009. Legislation can be important because of the barriers to energy-providers to setting up these programmes. The core business model for most energy-providers remains selling energy.

\section{Main points:}

- On-bill financing can increase the willingness of property owners to invest, as no additional upfront costs are incurred and it can be designed to be off-balance sheet financing.

- As the repayment of the investment is via the energy bill and can be tied to the building rather than initial investor, the split incentive barrier can be overcome.

- On-bill financing can be structured in many different ways to suit the local context and to provide long-term finance for deep retrofit.

- Legislative changes may be needed to enable energy providers to engage in on-bill financing.

- Energy-providers may be only interested in financing the low cost energy efficiency measures, as there is a greater rate of return on investment and therefore without additional policies it may be difficult to achieve deep retrofit.

- Motivating energy providers to provide on-bill finance may be difficult (especially if their business model is still focussed on selling energy only), as they are likely to need to change their billing system to do so and they may be reluctant to engage in financing activities.

\section{Property assessed clean energy}

Property assessed clean energy (PACE) programmes have been used in the United States to provide public financing facilities mainly through local or municipal bonds for energy efficiency investments for residential and commercial buildings.

PACE loans may not be used to fund portable items, such as light bulbs or refrigerators, but only investments that will stay with the property. The US Department of Energy also proposes a minimum size of PACE loans of USD 2 500, due to the significant legal and administrative costs involved in setting up such programmes (US DoE, 2010 chapter 12 pp. 3). PACE allows for longterm financing, as loans are attached to the property rather than the initial investor. If the building is sold before the lien is repaid, the lien is automatically taken over by the new owner. PACE loans have a repayment period of up to 20 years (Rezessy and Bertoldi, 2010 pp. 38-39). Long repayment periods and the limited applicability to appliances make PACE loans very suitable for deep refurbishment of buildings if stringent energy requirements are attached to the disbursement of PACE loans.

Funding remains a challenge also for PACE programmes. Local communities or cities are unlikely to have sufficient funding available in their local budgets for a high scale-up of programmes. Funding can be provided through national budget allocations or local governments can decide to 
issue bonds (Rezessy and Bertoldi, 2010 pp. 38-39). A precondition for bundling PACE loans and securitizing them through bonds, is that the metric used for household energy efficiency assessments is standardised over the whole area covered by the PACE programme (Della Croce, Kaminker and Stewart, 2011 pp. 43-44). Bond issuing, however, can add significant transaction costs to the issuer, especially when the area covered is small and only a limited number of bonds are issued, which is likely to be the case if programmes are run on community or city level (Rezessy and Bertoldi, 2010 pp. 38-39). Due to significant administrative needs, it is estimated that setting up PACE programmes needs at least 6-12 months of lead time (Kats et al., $2011 \mathrm{pp}$. 24-25).

\section{Box 9 - Experiences with PACE in the United States}

Although 26 US states have passed laws authorising PACE, due to the uncertainty raised by the Federal Housing Financing Agency, only three states (California, Colorado and New York have continued with PACE programmes for commercial buildings. It is expected that Vermont and Maine will soon launch programmes also (Hesser 2012). In 2011, 71 commercial PACE projects were implemented in these three states, funding a mixture of renewable energy and energy efficiency projects. Further projects were planned to be launched in 2012. While the current projects have been funded mainly by government capital or credit, future programmes will rely more on private capital.

The four PACE programmes in operation differ considerably in terms of design, size and funding source. Funding models include using federal funds, county treasury, moral obligation bonds and city-backed funds. In Boulder, Colorado, more residential projects were completed with project sizes between USD 2000 and USD 200 000. A diversity of building types and measures were involved and the majority of measures were energy efficiency improvements. A pooled bond approach was used to finance the scheme. In Palm Desert, California, mainly residential buildings were renovated under the PACE programme there. The scheme provided 100\% financing for up to 20 years at $7 \%$ interest rate paid semi-annually. The scheme was funded with USD 2.5 million by the city's General Fund in addition to the issuance of bonds funding. Sonoma County and Placer County in California also have up and running PACE programmes.

\begin{tabular}{lllllll}
\hline Programme & $\begin{array}{l}\text { Approved } \\
\text { projects }\end{array}$ & $\begin{array}{l}\text { Total } \\
\text { approved } \\
\text { funding } \\
\text { (millions) }\end{array}$ & $\begin{array}{l}\text { Average project } \\
\text { size } \\
\text { (thousands) }\end{array}$ & $\begin{array}{l}\text { Interest } \\
\text { rate }\end{array}$ & $\begin{array}{l}\text { Term } \\
\text { (years) }\end{array}$ & Source of funding \\
\hline $\begin{array}{l}\text { Sonoma } \\
\text { county, CA }\end{array}$ & 37 & USD 7.27 & USD 196 & $7 \%$ & $<20$ & County treasury \\
$\begin{array}{l}\text { Boulder } \\
\text { county, CA }\end{array}$ & 29 & USD 1.52 & USD 51 & $\begin{array}{l}1.04 \% \text { or } \\
2.29 \%\end{array}$ & 5 or & $\begin{array}{l}\text { Moral } \\
\text { obligation } \\
\text { bond } \\
\text { issuance }\end{array}$ \\
$\begin{array}{l}\text { Placer } \\
\text { County, CA }\end{array}$ & 2 & USD 0.319 & USD 160 & $7.25 \%$ & $<20$ & County Treasury \\
$\begin{array}{l}\text { Palm Desert, } \\
\text { CA }\end{array}$ & 3 & USD 0.575 & USD 192 & $7 \%$ & $<20$ & $\begin{array}{l}\text { City-backed } \\
\text { Fands }\end{array}$ \\
\hline
\end{tabular}

Sources: Hayes et al., 2011; Renewable Funding, Clinton Climate Initiative, LBNL, 2011; and Hesser, 2012

Even though the approach seems very promising, PACE has experienced legal hurdles in its implementation. In most residential PACE programmes, the PACE loan repayment takes priority (i.e. senior lien position) over the repayment of other existing mortgage on the building in the case of the owners default. In July 2010, the Federal Housing Finance Agency (FHFA) reacted by publishing a statement that this runs contrary to standard mortgage contracts and "presents significant safety and soundness concerns" (US DoE, 2010 chapter 12 pp. 4-5). These concerns have led to a quasi-complete moratorium of PACE loans in the residential sector. However, the 
FHFA is due to propose a rulemaking on PACE financing in 2012, so these issues may yet be resolved.

For PACE programmes in the commercial sector, the same legal problems have not arisen, as the consent of the mortgage holder is required in order to take on the additional loan (Kats et al., 2011 pp. 24-25). Mortgage holders are yet hesitant to agree to an additional lien on the property

Page | 50 which has slowed the uptake of the programme (WEF, 2011 p. 27).

Up to the beginning of 2012, 26 US state governments had enacted legislative changes to enable PACE financing. Yet only in three states (California, Colorado and New York) have there been a significant number of projects financed through this mechanism (Hesser, 2012 pp. 13-16).

Main points:

- PACE loan programmes show good potential to facilitate deep retrofits if stringent energy requirements are required, as they enable long repayment periods. PACE loans have been used in the United States in the residential and commercial sector.

- PACE loans address the split-incentives barrier if costs for property taxes can be handed on to tenants as part of the charges and their liability transfers with ownership of the property.

- Sourcing the funds for PACE loans remains a problem for many local governments/municipalities.

- Legal hurdles need to be overcome to address whether PACE debt has seniority over other debt such as mortgages to upscale the approach.

\section{Energy performance contracting}

There are three main ways (even though many others exist) in which ESCOs can facilitate financing for EE improvements in buildings through Energy Performance Contracting (EPC).

Under a "guaranteed savings" contract, the ESCO does not provide funding, but identifies and carries out the energy efficiency measures in the building and guarantees a certain amount of savings, and thus bears the risk of non-performance of the investment. This guarantee can help the customer negotiate a regular loan where the performance guarantee backs up the loan, as it ensures a positive cash flow. If the savings are not achieved, the ESCO guaranteeing the savings has to compensate the customer by paying the difference between the guaranteed and the realised savings. Thus, the assessed risk may be substantially lowered, leading to better lending terms. The customer may also use its own resources to undertake the investment, thus not resorting to third-party finance. The willingness of the customer to invest own equity might also be enhanced, as the recovery of the investment is guaranteed by the ESCO. In both cases, the customer provides the financing (through its own resources or through a loan) and thus it appears on his balance sheet. This is a particularly important issue for buildings in the public sector clients due to restrictions regarding public debt.

"Shared savings" contracts are another way of providing EPC. Under this arrangement, the ESCO provides or arranges most of the finance while the customer agrees that part of the savings will accrue to the ESCO for a specified period, in order to refund its investment and service costs. It is the ESCO that shoulders the upfront investment costs, which in principle do not appear on the balance sheet of the customer. In this case, the ESCO takes on not only the performance risk, but also the financing risk. As ESCOs usually have limited resources to invest, it is likely that they will seek third-party financing though local financing institutions. Yet, with an increasing debt-toequity ratio, due to the accumulation of projects, the ESCO may also find it increasingly difficult to find funding for new projects. Financing costs under "shared savings" contracts are usually higher than for "guaranteed savings" contracts. When using "shared savings" contracts, ESCOs 
prefer projects with short payback-periods and are unlikely to fund comprehensive projects. This type of contract works better for large and well-established ESCOs, due to the need to take on debt, yet it also allows the opening up of new markets where the financial sector is less developed or is yet reluctant to lend to individual investors in energy efficiency (Bertoldi and Rezessy, 2005). For public sector clients, the obligation to repay the ESCO over a certain period may still appear in their accounting system as public debt, making it difficult to engage in such kind of contracts.

The Energy Service Agreement (ESA) is a "pay-for-performance" service contract between a third-party investor and a building owner to deliver energy savings as a service to the building. The ESA is in some ways an evolution of the traditional shared-savings model, but it is structurally more like a Power Purchase Agreement (PPA) used typically in the renewable energy space. A third party investor or ESCO and a building owner enter into an ESA contract where the building owner agrees to pay their historical utility bills to the third party. An upfront "access fee" or an ongoing utility bill discount may be paid to the building owner. That third party invests money in energy efficiency measures that deliver energy bill savings. The third party owns and operates that equipment to provide "energy services" to the building. The difference between the historical utility bills and the new, lowered utility bills pays for the equipment and required profit to the third party investor. The ESA lasts for a set-period, usually 10 years. ESA's can help scale market adoption of EE via aligning incentives between the building owner, who is a user of EE services, and the third party investor, who provides the capital to deliver the EE services. ESA deals can benefit from many different types of policy structures and incentives, but they are structurally a bi-lateral agreement between a third party investor and a building owner. The ESA can be applied to both public and private sector buildings, as the finance does not appear on the building owner's balance sheet.

Comparing the three forms of EPC's, the guaranteed savings variant of EPC still needs a developed banking sector, with institutions that will be willing to integrate an ESCOs performance guarantee in its risk assessment of an investment in energy efficiency in a building. Financing costs may, however, be lower, than in the shared savings option, which could allow more comprehensive projects with lower pay-back times. It can also facilitate the entry of newly established ESCOs and thus lead to growth in the sector, as new ESCO's will it find difficult to provide the financing themselves due to limited equity and a lacking credit history (Bertoldi and Rezessy, 2005). ESA's can allow a retrofit solution to be packaged in such a way that it puts all parties in a position where they are incentivized to achieve the deepest, persistent savings for the best value.

The biggest ESCO market exists today in the US; with a market activity of over USD 5 billion in 2011 (O'Donnell and Gibson, 2012) (see also Box 10). The widespread tradition of philanthropy which endows many public institutions (such as hospitals and universities) with funds at their disposal has enabled the quick development of the ESCO market. ${ }^{45}$ Even though market growth forecasts were substantially down-sized as a result of the economic and financial crisis, conservative estimates still anticipate an annual growth rate of $11 \%$, leading to a potential market size of USD 13 billion in 2020 (O'Donnell and Gibson, 2012). However, it is important to note that these investments may not entirely be related to energy efficiency, as ESCOs often provide a much wider range of measures, including also renewable energy, water management and sustainable material use (Larsen et al., 2012). About three-quarters of total revenues relate to energy efficiency measures (i.e. $73 \%$ in 2006 and $75 \%$ in 2008) (Satchwell et al., 2010).

\footnotetext{
${ }^{45}$ Observation made by Ingrid Holmes, E3G
} 


\section{Box 10 - ESCO market and performance contracting in the United States}

An analysis of more than 3000 ESCO projects completed between 1990 and 2008 in the United States showed that $68 \%$ used performance contracting, with significant differences between public and institutional projects (73\%) and private sector projects (40-45\%). The public and institutional sector dominates the market with $85 \%$ of the projects, including schools (33\%), state/local government (15\%), federal government (14\%), universities/colleges $(12 \%)$, health/hospitals $(8 \%)$ and public housing (3\%). Private sector projects only present $15 \%$ of the market, including commercial offices $(6 \%)$, industry $(4 \%)$, retail $(2 \%)$, hotel/hospitality $(1 \%)$, residential $(1 \%)$ and other $(2 \%)$.

The analysis shows that schools had the longest median payback periods of 7-15, which can, however, partly be explained by the fact that they include greater shares of non-energy related investments (including e.g. asbestos removal and wiring) that address accumulated deferred maintenance needs. Other public/institutional projects have median payback times of 2-3 years for lighting-only projects and 7-10 years for major HVAC retrofits, non-energy measures and on-site generation. Private sector median repayment periods range between 1 year (for lighting-only) and 3 years (for major HVAC).

Calculated typical benefit-cost ratios are 1.4 for public sector projects and 2.6 for private sector projects (using a $3 \%$ discount rate for public sector projects and $8 \%$ for private sector projects). Schools have the lowest typical benefit-cost ratio (1.1) and about $50 \%$ of all school projects are estimated to have negative net benefits (compared to less than $20 \%$ of projects in other markets). Additional to the above-mentioned high number of non-energy measures in schools, this is also a result of lower operation hours and a generally lower energy-intensity of schools. It is estimated that ESCO projects implemented between 1990 and 2008 have generated net direct benefits of around USD 23 billion (USD 2009) for customers. The calculations include only direct benefits, which resulted from reduced energy and operational costs. Whereas the importance of other, not quantified, benefits, such as equipment modernisation, improved lighting and air quality, employee productivity gains and environmental improvements, was highlighted and their inclusion into the calculation would certainly increase the share of cost-effective projects.

Municipal governments, universities, schools and hospitals (MUSH) have in the majority opted for guaranteed savings contracts as many of them can obtain tax-exempt financing at much lower financing costs than the ESCOs could provide. They also prefer the greater certainty of savings and decreased transaction costs as the ESCO can focus on its core business and ensure the project performance.

Measures implemented are of a very wide range and also include non-energy related measures, such as water conservation measures: lighting measures are at the top of the list (implemented in over $80 \%$ of school projects, over $70 \%$ of other public projects and over $60 \%$ in private sector projects) followed by installed HVAC controls, such as thermostats or energy management systems (schools over $70 \%$, other public over $50 \%$ and private over $20 \%$ ). These measures either guarantee short payback periods for stand-alone projects or are implemented in order to push a larger package of measures towards cost-effectiveness. Building envelope measures were only implemented in around $30 \%$ of schools projects, over $10 \%$ of other public projects and less than $10 \%$ in private projects.

Source: Larsen, Goldman and Satchwell, 2012

In the European Union the level of development of the ESCO market is quite uneven. Three countries, for example, have more than 40 active ESCOs with a collective annual market above EUR 200 million. In most member states, however, the market is still poorly developed and in almost half of the countries the annual ESCO market is below 25 million EUR and there are only a couple of active ESCOs (Ozolina, 2010). The Joint Research Centre of the European Commission considers the ESCO market in Europe to "be far from utilizing its full potential, even in countries with a particularly developed ESCO sector". The 2010 status report on ESCOs in Europe finds that the concept has not been applied in the private residential sector (Marino et al., 2010). It is also unlikely to do so in the future, as project sizes in the residential sector are too small to be profitable under this concept unless they are bundled into larger investment schemes. Project 
examples cover mainly complex public building projects but also industrial buildings and private non-residential buildings (Marino et al., 2010). The public sector is particularly attractive to ESCOs as they target large energy users with few risks attached. ${ }^{46}$ In order to further develop ESCO activities in the public sector the ELENA facility of the EU (see also Box 16) provides grants for project development in this area. One example of projects funded is the development of an EPC scheme to finance the refurbishment of 300 schools in Paris, France. A first contract over the refurbishment of 100 schools has been signed, which includes a bonus/malus scheme for the achievement of the savings. ${ }^{47}$ The ESCO provides the funding and guarantees minimum savings of $30 \%$ (EC, 2012b).

A number of barriers have been identified that hamper the further development of the ESCO market at least in Europe (Marino et al., 2010):

- Public procurement rules in many cases add transaction costs due to complex procedures and the fact that they often do not consider life-cycle costs of investments.

- In many cases, local authorities are not able to take advantage of financial savings generated in terms of reduced expenditure since their operating budget is adjusted accordingly.

- Unstable and low energy prices, lacking consumption data, repercussions of the financial crisis, still significant business and technical risks as well as remaining general mistrust in the ESCO model present further impediments in many countries.

The IEA Policy Pathway "Joint public-private approaches for energy efficiency finance" (IEA, 2011a) sets out the policy steps needed to enable energy performance contracting. It also includes a case study on the US Federal government scheme to enable ESCOs to deliver energy performance improvements in the public sector.

\section{Main points:}

- Energy Performance Contracting reduces the technical performance risk of energy efficiency investments and thus can positively influence financial risk assessments.

- In certain cases it can also address the problem of a lack of credit history of customers as offbalance sheet financing is possible.

- So far successful examples exist mainly for the public sector and big clients from the commercial sector; it is unclear if the model is adaptable to the residential sector.

- EPC has so far has been focussed on very profitable quick win measures such as lighting or HVAC controls even though examples of deeper retrofit (insulation and packages of measures) do exist.

- Financing remains a problem if banks do not trust the EPC model.

\section{White certificate markets and obligation schemes}

Global estimations for energy efficiency finance delivered by energy providers added up to about USD 10.6 billion in 2011, 80\% of which was delivered as a result of regulations to comply with obligation schemes. Most schemes are located in the United States and in Canada, but important experiences exist also in Europe (notably the United Kingdom, Italy, France and Denmark) and

\footnotetext{
${ }^{46}$ Refers to the presentation by Alexandra Langenheld (JRC) given at the IEA expert workshop and the following discussion: http://www.iea.org/media/workshops/2012/energyefficiencyfinance/2d4Langenheld.pdf

${ }^{47} \mathrm{~A}$ bonus is paid if savings are achieved and a penalty if they are not.
} 
Australia (Heffner, Lees et al., 2012). Another push for the implementation of obligation schemes has been agreed in the European Union, where the new Energy Efficiency Directive will make obligation schemes mandatory in all member countries. ${ }^{48}$ The IEA Policies for Energy Provider Delivery of Energy Efficiency (PEPDEE) work programme assesses existing experiences, reviews related policies and engages in a number of regional dialogues to promote co-operation and knowledge-sharing worldwide. ${ }^{49}$

So far the replacement of small appliances, such as light bulbs and low-flow showerheads, seem to account for the bulk of savings achieved in many countries, even though a wider range of equipment, such as HVAC, refrigerators, electronics, kitchen equipment etc. was initially planned as targets. In some cases, weatherisation and insulation measures are included, yet seem to be more complicated to implement (Heffner et al., 2012; Lees, 2012). Especially these more costly measures, which have longer payback times, seem to need additional support through complementary financing and fiscal policy measures and regulation (Heffner, Lees et al., 2012).

An important aspect of energy-provider delivered approaches is their ability to directly engage with a wide range of customers, which enables them to rapidly deploy small equipment, such as smart meters, and to promote behavioural changes (Heffner, Lees et al., 2012; Crossley and Swanson, 2011). These schemes also engage a broad group of actors in installing equipment and retrofitting insulation and therefore can be a useful way to familiarise the buildings sector and the public with energy efficiency measures.

Most measures implemented as part of obligation schemes focus on the residential sector even in countries where other sectors are eligible (see Table 2).

Table 2 - Obligation schemes with trading options in Europe

\begin{tabular}{|c|c|c|c|}
\hline & Italy & France & United Kingdom \\
\hline Obliged entities & $\begin{array}{l}\text { Electricity and gas } \\
\text { distributors }\end{array}$ & $\begin{array}{l}\text { Energy retailers and } \\
\text { importers of transport fuel }\end{array}$ & $\begin{array}{l}\text { Electricity and gas } \\
\text { retailers }\end{array}$ \\
\hline Eligible sectors & All including transport & $\begin{array}{l}\text { All except those covered } \\
\text { by the EU ETS }\end{array}$ & Residential only \\
\hline $\begin{array}{l}\text { Measures } \\
\text { undertaken }\end{array}$ & $86 \%$ residential (2008) & $87 \%$ residential (2009) & $100 \%$ residential \\
\hline Spending (2011) & EUR 200 million & EUR 300 million & EUR 1200 million \\
\hline $\begin{array}{l}\text { Trading of white } \\
\text { certificates }\end{array}$ & $\begin{array}{l}\text { Intense trading } \\
\text { activities via spot } \\
\text { market }\end{array}$ & $\begin{array}{l}\text { Some trading activity on } \\
\text { bilateral basis }\end{array}$ & $\begin{array}{l}\text { Trading allowed but } \\
\text { basically not used }\end{array}$ \\
\hline $\begin{array}{l}\text { Costs per kWh } \\
\text { saved }\end{array}$ & Not available & EUR 0.009 & EUR 0.037 \\
\hline
\end{tabular}

Source: Heffner, Lees et al., 2012 and Giraudet, Bodinau and Finon, 2011

In some cases, but not always, a trading scheme is attached to the obligation scheme (often called a white certificate scheme). White certificate schemes exist e.g. in France, Italy and the United Kingdom (see Table 2). They imply creating a market for the energy efficiency improvements or energy saving measures undertaken by energy providers. In order to allow trading, energy savings achieved under the obligation scheme need to be certified. Through the use of standardised calculations, transaction costs of certification can be lowered (Giraudet, Bodineau and Finon, 2011). This facility can be especially important when small providers fall

\footnotetext{
${ }^{48}$ http://ec.europa.eu/energy/efficiency/eed/eed_en.htm

${ }^{49}$ Established by the International Partnership on Energy Efficiency Cooperation (IPEEC) and implemented by the IEA in cooperation with the Regulatory Assistance Project (RAP): www.ipeec.org/Task_PEPDEE.aspx
} 
under the obligations, as these may not be able or willing to source customers for energy savings or shoulder the transaction costs and it might be less costly for them to buy certificates.

The buying and selling of white certificates provides revenues to those energy suppliers who can make the most cost-effective energy savings. The trading option may also engage third parties and stimulate innovation (Heffner, Lees et al., 2012). Experience from European countries shows that the trading option delivers cost-efficiency where the energy saving targets are challenging to deliver, where the coverage of sectors and project types is large and where non-obliged actors can participate in the scheme (EC, 2009). Further analysis has shown that significant differences need to exist in costs to obliged suppliers in order to engage in trading. As trading may require providing commercially sensitive information to competitors, suppliers may have a preference for "non-trading" and need to see considerable advantages that outweigh the costs of trading. In EU white certificate schemes, trading activity has only been high in Italy (with $79 \%$ of certificates traded, compared with $4 \%$ in France and nearly zero in the United Kingdom and Denmark) (Giraudet, Bodineau and Finon, 2011).

Trading white certificates add complexity to the system and could motivate speculation. Whether a trading scheme is beneficial overall or not will, thus, depend greatly on the local context. This dependency on the local context may also make larger-scale (i.e. interregional) trading of white certificates less likely (Heffner, Lees et al., 2012).

Comparisons of experiences from France, Italy and the United Kingdom confirm the importance of the local context. Even though all schemes are evaluated as cost-effective, great differences in related costs and therefore relative prices of white certificates exist. The White Certificates scheme in the United Kingdom has achieved energy savings at a cost three times higher than France per unit kWh saved, mainly because of the limitation to the types of measures eligible for the scheme in the United Kingdom; all were in the residential sector. Low income houses and insulation measures were also targeted in the United Kingdom scheme, which tend to be higher cost energy efficiency measures.

These differences are likely to be influenced by different starting points, i.e. differences in the level of efficiency existing before the start of the scheme. But also the underlying obligation schemes vary significantly in many aspects, such as the type and number of parties obliged, fuels targeted, sectors covered, other public policies in place, and the general state of energy market liberalisation (Giraudet, Bodineau and Finon, 2011). In France and Italy, tax incentives schemes were implemented at the same time as the white certificate schemes that encouraged householders to undertake investment in energy efficiency in buildings. The increased interest among the public ultimately benefitted the energy providers in meeting their targets and therefore assessment of the schemes should include the government subsidies in determining their cost-effectiveness.

\section{Main points:}

- Obligation schemes have created a significant level of investment in energy efficiency improvements in the residential buildings sector and, even though other sectors were also eligible, the bulk of activities have taken place in the residential sector.

- So far there has been a focus on quick wins such as the distribution of efficient light bulbs and equipment replacement but little improvement of the building envelope. But energy suppliers will have to go deeper in the future, as quick win potentials are diminishing and obligations are rising. However, since energy suppliers are first and foremost profit-making businesses, they will always seek the least cost options which may mean that they are likely to target shallow rather than deep retrofits to meet obligation targets. 
- White certificates add flexibility to obligation schemes and allow other eligible actors to engage and to raise funding for energy saving opportunities.

- The additional revenue generated through the selling of white certificate can reduce paybackperiods and can therefore encourage investments of a greater size.

More in-depth information on experiences with white certificates can be found in the case study on Italy in the Annex.

\section{Carbon markets}

Greenhouse gas emissions trading schemes and carbon offset schemes, such as the Joint Implementation (JI) and the Clean Development Mechanism (CDM) under the Kyoto Protocol, are the two main types of market mechanisms that have been set up to reduce greenhouse gas emissions.

Buildings have so far hardly been directly targeted by emissions trading schemes. Under the European Emissions Trading Scheme (EU ETS) power generators are obliged to have emissions allowances for the electricity they generate. Thus there is effectively an incentive to reduce emissions from electricity consumption in the buildings sector. This can be done by reducing the carbon content of electricity generation or by reducing the electricity consumed in end-use sectors, including buildings. However, the system only gives an incentive to the energy end-user to reduce his consumption if the price of the emissions allowance is passed through to the consumer. The price signal generated by the EU ETS is to date unlikely to be strong enough to influence the consumption decisions made by the end-user. ${ }^{50}$ One example of an emissions trading scheme that targets buildings GHG emissions directly is the Tokyo urban cap-and-trade programme (Box 11).

There is potential for significant overlap between emissions trading schemes covering electricity and energy efficiency policy across sectors. For example, when an ETS covers electricity in the buildings sector, policy measures targeting the same energy consumption will not lead to additional emission savings but will only shift emissions to be produced into another sector or elsewhere in the geographic area covered under the cap. Careful analysis is needed to decide whether or not in that circumstance additional policies will lead to additional positive outcomes (OECD, 2011c; Hood, 2011; and Ryan et al., 2011). Subsidies for energy efficiency policies may in fact benefit the energy providers covered by the ETS cap. A final point on emissions trading schemes is that revenues from the auction of emissions allowances may be a source of funding for energy efficiency measures in the buildings sector (See Part III for more detail).

Under carbon markets, CDM and JI projects are subject to strict criteria: they are supposed to deliver real, measurable, additional and long-term greenhouse gas emission reductions. So far energy efficiency projects have made up less than $1 \%$ of projects funded by CDM and this is mainly due to the transaction costs associated with funding small-scale projects through this mechanism and the additionality criteria when energy efficiency projects are in theory costeffective. For this reason buildings have not been easy to fund through this mechanism, although this may be starting to change through the creation of mechanisms designed to account for smaller-size projects.

The CDM provides in principle two ways of accrediting small-scale projects. A bundle of smallscale projects can be registered, comprising an unlimited number of similar projects. With regard

\footnotetext{
${ }^{50}$ EU ETS carbon prices have remained between EUR 6-7 per tCO2 emissions during 2012.
} 
to energy efficiency activities, bundles are limited in terms of size to a maximum yearly energy reduction of $60 \mathrm{GWh}$. This kind of accreditation is not very flexible, as the composition of the bundle may not change and all activities in terms of number, location and timing need to be known from the start. As a second option under the CDM, so-called Programmes of Activities (PoA) can be registered. Under a PoA, one coordinator and a number of activities are registered. Activities maybe take place in one or several countries and during the programme durations, additional activities can be added with little administrational effort through the coordinator. Also the limitations in terms of size are less strict (UNEP, 2012 pp. 18-23). In 2009, procedures were developed to also allow PoA for JI projects. ${ }^{51}$

\section{Box 11 Emission trading for buildings: The Tokyo urban cap-and-trade programme}

The Tokyo Metropolitan Government was the first worldwide to launch an emissions trading scheme that targets emissions from commercial, industrial, and public buildings in April 2010. Tokyo's annual $\mathrm{CO}_{2}$ emissions are in the same range as those of some countries, like Norway or Sweden (65 million tonnes in 2007), with the largest and also growing portion (49\%) coming from commercial and industrial sector buildings. A mandatory reporting programme for large emitters, which included also plans for voluntary emission reductions, was introduced in 2002 and prepared the ground for the emission trading scheme, as it provided the data necessary for a reasonable setting of the emission cap. Under the trading scheme, 1300 commercial and industrial facilities are obliged to reduce their carbon emissions. They represent about $40 \%$ of Tokyo's emissions from the commercial and industrial sector and $20 \%$ of Tokyo's overall emissions. Starting from a baseline, each facility has to reach an individual reduction rate over 5 -year terms based on historical emissions and feasibility studies. The baseline can be set to take account of earlier voluntary efficiency investments. The base unit is the building as a whole, and the building owner is responsible for reductions irrespective if he is occupying the building or if it is let.

The scheme is structured as a baseline and credit system; only certified excess reductions can be traded. The overall cap is set to ensure that participating building owners contribute their share towards reaching Tokyo's emissions reduction goal of 25\% reductions between 2000 and 2020. During the first period (2010-2014), the cap is set to deliver a 6\% reduction from the buildings sector, and plans for the second period (2015-2019) are to decrease the cap in order to achieve a 17\% emissions reduction. Instead of implementing energy conservation measures (including efficiency and demand management measures), building owners may purchase excess reduction credits from other participants in the scheme or from voluntary emissions reduction actions implemented outside the Tokyo metropolitan area under the same conditions. Another option available is the purchase of renewable energy credits, created through eligible and certified renewable energy measures. Fines and administrative penalties exist in case of non-compliance. The first trading activities under the scheme occurred in 2010, with a carbon price of USD 142 per tonne of $\mathrm{CO}_{2}$, which is high enough to motivate significant abatement in the building sector, but probably very economically inefficient, as much cheaper abatement options than this are likely to exist elsewhere. A fair and simple programme design, available baseline data, as well as a very high level of stakeholder involvement in the design and setting up of the scheme were seen as positive elements of the scheme.

The design of the scheme does not allow for an auctioning of emission permits and in practice allocates emission permits for free. Another critical point is that, due to the eligibility of early actions, emission reduction targets for the first phase were already over-achieved in the year preceding the start of the scheme. In 2009, 60\% of the participating companies achieved excess reductions for the first phase already and $22 \%$ of the companies even exceeded the targets for the second phase. It is difficult to comment on the additionality of the scheme to date but future caps may drive more ambitious improvements in the energy performance of the buildings sector.

Source: Nishida and Hua, 2011 and Rudolph and Kawakatsu, 2012

\footnotetext{
${ }^{51}$ http://ji.unfccc.int/JI_PoA/index.html
} 
In 2010, an estimated USD 1.9 to 2.0 billion were invested in CDM projects and about USD 0.3 billion were invested in Jl projects (Buchner et al., 2011 pp. 19). However, energy efficiency projects are hardly ever part of the CDM and JI portfolio. The UNEP RIS $\varnothing$ database on CDM and JI projects lists 109 CDM energy efficiency projects in the residential buildings sector $1.2 \%$ of overall projects) and 37 CDM energy efficiency projects in the service sector ( $0.4 \%$ of overall projects). ${ }^{52}$ Combined, they issued less than $0.02 \%$ of all certified emission reductions under the CDM. With regard to $\mathrm{Jl}$, one project is registered in the household sector and 11 projects exist in the services sector ( $2 \%$ of overall $\mathrm{JI}$ projects, with 2 already determined, 3 registered and 6 requesting registration). Combined, they issued $0.7 \%$ of all certified emission reductions under the Jl.

Several reasons for the low success of $\mathrm{JI}$ and CDM projects in the area of buildings energy efficiency have been given. Split incentives in the building sector, monitoring difficulties, lacking methodologies adapted to energy efficiency projects, problems of proving additionality for energy efficiency projects, a general incompatibility of the modalities of the mechanism and energy efficiency as well as a lack of buyers' interest for credits generated through energy efficiency projects (Türk et al., 2008; Ryan et al., 2012).

\section{Box 12 - CDM Programme of Activities for sustainable housing in Mexico}

The Mexican National Housing Commission CONAVI has registered a small-scale PoA project which provides subsidies as well as loan supplements for the purchase of homes equipped with energy efficient and renewable energy technologies. Originally, the programme was created in 2007 to provide subsidies to low-income families for the purchase of affordable houses. The programme has evolved to also include environmental concerns. Energy efficient technologies used include CFL lighting and thermal insulation. As the subsidies are distributed via mortgage issuers, they have often been combined with loan programmes and used as partial debt relief. Mortgage providers have also developed new schemes, such as the green mortgage programme implemented by the National Fund for Housing, which is the largest provider of residential mortgages in Mexico. Mexico has applied for registration of these programmes as a CDM PoA. All green residential financing in Mexico is eligible under this PoA, meeting the additionality criteria. Given the long lead times of registration and issuance of certified emission reductions (CER), the programmes will benefit from a successful registration only from 2013 onwards. Funds acquired through the mechanism could then be used to refund the participating programmes.

Source: UNEP, 2012 pp. 44-45

With the future of the Kyoto protocol currently under discussion, it needs to be seen how this mechanism will evolve and if it can be better used for buildings energy efficiency projects in the coming years. The crash in CER prices this year (currently EUR 1.25, down from EUR 7 in October 2011), is likely to limit the capability of the carbon market to drive improvements in energy efficiency. Current forecasts are for the price to fall to even further to 0.50 by 2020, averaging EUR 1.60 from now until then. The key to correcting this will be increasing the ambition of climate commitments, both in developed and developing countries (some ETS schemes in developing countries envisage use of offsets), but these forecasts already take into account known plans. ${ }^{53}$

\footnotetext{
52 UNEP Risoe CDM/JI Pipeline Analysis and Database, July 1st 2012": http://www.cdmpipeline.org/

${ }^{53}$ http://www.pointcarbon.com/1.2010122?date $=20121005 \&$ sdtc $=1$
} 
Main points:

- Carbon markets in the form of emissions trading schemes or CDM and JI measures have potential to deliver energy efficiency in the building sector but so far have not been welladapted to the sector.

- Main issues are the small size of buildings projects and the strict eligibility criteria that create high transaction costs due to the dispersed nature of energy efficiency potential in the building sector.

- The PoA mechanism has been more successful in attracting energy efficiency projects in the buildings sector and provides first lessons learned that could be used in the ongoing discussions on the future of the Kyoto protocol and future climate finance.

- Emission trading schemes, once in place, can render other policies targeting the same sector ineffective; careful analysis is needed to identify overlapping policies.

- Lack of demand in the EU ETS and for CDM and JI units, and corresponding low prices, are seriously undermining the use of carbon markets to promote energy efficiency.

\section{Public procurement and infrastructure investment}

Public procurement and direct public investment in infrastructure can be key drivers of markets as government spending represents a significant market share. In recognition of this, many countries and municipalities have introduced energy efficiency criteria as part of public procurement and infrastructure requirements.

The draft EU directive on energy efficiency (of June 2012) includes several items that would require national governments to procure energy efficiency products, renovate buildings to reduce energy consumption, and encourages the use of Energy Performance Contracting (EPCS).

On the first of these, the draft Directive sets out in Article 5 on purchasing by public bodies, that all central governments should purchase:

"Only products, services and buildings with high-energy efficiency performance, insofar as this is consistent with cost-effectiveness, economical feasibility, wider sustainability, technical suitability, as well as sufficient competition".

Public bodies at regional and local level are encouraged to do the same.

The new Energy Efficiency Directive also requires governments to renovate central government buildings (in Article 4). EU Member States are required to renovate 3\% of their total (owned and occupied) floor area in heated or cooled buildings to minimum energy performance requirements as set by the individual member states (in application of Article 4 of the Energy Performance of Buildings Directive) or to take measures leading to equivalent energy savings. ${ }^{54}$ This would effectively require renovation to a level of nearly zero energy buildings. Although the scope of this element was significantly diluted from the original proposal to require renovation of $3 \%$ of all

\footnotetext{
${ }^{54}$ The Energy Performance of Buildings Directive (EPBD 2010/31/EU) would require "public authorities to become early adopters of energy efficiency improvements" as well as "MS shall (...) following the leading example of the public sector develop policies and take measures such as targets in order to stimulate the transformation of buildings that are refurbished into nearly zero buildings (...)" Finally green public procurement policies should also support national public authorities in complying with the new obligation in the recast that all new buildings owned and occupied by public authorities should be nearly zero energy buildings after December 2018."

http://ec.europa.eu/energy/efficiency/studies/doc/2010_05_irc_ee_public_procurement.pdf
} 
government buildings, it can be expected that the levels of investment required will help the low energy buildings market scale-up some services and technologies than would otherwise occur.

Centrally-owned public buildings make up only around 10 percent of all public buildings across the EU. However, public spending represents around 19\% of the Union's gross domestic product and so even a small portion of this spent on energy-efficient buildings could make it a key driver Page | 60 for the nascent energy-efficiency services and products market, which targets buildings as a priority. This should also bring economic benefits to public authorities in reduced energy bills and release public money for other spending. ${ }^{55}$

The EU Energy Efficiency Directive also encourages all public bodies including at regional and local level, including social housing bodies, to use Energy Performance Contracting to finance renovations and undertake energy efficiency investments. Again, this should provide a driver to the EPC market in the European Union, which has been slow getting started compared with early North American successes.

In the United States the Federal Energy Management Programme (FEMP) has overall responsibility to implement energy management and energy-efficient "investment practices" in United States federal agencies and facilities. There are several categories of activities and those most relevant to buildings are those related to:

- Public procurement of energy-efficient products: federal agencies are obliged to purchase either products with the Energy star label or those that have been selected by the Federal Energy Management Programme (FEMP). ${ }^{56}$ Product categories range from the building envelope, heating and cooling, over lighting, appliances, plumbing, information technologies and electronics, to food services. ${ }^{57}$

- Requirements related to the energy performance of buildings: the Energy Independence and Security Act (EISA) of 2007 mandates the reduction of energy intensity of federal buildings over time relative to a 2003 baseline. By 2015, buildings should have an energy intensity $30 \%$ lower than 2003. In addition there are requirements related to the use of energy-efficient lighting fixtures and bulbs in Federal buildings and to ensure that major replacements of installed equipment, renovation, or expansion of existing space employ the most energy-efficient designs, systems, equipment, and controls that are life-cycle cost-effective. Federal agencies are prohibited from leasing buildings that do not have an Energy Star label, except under certain circumstances. Finally, it is specified that new buildings must be designed to reduce fossil fuel-generated energy consumption by the 65 \% by 2015 and $100 \%$ compared to a similar building in FY 2003.

- Energy performance and utility services contracting: On December 2, 2011, the White House issued a memorandum to the heads of executive departments and agencies committing the Federal Government to enter into a combined \$2 billion in energy savings performance contracts (ESPCs) and utility energy savings contracts (UESCs) by the end of 2013. These contracts enable federal agencies to work with utilities and ESCOs to deliver energy services by streamlining the contracting process for the broad spectrum of energy management services offered by utilities and ESCOs. Federal agencies may use either appropriated funds or secure third party project finance.

Australia's Energy Efficiency in Government Operations (EEGO) policy aims to reduce the energy consumption of Australian Government operations with a particular focus on the energy

\footnotetext{
${ }^{55}$ See article at: http://www.euractiv.com/specialreport-energy-efficient-b/europe-takes-baby-steps-revamp-p-news-513190

${ }^{56}$ See: http://www1.eere.energy.gov/femp/technologies/eep_fedrequirements.html

${ }^{57} \mathrm{http} / / / \mathrm{www} 1 . e e r e . e n e r g y . g o v /$ femp/technologies/eep_purchasingspecs.html
} 
performance of its buildings. Energy performance standards for office buildings and portfoliowide energy intensity targets have been established and are reported on annually. ${ }^{58}$

Japan also introduced a green procurement law in 2000 to promote green procurement by government and public institutions. ${ }^{59}$

\section{Main points:}

- Public procurement of energy-efficient products and services is an important tool to bring energy efficiency markets to greater scale.

- Countries are increasingly recognising this and pass legislation to oblige governments to purchase efficient products and services.

- Public procurement rules can also require publicly-owned buildings to meet comprehensive energy performance criteria as well as comprise technical energy specifications for individual components.

- Policy to support public procurement of low-energy buildings should include removing barriers to public sector purchasing and financing of low-energy equipment and buildings.

\section{R\&D support for energy efficiency}

Energy-related public R\&D spending in general represents only a small and declining percentage of overall public R\&D budgets in OECD countries. Energy-related public R\&D stayed below $5 \%$ of total public R\&D budgets in the last decade; lower than other research areas such as defence, health and environment, space programmes, non-oriented research and general university funds. However, the distinction is not always so clear and research undertaken in other areas, e.g research undertaken in chemistry and material science funded through general university funds, may also be relevant for energy issues (IEA, 2012a).

IEA data shows that public R\&D spending for energy efficiency in residential and commercial buildings as well as appliances and equipment has been relatively high in the United States and Japan over the last two decades (see Figure 2). Adding up public spending by IEA member countries in the European Union brings them to a comparable level. Effects on public R\&D budgets of the stimulus funding to counter the economic crisis are clearly visible in 2009 but do not seem to be of a lasting nature.

The impact of RD\&D spending can be approximated in terms of the number of patents filed. The increased spending with regard to energy efficiency in the buildings sector as well as appliances and equipment shows effects so far mainly in the area of lighting, with visible growth in the number of patents for LED and CFL lighting solutions. Yet little growth can be seen in the development of building insulation technologies as well as technologies for heating and cooling (IEA, 2012a).

The European Union funds a substantial R\&D programme in buildings under the Framework Programme 7 in the thematic area "energy". Within energy, energy efficiency appears as one of many subareas. The energy thematic area comprises R\&D funds of EUR 2350 million for the FP7 period 2007 to 2013. Energy efficiency in buildings has received a sizeable portion of that funding, amounting to EUR 426.1 between 2007 and 2012 (Schubert, T. 2012).

\footnotetext{
${ }^{58}$ See: www.climatechange.gov.au/government/initiatives/eego/government-energy-use-reporting.aspx

${ }^{59}$ See: http://www.env.go.jp/en/laws/policy/green/index.html
} 
The data in Figure 2 includes EU data for R\&D spending on energy efficiency and buildings over 2007 - 2010. However, funding in 2011 and 2012 in the EU was substantially increased to EUR 90.5 and 179.7 million respectively, which would bring the overall level of R\&D spending on energy efficiency in buildings in Europe from national and EU R\&D funds to more than three times the next highest funder (the United States) in 2010.

Figure 2 - RD\&D national public spending for EE in buildings, appliances and equipment

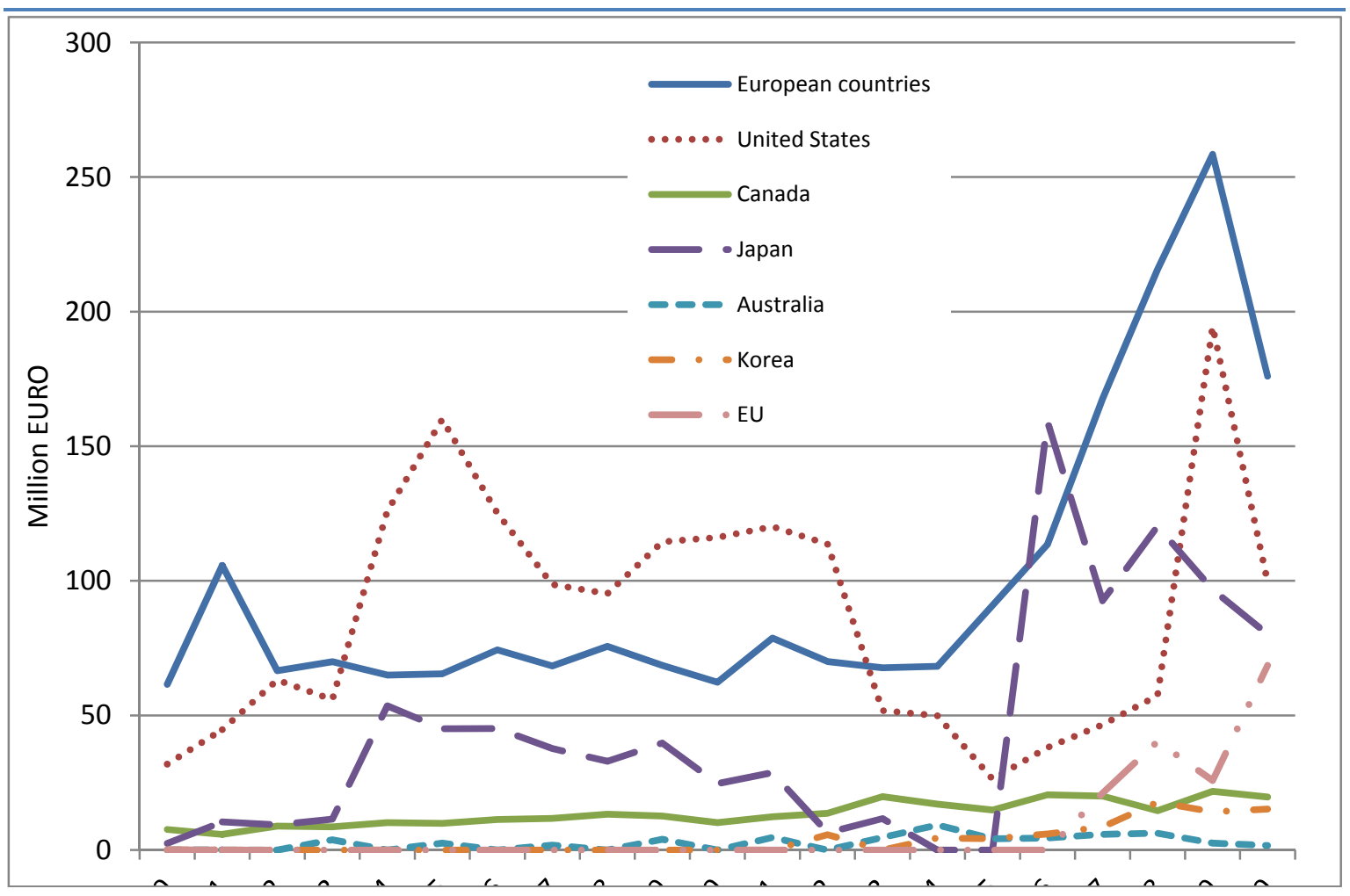

Notes: includes RD\&D spending for residential and commercial buildings; uses 2010 prices and exchange rates; "European countries" comprises sum of national spend by Austria, Belgium, Czech Republic, Demark, Finland, France, Germany, Greece, Hungary, Ireland, Italy, Luxembourg, Netherlands, Norway, Poland, Portugal, Slovak Republic, Spain, Sweden, Switzerland, and United Kingdom. EU comprises R\&D funding under central European Union funding under Directorate Gerneral Research.

Source: IEA data, EU Commission.

In the United States, the Department of Energy implements the research programme Building America, in partnership with industry to improve energy technologies and practices for new and existing residential buildings. ${ }^{60}$ The aim of the programme is to identify cost-effective strategies that achieve reductions in home energy use by up to $50 \%$ in all climate regions by 2017 .

\section{Main points:}

- Public R\&D funding can be an important way to ensure permanent innovation and technological improvement to increase the cost-effectiveness of energy-efficiency investments.

- The share of public R\&D funding that is specifically denominated for energy is very small and even smaller for energy efficiency improvements in buildings.

- It is not easy to establish a clear link between public R\&D funding and real-life impacts.

\footnotetext{
${ }^{60}$ See: http://www1.eere.energy.gov/buildings/residential/ba_research.html
} 
- Outcomes that can be observed with regard to patent development are so far mainly in the area of lighting and not in the important areas of insulation and HVAC, which remain investments with relatively long pay-back periods.

\section{II.3 Discussion of current use of economic instruments for low- energy buildings}

Nearly all IEA countries have at least one economic instrument in place to support energyefficient buildings on the national level, as seen in the IEA Policies and Measures database. ${ }^{61}$ The use of economic instruments to mobilise investment in energy-efficient buildings is very contextspecific and depends on the policy objectives and priorities, the regulatory framework in place, the market segment targeted, and the financial resources available, among others. Some countries also have instruments on a sub-national level, e.g. the United States has hundreds of financial incentive programmes for energy efficiency in the residential sector at state level. ${ }^{62}$

Historically, energy taxes, grants and tax relief have been the schemes favoured by most governments to support energy-efficient buildings. All IEA countries levy energy taxes in some form, although in most countries their main purpose is as a source of revenue rather than as a strategic instrument to conserve energy in buildings. More than one third of economic instruments used at national level to support investment in energy efficiency in buildings in IEA countries are in the form of grants to owners of residential and commercial buildings. Loans and tax relief are also widely used. Policy and capital to facilitate $3^{\text {rd }}$ party finance is a more recent phenomenon in some countries, however, it is a trend set to continue with further programmes planned in some countries. Often several programmes exist in parallel in a single country which address different target groups.

Economic instruments (excluding taxes) with the aim of improving energy efficiency in buildings are currently expending considerable public funds. However, little information is available on the environmental effectiveness and economic efficiency of many of the instruments, even where programme evaluation reports are available. This is surprising given the significant amount of funding involved.

Yet, from the review carried out for this report it can be concluded that the targets and eligibility requirements attached to the instruments are so far, with few exceptions, not very ambitious. Subsidies have been mainly attached to single component-based energy efficiency measures and do not take a whole-building-approach, as is needed to achieve low-energy buildings. There is a strong focus on cheap and quick wins through the replacement of equipment (lighting and HVAC), rather than improvements in the building envelope or whole building energy performance.

Most schemes have delivered improvements in energy efficiency of buildings rather than lowenergy buildings. Economic instruments have brought reductions in energy consumption in individual buildings of on average between $10-30 \%$ rather than the $50-80 \%$ expected to be needed in existing buildings in IEA countries. There are few examples of economic instruments or subsidies where ambitious levels of overall building performance improvements are applied, however some do exist (e.g. the German KfW and the French Eco-PTZ loan schemes).

Economic instruments in energy efficiency policy should be targeted to encourage deep cuts in

\footnotetext{
${ }^{61}$ Available at http://www.iea.org/policiesandmeasures/energyefficiency/

${ }^{62}$ According to the national database DSIRE (www.dsireusa.org/).
} 
energy consumption leading to buildings with overall much lower energy consumption than the current market norm. They should be part of a strategic policy package which mandates stringent building energy codes and certification. Future economic instruments will need to move from subsidies such as grants and tax relief to long-term finance to scale-up investment in low-energy buildings.

Page | 64

\section{II.4 Moving towards deep retrofit - how can economic instruments help?}

Given the importance of achieving deep retrofit of the existing buildings stock in IEA countries to deliver deeper cuts in overall buildings' energy consumption and related emissions, this subsection focuses on how future economic instruments can help achieve this goal. As seen above, the current crop and use of economic instruments have mainly achieved improvements in energy efficiency without delivering a shift to low-energy buildings. The IEA Sustainable Buildings Centre recommends a goal of net zero energy buildings whenever this is technically feasible and economically viable. ${ }^{63}$ Deep retrofit of existing buildings is needed.

The building envelope should be prioritised over buildings equipment, since a high-quality building envelope will not require the same size specification for heating and ventilation equipment as a low-quality building envelope. A requirement to implement several energy efficiency measures at once may foster thinking in terms of the overall energy performance of the buildings rather than simply the unit to be replaced.

In order to deep retrofit the existing building stock, many hurdles need to be overcome and will require changes to the way governments approach the use of economic instruments. The next pages list these hurdles and outline how different economic instruments can be used to address them.

\section{Challenge 1: High costs of deep retrofit}

Broad-scale deep retrofit of existing buildings will need more resources allocated in terms of investment than currently allocated. Payback times are often long for significant energy performance improvements, even if the 30-year lifecycle costs are negative in many cases. Economic instruments have mainly been used to incentivise the purchase of energy efficiency equipment, covering a significant share of the costs. For whole building retrofits, governments are not likely to be able to provide the amount of funding required as grants and other subsidy programmes, nor would they want to.

Solutions: Policy makers need to replace or complement direct subsidies with other financing instruments, which are less capital-intensive for the public budget, leverage more private investments and provide more stable long-term financing opportunities. Loan guarantees, preferential rate loans, or setting up third party financing options through other innovative mechanisms are in place or are being considered in several countries.

There needs to be a shift in economic instruments from playing the role of incentives to enabling access to finance for deep retrofits. Energy prices play a crucial role and energy taxes or strengthened trading schemes help to increase the cost-effectiveness of deep retrofit investments. Other incentives such as grants or tax relief may be awarded for individual buildings components to develop the particular markets; however these are not likely to encourage whole

\footnotetext{
${ }^{63}$ See http://www.sustainablebuildingscentre.org/pages/aboutus
} 
building deep retrofits.

Examples: On-bill and PACE funding in the United States, Central and Eastern Energy Efficiency Fund, energy taxes in Denmark, KfW loans in Germany.

\section{Challenge 2: Access to finance}

Financial institutions have little experience with providing loans for investments in energy efficiency. These may require quite different features compared with their core lending business, as their security is based not on collateral but on future energy savings. Private lenders may not freely develop loan packages for energy efficiency measures without public policy or funding intervention.

Solutions: Governments can help provide liquidity and assurance to the market for low-energy buildings by:

- Setting up loan programmes at concessional or market rates, where investors apply directly to public banks or institutions. Concessional rates are needed at the earlier stages of market development;

- Assisting financial institutions with risk guarantees or credit lines until they have built up experience with investments in energy efficiency measures. This can provide access to more potential customers but technical assistance to the financial institutions to assess energy efficiency applications is likely to be required;

- Encouraging the private sector through changes to legal requirements facilitating public procurement, energy performance contracting, on-bill financing of energy efficiency measures. This is a lower cost option for the public budget but the energy efficiency market needs to be more developed; stringent building energy codes creating demand for investment is needed.

- Promoting the standardisation of loan underwriting for energy efficiency measures in a technically sound, consistent and fully transparent manner (Buonicore 2012). This will increase the confidence of lenders and investors in the low-energy buildings sector.

Examples: Norway (Norwegian Housing Bank), Germany (KfW Bank), ElB, see also chapter on funding issues.

\section{Challenge 3: Prioritising whole building energy performance improvements}

It is important that the energy consumption of the whole building is reduced. This requires a comprehensive approach with targets and economic instruments based on the energy performance of the whole building rather than individual components. A prerequisite is to implement and enforce building energy codes based on the whole building energy consumption; stringent future building codes should be announced well in advance to allow investors to make the necessary investment at the next opportune point in the renovation cycle.

Solutions: tie all energy efficiency finance for buildings to the requirements of existing and future building energy codes which in turn should be based on comprehensive building energy performance.

Examples: The German KfW loans programme for refurbishment of buildings links public finance to investments in energy efficiency that are based on metrics related to the building energy code (EnEV) requirements. Partial debt relief is awarded in proportion to the performance of the building relative to the building code, i.e. the percentage reduction in energy consumption compared to that permitted by EnEV. This provides incentives to investors to outperform legal requirements under the building code. 


\section{Challenge 4: Split incentives}

There may be little incentive to carry out a deep retrofit at the time of a building refurbishment either because the owner is not the occupier and therefore does not benefit from the reduced energy bills, or even as the occupier the payback period would be so long that the current occupier would no longer live in the building at the time of the future savings.

Solutions: the first split incentive - the landlord-tenant problem - is likely to only be resolved through mandatory retrofitting obligations. The second barrier can be addressed through innovative financing mechanisms whereby the loan is attached to the property rather than the initial investor.

Examples: The United Kingdom Green Deal plans to tie energy efficiency finance to buildings, rather than the original investor, and includes public-private funding, while in the United States, PACE is funded through municipality bonds and tied to properties rather than owners. Also in the United States and Canada, many on-bill loan schemes operated by energy providers are structured as debt on the property rather than the initial investor.

\section{Challenge 4: Low renovation rates}

The number of properties undergoing deep retrofit needs to be significantly increased in order to achieve much lower energy consumption of the buildings stock in the future. Policy makers need to encourage and mandate property owners and independent investors to carry out deep energy retrofits each time any kind of renovation is under consideration.

Solutions: If deep retrofit is not mandated, incentives will play an important role in encouraging investors to undertake renovation and deep retrofit. However, it is unlikely that any financial incentive on its own would be large enough to encourage the depth of retrofit needed unless future regulatory requirements or significant energy price hikes are feared. The announcement of future stringent energy performance buildings regulations should be combined with straightforward access to finance with favourable terms, which might include some incentives, can make future regulation more palatable to investors and politically acceptable.

Examples: the EU and some Member States have set renovation rate targets, however the way to achieve them is not yet in place.

There is a wide variety of policy instruments available, yet scaling-up activities in terms of reaching the rates of uptake needed as well as in terms of achieving much higher levels of energy savings, remains a challenge. Overcoming legal hurdles and achieving broad consensus among all parties concerned, including the financial sector, remain important tasks to be worked on for many of the more innovative financing instruments discussed.

\section{II.5 Selection and design of economic instruments for low-energy buildings}

The economic instruments discussed in this report are very diverse in the way they work, are funded, and the way they address different kinds of market failures and barriers relating to lowenergy buildings, such as low energy prices, higher upfront costs and long payback periods of energy efficiency measures, high transaction costs, lack of familiarity with energy savings as a return on investment, lack of access to finance, and/or split incentives. This subsection outlines some recommendations for the process of selection and design economic instruments for lowenergy buildings.

Table 3 compares the main characteristics of economic instruments in relation to their role in 
improving the energy performance of buildings. As can be seen, all instruments have advantages and disadvantages and while it is clear that the focus will need to be on increasing finance and loans for low-energy buildings, no "silver bullet" exists that will overcome all barriers.

Before choosing and implementing an economic instrument, a market assessment should identify the level of private sector activity in the low-energy buildings market and determine where the main targets of policy need to be. Understanding consumer behaviour in the national and economic context is important to determining which economic instruments will be effective in achieving low-energy buildings.

A mix of economic instruments is likely to be needed, providing different forms of incentives and finance at various stages of development of the market for low-energy buildings (see Figure 3 ).

Figure 3 - Development of economic instruments over time

\begin{tabular}{|c|c|c|c|}
\hline $\begin{array}{l}\text { Early movers - } \\
\text { adopt innovations } \\
\text { before the } \\
\text { majority for } \\
\text { environmental or } \\
\text { technical reasons }\end{array}$ & $\begin{array}{l}\text { The early majority - } \\
\text { thoughtful people } \\
\text { who accept change } \\
\text { more quickly than } \\
\text { the average person }\end{array}$ & $\begin{array}{l}\text { The late majority - } \\
\text { will only adopt } \\
\text { innovations when } \\
\text { the majority are } \\
\text { using it }\end{array}$ & $\begin{array}{l}\text { Laggards are } \\
\text { sceptics who will } \\
\text { only adopt an } \\
\text { innovation once } \\
\text { it is mainstream }\end{array}$ \\
\hline
\end{tabular}

\section{Incentives and}

public finance
Public and private finance
Private sector

finance takes over

Page | 67

Source: adapted from Holmes 2012.

In the early phases of the implementation of a low-energy buildings strategy, incentives and public finance are required to encourage the early movers to invest in energy efficiency. Direct subsidies in the form of grants and tax incentives have a role in scaling up the market for lowenergy buildings, at least initially, as well as for special target groups such as low-income households. Subsidies even at a low level can be successful in encouraging people to take the first step in investing a set of measures that they might not have otherwise considered. Simply providing consumers with access to finance may not be enough to encourage them to actually make the move to undertake investment in energy efficiency measures. Hybrid instruments which provide incentives and finance are needed to push potential investors to invest and then enable the finance needed. For this reason, in France and Germany, a combination of loans with grants and tax relief are available for EE renovation of buildings.

However, as the market develops and investments in low-energy buildings become more widespread (partly as a result of the subsidies given to energy efficiency in buildings), the role of governments and economic instruments evolves to ensure access to finance is available (see Figure 3). Regulations can be introduced and tightened to require more stringent energy performance. Public funds can be routed through financial institutions to provide liquidity and familiarise financial institutions with energy efficiency projects. The combination of public and 
private finance provides access to cheaper finance to enable implementation of the regulations. Finally, when low-energy buildings are required by law, subsidies can be phased out and private financial institutions should be ready to take over financing low-energy buildings.

Energy taxes and prices can increase slowly over time where necessary to accompany this process and reduce rebound effects. Setting out a clear pathway of gradual tax increases over the years provides a clear price signal and reduces the uncertainty of rate of return on investments.

\section{Recommendations for the design of economic instruments}

The design of economic instruments can be as important as the right choice of instrument. Weak design can not only lead to a waste of public funds, but also discredit the reputation of investments in energy efficiency in public opinion.

Loan programmes are gaining increasing importance in economic instruments, as governments seek to enable the finance of long-term strategies to move to low-energy buildings, and careful design is needed. Governments should consider the target group, the market barriers that need to be overcome, the level and source of funding available, and the deliverer of funds in designing loan programmes. Figure 4 illustrates some of the options that are available in terms of types of loan support, i.e. subsidy, guarantee, or technical assistance; loan repayments; and the source and disburser of funds.

\section{Figure 4 - Design options for government involvement in loans for low-energy buildings}

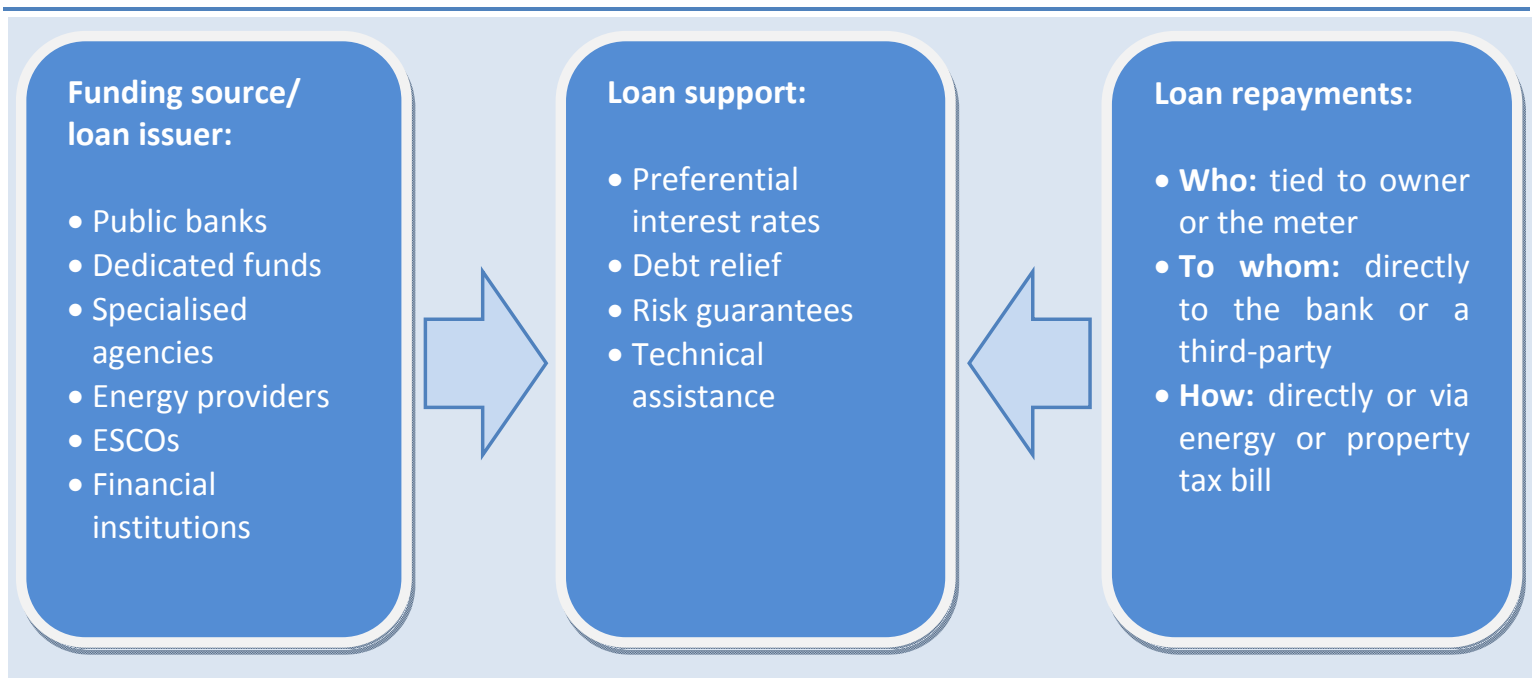

Source: IEA

From this review, the most important design elements contributing to the success of all economic instruments in delivering low-energy buildings appear to be:

- Clear communication and easy-to-understand, but strict eligibility energy requirements;

- Reducing the complexity of procedures;

- Sufficient lead times to set up programmes and train professionals;

- Stable streams of funding for programmes involving subsidies.

To guarantee a stable stream of funding for economic instruments, the right type and mix of funding sources are required; this is discussed in the next part of this report.

At the same time, regular evaluation on the effectiveness of funds used and validation of the initial reason for setting up the programme is needed, in order to make sure that public funding 
is used most effectively. Better evaluation of energy efficiency investments is likely to help reduce the high risk premiums currently still attached to these investments. Designing new programmes in such a way that facilitates better evaluation would be an important start. A definition of commonly accepted evaluation criteria could help comparison of experience in different countries.

Training and capacity building is needed at many levels in financial institutions and in the construction industry to support the effective implementation of economic instruments and other policies for low-energy buildings. For financial institutions that are not familiar with energy efficiency investments, as well as for involved public institutions, capacity-building should be provided in advance of the introduction of the programme to ensure success and quality of implementation. If there is a lack of competent and certified assessors of energy efficiency in buildings, the credibility of the programme may be put at risk. Finally, but importantly, the construction industry should be up-skilled so that they are able to provide informed advice and implementation of low-energy buildings renovation and construction so that consumers can easily take advantage of economic instruments to undertake energy efficiency measures.

\section{II.6 Return on public investment in low-energy buildings}

Traditional cost-benefit analysis of government programmes using economic instruments to improve the performance of buildings has mainly considered the cost of the economic instruments compared with the value of the energy saved. Recent analysis of the non-energy benefits of programmes applying economic instruments to low-energy buildings demonstrates that the net cost benefit ratio of such programmes is less clear than it first appears. There can be large benefits associated with improving the quality and energy performance of the buildings stock. These benefits include improvements in health and wellbeing, better energy affordability, increased disposable income, increased asset values on an individual level as well as from a public sector perspective reduced public expenditure, job creation, energy security, GDP growth, and of course climate change mitigation (see Figure 5).

Most of these benefits relate to improvements in the energy performance of buildings regardless of the policies used. Some of these benefits could also positively influence the bankability of investments in buildings, if for example increases in asset values, increased rents and occupancy rates as well as the higher solvability of loan takers are taken into account by banks when doing a loan assessment. Analysis of the impact of the economic instruments for low-energy buildings programmes indicate that public budgets may actually improve from the programme as a result of increased revenues from income and VAT taxes, spending of the higher disposable income and reduced public health bills, for example. Monetising these benefits can positively change an assessment of the outcomes from introducing economic instruments.

Several countries have approximated the non-energy monetised benefits from their buildings programmes, as well as the energy savings. New Zealand estimated that the health benefits from their grants for insulation programme exceeded NZD 1.2 billion while total costs amounted to NZD 332 million (Grimes et al., 2012). Germany estimated the value of the increased revenue from income taxes and VAT as a result of their loans for buildings energy refurbishments outweighed the programme costs by between 2:1 and 3:1 on average during 2005 and 2010 (calculated from Kuckshinrichs et al., 2011). ${ }^{64}$ In Ireland, it has been estimated that for every

\footnotetext{
${ }^{64}$ The study evaluates two scenarios. The first assumes all related working hours are covered by overtime hours in existing jobs (result 2:1) and the second assumes that related working hours are covered by the creation of new jobs (result 3:1). In reality a mix of the two scenarios is more likely.
} 
million Euro spent on refurbishment of buildings 24.4 jobs were supported. ${ }^{65}$

Figure $5 \cdot$ Multiple benefits of low-energy buildings

Page | 70

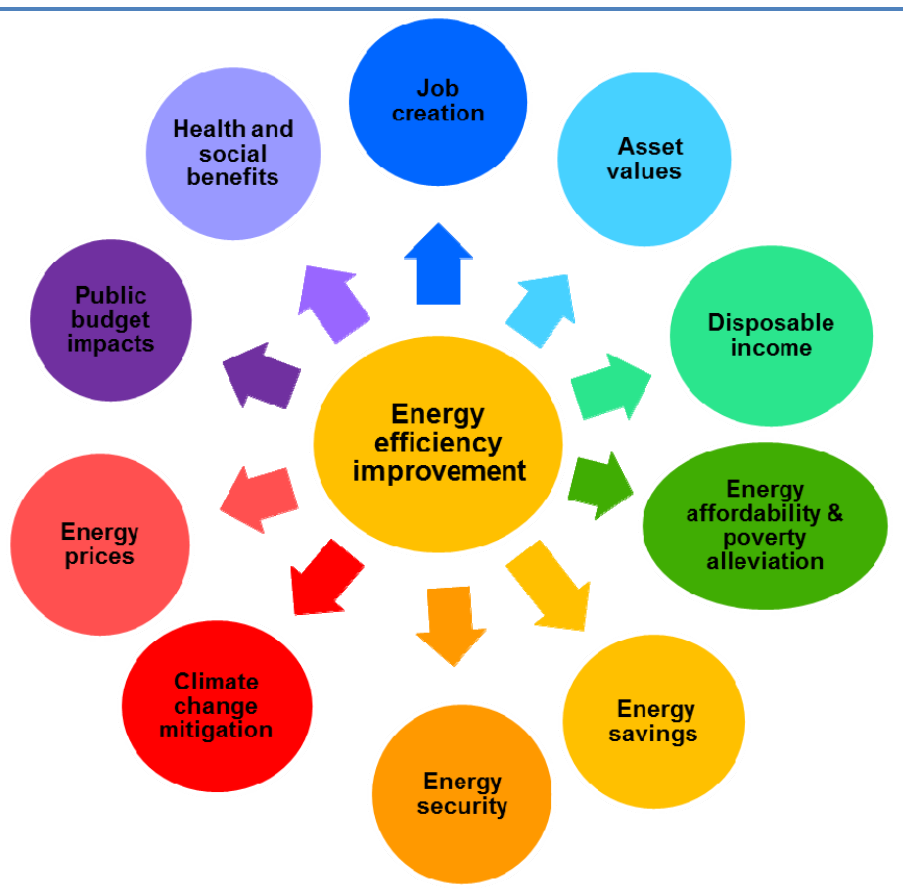

Source: IEA 2012.

More evaluation of relevant benefits is needed to be able to properly include non-energy benefits in policy impact assessments as many remain very rough approximations. Also the interaction between some of the impacts needs to be better analysed, as for example achieving health benefits (due to higher room temperatures) may reduce the overall amount of energy savings. ${ }^{66}$

In countries in the midst of economic recession, policy makers may be more interested in the macroeconomic, public budget and social effects than energy savings that can be delivered by energy efficiency measures. Economic instruments in this context may be part of a stimulus programme that targets environmental and economic objectives simultaneously. Therefore the net costs to society of the use of public funds for economic instruments should be estimated in the wider socioeconomic context.

65 This includes both public and private funds (Scheer, 2012, Sustainable Energy Authority of Ireland, personal communication).

${ }^{66}$ The IEA is working on evaluating the wider socioeconomic outcomes from energy efficiency and has recently published a first overview as an input into ongoing discussions, see Ryan and Campbell, 2012. 


\section{Table 3 - Comparison of economic instruments for low-energy buildings}

\begin{tabular}{|c|c|c|c|c|c|}
\hline $\begin{array}{l}\text { Instrument/ } \\
\text { approach }\end{array}$ & Enablers and preconditions & Strengths & Weaknesses & Funding & $\begin{array}{l}\text { Examples } \\
\text { discussed }\end{array}$ \\
\hline $\begin{array}{l}\text { Energy taxes } \\
\text { and prices }\end{array}$ & Policies to address energy poverty & $\begin{array}{l}\text { - Long term signals for investors; } \\
\text { - Addresses low rates of return; } \\
\text { - Source of revenue for governments. }\end{array}$ & $\begin{array}{l}\text { - Lack of public and political } \\
\text { acceptance; } \\
\text { - Impact not high if price elasticity of } \\
\text { demand is low }\end{array}$ & no funding needed & $\begin{array}{l}\text { All IEA } \\
\text { countries at } \\
\text { different levels }\end{array}$ \\
\hline Tax relief & $\begin{array}{l}\text { - Energy performance } \\
\text { requirements; } \\
\text { - Trained professionals } \\
\text { - Available finance }\end{array}$ & $\begin{array}{l}\text { - Raises awareness and rates of return; } \\
\text { - Provides incentive }\end{array}$ & $\begin{array}{l}\text { - Focuses on quick wins, no deep } \\
\text { retrofit; } \\
\text { - can be complicated to administer and } \\
\text { apply; } \\
\text { - data records weak }\end{array}$ & public budgets & IT, FR, US \\
\hline Grants & $\begin{array}{l}\text { - Energy performance } \\
\text { requirements; } \\
\text { Trained professionals }\end{array}$ & $\begin{array}{l}\text { - Raises awareness and rates of return; } \\
\text { - Provides easy incentive }\end{array}$ & $\begin{array}{l}\text { Focus on small sized investments (quick } \\
\text { wins), no deep retrofit }\end{array}$ & $\begin{array}{l}\text { public banks, } \\
\text { dedicated funds, EE } \\
\text { agencies }\end{array}$ & IRE, CA, DE, NZ \\
\hline $\begin{array}{l}\text { Loan } \\
\text { programmes }\end{array}$ & $\begin{array}{l}\text { - Technical assistance for local } \\
\text { financial institutions } \\
\text { - Link to building energy codes }\end{array}$ & $\begin{array}{l}\text { - Provides liquidity in financial markets; } \\
\text { - Reduces costs of finance; } \\
\text { - Raises awareness } \\
\text { - Funds repaid }\end{array}$ & $\begin{array}{l}\text { - Larger source of initial funding } \\
\text { needed } \\
\text { - Less attractive to consumers than } \\
\text { grants }\end{array}$ & $\begin{array}{l}\text { public banks, } \\
\text { dedicated funds, EE } \\
\text { agencies, local } \\
\text { financial institutions }\end{array}$ & $D E, F R$, AUS \\
\hline Guarantees & $\begin{array}{l}\text { - Technical assistance for } \\
\text { participating local financial } \\
\text { institutions }\end{array}$ & $\begin{array}{l}\text { - Reduce perceived high risks } \\
\text { - Less public funding needed }\end{array}$ & $\begin{array}{l}\text { - Not always be attractive to Fls } \\
\text { - Lower interest rates may not be } \\
\text { passed on to investors }\end{array}$ & $\begin{array}{l}\text { public budgets, } \\
\text { public banks, } \\
\text { dedicated funds, EE } \\
\text { agencies }\end{array}$ & $\begin{array}{l}\text { Central and } \\
\text { eastern Europe }\end{array}$ \\
\hline $\begin{array}{l}\text { On-bill } \\
\text { finance } \\
\text { (loans and } \\
\text { tariffs) and } \\
\text { PACE }\end{array}$ & $\begin{array}{l}\text { - Enabling legislation to engage } \\
\text { utilities and tax authorities; } \\
\text { - Technical assistance for } \\
\text { participating local financial } \\
\text { institutions }\end{array}$ & $\begin{array}{l}\text { - Reduces split-incentives; } \\
\text { - Addresses long payback periods and poor } \\
\text { credit history, potentially off-balance sheet } \\
\text { finance (tariffs) }\end{array}$ & $\begin{array}{l}\text { - Investors might not like leaving debt } \\
\text { on property; } \\
\text { - May be difficult to understand }\end{array}$ & $\begin{array}{l}\text { public banks, } \\
\text { dedicated funds } \\
\text { and agencies, local } \\
\text { financial institutions }\end{array}$ & US, UK \\
\hline
\end{tabular}




\begin{tabular}{|c|c|c|c|c|c|}
\hline $\begin{array}{l}\text { Instrument/ } \\
\text { approach }\end{array}$ & Enablers and preconditions & Strengths & Weaknesses & Funding & $\begin{array}{l}\text { Examples } \\
\text { discussed }\end{array}$ \\
\hline $\begin{array}{l}\text { Performance } \\
\text { contracting }\end{array}$ & $\begin{array}{l}\text { - Policies to enable ESCO business } \\
\text { model; } \\
\text { - Liquid financial markets willing } \\
\text { to accept ESCO guarantees; } \\
\text { - Technical assistance for } \\
\text { participating Fls }\end{array}$ & $\begin{array}{l}\text { - Overcomes high risk perception; } \\
\text { - Potentially off-balance sheet (shared } \\
\text { savings); } \\
\text {-provides one-stop shop for finance and } \\
\text { implementation (shared savings) }\end{array}$ & $\begin{array}{l}\text { - Profit-making so focus on quick wins, } \\
\text { no deep retrofit }\end{array}$ & $\begin{array}{l}\text { local financial } \\
\text { institutions, ESCOs }\end{array}$ & US, EU \\
\hline $\begin{array}{l}\text { White } \\
\text { certificates }\end{array}$ & Energy supplier obligations & $\begin{array}{l}\text { Raises priority of EE investments, provides } \\
\text { finance to most cost-effective investments }\end{array}$ & $\begin{array}{l}\text { - Trading interest of obliged parties } \\
\text { depends on country context } \\
\text { - Profit-making so focus on quick wins, } \\
\text { no deep retrofit }\end{array}$ & $\begin{array}{l}\text { Directly or via } \\
\text { trading platforms }\end{array}$ & FR, IT, UK \\
\hline $\begin{array}{l}\text { Carbon } \\
\text { markets }\end{array}$ & $\begin{array}{l}\text { - Trading schemes that target } \\
\text { buildings sector and generate } \\
\text { - Need to consider carefully } \\
\text { overlap with other policies }\end{array}$ & $\begin{array}{l}\text { - Directly finances EE projects; raises rates } \\
\text { of return } \\
\text { - Can generate revenues to fund EE } \\
\text { projects }\end{array}$ & $\begin{array}{l}\text { - Difficult to target the building sector, } \\
\text { due to monitoring, verification and } \\
\text { design issues of trading schemes, CDM } \\
\text { and JI } \\
\text { - Small size of EE projects may be } \\
\text { difficult }\end{array}$ & $\begin{array}{l}\text { Directly or via } \\
\text { trading platforms }\end{array}$ & EU, KOR, MEX \\
\hline R\&D support & $\begin{array}{l}\text { - Buildings components } \\
\text { manufacturing industry }\end{array}$ & $\begin{array}{l}\text { - Encourages private sector investment in } \\
\text { supply of } \mathrm{EE} \text { technologies } \\
\text { - Reduces risk to early mover companies in } \\
\text { advanced technologies } \\
\text { - Can create jobs in industry }\end{array}$ & $\begin{array}{l}\text { Does not create demand for } \\
\text { technologies } \\
\text { - No guarantee that technologies will } \\
\text { be brought to market }\end{array}$ & Directly & US, J, EU \\
\hline $\begin{array}{l}\text { Public } \\
\text { procurement/ } \\
\text { infrastructure }\end{array}$ & $\begin{array}{l}\text { - Legal framework simplifying } \\
\text { procurement for EE } \\
\text { - Changing operating budget } \\
\text { rules to encourage energy savings }\end{array}$ & $\begin{array}{l}\text { - Can kick-start EE market in early stages } \\
\text { - Scales up deployment of EE technologies } \\
\text { and services } \\
\text { - Raises awareness by providing leadership } \\
\text { and example for private sector }\end{array}$ & $\begin{array}{l}\text { - Can put strain on public budget if not } \\
\text { managed } \\
\text { - Lack of competition can cause rising } \\
\text { costs } \\
\text { - EE technologies may not be } \\
\text { deployable in residential buildings and } \\
\text { therefore experiences less useful }\end{array}$ & Directly & US, EU \\
\hline
\end{tabular}




\section{PART III: Funding economic instruments}

Many of the economic instruments discussed in the report need public funding. While taxes raise revenues, the other economic instruments described in the previous section mainly comprise different kinds of public subsidies in some form or other for energy efficiency projects which require funding. This may be to fund private investors directly (e.g. tax incentives, grants, or special credit lines), used to enhance loan conditions (e.g. for loan guarantees or interest rate buydown), as well as for the administration and implementation of financing policies (including training, information and awareness raising activities). This section of the report discusses (i) the sources of funding for economic instruments for low-energy buildings and (ii) the intermediaries and arrangements that can be used to bring together and disburse funds.

In deciding whether and which economic instrument is needed to push energy efficiency finance in a country or jurisdiction, key issues are how the policy can be funded and delivered. The type of economic instrument may to some point decide the most appropriate source of funding. In reverse, the funding available may also determine the choice of economic instruments that are available to the policy maker.

A framework for analysing sources of funds for economic instruments can include:

- General public budget allocations (on national or sub-national levels), including earmarked taxes;

- Revenues from emissions allowance auctioning;

- Private funds and institutional investors.

Traditionally, promotional policies have been funded by the public budget. Public-private approaches have also been tried and are increasingly popular. Faced with ever tighter public budgets, using public funds to maximise the leverage of private capital has become a key concern of policy makers.

Once the source of funding is identified, appropriate institutional arrangements need to be put in place. Such intermediaries and funding arrangements may serve various purposes: First, in many cases, they provide an institutional set-up to blend public and private funds from various sources and thus form a focal point for regrouping many smaller sources of funding to a single budget. Secondly, intermediaries can administer the distribution of the funds to the target groupp. The main types of intermediaries and funding arrangements found for energy efficiency projects are:

- Specialised agencies (e.g. national energy agencies),

- Dedicated funds,

- Public banks

- Green bonds

This section is broken into two subsections to discuss the advantages and challenges with regard to both the different sources of funding, as well as the various intermediaries and funding arrangements for gathering and disbursing funds.

Many of the issues discussed in this chapter are not exclusive to the building sector, but apply to funding issues for economic instruments for energy efficiency in other sectors (e.g. industry and transport) too.

\section{III.1 Sources of funding}

This subsection describes the options to policy makers in sourcing funds to deliver economic instruments that require funding. The goal of these instruments is to increase overall funds available to finance energy efficiency measures. Public funds are therefore not only used to 
complement private sources of funds, but are designed to leverage the maximum amount of private funds for energy efficiency measures.

The framework for sources of funds listed above is used to describe the three types of funding categories employed for economic instruments: public funds in the form of general budget allocation or earmarked taxes; revenues from carbon markets and private funds and institutional investors.

Page | 74 Public banks can also be a source of funds, but are discussed in the chapter on intermediaries as they are important institutions in leveraging more private funding and disbursing funds.

Some sources of public funds for energy efficiency economic instruments discussed in this chapter, such as budget allocations, environmental taxes, charges, and revenues from the auctioning of emission permits, represent potential sources of funding not only for financing policies but also for other energy efficiency policy instruments, such as regulation and information. This is, however, not discussed in any further detail as the focus is on economic instruments.

\section{General budget allocations and earmarked tax revenues and charges}

Energy efficiency funding can come directly from (national or local) public budgets through budget allocations. This can be done in several ways. One is the regular budget allocation process, in which energy efficiency programmes receive funding in proportion to their relative importance with regard to other political priorities, e.g. education, health care or public debt reduction. This means that energy efficiency has to compete for funds with other issues on the political agenda and the level of funding will vary according to budget negotiation results. Funding is thus secured mainly for the respective budget period.

General allocation provides governments with most flexibility and control over public funds, as the relative amounts allocated can change year-on-year. In order to enable some longer-term planning, so-called commitment authorisations can be voted as part of the budget negotiations to specify how funding for this budget item should evolve over the following budget periods. However, uncertainties remain for longer-term planning as political priorities are susceptible to change.

\section{Earmarked taxes}

The second option is to earmark certain public revenues (fully or in part) for the use of energy efficiency spending. Earmarking can make funding somewhat more steady and reliable, but it still depends on the continued political support for earmarking these funds. Uncertainties remain also regarding the size of earmarked revenues to be expected. Often environmentally related (or more specifically energy consumption-related) taxes are earmarked for energy efficiency promotion (see Table 4 for examples). Since their primary purpose is to give a disincentive to energy- or carbon-intensive production and consumption, the tax base may eventually decrease or even eroded over time if the tax is successful in that regard (OECD, 2010b pp. 141). But even if the tax is not a disincentive enough to change behaviour, the revenues may also depend on the overall economic situation (and thus decline in phases of economic downturns) or on other factors such as the weather, e.g. mild winters (see also OECD, 2010b, pp. 34). 
Table 4 • Examples of earmarked environmentally related taxes

\begin{tabular}{lrr}
\hline Country & Type of tax & Earmarking \\
\hline Korea & $\begin{array}{r}\text { Tax on high-consuming or large } \\
\text { appliances }\end{array}$ & $\begin{array}{r}\text { Subsidy for low-income energy } \\
\text { efficiency }\end{array}$ \\
\hline Mexico & Tax on oil production & Sustainable Energy Fund \\
Moldova & $\begin{array}{r}\text { Fines for violation of provisions of } \\
\text { the Law on Energy Conservation }\end{array}$ & Energy Conservation Fund \\
\hline Tunisia & Duty levied on imported air \\
conditioners & National Energy Savings Fund \\
\hline United Kingdom & Climate change levy on & Energy supplier obligations \\
\hline
\end{tabular}

Source: IEA and EBRD, 2010

There is a clear trade-off between public accounting good governance rules and long-term steady funding needs for energy efficiency. Even though earmarking of public revenue streams is a widely used practice and about one third of environmentally related taxes in OECD member countries are earmarked to some extent (OECD, 2006 pp. 171), the practice receives a number of criticisms. Earmarking goes against good fiscal practice as it deprives the budget decision-making process of control over the earmarked funds. There is a large "double-dividend" literature which finds that the optimal use of environmental tax revenues (from an economic welfare perspective) is to reduce other distortionary taxes, such as labour taxes (see for example Blovenberg 1999). Earmarking reduces the flexibility of the budget to respond to changing needs and priorities and decreases budgetary transparency and control. Earmarked funds can also be more easily captured by special interests (Heffner and Ryan, 2011 pp. 24). Earmarking tax revenues for specific programmes can also make it more difficult to revise the tax specifications and may keep programmes running longer than optimal as vested interests may prevent reforms (OECD, 2006 pp. 172).

From a political economy perspective, earmarking has the advantage of potentially increasing public acceptance of new taxes, especially where earmarked funds finance programmes accessible to those groups that paid the tax (Heffner and Ryan, 2011 pp. 23). Even though it seems equitable to channel revenues back to the tax payers, this can be seen as opposing the "polluter-pays" principle unless the recycled revenue is used for pollution mitigation and only recycled to the tax base as a flat rate rather than in proportion to the amounts paid (OECD, 2010b pp. 142). A stronger argument can be constructed for using the revenues to support low-income households to reduce their energy bill through energy efficiency measures, although there may be a trade-off between equity and economic efficiency (see for example, Burtraw and Parry, 2011). Low-income households can be disproportionally more affected by rising energy prices, depending on the energy sources taxed and their respective uses by poor households (Heffner and Ryan, 2011 pp. 25).

A way of achieving public acceptance without formally earmarking funds can be the formulation of a policy package with simultaneous implementation and announcement of a new or increased energy tax with an energy efficiency programme (OECD, 2006 pp. 172). This does, however, not solve the issue of steady and reliable funds needed for energy efficiency programmes.

Environmentally-related taxes form a non-trivial stream of revenues to OECD governments, well above $1.5 \%$ of GDP or $5 \%$ of total tax revenues in 2010, with a slight downward trend and significant differences between member countries. ${ }^{67}$ Two-thirds of these revenues stem from energy consumption taxes, with most coming from taxes on motor fuels. Where taxes on light fuel oil for non-road uses exist (for heating and industrial processes), these are often significantly

\footnotetext{
${ }^{67}$ See: www.oecd.org/env/policies/database
} 
lower than the rates for on-road fuel use. In January 2010, only 16 OECD member countries (mostly European, plus Japan and Korea) had tax rates on light fuel oil for non-road use over EUR 0.05 per litre (OECD 2010b, pp. 44+46). Electricity taxes exist in half of OECD member countries, and countries without direct taxation of electricity often have other tax bases related to electricity generation such as fuels or $\mathrm{CO}_{2}$ emissions (OECD, 2010b pp. 54ff).

\section{Charges}

Table 5 compares general budget allocations, earmarked taxes and system public benefit charges. Revenues of significant size have been generated in various countries through charges. These can have many different names: pollution charges, system or public benefit charges, line charges, network or wire charges, etc. ${ }^{68}$ Just as (other) environmental taxes, they are mainly paid by consumers via the regular energy bill. However, they may not be accounted for in public budgets although collection is empowered by public policy. In the United States, system or public benefit charges are collected by energy providers and can either be used directly by the energy provider to fund activities related to obligations schemes or provide a source of funding for funds dedicated to energy efficiency measures (Heffner and Ryan, 2010). The use depends on the legislation in force.

As the charge is often paid by all energy users and sometimes independently of the amount of energy usage, it can provide substantial and long-term sources of funding. Charges can be used to fund energy efficiency programmes that aim to transform the markets (IEA and EBRD, $2010 \mathrm{pp}$. 64-65). Given that the charge is raised among a very large group, the charge can be relatively small, thus also keeping the burden to the individual customer small, but still raise substantial amounts of funds. The primary goal of these charges is to raise revenues for a particular purpose, i.e. energy efficiency measures, while other environmental taxes are often designed to give an incentive to change polluting behaviour and as a consequence erode the tax base over time.

The fact that charges often do not appear in the public accounting system gives rise to criticism from a good governance point of view. As with earmarked taxes, these energy efficiency funds are not allocated according to policy priorities (Heffner and Ryan, 2011 pp. 22-23). However, there have been some instances where the funds have been diverted to purposes other than energy efficiency or the original intended purpose, despite the earmarking in the first place due to more urgent priorities appearing. Such practice has been reported from the state of Wisconsin in the US for some years starting in 2001 (Brown, 2008 pp. 3). This harms the credibility of the approach and could create public resistance to paying the charge.

If charges are levied on just a few energy sources, they risk creating relative price distortions between fuels. This may especially be the case if the level of charges is set according to the level of funding needed for identified programmes and does not take into account overall effects on demand. Similar to environmental taxes, charges potentially pose a heavier burden on poor households, depending on the design of the charges and the energy demand patterns. On the other hand, given that the collection and disbursement of charges is often overseen by specialised independent regulators, these may be less influenced by special interest groups (Heffner and Ryan, 2011 pp. 25-26).

\footnotetext{
${ }^{68}$ Strictly speaking, many of these charges are taxes, according to the OECD definition, because there is not an equivalent service provided in return to the consumer who is paying the charge. Charges are defined by the OECD as "requited compulsory payments to the government that are more or less in relation to a service provided" (http://www2.oecd.org/ecoinst/queries/index.htm), which means that the person required to pay the charge receives a service in return which is in relation to the size of the charge paid.
} 
Table 5 - Comparing charges, earmarked taxes and general budget allocations

\begin{tabular}{|c|c|c|c|c|c|c|c|}
\hline \multirow{3}{*}{$\begin{array}{l}\text { Funding } \\
\text { source }\end{array}$} & \multirow{3}{*}{$\begin{array}{l}\text { Collec- } \\
\text { tion } \\
\text { agency }\end{array}$} & \multirow{3}{*}{$\begin{array}{l}\text { Disburse- } \\
\text { ment } \\
\text { decision- } \\
\text { making }\end{array}$} & \multicolumn{5}{|c|}{ Evaluation criteria } \\
\hline & & & \multicolumn{3}{|c|}{ Classic economics considerations } & \multicolumn{2}{|c|}{$\begin{array}{l}\text { Political economy } \\
\text { considerations }\end{array}$} \\
\hline & & & $\begin{array}{c}\text { Fiscal and } \\
\text { governance } \\
\text { issues }\end{array}$ & Equity issues & $\begin{array}{l}\text { Economic } \\
\text { efficiency }\end{array}$ & $\begin{array}{c}\text { Adequacy } \\
\text { and } \\
\text { stability }\end{array}$ & $\begin{array}{c}\text { Political } \\
\text { acceptance }\end{array}$ \\
\hline $\begin{array}{l}\text { Earmark } \\
\text { ed taxes }\end{array}$ & $\begin{array}{l}\text { Govern- } \\
\text { ment }\end{array}$ & $\begin{array}{l}\text { Special } \\
\text { purpose } \\
\text { agencies }\end{array}$ & $\begin{array}{c}\text { "Special } \\
\text { funds" could } \\
\text { be abused by } \\
\text { special } \\
\text { interest groups }\end{array}$ & $\begin{array}{l}\text { Disbursement } \\
\text { can be targeted } \\
\text { to specific } \\
\text { segments; } \\
\text { potential for } \\
\text { regressive } \\
\text { impacts }\end{array}$ & $\begin{array}{l}\text { Depends on } \\
\text { size of GDP; } \\
\text { less } \\
\text { distortion } \\
\text { between fuel } \\
\text { types; least- } \\
\text { cost } \\
\text { mitigation } \\
\text { possible }\end{array}$ & $\begin{array}{l}\text { Steady long- } \\
\text { term funding } \\
\text { can be } \\
\text { locked-in }\end{array}$ & $\begin{array}{c}\text { Stakeholders } \\
\text { are } \\
\text { supportive } \\
\text { because of } \\
\text { the potential } \\
\text { to benefit }\end{array}$ \\
\hline
\end{tabular}

Source: Heffner and Ryan, 2011

The use of charges on electricity for energy efficiency measures is particularly widespread in the United States, where they present the largest single source of energy efficiency funding at the state level for energy efficiency programmes mandated by energy regulators. The aggregate funds sourced through public-benefit charges and other rate-payer funds by all U.S. states amounted to more than USD 8 billion in 2011. Ratepayer funds have been rising steadily over the last years in the US; they have far more than doubled since 2007 (USD 3.1 billion) (CEE, 2012 pp. 15).

\section{Emission allowance auctioning}

Governments can generate revenues from the carbon markets, either through auctioning emission allowances in the framework of emission trading schemes (ETS) or through the selling or auctioning of their assigned amount units (AAU) under the Kyoto Protocol (Buchner et al., 2011 pp. 11)

The UN High-level Advisory Group on Climate Change Financing estimated annual revenues from ETS and AAU auctioning would amount to USD 8 to 38 billion in 2010 on the basis of a carbon price of USD 25 per tonne $\mathrm{CO}_{2} \mathrm{e}$, assuming that $2-10 \%$ of the total market would be auctioned. Using a lower carbon price of USD 15 per tonne $\mathrm{CO}_{2} \mathrm{e}$ estimated revenues amount to USD 2 to 8 billon (AGF, 2010). 
Table 6 gives an overview of global emission trading systems currently in force. Yet a number of additional schemes are under discussion or already in the planning in Brazil, California, Chile, China, Japan, Korea, Mexico, Turkey and the US (OECD, 2012 pp. 95).

Table 6 - Overview of existing emission trading schemes

\begin{tabular}{ll}
\hline Name of the scheme & Year \\
\hline European Union Emissions Trading Scheme & 2005 \\
\hline Alberta, Canada, Climate Change and Emissions Act (see note) & 2007 \\
\hline The New Zealand Emissions Trading Scheme & 2008 \\
\hline The Swiss Emission Trading Scheme and $\mathrm{CO}_{2}$ Tax & 2008 \\
\hline The Regional Greenhouse Gas Initiative in the northeast of the US & 2009 \\
\hline The Tokyo Cap and Trade Programme & 2010 \\
\hline Australian Emissions Trading Scheme & 2012 \\
\hline
\end{tabular}

Note: The Canadian programme is an emission intensity reduction programme, not a cap-and-trade system.

Source: adapted from OECD, 2012 pp. 95 and Hood, 2010.

The European Union Emission Trading System (EU ETS) is the largest existing emissions trading scheme globally and also one of the first markets to be set up for carbon emissions. Participating countries are the EU 27 member countries and Norway, Iceland and Lichtenstein. It covers major emitters from the industry and energy sectors, overall more than 10900 large installations, which account for about half the $\mathrm{CO}_{2}$ emissions from the $\mathrm{EU}$ (OECD, $2012 \mathrm{pp}$. 95-96). In the third phase of the scheme, starting from 2013, it is planned to extend the coverage to further subsectors and additional greenhouse gases such as nitrous oxide $\left(\mathrm{N}_{2} \mathrm{O}\right)$ and perfluorocarbons. ${ }^{69}$ The aviation sector has already been included in the EU ETS since the start of 2012. ${ }^{70}$

Revenues raised in 2010 from auctioning of permits under the EU ETS have been estimated at USD 1.4 billion. This figure is expected to increase significantly due to the planned extension of the coverage and the decision to increase the share of permits that are auctioned (Buchner et al., 2011 pp. 11). Auctioning was restricted to maximum 5\% in the first period (2005-2007) and to $10 \%$ in the second period (2008-2012). However, the auctioning levels stayed well below these restrictions and many countries did not use auctioning at all. For the third period (2013-2020), it is planned to bring auctioning to a level of $50 \%$ of all allowances (Enting and Reich, forthcoming). The European Commission estimated that this could bring revenues from ETS auctioning up to EUR 20 billion per year by 2020, to which EUR 600 million per year could be added if the aviation sector is included, based on a carbon price of EUR 20 per tonne of $\mathrm{CO}_{2}$ (EC 2011a pp. 9).

Of all the auctioning revenues, $50 \%$ are recommended to be used for further emission reduction purposes as prescribed in the EU directive 2009/29/EC, including energy efficiency and insulation measures in the buildings sector (Enting and Reich, forthcoming).

\footnotetext{
${ }^{69}$ See EC homepage: http://ec.europa.eu/clima/policies/ets/cap/index_en.htm

${ }^{70}$ See EC homepage: http://ec.europa.eu/clima/policies/transport/aviation/index_en.htm
} 


\section{Box 13 - German experience in earmarking revenues from ETS allowance auctioning}

Germany started auctioning about $10 \%$ of its emission allowances already in 2008 with the beginning of the second trading period. More than half of the revenues were used for the funding of climaterelated activities and directly transferred to the budget line of the Ministry of Environment. A dedicated fund was set up to administer the climate-related funding, which has a national and an international window (National and International Climate Initiative ${ }^{71}$ ). As of 2010, the revenues were transferred to the Ministry of Finance and first included in the general budget in order to be distributed to several ministries implementing climate-related activities during regular budget negotiations. Even though the funds were still partly politically earmarked, there was no legally binding obligation anymore.

With the decision to phase out nuclear energy in Germany faster than initially planned ${ }^{72}$, the government set up an Energy and Climate Fund and decided to earmark $100 \%$ of all auctioning revenues directly for the fund as of 2012. Even though the fund's budget is separate from the general budget, spending decisions are taken annually in form of a special economic plan and discussed during the general budget discussions. An annex to the law which is setting up the fund, describes these annual economic plans in principle and already sets out quite detailed annual commitment authorisations for a number of programmes, some of which are running up to the budget year 2021. This allows longer-term planning on the one hand and some flexibility for annual adjustments on the other hand. The fund has a budget of EUR 300 million for 2011 and EUR 780 million for 2012. The government is hoping to bring the budget to EUR 2.5 billion annually from 2013 through the rising share of permissions auctioned. Funds are used inter alia for the $\mathrm{KfW}$ " $\mathrm{CO}_{2}$ refurbishment programme" (see Germany case study), as well as a number of other initiatives related to the promotion of energy efficiency.

Source: Enting and Reich, forthcoming and BMF, 2011

Another option for funding energy efficiency projects through carbon markets for some countries is to sell Assigned Amount Units (AAUs) which are related to the trading mechanisms under the Kyoto Protocol. ${ }^{73}$ Green Investment Schemes (GIS) have been set up by governments with surplus AAUs, under which they commit to use the revenues from AAU sales for predefined emissions reduction activities (Blyth and Baron, 2003). Even though this concerns only a small group of countries, there are lessons to be learned from this experience. ${ }^{74}$ Out of eight countries that have set up a GIS, Czech Republic, Estonia, Hungary, Latvia, Lithuania, and Poland have made buildings' energy efficiency projects a priority for spending of revenues. Table 7 shows the main characteristics of the 3 most mature GIS schemes.

One reason why governments use GIS to target specifically the building sector is not only the emission reduction potential of this sector but also that instruments under the Kyoto Protocol, such as the Clean Development Mechanism (CDM) or the Joint Implementation (JI), have not been suitable for the buildings sector (see discussion on carbon markets above) (Selmet et al. 2012). Unlike the first generation of CDM projects, many of the GIS allow for a bundling of projects, which reduces transaction costs and provides a basis to address the vast, but scattered, energy efficiency potentials in the building sector, as well as a simplified approach to calculate energy

\footnotetext{
${ }^{71}$ For more information on the Climate Initiative: www.bmu.de/english/climate_initiative/general_information/doc/42000.php

${ }^{72}$ For more information on the transformation of the German energy system: www.bmu.de/english/transformation_of_the_energy_system/general_information/doc/48050.php

73 The protocol included national emission commitments for the participating parties. With regard to the economies in transition of the former Soviet Union, which were facing sharp economic downturns, these were allocated so-called assigned amount units (AAUs) well above there current emissions in order to make sure that the cap and trade system would still allow these economies to pick up economic growth. Under the flexibility mechanisms these surplus emission allowance could be sold to other countries which would have emissions in excess of their commitments (Tuerk et al., 2010).

74 namely Czech Republic, Latvia, Hungary, Poland, Estonia, Romania, Bulgaria, Lithuania, Ukraine, Russia and Slovakia
} 
consumption reductions achieved (Tuerk et al., 2010).

Table 7 • Examples for Green Investment Schemes in Hungary, Latvia and Czech Republic

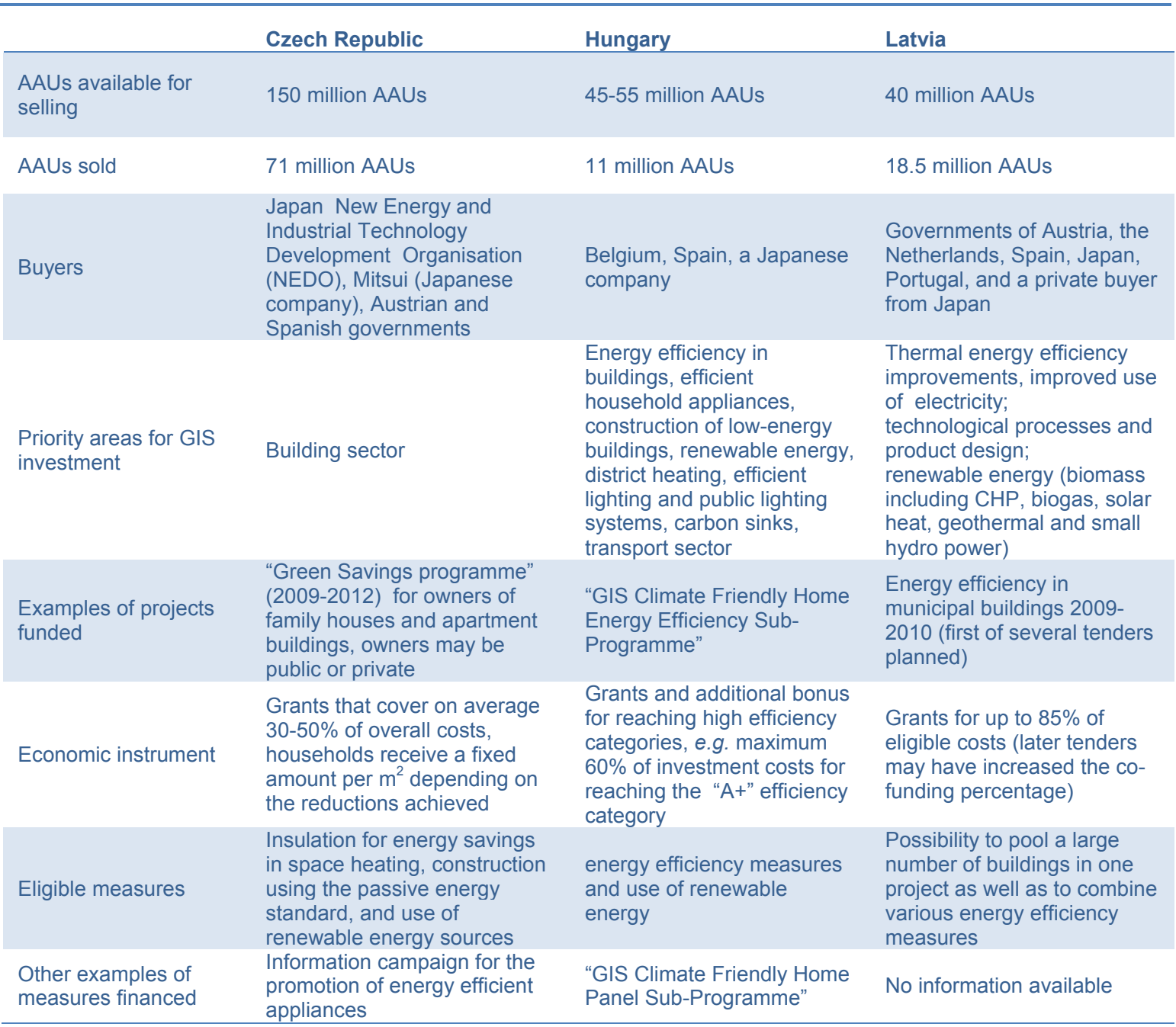

Source: Tuerk et al., 2010

\section{Institutional investing and private investment funds}

Private funds can also be a source of funds for economic instruments; they can be blended with public funds and disbursed by intermediaries or enabled through public policy approaches, i.e. see guarantees, EPCs,on-bill financing in Part II. Governments are increasingly interested in employing private funds to invest in energy efficiency measures, as a way of relieving pressure on public budgets and encouraging private capital markets to engage in sustainable investment in energy efficiency over the long-term.

In 2010, global capital markets amounted to about USD 212 trillion, of which USD 117 trillion were assets under management mainly in the form of funds. These assets are growing over $6-7 \%$ annually (IEA, 2012a). Conventional funds, such as pension funds, insurance companies, and investment funds, combine assets of USD 71 trillion in 2011 (Kaminker and Stewart, 2012) and look for low-risk investment opportunities with average annual returns of 4-8\%. Sovereign wealth funds, which are state owned funds, have shown the largest growth rates, rising to USD 4.8 trillion in 2011 (IEA, 2012a). Pension, investment, and sovereign wealth funds look for longer-term investments and need less flexibility in terms of being able to access the invested assets on a daily basis. These funds thus seem to be a good funding source for renewable energy and (aggregated or bundled) energy efficiency projects, however, to date only a fraction has been invested in green projects (IEA, 2012a). 
The Climate Change Property Fund ${ }^{75}$ is a private sector initiative to provide finance to retrofitting existing commercial buildings to improve their energy performance. It is managed by Climate Change Capital, a private company providing investment management and advisory services. Institutional investors from Europe and Australia have made available GBP 150 million for investing in urban retail and office buildings with a special focus on improving energy and resource efficiency. Activities of the fund are focused on the United Kingdom, where the legislation and the property market are favourable. Climate Change Capital reports a rental increase of $6-7 \%$ and capital appreciation of $16 \%$ due to the investments undertaken. Green assets appear to be showing a better performance for a number of reasons according to Climate Change Capital ${ }^{76}$. These include, among others, a growing importance of Corporate Social Responsibility issues, better working environments, legislative pressures to invest in "green" buildings. For these reasons tenants prefer green buildings in many cases. Rather than regulation, carbon pricing instruments and mandatory disclosure schemes were named as important factors to motivate the private sector to investing in these kinds of assets.

Source: workshop proceedings: www.iea.org/newsroomandevents/workshops/name,14184,en.html

Despite the potential, few funds specifically for energy efficiency have been set up by institutional investors. Challenges expressed by the investors include the limited experience with energy efficiency funds so far, a lack of benchmarks, and the fact that energy efficiency faces tough competition in-house from other investment opportunities (WEF, 2011 pp. 35). Energy efficiency can appear to be riskier than other investments when the security is based on energy savings rather than collateral in the form of assets (Brodach, 2012). The absence of aggregation mechanisms is especially problematic for energy efficiency investment in residential and commercial buildings due to their disbursed nature (see the section on green bonds below for a further discussion of the issue). However, some cases of private funds with an energy efficiency focus do exist, particularly where the investment does not consist solely of energy efficiency measures, but is also based on an asset such the building itself, as shown in the example in Table 8.

A number of studies looking at the United States and Australian commercial buildings confirm the experience of Climate Change Capital in the UK and shows that green buildings deliver a market premium in terms of increased rents, higher occupancy rates and an increase in resale value (Newell, McFarlane, and Kok, 2011). Eichholtz, Kok and Quigley (2011) analysed the impact of Energy Star ratings on rent and sales values for office buildings in the United States, both compared with non-rated buildings and other Energy Star buildings and found that a one dollar saving in energy costs of a building is on average associated with a $3.5 \%$ higher rent and a $4.9 \%$ premium in market valuation. ${ }^{77}$

Table 8 - The market premium of green commercial buildings in the United States and Australia

\begin{tabular}{l|c|c|c}
\hline Premium & Range in \% & Median in \% & Number of Studies \\
\hline Rental rates & $0-16$ & 4.5 & 7 \\
Sales price & $0-26$ & 11 & 6 \\
Occupancy rate & $0-18$ & 3 & 3
\end{tabular}

Source: adapted from Newell, McFarlane and Kok, 2011.

\footnotetext{
${ }^{75}$ www.climatechangecapital.com/property/climate-change-property-fund.aspx

${ }^{76}$ Refers to the presentation held by Ben Caldecott given at the IEA expert workshop: www.iea.org/media/workshops/2012/energyefficiencyfinance/3bCaldecott.pdf

${ }^{77}$ The Energy Star label is awarded to buildings with energy performance of at least $15 \%$ better than the 2006 IEEC code.
} 
The OECD underlines the role of institutional investors to bring the issue of unlocking the potential of energy efficiency to the boardrooms in order to drive change in company decision making (Kaminker and Stewart, 2012). An important investor-led initiative is the Carbon Action Initiative of the Carbon Disclosure Project which was signed by 34 investors representing USD 7.6 trillion in assets. ${ }^{78}$ In 2011 requested the 500 largest companies in terms of market capitalisation to achieve annual emission reductions by making investments with "satisfactory positive returns on investment" as well as to set and publicly report on emission reduction targets (CDP, 2011). ${ }^{79}$ $25 \%$ of emission reduction activities reported under the initiative by companies in 2011 fall into the area of buildings energy efficiency (including building services and building fabric) (CDP, 2011).

Given the relative abundance of private investment funds available and the growing awareness by investors that low-energy buildings could become an interesting investment option for long-term investments with medium returns and low risks attached, policy makers are more and more interested in determining how to best leverage these private funds.

\section{III.2 Intermediaries and green bonds}

The previous subsection has described different sources of funding for energy efficiency projects. Another important part of the issue of public funds is how to gather and disburse the funds via intermediaries, as this can be critical to the uptake and efficiency of public funds for energy efficiency. The following subsection describes in more detail three different intermediaries that are often used for these purposes:

- Specialised energy efficiency agencies,

- Dedicated funds,

- Public banks

- Green bonds.

Energy efficiency agencies, dedicated funds, and public banks co-operate in many cases with diverse entities that can serve as local contact points for programme applicants. In other cases, programme applicants may directly interact with the intermediary, often via an online information and application portal. Combinations are also possible, e.g. applicants have to first pass through a mandatory assessment procedure done by a local partner before applying directly via a central application portal.

This section also discusses green bonds discussed for their role in providing a vehicle for funds to be collected and disbursed to energy efficiency projects. They can aggregate projects and achieve sufficient scale to reach new groups of private investors.

\section{Energy efficiency agencies}

Energy efficiency agencies can be defined as "a body with strong technical skills, dedicated to implementing the national energy efficiency policy, as well as in some cases the environmental policy" (WEC, 2010 pp. 45). Most OECD countries have at least one agency charged to work on energy efficiency. These can be part of a national ministry (e.g. in Denmark, Canada, and the United States), or exist as separate institutions (e.g. in Korea, UK, Ireland, Norway, and Estonia). In many cases, they may be part of a broader energy or environment agency, covering a wider range of environmental issues (e.g. in France and the Netherlands). They may also be set up as publicprivate partnerships (e.g. in Germany and Poland) and additionally exist at sub-national level (e.g.

\footnotetext{
${ }^{78}$ See: www.cdproject.net/en-US/Programmes/Pages/initiatives-cdp-carbon-action.aspx

${ }^{79}$ listed in the FTSE Global Equity Index Series or "Global 500"
} 
in Austria, Belgium, Canada, Germany, Spain, and the United States). A more detailed description of the governance issues around setting up energy efficiency agencies and the merits of doing so are included in other IEA work (IEA and EBRD, 2010 pp. $72-87$ and WEC, 2010 pp. 44-46). Probably the largest variety of administrative set-ups can be found in the different states of the United States, where rate-payer funds are administered by energy providers, by government agencies, by third parties or through various hybrid forms (Sedano, 2011). Box 15 describes an innovative arrangement from the state of Vermont using a public-private approach.

\section{Box 15 - Efficiency Vermont}

The state of Vermont in the United States has opted for a public-private approach to providing energy efficiency services and delivering financing mechanisms. In 2010, an Energy Efficiency Utility was set up, adopting a franchise-like model through which a private contractor is appointed for a 12-year period to deliver energy performance services to ensure that public goals set are met. Activities cover technical assistance, financial incentives and public information and target all demand-side markets. Funding comes principally through an energy efficiency charge, which is collected by energy providers and appears on the energy bills of consumers. The charge has been growing over the years and comprised a surcharge of $5 \%$ on energy bills in 2011 . Collected funds are held by a contracted fiscal agent and the legislation specifies that collected funds are not to be considered funds of the state, to prevent a redirection of funds away from their dedicated use. The energy efficiency utility sets up a forward-looking budget over 20 years, which is adjusted every three years. Budgets include no profit margin and only a small operation fee of $0.75 \%$ is granted. Performance-based compensation is dependent on a three-year performance cycle. Innovative financing mechanisms used include Property Assessed Clean Energy (PACE) financing, loan guarantees and further credit enhancements.

Vermont is the first state in the United States to have achieved energy savings that offset growth in electricity use in each year since 2007, turning load growth negative. Average reductions in annual household electricity bills between 2000 and 2008 are estimated to amount to USD 144, and while for business and institutional customers, the average annual reductions are estimated to USD 707. Vermont is aiming to achieve nearly zero emissions from its buildings stock by 2050.

Source: Hamilton, 2011

Energy efficiency agencies take on the responsibility for the design, implementation as well as evaluation of public programmes to promote energy efficiency (WEC, $2010 \mathrm{pp}$. 44-46). They can manage funds, administer grants or loan programmes, or undertake direct investments in projects. An IEA survey among over 100 energy efficiency experts in 27 countries revealed that financial expertise is key for energy efficiency organisations and was ranked only second to technical expertise (IEA and EBRD, 2010 pp. 72-87). Good processes and capacity to disburse funds may be critical to the success of a financial instrument (as seen in the Australian Green Loan case, Box 5).

The advantage of having an energy efficiency agency implementing economic instruments compared with a government ministry is the additional specialised expertise in energy efficiency available. In many countries, public employees in government ministries tend to have more general, all-round expertise as they are required to regularly change post and the types of policies they work on. However, staff at energy efficiency agencies can be recruited with specific expertise that is needed in implementing energy efficiency programmes.

\section{Dedicated funds for energy efficiency}

Dedicated funds for energy efficiency are funds that are earmarked or set aside specifically for energy efficiency purposes. They are outside regular public budgets and use one or several instruments, such as loan or grant programmes, in order to disburse funds to the target group. The funds can be sourced in multiple ways, including through revenues from earmarked taxes or system public benefit charges, through general budget allocations or special government 
revenues, e.g. from the auctioning of emission permits. The fund volume can also be enhanced through the use of green bonds (see below).

Such funds can be administered by the environment, energy or finance ministry, by a specialised (energy) agency, by public or private banks, by energy providers or by a competitively selected professional fund manager. The institution that administers the fund needs to have sufficient resources and expertise with regard to fund management, otherwise capacity-building action

Page | 84 must be taken. The lack of fund management capacity in public institutions can be a reason to partner with a private financial institution, which can provide the needed expertise. For example the UK government put out for tender a competition seeking experienced fund managers to manage Government investments in non-residential energy efficiency projects in March 2012. Two specialised fund managers - Equitix and SDCL - were chosen to make and manage investments in non-residential energy efficiency projects that may range from energy performance contracts to measures to reduce energy consumption in public and private sector buildings. $^{80}$

Using dedicated funds for energy efficiency investment can be appropriate to address the barrier of lack of liquidity in the banking sector for financing energy efficiency investments. A precondition for success is that bankable projects in need of finance do exist. The fund may have a technical assistance component to provide assistance with the development bankable projects. Dedicated funds can be used for various mechanisms to provide energy efficiency finance, such as loan guarantees and funding for long-term private sector loans eventually combined with public sector grants (Rezessy and Bertoldi, 2010 pp. 24).

Dedicated funds can be organised as revolving funds. Revolving funds do not use repayments to reimburse the original funding sources, but keep them in the fund to finance future loans. This means that funds can be used again and again over time and benefit many recipients (Kats et al., 2011; IEA, 2011). Revolving funds require a significant initial investment but are subsequently selfsustaining if operated successfully. Systematic monitoring is necessary for these kinds of funds to ensure the loan repayments and to keep the balance between out-flowing and in-flowing funds. Therefore administration costs may be relatively high. Revolving funds are especially designed to deal with a lack of liquidity in a specific area, such as energy efficiency (Rezessy and Bertoldi, 2010, pp. 24). The advantage of revolving funds over non-revolving forms of dedicated funds is that they present a sustainable, long-term and stable source of funds which is less dependent on external investors. 
In the European Union, a multitude of funds exist at Community level which are partly or fully dedicated to financing energy efficiency in member states.

The European Structural and Cohesion Funds provide EUR 4.6 billion Euro to member states for investments in energy efficiency, co-generation and energy management during the period 20072013.

Up to $4 \%$ of national allocations of the European Regional Development Fund (ERDF) may be used to improve energy efficiency, as well as to use renewable energy in existing residential buildings. Estonia made use of this provision and set up a revolving fund in 2009 for energetic refurbishment of houses. The funds provides long-term (up to 20 years), low-interest loans. The revolving fund combines funding from the ERDF (EUR 17 million), the national fund KredEx (49 million) and the Council of Europe Development Bank (EUR 29 million). Applicants are required to provide $15 \%$ of self-funding, which may be recovered through a separate grant programme. In the first year, 122 multi-apartment buildings were refurbished through the programme, leading to average energy savings of $33 \%$ (with $20 \%$ as minimum required savings).

The European Local Energy Assistance (ELENA) Facility provides grants to local and regional public authorities (e.g. towns) for technical assistance in order to develop structure and launch large-scale investments in energy efficiency and renewable energy. The facility is administered by the European Investment Bank $^{81}$ and other international financial institutions, and covers up to $90 \%$ of costs incurred by technical support needed for feasibility and market studies, programme structuring, energy audits and the preparation of tendering procedures. Up to March 2012, the facility provided about EUR 27 million in support to launch investments of about EUR 1.5 billion. The Facility has been extended in 2011 and the technical assistance support is administered further by the KfW, CEB and the EBRD.

The European Energy Efficiency Fund was established in 2011 with a volume of EUR 265 million. The fund is organised as a public-private partnership and managed by the Deutsche Bank on behalf of the management board. Funding has come so far from the European Union, the European Investment Bank, the Deutsche Bank, and the Italian public bank CDPP. The fund provides debt, equity and guarantee instruments for commercially viable projects and technical assistance grants to support project development services (legal, financing and technical structure of the project). Beneficiaries are local and regional public authorities or private entities acting on their behalf. Projects must achieve at least $20 \%$ savings in primary energy demand. Requirements for buildings are stricter, as they must achieve a performance improvement of at least two categories related to the performance certificate. The fund aims also to strengthen the Energy Service Company (ESCO) market in Europe. The first signed project involved the EE refurbishment of the Jewish Museum in Berlin, Germany. ${ }^{82}$ Another 25 projects are in the pipeline.

Source: EC, 2012a and BPIE, 2010 pp. 19

\section{Public banks}

Public banks are banks majority-owned by a government. They may receive funds from the general public budget and are able to procure further funds from the private financial markets. As their activities are usually covered by a government guarantee, they may benefit from good ratings of the national government and be able to source funds with relatively low interest rates. This combination of funding allows public banks to provide grants and finance at lower-thanmarket interest rates. Public banks can also be considered as I a source of funds as they have their own equity.

Public banks exist in a number of OECD member countries and at different levels of national, sub-

\footnotetext{
${ }^{81}$ Homepage: http://www.eib.org/products/elena/index.htm?lang=en\&

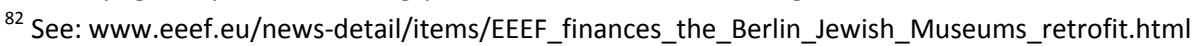


national as well as regional government. Some are set up to increase competition in the private banking sector (e.g. the Kiwibank in New Zealand) while others aim at promoting a specific sector, such as the industrial sector (e.g. Nafinsa in Mexico) or small and medium sized enterprises (e.g. the Czech-Moravian Guarantee and Development Bank). To date, only the Norwegian Husbanken (the National Housing Bank) and Germany's KfW bank target specifically the building sector. Therefore public banks often need technical assistance with regard to building up know-how in the field of energy efficiency and buildings when beginning engagement in this new sector.

In Europe, the European Investment Bank (EIB $)^{83}$ is the public bank of the European Union, with its 27 member state as its shareholders. On average $8 \%$ of its investments are channelled into energy efficiency. In 2011, EUR 1.3 billion was invested in energy efficiency projects via lending programmes, a number that has increased by $70 \%$ over the last 4 years (Rezessy and Bertoldi, 2010).

The idea of public banks also seems to be on the rise, with the UK setting up a Green Investment Bank (see Box 8), ${ }^{84}$ Australia's Clean Energy Finance Corporation planned to be operational from mid-2013, ${ }^{85}$ France is working on a new public investment bank ${ }^{86}$ and 18 states in the US are investigating the issue (to date only North Dakota has a public bank and Connecticut has set up a Clean Energy Finance and Investment Authority in mid 2011). ${ }^{87}$

\footnotetext{
${ }^{83}$ Homepage: www.eib.org

${ }^{84}$ Homepage: http://www.bis.gov.uk/greeninvestmentbank.

${ }^{85}$ Homepage: www.cefcexpertreview.gov.au/content/Content.aspx?doc=thecefc.htm

${ }^{86}$ Homepage: www.economie.gouv.fr/lancement-de-la-mission-de-prefiguration-de-la-banque-publique-d-investissement

${ }^{87}$ Homepages: www.publicbankinginstitute.org/state-info and www.brookings.edu/blogs/the-avenue/posts/2011/06/28green-connecticut-muro
} 


\section{Box 17 Experience with public banks from Germany and United Kingdom}

Germany's public bank $\mathbf{K f W}^{88}$ was set up by law in 1948 as a reconstruction agency and pipeline for the Marshall Plan funds. KfW is today owned $80 \%$ by the Federal Republic of Germany and $20 \%$ by the federal states ("Länder"). With a balance sheet total of more than EUR 450 billion, KfW is one of Germany's three largest banks. The Federal Republic guarantees all obligations of the institution in respect of loans extended to and debt securities issued.

$\mathrm{KfW}$ provides financing inter alia for small and medium enterprises (SME) and entrepreneurs, risk capital, the residential sector, environmental protection, infrastructure, technology and innovation, internationally agreed promotional programmes and development cooperation. Financing for promotional activities is provided for selected programmes by the Federal Budget, otherwise by $\mathrm{KfW}$ itself. KfW refinances its lending business almost exclusively in the international capital markets. In 2011, KfW approved more than EUR 70 billion of finance over all its areas of activity, of which energy efficiency made up over EUR 10 billion split between the housing sector (EUR 8.7 billion), followed by the SME/ industry sector (EUR 1.2 billion) and the public infrastructure sector (EUR 370 million). ${ }^{89}$

KfW's promotional activities target energy efficiency in buildings started in 1993. Today, it offers a set of differentiated promotional programmes. As the bank has no branch network, funds are extended to the customers by using the concept of "on-lending" via commercial and savings banks. In order to make sure that potential customers are aware of the promotional offers, regular information and advertising campaigns are carried out. More information on KfW programmes in the buildings sector can be found in the case study on Germany.

The United Kingdom is in the process of setting up a public Green Investment Bank (GIB) ${ }^{90}$ as part of a policy package to "create a low-carbon, climate-resilient and environmentally sustainable ("green") economy" (vivideconomics, 2011a). The 2011 national budget has committed GBP 3 billion of funding for the GIB until 2015 and plans are to establish a stand-alone institution with state aid approval by autumn 2012. Until then the government is investing directly through the United Kingdom Green Investment team. A number of sectors have been identified as possible targets for GIB activity; these include the transport sector (railway transport, electric vehicle infrastructure), the energy sector (renewable and nuclear energy, carbon capture and storage, smart meters) and the building sector, as well as flood defence. The rationale for intervention comprises several aspects, ranging from addressing the under-provision of capital to supporting novelties in terms of technology, business model or commercial arrangements in order to speed up the adoption and deployment (vivideconomics, 2011b).

The use of already existing public institutions to set up new financing mechanisms for the promotion of low-energy buildings has benefits. The use of existing and well-functioning institutions should lower transaction costs, as existing structures, procedures, know-how and network of customer relations can be accessed.

As public banks are set up with the aim to promote the public good rather than making profits, they should also be more inclined to engage in business with longer payback periods and to take the risk of engaging in new sectors with little experience but high potential to serve the public interests.

Public banks, similar to specialised funds, must be very careful in choosing their activities with a view to leveraging private investment and not replacing existing private engagement (also known as "crowding-out"). They must ensure that they finance activities which are not currently served by private financing institutions (vivideconomics, 2011a pp. 45).

\footnotetext{
${ }^{88}$ Homepage: www.kfw.de/kfw/en/index.jsp

${ }^{89}$ Source: KfW.

${ }^{90}$ Homepage: www.bis.gov.uk/greeninvestmentbank
} 


\section{Green bonds}

Green bonds could provide a way of financing a portfolio of energy efficiency projects by aggregating a large number of smaller projects that otherwise may be difficult to finance individually (IEA, 2012a).

Bonds offer an alternative to bank debt, providing instead the opportunity to borrow directly from the capital markets. They have a fixed repayment period (maturity) and a fixed or variable rate of interest (the coupon) is usually ${ }^{91}$ paid along with the repayment of the principal.

"Green bonds" or "climate bonds" differ from regular bonds mainly in that the funds raised are exclusively used for specified environmental and sustainable development purposes. This allows targeting especially, yet not exclusively, investors that are looking for socially responsible investments (SRI). They could have great potential for stimulating large-scale investment, as they provide a financing structure which is potentially interesting to institutional investors and debt capital markets and they benefit from using a well-known and proven mechanism (Caldecott, 2010).

So far green bonds have been mainly issued by the United States government, multilateral development and investment banks and a few private companies (see Table 9). Most of the bonds are dedicated to renewable energies, but there exist also bonds specifically for energy efficiency projects, as well as for both areas (Della Croce, Kaminker and Stewart, 2011).

Table 9 - Existing green bonds for energy efficiency

\begin{tabular}{|c|c|c|c|c|c|}
\hline $\begin{array}{l}\text { Size } \\
\text { Rank }\end{array}$ & Issuer & Year(s) & Type & $\begin{array}{l}\text { Amount } \\
\text { USD Mio. }\end{array}$ & Notes \\
\hline 1 & $\begin{array}{l}\text { US government } \\
\text { agencies and } \\
\text { utilities }\end{array}$ & $\begin{array}{l}2009- \\
2012\end{array}$ & $\begin{array}{l}\text { Qualified Energy } \\
\text { Conservation Bonds } \\
\text { (QEBS) program }\end{array}$ & $3,200.00^{1}$ & $\begin{array}{l}\text { Originally tax credit enhanced bonds } \\
\text { for EE, changed in } 2010 \text { to direct } \\
\text { subsidy bonds }\end{array}$ \\
\hline 4 & $\begin{array}{l}\text { European } \\
\text { Investment Bank }\end{array}$ & $\begin{array}{l}2007- \\
2010\end{array}$ & $\begin{array}{l}\text { Climate Awareness } \\
\text { Bonds }\end{array}$ & $1,630.00$ & $\begin{array}{l}\text { For investment in renewable energy } \\
\text { and energy efficiency, 3-8 year term }\end{array}$ \\
\hline 14 & $\begin{array}{l}\text { Asian } \\
\text { Development } \\
\text { Bank }\end{array}$ & 2010 & Clean Energy Bond & 243.00 & $\begin{array}{l}4-7 \text { year tranches for renewable } \\
\text { energy and energy efficiency } \\
\text { investment }\end{array}$ \\
\hline 15 & Destiny USA & 2007 & $\begin{array}{l}\text { Energy Efficiency } \\
\text { Green Bond }\end{array}$ & 228.00 & $\begin{array}{l}\text { For the construction of a green retail } \\
\text { complex, } 30 \text { year term }\end{array}$ \\
\hline 18 & $\begin{array}{l}\text { Nordic Investment } \\
\text { Bank }\end{array}$ & 2010 & $\begin{array}{l}\text { Environmental Support } \\
\text { Bond }\end{array}$ & 200.00 & $\begin{array}{l}\text { For financing its CLEERE lending } \\
\text { facility on climate change, energy } \\
\text { efficiency and renewable energy, } 3 \\
\text { years maturity }\end{array}$ \\
\hline 29 & $\begin{array}{l}\text { Georgetown } \\
\text { Special Taxing } \\
\text { District }\end{array}$ & 2006 & $\begin{array}{l}\text { Energy Efficiency } \\
\text { Green Bond }\end{array}$ & 14.50 & $\begin{array}{l}\text { For the construction of a green multi- } \\
\text { use complex }\end{array}$ \\
\hline 30 & $\begin{array}{l}\text { US municipal } \\
\text { governments }\end{array}$ & $\begin{array}{l}2009- \\
2010\end{array}$ & $\begin{array}{l}\text { Property Assessed } \\
\text { Clean Energy Bonds }\end{array}$ & 9.70 & $\begin{array}{l}\text { To fund residential and commercial } \\
\text { energy efficiency and renewable } \\
\text { energy installations }\end{array}$ \\
\hline 31 & Novacem & 2010 & $\begin{array}{l}\text { Energy Efficiency } \\
\text { corporate bond }\end{array}$ & 1.50 & $\begin{array}{l}\text { To fund the construction of a semi- } \\
\text { commercial green cement plant }\end{array}$ \\
\hline
\end{tabular}

Note 1: upper limit of bond volume authorised, but according to the HSBC, nearly $20 \%$ of the maximum volume had been issued by the middle of 2012 (Robins and Knight, 2012)

Source: adapted from Della Croce, Kaminker and Stewart, 2011

In principle, banks and large energy providers can also issue bonds, which need to be secured either by their own assets or through a government guarantee (IEA, 2012a). In most cases, the higher the credit rating of the issuing institution, the lower is the cost of borrowing.

Governments have several options to reduce interest rates for green bonds and thus the overall cost of funds for energy efficiency. Governments can issue green bonds themselves or give a

\footnotetext{
${ }^{91}$ Except in the case of zero-coupon bonds and other structured notes.
} 
guarantee to the bond-issuing institution (e.g. a public bank) taking on part or all of the default risk. Thereby investors need to be less worried about the risks at the individual project level. But also more indirect ways exist to decrease interest rates; e.g. by providing tax incentives for energy efficiency measures, the implementation of such measures become more profitable to the investor and reduce repayment times the attached credit risk (see chapter on tax incentives) (Della Croce, Kaminker and Stewart, 2011 and IEA, 2012a).

Green bonds need a special monitoring system, to track the investments made and prove that the environmental benefits have been actually achieved (CDC Climate, 2012). The Climate Bonds Initiative is developing certification criteria for energy efficiency projects to be included in the Climate Bond Standard, starting with low-energy buildings (both new and existing buildings retrofit) projects. ${ }^{92}$ The Climate Bonds Standards Board expects to recommend criteria in this area by the end of the year 2012. A credible and widely accepted certification of energy efficiency as green bonds is likely to increase attractiveness to large-scale investors.

To date no green bond market exists that targets institutional investors (WEF, $2011 \mathrm{pp}$. 40). Over USD 200 billion to USD 300 billion in bonds with a rating of BBB and better are estimated to be needed in order to set up a stable bond scheme that would be of interest to large investors (IEA, 2012a). Climate-related bonds represent up to now only a small share of global assets (see section on institutional investing and private investment funds) and do not represent a liquid market, which would be needed in order to attract institutional investors.

Using a conservative definition, the OECD estimated the green bond market at around USD 16 billion in 2012 (IEA, 2012a). HSBC provide higher estimates, amounting overall to USD 147 billion in 2012, most of which, however, relates to transport-related bonds. Only USD 1.5 billion relate to energy efficiency investments in buildings and industry and are issued mainly by firms producing LEDs as well as by United states' municipalities under the QECB programme (see Box 18). Worth noting is also the issuance of USD 67.4 million in 2011 by the Delaware Sustainable Energy Utility. HSBC also points at the high potential of Property Assessed Clean Energy (PACE) bonds in the United States which could amount to an annual market of USD 12 billion if the current regulatory hurdles are resolved (see also the section on PACE), yet in 2012 the PACE bond market remained marginal (Robins and Knight, 2012).

\footnotetext{
${ }^{92}$ The aim of the Climate Bond Standard is to provide assurance that funds raised using a Climate Bond are being used in ways consistent with delivering a Low-Carbon Economy. http://climatebonds.net/2012/07/climate-bonds-standards-energyefficiency-working-group-starts-work/
} 


\section{Box 18 Qualified Energy Conservation Bonds in the United States}

The issuance of Qualified Energy Conservation Bonds (QECBs) was authorised under the United States Energy Improvement and Extension Act of 2008. The objective of QECBs was to enable state, local and tribal governments to finance a broad range of energy projects, including energy efficiency investments in public buildings, green community programmes, investment in research and development, public education campaigns and more. They can be used to fund low-interest loan programmes for energy efficient retrofitting in the residential and commercial sector.

The bond volume was first limited to USD 800 million and later extended to USD 3.2 billion as part of the American Recovery and Reinvestment Act of 2009 (ARRA). The total bond volume is allocated to the states according to their relative population size, and then a portion is reallocated to large local governments. The majority of QECBs are issued as direct subsidy bonds, where the federal government pays a direct subsidy to the bond issuing authority which is used to pay part of the interest. In both cases, the burden of interest payments is lowered for the issuing authority. The most common QECBs have subsidised interest rates of below 2 percent and have a repayment period of around 15 years. Even when the administration costs (for bond issuing and loan programme administration) are factored in, this allows handing out energy efficiency loans with about 3-7\% interest, below typical market rates of $10 \%$ and more.

Yet by May 1012 only USD 614 million (nearly 20\% of the maximum amount) had been issued. The most commonly cited challenge to issuances is small allocation size. If a state has many large local governments, this necessitates dividing up the total allocation into many pieces, which can lead to increased administrative burdens and implementation delays. To overcome this barrier, some localities have bundled their QECBs with other bonds, used other ARRA funds to cover administrative costs, or pooled their allocations with other jurisdictions.

Source: US Database of State of State Incentives for Renewables and Efficiency (DSIRE); ${ }^{93}$ Della Croce, Kaminker and Stewart, 2011; LBNL, 2011; CDC Climat, 2012; Robins and Knight, 2012, communication with US DoE.

\section{III.3 Discussion of funding for low-energy buildings}

This section has focused on how economic instruments can be funded when public outlay is needed. Economic instruments can both raise revenue through taxes, charges and auctioning of allowances in trading schemes, and expend public funds to provide subsidies and finance for improving energy efficiency.

Public funding mechanisms and intermediaries were also examined for their potential to leverage private finance for energy efficiency measures. Private funding in the form of institutional investors and other private investment funds were discussed in the context of contributing to public funds used for economic instruments. Other private sector financing options directly to investors of low-energy buildings, such as traditional debt or equity finance, were not in the scope of this work.

There are a range of public funding sources that can be used to fund economic instruments such as budget allocations, earmarked taxes and charges and revenues from emission allowance auctioning that can be disbursed by different agencies, public banks, dedicated funds etc. These are not specific to the buildings sector and are valid for energy efficiency projects in other sectors also. In fact, in many countries, the funds discussed are allocated not only for financing energy efficiency measures in various sectors but also for renewable energy measures. Joint allocations and funding arrangements may create competition around the use of the funds between sectors. It needs to be ensured that funding is allocated according to their politically determined priority.

\footnotetext{
${ }^{93}$ See: http://www.dsireusa.org/incentives/incentive.cfm?Incentive_Code=US51F\&re=0\&ee=1
} 


\section{Choosing between funding sources}

Table 10 summarises the main features of the funding sources discussed in the previous subsections.

Policy makers should consider several criteria when deciding between appropriate sources of funding streams to finance energy efficiency policy:

- Stability and sustainability of funding stream;

- Least overall cost to society - including public and private costs;

- Split between costs paid by public and private funds;

- Administrative simplicity;

- Ability to leverage private funds.

Steady, reliable and adequate funding for economic instruments is critical to build up new energy efficiency markets, achieve market transformation, and to increase investor confidence in energy efficiency investments. However, many funding decisions are dependent on short-term public budget cycles where changes in economic conditions frequently lead to "stop-go" funding of programmes (IEA and EBRD, $2010 \mathrm{pp} .60$ ). Political uncertainty expressed through continuously changing programme conditions may be even more harmful to investment decisions than the absence of subsidies in the first place, as investment decisions may be delayed or not taken at all if no clear business strategy can be made. Sustainability of funds is also important and refers to the ability of the funds to be self-sustaining, such as a revolving fund or earmarked revenues from a stable source, i.e. taxes.

Policy objectives should be achieved at least overall cost to society. Economists argue against dedicated funds or earmarking for energy efficiency because of the potential for "wastage". The theory is that when funds are set aside for a particular purpose such as energy efficiency measures, they will all be spent on that purpose, whether they are needed or not. When funds come from the central budget, spending amounts can be reviewed periodically and adjusted as governments' priorities or revenues change. However the downside of this flexibility is that funding streams from central budgets may be adjusted frequently and thus unstable.

The desired share of costs between private and public funds should also be considered. If the priority is to engage the private sector from the beginning as a source of funds for energy efficiency, then a public-private approach is more suitable. If there are significant capital market constraints due to underlying weaknesses in the financial market, it may be difficult to engage private financial institutions in energy efficiency lending. In many cases, the objective may be to kickstart the market initially with public funds in order to achieve more ambitious, perhaps less bankable energy performance targets, in which case a sizeable share of public funds is likely to be required. The ability to leverage private funds may also be dependent on the source of public funds.

In addition to the source of funding, careful consideration should be given to the intermediary selected to gather together public and private funding and organise disbursement, as it may also be a key determinant of the success or failure of an economic instrument. While specialised energy efficiency agencies hold advantages in terms of capacity to provide technical energy efficiency advice and implement energy efficiency policy, that capacity may not include core tasks associated with financial and economic such as managing and disbursing funds. Public banks or dedicated funds may be more suitable as public fund managers, however they may not have the technical capacity in energy efficiency to determine eligibility for financing and will need assistance from perhaps external contractors for this task. 
Table 10 - Summary of funding sources for economic instruments for energy efficiency

\begin{tabular}{|c|c|c|c|c|}
\hline $\begin{array}{l}\text { Funding } \\
\text { source }\end{array}$ & Strengths & Weaknesses & Disbursement by & $\begin{array}{l}\text { Assessment for EE } \\
\text { economic instruments }\end{array}$ \\
\hline $\begin{array}{l}\text { Central } \\
\text { budget } \\
\text { allocations }\end{array}$ & $\begin{array}{l}\text { Efficient allocation of } \\
\text { funds compared with } \\
\text { other policy priorities }\end{array}$ & $\begin{array}{l}\text { Unstable source of } \\
\text { funding in current } \\
\text { economic climate; } \\
\text { May be vulnerable to } \\
\text { political variability. }\end{array}$ & $\begin{array}{l}\text { Government ministry; } \\
\text { Specialised agencies; } \\
\text { Dedicated funds, public } \\
\text { banks. }\end{array}$ & $\begin{array}{l}\text { Widely used for EE } \\
\text { grants and tax } \\
\text { incentives schemes; } \\
\text { Likely to be reduced in } \\
\text { the future. }\end{array}$ \\
\hline $\begin{array}{l}\text { Earmarked } \\
\text { taxes }\end{array}$ & $\begin{array}{l}\text { Reliable funding } \\
\text { stream dedicated to } \\
\text { EE }\end{array}$ & $\begin{array}{l}\text { Difficult to predict } \\
\text { amount in beginning; } \\
\text { May be wastefully } \\
\text { used to meet } \\
\text { spending targets; } \\
\text { Revenues may drop } \\
\text { over time if criteria } \\
\text { not adjusted. }\end{array}$ & $\begin{array}{l}\text { Specialised agencies; } \\
\text { Dedicated funds; } \\
\text { Public banks. }\end{array}$ & $\begin{array}{l}\text { Used in some countries } \\
\text { for EE economic } \\
\text { instruments, e.g. Korea, } \\
\text { United Kingdom, Mexico }\end{array}$ \\
\hline $\begin{array}{l}\text { User } \\
\text { Charges (e.g. } \\
\text { system } \\
\text { public } \\
\text { benefit } \\
\text { charges) }\end{array}$ & $\begin{array}{l}\text { Reliable funding } \\
\text { stream dedicated to } \\
\text { EE }\end{array}$ & $\begin{array}{l}\text { Utility charge revenue } \\
\text { less difficult to } \\
\text { predict; } \\
\text { May be wastefully } \\
\text { used to meet } \\
\text { spending targets. }\end{array}$ & $\begin{array}{l}\text { Third parties (i.e. utilities) } \\
\text { Dedicated funds }\end{array}$ & $\begin{array}{l}\text { Widely used in the } \\
\text { United States for utility } \\
\text { energy efficiency } \\
\text { programmes. } \\
\text { Likely to grow in the EU } \\
\text { under energy-provider } \\
\text { obligations }\end{array}$ \\
\hline $\begin{array}{l}\text { Carbon } \\
\text { market } \\
\text { revenues }\end{array}$ & $\begin{array}{l}\text { Potentially large } \\
\text { source of funding for } \\
\text { EE. } \\
\text { Public and political } \\
\text { acceptability since } \\
\text { polluter pays. }{ }^{1}\end{array}$ & $\begin{array}{l}\text { Variable carbon price } \\
\text { may reduce stability } \\
\text { of funds raised; } \\
\text { May be wastefully } \\
\text { used to meet } \\
\text { spending targets; } \\
\text { May force EE to } \\
\text { compete with } \\
\text { renewable energy } \\
\text { funding }\end{array}$ & $\begin{array}{l}\text { Specialised agencies; } \\
\text { Dedicated funds; } \\
\text { Public banks }\end{array}$ & $\begin{array}{l}\text { Relatively widely used in } \\
\text { Eastern Europe, } \\
\text { Germany, Mexico. } \\
\text { Likely to grow under the } \\
\text { EU ETS. }\end{array}$ \\
\hline $\begin{array}{l}\text { Institutional } \\
\text { investing } \\
\text { and private } \\
\text { investment } \\
\text { funds }\end{array}$ & $\begin{array}{l}\text { Important co-finance } \\
\text { for government } \\
\text { funding - stretches } \\
\text { public funds further } \\
\text { May bring established } \\
\text { commercial clients to } \\
\text { EE } \\
\text { May familiarise Fl's } \\
\text { with EE lending }\end{array}$ & $\begin{array}{l}\text { May be legally } \\
\text { complicated to set up } \\
\text { Seniority of creditors } \\
\text { may be issue }\end{array}$ & $\begin{array}{l}\text { Specialised agencies, } \\
\text { public-private } \\
\text { approaches } \\
\text { Dedicated funds; } \\
\text { Public banks } \\
\text { Green bonds may help } \\
\text { accessing these funds } \\
\text { better in the future }\end{array}$ & $\begin{array}{l}\text { United Kingdom starting } \\
\text { (purely private initiatives } \\
\text { Bond issuance on a } \\
\text { small scale mainly in the } \\
\text { US and EIB } \\
\text { One for the future. }\end{array}$ \\
\hline
\end{tabular}

In many countries, there is a trend away from central budget allocations towards arrangements that involve the private sector, such as public-private partnerships or initiatives such as green or climate bonds. Institutional investors and private investment funds could provide significant liquidity to the market if energy efficiency projects can be clustered sufficiently to create large enough investment opportunities. This helps supplement the current weak public budget situation in many countries and also readies the market for increased mobilisation of private funds for energy efficiency. Dedicated funds (a mix of public and private funds) can be useful in ensuring finance of energy efficiency priorities in times when national current budgets are constrained.

In all cases, establishing clear eligibility criteria and measurement methodologies for energy savings that provide transparent calculations of the returns on investment are extremely 
important to enable reliable estimations of risk. ${ }^{94}$ As energy-providers increasingly are being obligated to deliver energy savings through their customers, the raising of funds through system public benefit (or similar) charges) is also becoming more common. In the cases where central budget funds are used to encourage investment in low-energy buildings, the economic instruments used to disburse the funds are changing from grants- to finance-based instruments that are repaid over time.

${ }^{94}$ Work is underway in this area internationally under several initiatives - the Climate Bonds Initiative as part of the Climate Bond Standards and Certification Scheme; increased sharing of information on investments in energy efficiency projects by multilateral development banks through OECD databases; and capacity building in financial institutions. 


\section{Conclusions}

Economic instruments play an important role in energy efficiency policy across all sectors. They provide incentives for investment in energy efficiency and can make stringent regulations more palatable to end-users. However, due to the variety of market barriers and failures to implementing energy efficiency, economic instruments on their own are unlikely to maximise the

Page | 94 potential of energy efficiency measures. Other policies are needed.

There is a range of societal and non-energy benefits associated with implementing economic instruments as part of energy efficiency policy. The net return on investment of public budgets in economic instruments for energy efficiency improvements may be positive when macroeconomic, health, employment, industrial competitiveness, and energy security benefits are taken into account.

\section{Policy packages for a holistic approach to low-energy buildings}

Moving to low-energy buildings is key to achieving significant reductions in energy demand in the future. Near-zero energy new buildings and deep retrofit of existing buildings are needed. In IEA countries with low rates of buildings construction, it is the latter that will play a more important role in delivering energy savings across the buildings stock and should be targeted.

Economic instruments are used by governments both in support of regulatory measures and independently to improve the energy efficiency of buildings. With higher levels of investment needed to achieve deep energy savings from buildings, the focus of economic instruments needs to shift from mainly incentives to providing more access to finance. Packages of economic instruments may be needed, at least initially, combining energy taxes, incentives, and finance to encourage uptake and scale of investment in low-energy buildings.

Economic instruments should be part of a coherent policy package whereby building energy codes form the core of the package, setting minimum and future long-term ambitious energy performance targets for new and existing buildings. A combination with other policy instruments, regulatory, information and perhaps other incentive measures is needed to scale-up widespread investment in ambitious low-energy buildings. Mandatory whole house audits could lead the way from "reactive" replacement of worn out appliances to the proactive identification of larger savings potentials. Detailed but understandable and affordable service packages (including technical assistance, awareness raising activities and energy audits) provided by agents in close proximity to end users are a pre-requisite for behavioural and economic shift towards a better profile of energy efficiency investment projects which will satisfy financing criteria of banks.

While often several programmes may be needed to address all the barriers to energy efficiency, it is important to ensure that the programmes are complementary and do not overlap in order to avoid wasting public money. More evaluation is needed to examine the impact of economic instruments in delivering the long-term policy goal of low-energy buildings.

\section{Funding economic instruments}

Energy taxes and charges raise significant revenues that can be used for investment in energy efficiency measures. Most other economic instruments require public funding and/or policy. There are a range of options open to governments to fund economic instruments including general budget allocation, earmarked taxes, carbon market revenues, and institutional investors, as well as different means of collecting and/or disbursing them such as dedicated funds, public banks, energy efficiency agencies and green bonds.

Governments should seek to find ways to engage the private sector as funding partners with the aim of reducing the share of public funds involved in the long-run. Policy makers need to balance the financial incentive that is needed to entice energy efficiency investments with the level of 
private finance in the economic instrument required to minimise costs to the public budget, as a trade-off is likely. 


\section{Annex - selected case studies}

Page | 96 


\section{Canada: ecoENERGY Retrofit - Homes Program}

This case study examines the use of grants to improve the energy efficiency of residential buildings in Canada.

\section{Context}

Canada has higher energy intensity, adjusted for purchasing power parity, than any other IEA member country. This is largely attributable to its high concentration of output in energyintensive sectors, cold climate, vast geography and high standard of living, with minimal constraints on space occupation. Final energy consumption has grown continuously over the past decade, though at a lower rate than the economy as a whole. Canada's energy intensity improved $21 \%$ between 1990 and 2009. The majority of annual intensity improvements from 1990 to 2009 were due to energy efficiency gains, while the remainder resulted mainly from a switch to less energy-intensive industries (NRCan, 2012a).

Buildings (commercial, institutional and residential) make up over $30 \%$ of end-use energy consumption in Canada; residential buildings account for more than half of this. Residential energy per capita in Canada is one of the highest in the IEA, partly due to the climate and the size of residential buildings. Space heating is the biggest contributor to residential energy consumption. The energy intensity of space heating in Canada has, on average, improved annually between 1990 and 2009, for a total reduction of 24\% over that period. However, population growth, increased dwelling size, and fewer occupants per household have resulted in a $13 \%$ increase in total space heating energy use over the 1990 to 2009 period.

Governments at all levels in Canada have become of aware of the potential of energy efficiency to save energy, reduce GHG emissions, and save money. Many policies and measures have been implemented to expand awareness of energy efficiency, to encourage energy-efficient behaviour, and to accelerate the uptake of energy-efficient equipment and technologies. This case study specifically focuses on the use of grants to encourage energy-efficient retrofits of residential buildings.

\section{Residential buildings energy efficiency policies in Canada}

Canada's federal government has a range of policies in place to improve the energy efficiency of housing, including codes, equipment regulations, voluntary standards (such as ENERGY STAR ${ }^{\circledR}$ for New Homes and R-2000), the EnerGuide Rating System, information, financial incentives, training, and capacity building. In analysing the use of grants to improve energy efficiency in houses, it is important to understand the policy context for the incentive programme. Relevant policies may reinforce or counteract the effect of the incentives available.

One of the key challenges to energy efficiency policy in Canada is the separation of powers between the federal and provincial/territorial levels. Energy management and production are under provincial-territorial jurisdiction, and as such, the Government of Canada does not establish nationwide targets for energy efficiency. Instead, it implements national programmes and standards to ensure energy efficiency coverage across the country and it plays a 'convenor' role in this area, bringing together the provinces and territories to discuss strategic energy efficiency policies and best practices, and championing programmes that can be used by multiple jurisdictions to improve energy efficiency in Canada. The synergy of this collaborative approach avoids duplications and achieves economies of scale. Provinces and territories may choose from a menu of policy instruments or tools to realize energy savings, subject to factors such as climate and policy priorities. The one exception is the national Energy Efficiency Act, which governs minimum energy performance standards for equipment and appliances that are traded across national or provincial/territorial borders. Otherwise, this separation of powers is of particular 
relevance in the housing sector, where jurisdiction over building codes lies with the provincial and territorial governments.

The federal government also provides tools that can be used in all provinces and territories to promote energy-efficient home construction and renovation. The EnerGuide Rating System, one such tool, is a system that rates and labels the energy performance of a home. It can be used to optimize the energy-efficient design of a new home or to provide recommendations on energy-

Page | 98 efficient retrofits in existing homes. Energy performance ratings may also be used by consumers to inform home purchasing decisions, which will help to pull the market toward more efficient housing. However, it is not mandatory to carry out energy rating of a building.

Training and capacity-building is provided through Natural Resources Canada for professionals in the buildings sector. Under the ecoENERGY for Buildings and Houses programme, which was administered by Natural Resources Canada and ran from 2007 to 2011, 6000 professionals were trained to improve the energy efficiency of buildings in the residential sector.

\section{Description of ecoENERGY Retrofit - Homes programme}

Economic instruments in the form of grants have been available in Canada for energy-efficient buildings since 2001. This analysis focuses on the grants provided for energy-efficient houses through the ecoENERGY Retrofit - Homes programme, which ran from 2007 to early 2012.

ecoENERGY Retrofit - Homes encouraged the existing low-rise housing sector in Canada to become more energy-efficient, reduced emissions produced through energy use, and contributed to clean air, water and energy. ecoENERGY Retrofit - Homes provided property owners with the information required to make good home energy retrofit decisions, and rewarded energy and water saving measures with grants.

The programme was launched on April 1, 2007, and was originally scheduled to end on March 31, 2011. As part of Budget 2011, however, the programme was renewed and extended from June 6 , 2011 to March 31, 2012. Since its inception, the Government of Canada has committed a total of CAD 1.145 billion for the ecoENERGY Retrofit - Homes programme. Natural Resources Canada's Office of Energy Efficiency administered the programme and issued the grants.

Under ecOENERGY Retrofit - Homes, grants were provided to homeowners of low-rise residential properties who improved the energy performance of dwellings. This included owner-occupied as well as rental units. Housing on First Nations territories and band-owned lands, social housing and housing cooperatives also qualified. The programme used a third-party delivery system with energy assessment services under license to Natural Resources Canada. These organisations hired and trained energy advisors and quality control personnel and provided local energy audit services. Energy advisors performed pre-retrofit assessments and provided a checklist of recommended upgrades, along with an EnerGuide for Houses home energy rating to the property owner, who chose from the recommended retrofits and implemented them within an 18 month time period. Energy advisors performed post-retrofit assessments, determined that retrofits had been done, and submitted the grant application for the property owner.

The grants were based on the total of the amounts allocated for each of the eligible retrofits. Grants were available for heating, cooling and ventilation (HVAC) equipment, insulation, air sealing, windows/doors and water conservation. Lists of eligible equipment were specified by the Office of Energy Efficiency and were published online. The grant amounts for home insulation upgrades were determined according to the increase in insulation between the pre-retrofit and post-retrofit evaluation. The programme was supported by stakeholders such as provincial, territorial and municipal governments and utilities who may have partly subsidised the audits and/or offered complementary grants. These and other stakeholders (e.g. environmental and community groups, product suppliers and manufacturers, renovation and mechanical contractors, 
home inspectors, trade associations, etc.) also promoted the programme (NRCan Office of Energy EFficiency, 2012a).

At the beginning of the programme, funding was sufficient to provide 140000 homes with an average CAD 1070 grant. Several extensions of the programme in 2009, 2010 and 2011 led to retrofit of an additional 500000 over 2009-2012.

Under the programme, Natural Resources Canada developed a delivery infrastructure for home energy assessments and labelling, and over 2000 energy advisors have been hired and trained by service organizations since the programme's inception. Natural Resources Canada's continues to support the EnerGuide Rating System. This will allow Natural Resources Canada to continue to process Canadians' applications for provincial and territorial partner programmes, undertake quality assurance, provide the labelling system and software, and train and certify energy advisors.

\section{Assessment of programme}

\section{Effectiveness}

Impact

Under the ecoENERGY Retrofit - Homes programme grants were provided to over 640000 homeowners over the period April 2007 to June 2012. This represents approximately 5\% of the low-rise housing stock in Canada.

\section{Energy savings and $\mathrm{CO}_{2}$ emissions}

The average improvement in energy performance of participating homes is estimated at $24 \%$ per home, however the amount of energy savings varies depending on the initial energy consumption of the building and its vintage (see Table 11).

Table 11 Residential Energy Use and Energy Savings per Household, Pre-1945 to 2000-2009

\begin{tabular}{lllllllll}
\hline & $\begin{array}{l}\text { Pre- } \\
1945\end{array}$ & $\begin{array}{l}1945- \\
1959\end{array}$ & $\begin{array}{l}1960- \\
1969\end{array}$ & $\begin{array}{l}1970- \\
1979\end{array}$ & $\begin{array}{l}1980- \\
1989\end{array}$ & $\begin{array}{l}1990- \\
1999\end{array}$ & $\begin{array}{l}2000- \\
2009\end{array}$ & Average \\
\hline Energy use pre-renovation (GJ) & 271 & 200 & 187 & 174 & 174 & 163 & 149 & 193 \\
$\begin{array}{l}\text { Actual energy savings after renovations } \\
\text { (GJ) }\end{array}$ & 85 & 52 & 44 & 40 & 35 & 29 & 31 & 47 \\
\hline
\end{tabular}

Source: NRCan Office of Energy Efficiency 2012b

Natural Resources Canada estimates that collectively, the 640000 grant recipients from 2007-12 reduced their greenhouse gas (GHG) emissions by more than $2.1 \mathrm{Mt}$ per year. If it is assumed that the homes retrofitted under the programme from 2007 to 2011 have an average 30-year lifespan beyond 2011, and that no further improvements take place, then it has been estimated that 63 Mt of GHG emissions could be saved between 2011 and 2041.

\section{Rebound effect}

The Office of Energy Efficiency has not explicitly factored rebound effect into its analyses to date.

\section{Economic efficiency}

\section{Costs}

The average federal grant for a property over the lifetime of the programme has been CAD 1400 , and overall, more than CAD 934 million in incentives has been paid to participating homeowners. 
Energy savings are estimated at more than CAD 400 million a year. ${ }^{95}$ Programme costs can be broken down as approximately $95 \%$ for grants and $5 \%$ for administration.

The investment cost for the ongoing GHG emissions reduction of $2.1 \mathrm{Mt}$ per year was CAD 444 per tonne. However, the cost per tonne for the emission reduction is CAD 14.80 if spread over a 30year building lifespan. This may be a conservative estimate if the improved buildings last longer than 30 years.

Page | 100

\section{Free-ridership and spillover effects}

As part of the ecoENERGY retrofit - Homes programme evaluation, programme participants were interviewed to assess the level of free-ridershipp. The results of these interviews suggest that an important way to encourage unplanned retrofits is to couple incentives for retrofits with those for evaluations, as $30 \%$ of homeowners surveyed said they would not have carried out retrofits if evaluations weren't partially funded by another organization. While the ecoENERGY Retrofit Homes programme did not offer incentives for evaluations, many provincial programmes do. In addition, some homeowners carried out retrofits after an evaluation even without applying for grants.

Broader literature, such as studies conducted in the US, confirm that it is important to provide incentives for both evaluations and retrofits - the evaluation incentive provides a way of removing the initial barrier and encourage homeowners to participate, whereas grants encourage more retrofits than would have been done otherwise. If grants are too high, free-ridership is likely to increase. The level of free-ridership is estimated at approximately $25 \%$ through comparisons with similar programmes in New York and Oregon.

The spillover effects (i.e. the energy savings that have been caused by a programme, but are not included in the savings reported by the programme) are estimated at 12 to $15 \%$. From the freeridership and spillover estimates, the net-to-gross savings are estimated at $84 \%$.

An estimate of the cost per net GHG emissions savings gives a net value of CAD 12.40 per tonne of GHG emissions saved over the buildings' 30 -year lifetimes. The estimate is based on a gross cost estimate of CAD 14.80 per tonne of GHG emissions, and applying the free rider and spillover effect.

\section{Policy interaction}

A survey of 422 participants as part of the 2010 programme evaluation highlighted the importance of combining evaluations and information with fiscal incentives. This was identified as a clear strength of the programme. The survey showed that the combination of an evaluation, with energy advisor recommendations and a grant, led to a higher number of retrofits than homeowners had originally planned, as they were better informed regarding their options. Seventy-eight \% of homeowners planned to do an average of 1.6 retrofits, the energy advisor recommended 5.8 retrofits, and they carried out 3.7 retrofits.

\footnotetext{
${ }^{95}$ Information on ecoENERGY Retrofit - Homes programme: http://oee.nrcan.gc.ca/residential/6551
} 
Between 2007 and 2009:

- Over 14500 new houses were labelled under the EnerGuide Rating System (an increase for new houses from $6.5 \%$ to $35 \%$ ) and ENERGY STAR for new homes (increased from $1 \%$ to $25.5 \%)$;

- 1040 homes were certified through R-2000; and

- 7400 professionals were trained.

A survey of professionals found that $70 \%$ were building more efficient homes as a result of the training. However, many builders say they do not get their buildings certified or labelled, although they claim that they meet the requirements.

The EnerGuide Rating System is helping to increase the stringency of new home energy performance and is leading to inclusion of energy efficiency provisions in the National Building Code. Progress has also been made in having provincial and territorial governments include energy efficiency requirements in their building codes. However, harmonization of building codes can be challenging. Regional differences in geography, climate, resource availability and industrial capabilities influence differences in provincial codes.

\section{Other}

There appears to be some job creation in the area of energy consultants, although no numbers are provided. The ecoENERGY Retrofit - Homes programme supported the direct creation of 2000 energy advisor jobs from coast to coast. Indirectly, as homeowners upgraded their homes, the insulation, doors, and windows used have high Canadian content and support job creation in Canada. It is estimated that the overall Canadian content is $100 \%$ for insulation, $93 \%$ for windows and doors, and $50 \%$ for HVAC; the installation is by nature $100 \%$ Canadian. Also indirectly, the $20 \%$ on average householders saved on their energy bills may be re-invested in the economy, providing further opportunities for job creation.

Regional partnerships are very important to improve the cost-effectiveness of the ecoENERGY Retrofit - Homes programme. Regional incentive programmes are a good complementary measure to federal grants in helping promote energy-efficient retrofits. Regional and national programmes should be aligned as much as possible for the purposes of clarity. Regional programming can more easily tailor programme design to regional requirements, so continued collaboration between federal and regional programme administrators is needed.

Whole-home retrofits (i.e. upgrades that consider the total energy performance of the building, rather than replacing or upgrading individual components of the building) are needed, but evidence appears to show that not all retrofit options are included in evaluation reports, as some are carried out by equipment dealers (who can be energy advisors) who may exploit the opportunity to advertise more expensive high-efficiency options. Some standardisation of the information that should be included in evaluations could address this problem.

\section{Discussion}

Canada is making progress in improving the efficiency of the residential building stock through a combination of national grants, codes, and information programmes, in addition to local measures such as evaluations. 
Table 12 - Summary of ecoENERGY retrofit - Homes programme April 2007-2012

\begin{tabular}{ll}
\hline Grant size & CAD 1400 \\
No. of houses retrofitted & $\begin{array}{l}\text { Over } 640000 \text { (5\% of low rise residential } \\
\text { buildings) } \\
20 \%\end{array}$ \\
Average improvement in energy performance per house & 2.1 Mt per year \\
GHG emissions saved & CAD 1.14B \\
\hline Total funding &
\end{tabular}

The ecoENERGY Retrofit - Homes programme grants were component-based (i.e. based on the specific energy-efficient equipment or products installed) and were limited to a maximum of CAD 5000 per house. Grants based on the overall energy performance of a house tied to a mandatory rating or labeling system that is linked to ambitious building codes may be more effective. One way to do this is to define different levels of energy performance for a reference building. Grants would be calculated based on a home's energy performance after the retrofit, relative to the reference building. There may be scope to do this via a more transparent, updated version of the R-2000 system.

Although the current scheme has been relatively effective in delivering the expected results, some changes will be needed to reach a significant reduction in energy consumption from residential buildings of the order of $50 \%$ by 2050 . There are currently no incentives in place to make larger investments with the purpose of achieving a deeper retrofit of the existing housing stock.

The use of innovative, private sector financing mechanisms to support energy efficiency retrofits is being considered by Natural Resources Canada, as well as some provinces, territories, municipalities and utilities, as a way to maintain the momentum established by incentives programmes such as the ecoENERGY Retrofit - Homes programme and associated provincial programmes. This would cover the upfront cost of retrofits through a loan that homeowners repay on their energy or tax bills, and rely primarily on private capital instead of direct government incentives.

Natural Resources Canada provides its EnerGuide Rating System infrastructure and expertise to support partners interested in launching innovative financing mechanisms pilots or programmes. For example, Natural Resources Canada is currently providing support to pilots in the British Columbian cities of Nelson and Vancouver and is assisting the Province of British Columbia in its preparations to launch a province-wide utility on-bill financing programme. Natural Resources Canada believes that the EnerGuide Rating System is critical for the deployment of innovative financing mechanisms to attract the necessary private capital investment and induce retrofits (NRCan, 2012c).

The ecoENERGY Retrofit - Homes programme has been useful in raising awareness of the benefits of retrofitting residential buildings. As the programme has ended, the IEA recommends that the Canadian government leverage the momentum created by the programme, consider a long-term strategy for the energy performance of residential buildings, and put in place a financial and regulatory package to achieve an even more efficient housing stock, benefitting all Canadians. 


\section{France: Eco-PTZ green loan and tax incentives}

This case study illustrates the experience in France with tax relief (the CIDD scheme) and preferential rate loans (Eco-PTZ loan scheme) for energy efficiency improvements in buildings.

\section{Context}

Despite achievements in energy efficiency, energy consumption in the building sector in France rose by $30 \%$ between 1970 and 2000, largely due to increasing building stock, growing sizes of dwellings, comfort taking and new sources of energy demand. Since 2001 demand has been falling. About two thirds of energy demand and emissions from the buildings sector comes from the residential sector, with one third from the tertiary sector (MEDDTL et al., 2011).

In 2005, in the framework of the POPE law (Programme fixant les Orientations de la Politique Energétique) law on fixing energy policy orientations, France set targets to divide its greenhouse gas emissions by four during the period 1990 to 2050, to improve final energy intensity by $2 \%$ annually after 2015 and to increase renewable heating by $50 \%$ until 2010 (MEDDTL et al., 2011). The first Grenelle law, adopted in August 2009, introduced specific targets for the building sector, such as the reduction of building energy consumption by minimum $38 \%$ until 2020 . Other targets relate to the use of renewable energy and aim at reaching a share of $23 \%$ in final energy consumption by 2020 (MEDDTL et al., 2011).

As a means to achieve these aims, the French government extended the availability of tax credits until 2015 (sustainable development tax credits - CIDD) and introduced a new green loan scheme to push the EE refurbishment of buildings (Eco-zero interest loan - Eco-PTZ). ${ }^{96}$ The tax incentives originally aimed to promote single measures in building refurbishment as well as the market diffusion of most efficient new technologies (MEDDTL et al., 2011). The scheme was amended in 2012 to also contribute to the promotion of deeper refurbishment. The loan scheme is only focused on the promotion of deeper refurbishment and shall address credit shortages for these kinds of measures experienced by households (MINEFI, 2011 pp. 4).

The two instruments are part of a larger policy package which aims to promote environmental goals in the building sector. Demand side management measures include, beside the tax incentives and the loan scheme, also feed-in tariffs for renewable energy and obligation schemes for energy providers. The building energy code (réglementation thermique - RT) prescribes minimum performance standards for new equipment and material used for refurbishment measures. A refurbishment obligation is currently under discussion in the framework of the Grenelle de l'environnement, a national stakeholder discussion on sustainable development in France. Awareness-raising instruments are also implemented such as information campaigns by the French environment and energy agency ADEME (Agence de l'Environnement et de la Maitrise de l'Energie) (MEDDTL et al., 2011) .

Information on the CIDD and the Eco-PTZ schemes for this case study has been drawn from several recent evaluations. Both schemes were evaluated as part of a global benefit-cost analysis of tax exemptions and socially motivated measures in France covering overall 538 budgetary expenses. The final report was published in 2011. Also in 2011 the French Ministry for Ecology, Sustainable Development, Transport and Housing (MEDDTL) commissioned the strategic committee of the Grenelle Housing Plan to propose a dynamic development of state aid for EE refurbishment of residential buildings and specifically the two schemes CIDD and Eco-PTZ; the report was published in April 2011.

\footnotetext{
${ }^{96}$ See: http://ecocitoyens.ademe.fr/financer-mon-projet/renovation/credit-dimpot-developpement-durable
} 


\section{Tax credit for sustainable development and energy efficiency}

\section{Description of the instrument}

The sustainable development tax credit scheme CIDD (Crédit d'impôt développement durable) was first set up in 2005 and is scheduled to run until $2015 .{ }^{97}$ While it was initially seen as an instrument to diffuse highly-efficient new technologies into the market and to support an intermediate refurbishment of 9 million households (MINEFI, 2011 pp. 1), it was amended in 2012 to also encourage deeper refurbishment in buildings.

The tax credit rates and eligible equipment have changed over the years. In the first years rates were very high (between 25 and $50 \%$ of eligible costs depending on the type of equipment). Since then tax credit rates have been reduced several times as the costs to the public budget were rising sharply (see section on costs below) and because the market share of some equipment (e.g. heat pumps, windows and heating systems using condensation technologies) had increased. Also the types of equipment that are eligible under the scheme have evolved, e.g. air-to-air heat pumps have been taken off the scheme in 2009 due to the risk of subsidising the well-developed market for air conditioners. Heat pumps for hot water generation and the insulation of external doors were added to the scheme in 2010. Minimum technical performance criteria have also been tightened several times over the years (MEDDTL et al., 2011 annex 1 pp. 2-3).

Since 2012, the tax credit available under the CIDD scheme varies not only according to the equipment financed. Higher tax credits can be claimed for packages of measures, i.e. if at least two measures are implemented that are not part of the same category. Measures must also be applied to a significant part of the housing unit, i.e. $50 \%$ of all external walls isolated, $50 \%$ of all glazed areas insulated, $100 \%$ roof insulation, etc. ${ }^{98}$

Table 13 gives an overview of the respective size of available tax credits under the current scheme. In order to be eligible for the tax credit, minimum energy performance levels need to be for each type of equipment. ${ }^{99}$

Tax credits can be claimed as part of the annual tax declaration in the year following the purchase of the equipment. Owners living in their property can claim credits during consecutive years for different equipments up to a maximum amount of investment costs of EUR 8000 for a single person, EUR 16000 for a couple and additional EUR 400 for each child in care for a 5 year rolling period. Owners renting their property can claim credits for up to 3 residences and up to a maximum amount investment costs of EUR 8000 for each residence between 2009 and $2015 .{ }^{100}$

\section{Effectiveness}

\section{Impact on the market}

Overall 4.2 million households benefited from measures promoted through CIDD scheme between 2005 and 2008 which represents $15 \%$ of the target group (primary residences) or $13 \%$ of

\footnotetext{
${ }^{97}$ See legal text (accessed on 22.08.2012) at: www.legifrance.gouv.fr/affichCodeArticle.do;jsessionid=04909FF2E5E5ADFD07CC28ED6FA6BBEE.tpdjo10v_1?cidTexte=LEGITE XT000006069577\&idArticle=LEGIARTI000020038553\&dateTexte=

${ }^{98}$ ADEME homepage accessed on August $17^{\text {th }}, 2012$ : http://ecocitoyens.ademe.fr/financer-mon-projet/renovation/creditdimpot-developpement-durable

${ }^{99}$ See homepage of the Ministry of equality of territories and housing, information on the CIDD updated on $2^{\text {nd }}$ of July, 2012: www.developpement-durable.gouv.fr/Le-credit-d-impot-developpement.html

${ }^{100}$ Source: legal text accessed on 31.08.2012:

http://www.legifrance.gouv.fr/affichCode.do;jsessionid=6F119CDCC789CA27A0107C4875AA9821.tpdjo10v_1?idSectionTA=LE GISCTA000006191624\&cidTexte=LEGITEXT000006069577\&dateTexte=20120831
} 
the residential building stock. ${ }^{101}$ Tax credits claimed were mainly used for single family houses (83\%) which are used by the owners as their primary residence and not rented (95\%). The scheme has been used more by wealthier households. In 2008, only $1.6 \%$ of the poorest $20 \%$ of the population (in terms of declared income) filed a tax credit request compared to $9.1 \%$ of the richest $20 \%$ of the population (MEDDTL et al., 2011 pp. 10).

Table 13 - CIDD: tax credits available for various types of equipment

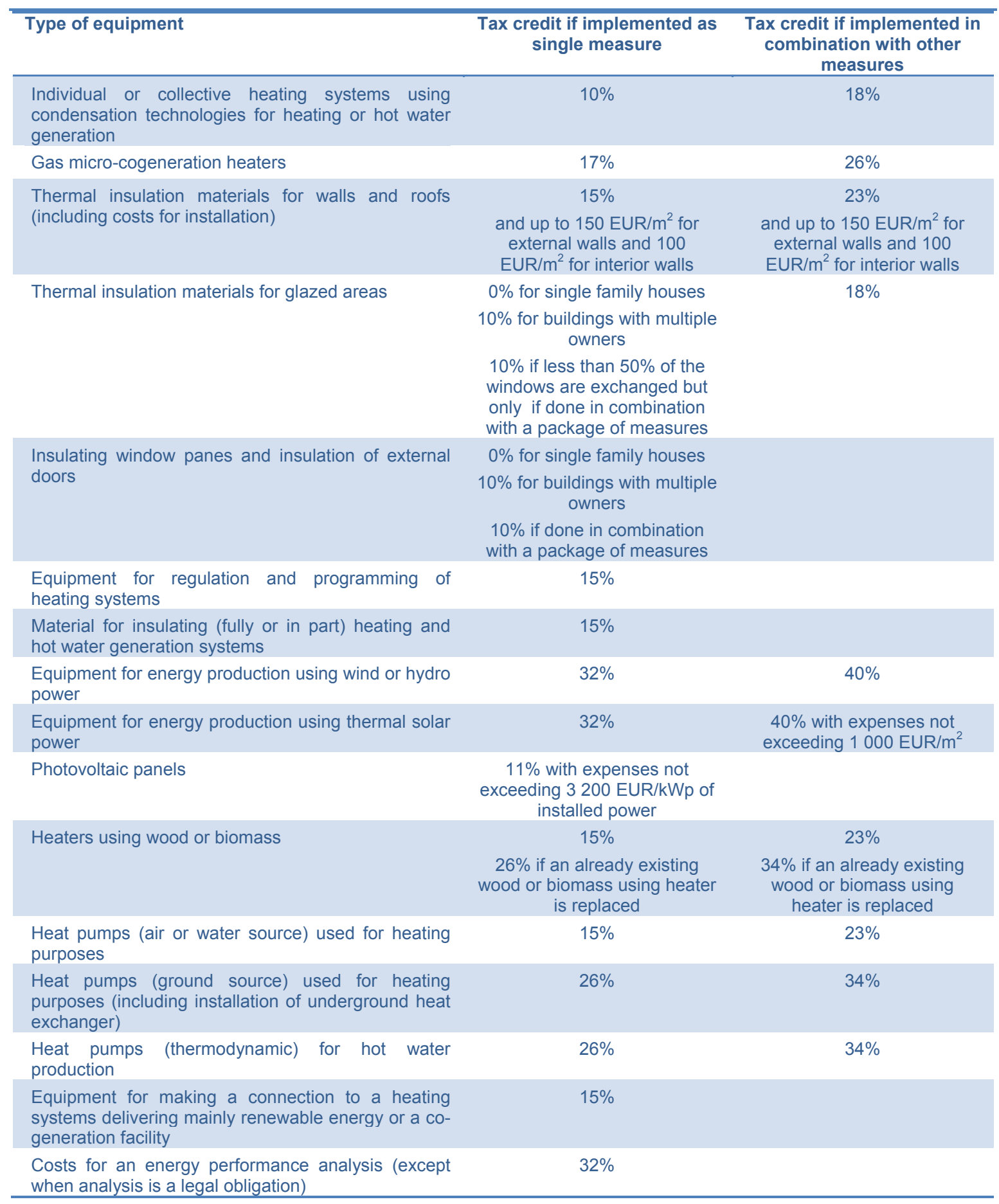

Source: ADEME homepage accessed on August 17 ${ }^{\text {th }}$, 2012: http://ecocitoyens.ademe.fr/financer-mon-projet/renovation/creditdimpot-developpement-durable

101 About 32 million residential buildings in France according to Source: ADEME page accessed on 21.08.2012: http://www.pcet-ademe.fr/domaines-actions/batiments/contexte-et-enjeux 
In $201057 \%$ of households that invested in energy efficiency measures made use of the CIDD scheme compared to $62 \%$ in 2008 . The reduced attractiveness of the scheme has been associated with tighter eligibility criteria and reductions of the tax credit amounts in 2009 and 2008. Only $20 \%$ of households, however, state in $\mathbf{2 0 1 0}$ that the availability of tax credits has been a decisive factor for engaging the works, compared to $24 \%$ in 2008 and 27\% in 2006 (ADEME, 2011 pp. 7172).

\section{Energy and $\mathrm{CO}_{2}$ emission savings}

Savings in terms of energy demand and $\mathrm{CO} 2$ emissions have been estimated using two different models: a bottom-up model called SceGES developed by the Ministry of Ecology, Sustainable Development and Energy ${ }^{102}$ where the results are based on the existing park of equipment installed. The second model used is the Menfis model developed by the French Environment and Energy Agency ADEME which assumes investment activities of households based on the costeffectiveness of available measures as well as other factors such as access to loans. Neither model takes potential rebound effects into account (MEDDTL et al., 2011 pp. 9 and annex 2 pp. 4).

Table 14 - CIDD: estimated energy demand and emission reductions

\begin{tabular}{lcc}
\hline & SceGES model & Menfis model \\
\hline $\begin{array}{l}\text { Emissions saved until } 2020 \text { through CIDD scheme } \\
\text { implemented between } 2008 \text { and } 2012 \text { compared to a } \\
\text { situation without the CIDD available }\end{array}$ & $5.04 \mathrm{MtCO}_{2}$ & \\
Primary energy saved until 2020 through CIDD & 17.1 TWh \\
scheme implemented between 2008 and 2012 & \\
compared to a situation without the CIDD available & - \\
Primary energy demand reduction of the residential & \\
sector between 2008 and 2010 due to CIDD scheme & \\
Greenhouse gas emission reductions of the \\
residential sector between 2008 and 2010 due to \\
CIDD scheme
\end{tabular}

Source: MEDDTL et al., 2011 pp. 10

As can be seen from Table 14, the two different models produce slightly different but not contradictory results. According to these estimations the CIDD scheme alone would achieve a reduction of energy consumption of the residential sector of $26 \%$ by 2020 , considering its implementation between 2008 and 2012. This would mean that a significant part of the $38 \%$ reduction target could be achieved via the scheme (MEDDTL et al., 2011 pp. 26). These estimations date from before the CIDD scheme was prolonged for a further 3 years (2013-2015) and conditions were changed as of 2012 to encourage deeper refurbishment instead of only single measures. The estimations of reductions for the years 2012-2020 do not take these changes into account (MEDDTL et al., 2011 pp. 10).

\section{Rebound effects and free-ridership}

Both models (SceGES and Menfis) do not account for potential rebound effects (MEDDTL et al., $2011 \mathrm{pp}$. 9). The direct rebound effect (i.e. occupants increasing average room temperatures after the implementation of insulation works) has however been estimated using another model (ResIRF) which models the behaviour of households and estimates a range between $5 \%$ and $50 \%$, depending on the original performance of the building and the improvements achieved through the measures implemented. The model concludes that the direct rebound effect is higher for buildings with a very low energy performance prior to improvement undertaken and for

\footnotetext{
${ }^{102}$ For more information (in French): http://www.developpement-durable.gouv.fr/SceGES-outil-d-evaluation-de-I.html
} 
occupants with relatively low living standards (MEDDTL et al., 2011 pp. 11).

A rough estimation of the free-rider effect has been attempted on the basis of Menfis modelling results by simply comparing costs to the public budget with general abatement costs. Results were less than one \%. The approach, however, ignored the fact that market failures exist which prevent owners from investing even in cost-effective measures and does also not differentiate between different measures eligible under the scheme (MEDDTL et al., 2011 pp. 16-17).

\section{Economic efficiency}

\section{Costs}

Costs of the CIDD scheme to the public budget have risen over the years as can be seen from Table 15. Due to the time lag of tax credits being claimed costs for 2010 were not available when the scheme was evaluated in 2011. But as a result of the economic crisis and also due to the fact that in 2010 significant reductions in the rates of tax credits were taking effect, costs are estimated to fall to around EUR 1.7 billion in 2010 and EUR 1.3 billion in 2011 (MEDDTL et al., 2011 pp. 12). ${ }^{103}$

Table 15 - CIDD: costs 2005-2009

\begin{tabular}{ccccccc}
\hline & 2005 & 2006 & 2007 & 2008 & 2009 & $\begin{array}{c}\text { average } \\
2005-2009\end{array}$ \\
\hline $\begin{array}{c}\text { total costs (million EUR) } \\
\text { costs for EE in \% of total costs }\end{array}$ & 985 & 1872 & 2196 & 2774 & 2626 \\
\hline $\begin{array}{c}\text { costs for windows as \% of EE } \\
\text { related costs }\end{array}$ & 80 & 71 & 50 & 40 & 45 & 50 \\
$\begin{array}{c}\text { costs for wall and roof } \\
\text { insulation as \% of EE related } \\
\text { costs }\end{array}$ & 0.3 & 0.5 & 0.6 & 15 & 16 & 72 \\
\hline $\begin{array}{c}\text { Costs for heating related } \\
\text { appliances as \% of EE related } \\
\text { costs }\end{array}$ & 16 & 19 & 19 & 34 & 32 & 24 \\
\hline
\end{tabular}

Notes: numbers given correspond to the year of purchase; costs are impacting the public budget with a time lag of one year as tax credits are only claimed in the beginning of year following the year of purchase. As various sources have been used in the2011 evaluation to provide details on overall costs and costs associated to each eligible technology, numbers do not exactly add up to 100 \%. Source: IEA analysis based on MEDDTL et al., 2011 pp. 12

About $50 \%$ of total costs incurred by the scheme between 2005 and 2009 relate to energy efficiency (EE) investments, whereas the other half relates to investments into renewable energy generation. Within the costs for energy efficiency related investments, the insulation of windows takes by far the biggest share: around $80 \%$ of all public spending on energy efficiency under the scheme was uniquely used for windows between 2005 and 2007. This share went down to about $60 \%$ in 2008 and 2009 but remains at a very high level. For 2010 and 2011 estimations predict a further reduction to slightly over $40 \%$. In contrast the share of insulation of walls and roofs has been negligible in the first three years but has gained in importance since 2008. Estimations for 2010 and 2011 predict that their share will continue rising at a slower pace but stay below $20 \%$.

Evaluations have estimated that the public budget spend per tonne of $\mathrm{CO} 2$ avoided for all

\footnotetext{
${ }^{103}$ All estimations for the years 2010 and 2011 are based on statistics of the development of overall sales of eligible equipment and results of the Menfis model, which takes into account the changes in tax credit rates.
} 
measures under this scheme implemented between 2005 and 2012 will be EUR 93 when a lifetime of 25 years for investments is assumed. However this is not the same as a cost-benefit analysis on an NPV basis, which would take into account electricity savings and other societal benefits. From a societal perspective, these are cost-effective investments, with negative cost per tonne $\mathrm{CO}_{2}$ emissions avoided.

The spend per tCO2 emissions avoided varies significantly for different types of equipment. Taking the level of public support for 2011, the insulation of walls and roof is the least costly to the public budget with only $21 \mathrm{EUR} / \mathrm{tCO}_{2}$ avoided. Insulation of windows, the efficiency measure most implemented is estimated to cost $70 \mathrm{EUR} / \mathrm{tCO}_{2}$ avoided. In 2011, solar thermal power installations (432 EUR/tCO 2 avoided) and photovoltaic panels (136 EUR/tCO $\mathrm{tCO}_{2}$ avoided) are the most costly to the public budget (MEDDTL et al., 2011 pp. 14).

\section{Other evaluated effects}

Multi-sectoral macroeconomic modelling results undertaken by ADEME have shown that most of the energy efficiency measures financed under the scheme have an internal rate of return that is higher than the interest rate, which means investors can use the resources freed up by reductions in energy bills to service the debt taken on for the investment (MEDDTL et al., 2011 pp. 23).

The effects on the public budget are negative in the short term, whereas in the medium to longer term the stimulus effect of the scheme should lead to additional revenues which more than cover the costs of the scheme (MEDDTL et al., 2011 pp. 23).

No co-benefits of the investments have been accounted for in the evaluation of this scheme such as reduced noise, increased energy security or development of the renewable energy industry (MEDDTL et al., 2011 pp. 15-16).

\section{Green loans with zero interest rates}

\section{Description of the instrument}

The French green loan scheme called Eco-prêt à taux zero (Eco-PTZ) was created in 2009. It provides zero interest loans for deeper EE refurbishments of residential homes (single family houses and apartments) that were built before 1990. Home owners can apply for the loan, both as owners or renters of a building, as long as it is used as a primary residence (MINEFI, 2011). Further data on the loan scheme can be accessed through the publically available statistics of the SGFGAS (see Box 19). Table 16 gives an overview of choices of eligible measures available under the Eco-PTZ scheme:

Energy efficiency measures that can be chosen under the "package of measures" approach may include the following (MINEFI, 2011):

- thermal insulation of the roof,

- thermal insulation of external walls,

- thermal insulation of glazed areas and external doors,

- change of heating systems eventually combined with efficient ventilation systems or water heating devices,

- heating devices using renewable energy; 
Table 16 - Eco-PTZ: eligible measures and maximum loan sizes and terms

\begin{tabular}{|c|c|c|}
\hline Eligible measures & $\begin{array}{l}\text { Maximum size of } \\
\text { loan (EUR) }\end{array}$ & $\begin{array}{l}\text { Maximum loan } \\
\text { term (years) }\end{array}$ \\
\hline A package of measures comprising two eligible efficiency measures & 20000 & 10 \\
\hline $\begin{array}{l}\text { A package of measures comprising three or more eligible efficiency } \\
\text { measures }\end{array}$ & 30000 & $10(+5)$ \\
\hline $\begin{array}{l}\text { Measures relative to non-collective sewerage systems with no energy } \\
\text { demand (measure not related to achieving energy efficiency gains) }\end{array}$ & 10000 & 10 \\
\hline
\end{tabular}

Source: MINEFI, 2011 and presentation by Mélanie Barcet (MEDDTL) during the IEA expert workshop in March $2012^{104}$

For each of the eligible measures, minimum performance standards have been set. ${ }^{105}$ For buildings constructed after January 1948 there exists also the option to achieve general performance requirements through measures validated by a thermal study. In this case buildings with an annual consumption of more than $180 \mathrm{kWh}$ of primary energy per $\mathrm{m}^{2}$ should to reduce their annual consumption to less than $150 \mathrm{kWh}$ of primary energy per $\mathrm{m}^{2}$. Buildings with an annual consumption of less than $180 \mathrm{kWh}$ of primary energy per $\mathrm{m}^{2}$ should reduce their annual consumption to less than $80 \mathrm{kWh}$ of primary energy per $\mathrm{m}^{2}$. The values take account for different climate zones and levels of altitude of the situation of the building.

Initially, the scheme provided interest free loans for up to 10 years. For deep EE refurbishment ( 3 measures or more and overall energy performance) the loan could be extended by another 5 years with the consent of the bank, however, the bank was not able to recover the interest subsidy for the additional 5 years. Since 2012, for deep EE refurbishments, the loan can be up to 15 years long and the banks now recover the interest subsidy for the whole loan period.

Only one loan per building is permitted, which does not allow for a step by step approach of refurbishment using the same scheme. ${ }^{106}$

There are no co-financing conditions attached to the Eco PTZ. The loan can be combined with subsidies from the national housing agency Anah or other local subsidies. During 2009 and 2010 the Eco-PTZ could be combined with the tax credit CIDD (discussed above) for households with revenues up to EUR 45 000. This option was revoked in 2011, then allowed again in 2012 for households with revenues up to EUR 30000 (see section on other evaluated effects below).

Loans are disbursed by banks that have signed a convention with the state and the SGFGAS (MINEFI, 2011). To date 16 banks and groups of banks have signed the convention. ${ }^{107}$ Banks participating in the scheme are responsible not only for the financial assessment of the creditworthiness of the clients but also for the eligibility assessment of measures to be financed under the scheme (MINEFI, 2011 pp. 3).

For each loan disbursed, the banks can recover the interest forgone as well as administrative costs incurred and a profit margin in the form of a tax credit. The amount is calculated annually for each participating bank by the SGFGAS. The tax credit thus calculated is spread over 5 years and annual tax credits obtained are taxable as revenues from regular non-concessional loans (MINEFI, 2011 pp. 5-6).

\footnotetext{
${ }^{104}$ http://www.iea.org/media/workshops/2012/energyefficiencyfinance/2d2Barcet.pdf

105 See: http://www.developpement-durable.gouv.fr/L-eco-pret-a-taux-zero-en-13.html

${ }^{106}$ presentation by Mélanie Barcet (MEDDTL) during the IEA expert workshop in March 2012: http://www.iea.org/media/workshops/2012/energyefficiencyfinance/2d2Barcet.pdf

${ }^{107}$ For more information see: http://www.developpement-durable.gouv.fr/L-eco-pret-a-taux-zero-en-13.html
} 
The society for guarantee fund management for the social accession of property (SGFGAS) was established in 1992 by the French government with the aim of promoting residential property ownership through the provision of public guarantees for mortgages to low-income households and to gather information on the credit risk associated with this category of debt-takers. Over the years the responsibilities of the SGFGAS have evolved and the public guarantee fund that has shaped the name of the institution was replaced by a direct public guarantee. It is responsible for managing the funding of the Eco-PTZ scheme.

The SGFGAS is legally established as a private company and all banks that benefit from the public guarantee scheme have the obligation to become shareholders. Seven banks and groups of banks are currently shareholders and have representatives in the board of directors: Société Générale, Groupe PNB Paribas, Groupe Crédit Mutuel - CIC, Groupe Banques Populaires et Caisses d'Epargne, Crédit Immobilier, Groupe Crédit Agrcole and La Banque Postale.

The public sector is not involved in the capitalisation of the SGFGAS but sends two commissioners representing the finance ministry and the housing ministry to the board of directors, which have a veto right with regard to all decisions that relate to financial engagements.

The government mandates the SGFGAS with various tasks in relation to its promotional schemes in the housing sector.

Source: https://www2.sgfgas.fr/web/guest/presentation-sgfgas1.

\section{Effectiveness}

\section{Impact on the market}

At its inception it was planned to increase the use of the Eco-PTZ with a goal of 50000 loans in 2009, 150000 loans in 2010, 240000 loans in 2011 and 320000 loans in 2012. From 2013, 400 000 loans were planned annually (MINEFI, 2011). With more than 32 million residential buildings in France, achieving these targets would lead to a refurbishment of about $6 \%$ of the building stock between 2009 and 2015 and another 6\% between 2016 and 2020. ${ }^{108}$

Table 17 gives an overview of the uptake achieved compared to the planned numbers as well as the average characteristics of loans disbursed. Between 2009 and 2011 about 190500 buildings (or about $0.6 \%$ of the building stock) where refurbished using the scheme. Whereas in the first year of implementation (2009) the uptake was very encouraging and by far exceeded the planned level, the development in the second year (2010) was only moderate, and the uptake in 2011 even decreased substantially. It was at first thought that this evolution in programme uptake coincided directly with reductions in the levels of CIDD tax incentives in 2010 and the abolishment of the possibility to combine the Eco-PTZ with the tax incentives in 2011. However, the possibility to combine again both schemes in 2012 did not change the trend. It is likely that the financial crisis has had a negative influence on the uptake of the scheme (MINEFI, $2011 \mathrm{pp}$. 11). According to the banks, another explanation is the technical complexity of the scheme (see section on other evaluated effects below).

In 2010 only about $5 \%$ of households investing in energy efficiency measures have used the EcoPTZ loan scheme and about $4 \%$ stated that the access to the Eco-PTZ scheme has been decisive for engaging the work (ADEME, 2011 pp. 71-72).

During the first two years average loan amounts were almost EUR 17000 which covered on average $87 \%$ of overall costs of measures implemented and had a repayment period of about 9 years (MINEFI, 2011 pp. 9). More than $90 \%$ of loans issued in the first two years have been used

\footnotetext{
${ }^{108}$ Source: ADEME page accessed on 21.08.2012: http://www.pcet-ademe.fr/domaines-actions/batiments/contexte-et-enjeux
} 
to refurbish individual houses while buildings with multiple apartments remain the clear minority (less than 1\%) of the (MINEFI, 2011 pp. 10).

Table 17 - Eco-PTZ: uptake and characteristics of loans

\begin{tabular}{lcccc}
\hline & $2009^{109}$ & 2010 & 2011 & 2012 \\
\hline Planned uptake (number of loans) & 50000 & 150000 & 240000 & 320000 \\
\hline Achieved uptake (number of loans) & 71000 & 78500 & 40800 & $\sim 31000$ \\
\hline Average loan amount (EUR) & 16589 & 16895 & 16992 & - \\
\hline Average costs of measures implemented & 18896 & 19473 & 19619 & - \\
\hline Average term of loans (years) & 8.9 & 9.1 & 9.2 & - \\
\hline
\end{tabular}

Source: MINEFI, 2011 pp. 9 and presentation by Mélanie Barcet (MEDDTL) during the IEA expert workshop in March $2012^{110}$ and communication with MEDDTL

According to statistics of the SGFGAS, the majority of loans (65.6\%) given out between 2009 and 2011 were used to finance a combination of two measures. $29.1 \%$ were used to finance a combination of 3 or more measures. The other options under the scheme (overall performance refurbishment and sewerage measures) were used very little accounting for $1 \%$ and $3 \%$ of loans respectively. ${ }^{111}$ In 2009 and 2010 the insulation of the roof and walls, the insulation of glazed areas and diverse measures related to heating systems (including renewable energy) each make up about one third of measures financed.

\section{Energy and $\mathrm{CO}_{2}$ emission savings}

On average energy demand in buildings and apartments refurbished with an Eco-PTZ loan has been reduced by about $50 \%$ (SGFGAS statistics). ${ }^{112}$

Savings in terms of energy demand and $\mathrm{CO} 2$ emissions have been estimated using a bottom-up model developed by the Ministry of Ecology, Sustainable Development and Energy called SceGES. ${ }^{113}$ Measures financed through the EcoPTZ scheme during 2009 and 2010 are estimated to have led to an annual reduction of $1431 \mathrm{MWh}$ of primary energy and $260000 \mathrm{tCO}_{2}$. Until 2020 it was estimated that overall cumulated savings of 14.9 TWh of primary energy and $2.8 \mathrm{MtCO} 2$ would be achieved. (MINEFI, 2011 pp. 11) However, this estimation was based on the rate of distribution of 400000 loans per year between 2013 and 2020 which is now clearly unrealistic.

\section{Rebound effects and free-ridership}

No estimations of rebound effects and free-ridership have been found. Yet due to the fact that during the first two years of existence $80 \%$ of the recipients of an Eco-PTZ loan have also benefitted from the tax relief CIDD it was assumed that there is a high degree of free-ridership through the accumulation of public subsidies for the same measures undertaken (MINEFI, 2011 pp. 13).

\footnotetext{
${ }^{109}$ The distribution started on April $1^{\text {st }}, 2009$.

${ }^{110} \mathrm{http}: / /$ www.iea.org/media/workshops/2012/energyefficiencyfinance/2d2Barcet.pdf

${ }^{111}$ Accessed on 08.08.2012 https://www2.sgfgas.fr/presentation/Stats/EPZ/EPZ_Bilan_de_production_annexes.pdf

${ }^{112}$ SGFGAS statistics on the Eco-PTZ: bilan de production - annexes: https://www2.sgfgas.fr/web/guest/statistiques1

${ }^{113}$ For more information (in French): http://www.developpement-durable.gouv.fr/SceGES-outil-d-evaluation-de-l.html
} 


\section{Economic efficiency}

\section{Costs}

Since interest rates have been rather low during 2009 and 2010, the interest rate subsidy and therefore the costs to the public budget are considered to be moderate. ${ }^{114}$ Costs to the public budget incur in the form of tax credits to participating banks which are spread over 5 years. For all

Page | 112 loans issued in 2009 and 2010 (about 150000 loans) the participating banks are able to claim tax credits worth EUR 408 million between 2010 and 2016, resulting in costs to the public budget of EUR 398 million over the same period (MINEFI, 2011 pp. 5-7).

The cost of energy and $\mathrm{CO} 2$ savings is estimated at EUR 0.10 per kWh of primary energy saved and EUR 56 per tonne of $\mathrm{CO}_{2}$ emission avoided (MINEFI, 2011 pp. 11).

\section{Other evaluated effects (on public budgets, employment, etc.)}

The evaluation has shown that Eco-PTZ loans have generally benefited high income groups. This is due to the assessment of creditworthiness which is done by the banks participating in the scheme. Banks use the same standards for the Eco-PTZ loan as for any regular loan and has not been adapted to assist low-income groups (MINEFI, 2011 pp. 12).

\section{Other interesting features (governance)}

Banks participating in the scheme have claimed that the complexity of the scheme has discouraged their commercial network which is responsible for issuing the loans. The main criticism is the fact that banks are responsible for assessing the technical eligibility of measures to be financed under the scheme, which is a task that is clearly outside the core business of the banks. Due to the lack of technical expertise within the banks this remains a challenge even though a number of documents have been developed to guide the process (MINEFI, 2011 pp. 1314).

\section{Option to combine Eco-PTZ loans and CIDD tax credits}

During the first two years (2009 and 2010) the Eco-PTZ loan could be combined with the tax credits for the same measures implemented by households with a taxable income of less than EUR 45000 (MEDDTL et al.,2011 pp. 17). They were seen as complementary schemes, with different objectives. While the CIDD scheme aimed to encourage market diffusion of highly efficient materials and equipment, the Eco-PTZ scheme was more focused on promoting deep refurbishment of buildings. Due to the issues of assumed high levels of free-ridership and the rising costs of the CIDD tax credit scheme this was no longer permitted from January 2011 (MINEFI, 2011 pp. 13 and MEDDTL et al., 2011 pp. 17). However, because the uptake of the scheme almost halved in 2011, the option to combine the schemes was reintroduced for low income households (maximum income EUR 30 000) for the year 2012 together with a number of other changes to make both schemes more effective. ${ }^{115}$

\section{Discussion}

According to a 2011 survey, overall only $28 \%$ of households investing in energy efficiency measures considered state aids (CIDD, Eco-PTZ and other general subsidies for refurbishment combined) to be a decisive factor for the investment, compared to 26\% in 2008 (ADEME, $2011 \mathrm{pp}$.

\footnotetext{
${ }^{114}$ In order to calculate the advantages for participants in the scheme the study is using a reference loan with an interest rate of $4 \%$ (MINEFI, 2011 pp. 3).

${ }^{115}$ ADEME homepage accessed on August $17^{\text {th }}, 2012$ : http://ecocitoyens.ademe.fr/financer-mon-projet/renovation/creditdimpot-developpement-durable
} 
72). This would indicate that there is still a lot of scope to increase the effectiveness of the schemes, given the substantive amounts of public funds that are allocated to them.

The relatively small maximum amounts for eligible costs under the CIDD tax incentives are unlikely to incentivise deep refurbishment. Even though the uptake of this instrument is relatively high with $15 \%$ of primary residences up to 2008 refurbished with the help of CIDD tax incentives, the level of refurbishment of each building is low and efficiency potentials in these buildings may be locked-in for years to come until the next refurbishment cycle. A technology-neutral approach, providing support according to the improvement of the buildings' overall performance level, would reduce the risk of inefficient public support.

The Eco-PTZ seems to be achieving its goal of supporting deeper refurbishment, with improvements of $50 \%$ in buildings' energy demand. But the uptake of the programme is still very low compared with the overall buildings stock (0.6\% between 2009 and 2011). In order to upscale the rate of deep renovation, there may be a need for changes to the design of these programme or other policies mandating improvement in buildings.

In 2011 both schemes were thoroughly evaluated and a number of problems identified, i.e. increasing costs to the public budget of the CIDD tax credits, dwindling uptake of the Eco-PTZ loans after a successful year of introduction and high risks of free-ridershipp. At the same time a commission set up under the Grenelle de l'environnement public consultation process published proposals for far-reaching modifications of both schemes. ${ }^{116}$ It recommended most importantly making the two schemes more coherent, ensuring that they build on each other and that they jointly promote deeper refurbishment (Plan Bâtiment Grenelle, 2011).

Some of the propositions were included in the changes decided in 2012 while other are still under consideration: The possibility to combine the two schemes for low-income households has been reintroduced and benefits under both schemes are now increasing stepwise for deeper steps of refurbishment. Future changes that are currently under discussion might include a harmonisation of technical eligibility standards of the two schemes, transferring the responsibility for the technical eligibility check for loans from the participating banks to technical experts and simplifying the Eco-PTZ for multi-family buildings under joint ownershipp. ${ }^{117}$

\footnotetext{
${ }^{116}$ Plan Bâtiment Grenelle (in French): http://www.legrenelle-environnement.fr/Qui-sommes-nous,1332.html

117 See presentation of Melanie Barcet (MEDDTL), at the IEA expert workshop in Paris in March 2012: http://www.iea.org/media/workshops/2012/energyefficiencyfinance/2d2Barcet.pdf
} 


\section{Germany: KfW loans and grants for energy efficiency in residential buildings}

This case study describes the experience of Germany with concessional loans and grants for the energy efficiency refurbishments of buildings.

\section{Context}

Energy consumption in Germany has been stable since the 1990's with energy intensity steadily improving. The 2007 National Energy Efficiency Action Plan aims at 9\% improvement in energy efficiency between 2007 and 2016 in all sectors. Most of the savings are likely to come from the residential sector, as it provides a still vast and cost-effective improvement potential (Pasquier and Saussay, 2012). The "Energy concept for an environmentally sound, reliable and affordable energy supply (Energiekonzept)" was published by the German government in September 2010. It formulates two central aims for the building sector to be achieved by 2050: a climate neutral building stock with a very low energy demand which can be supplied by renewable energies as well as $80 \%$ reduction of primary energy demand. A first evaluation on progress made is planned for 2020 (BMWi/BMU, 2010).

Germany applies strict energy requirements in building codes (EnEV) compared to other countries. It is also one of the few to support the construction of highly efficient new buildings, such as passive houses. With regard to the refurbishment of old houses, loans and grants are provided to assist customers to meet high upfront costs (Pasquier and Saussay, 2012).

The responsible ministry, the Federal Ministry for Transport, Building and Urban Development (BMVBS) calls its financial support programmes for energy efficient construction and refurbishment together with the Energy Savings Ordinance the most important instruments of the federal government for saving energy and protecting the climate (BMVBS, 2011).

\section{Box $20 \bullet$ The German Energy Savings Ordinance (EnEV)}

The EnEV (Energieeinsparverordnung) is a code that specifies energy performance requirements for buildings as well as for HVAC and water boilers. The EnEV was first introduced in 2002 and applies to all buildings that need either heating or cooling. Germany is one of the few countries to have specific energy performance requirements for the refurbishment of existing buildings. They apply when $10 \%$ or more of the existing building component surface is changed or more than $15 \mathrm{~m}^{2}$ are added. The EnEV replaced two separate ordinances on thermal insulation and heating systems. Thus for the first time buildings shell and technical appliances for heating, cooling and ventilation were conceived as an entity.

Smaller changes to the ordinance were introduced in 2003/2004 and 2007 due to changes in standards set by the German Standardisation Institute DIN and in order to implement the EU energy performance of buildings directive. In 2009, however, the EnEV was substantially changed and requirements were tightened. New aspects included the adoption of reference buildings in the residential area and measures to strengthen enforcement. Requirements for annual primary energy demand were tightened by $30 \%$ and thermal insulation ( $\mathrm{U}$-value) requirements were tightened on average by $15 \%$. Maximum transmission heat loss values $\left(\mathrm{H}_{\mathrm{T}}^{\prime}\right)$ range from 0.40 to $0.65 \mathrm{~W} /\left(\mathrm{m}^{2}{ }^{2} \mathrm{~K}\right)$, depending on the type of building (detached or not). In order to respect the code, existing buildings may exceed the values of the reference building for new buildings by maximum $40 \%$. (ASUE, 2009 / Galvin, 2010) The government has announced in the 2010 energy concept, that standards will be tightened again in 2012 (BMWi/BMU, 2010). 


\section{Description of programme}

The concessional loans and grants programme to promote energy efficient retrofits for private homes in Germany was first called " $\mathrm{CO}_{2}$ refurbishment of buildings" and was superseded in 2009 by the programme "Energy-efficient refurbishment".

Table 18 • "CO2 refurbishment of buildings" and "Energy efficient refurbishment": main features

\begin{tabular}{|c|c|c|}
\hline Characteristics & $\mathrm{CO}_{2}$ refurbishment of buildings & Energy efficient refurbishment \\
\hline Duration & August 2001 - March 2009 & April 2009 - ongoing \\
\hline Type & $\begin{array}{l}\text { Preferential loans, since } 2007 \text { also grants; no } \\
\text { possibility to apply for both: loan and grant. }\end{array}$ & $\begin{array}{l}\text { Preferential loans and grants. No possibility to } \\
\text { apply for both. Loans for very ambitious } \\
\text { retrofitting measures include a loan repayment } \\
\text { allowance. }\end{array}$ \\
\hline Target & Refurbishment of existing residential buildings & Refurbishment of existing residential buildings \\
\hline Eligible Measures & $\begin{array}{l}\text { Thermal insulation, HVAC, renewable energy } \\
\text { (for warm water and heating) }\end{array}$ & $\begin{array}{l}\text { Thermal insulation, HVAC, renewable energy } \\
\text { (for warm water and heating) }\end{array}$ \\
\hline $\begin{array}{l}\text { Efficiency } \\
\text { requirements }\end{array}$ & $\begin{array}{l}\text { Choice of predefined packages of measures or } \\
\text { since } 10 / 2008 \text { also measures leading to } \\
\text { compliance with EnEV standards for new } \\
\text { houses }\end{array}$ & $\begin{array}{l}\text { Introduction of the KfW Efficiency House as a } \\
\text { benchmark using the EnEV standard for new } \\
\text { houses. Size of grants and loans depends on } \\
\text { the efficiency level reached with regard to this } \\
\text { benchmark. Also single measures become } \\
\text { eligible. }\end{array}$ \\
\hline
\end{tabular}

Source: IEA analysis based on Clausnitzer et al., 2010

The programme " $\mathrm{CO}_{2}$ refurbishment of buildings" was available from August 2001 until March 2009. The programme provided mainly low interest loans for packages of energy efficiency measures including measures on thermal insulation, heating and ventilation. There were up to 6 different packages of measures defined. Most packages defined a specific combination of measures such as e.g. insulation of the outer walls AND the roof AND the cellar ceiling AND modernisation of windows. A more flexible package was first specified as measures that lead to an overall reduction of at least $40 \mathrm{~kg} / \mathrm{m}^{2} \mathrm{CO}_{2} \mathrm{e}$. Later this package was changed to three measures proposed by a certified energy specialist out of all eligible measures. The exact content of packages, as well as the eligibility of buildings changed over time. From October 2008 till March 2009, loans were also made available for refurbishments outside the prescribed packages that led to compliance with standards for heat loss and annual primary energy demand applied to new houses, as specified in the EnEV, i.e. outperforming legal requirements for refurbishment by $40 \%$. Special incentives, including a loan repayment allowance, were granted for refurbishments leading to even greater improvements (Clausnitzer, et al., 2010). The maximum size of the loans depended on the size of surface of housing units to be refurbished (source: questionnaire to $\mathrm{KfW}$ ).

Since the beginning of 2007 the programme also offered grants for packages of refurbishment measures as an alternative to a loan. The size of the grants depended on the intensity of refurbishment. They covered $5 \%$ of total costs and maximum EUR 2500 per apartment. After December 2007, $10 \%$ of eligible modernisation costs of measures that led to a compliance with the 2007 EnEV standard for new buildings up to EUR 5000 was supported with grants per apartment. If the standard was outperformed by $30 \%$ the grant covered $17.5 \%$ of eligible costs and maximum EUR 8 750. Since January 2009 also specific single measures were eligible for a grant as long as the EnEV regulations are met (Clausnitzer, et al., 2010).

In April 2009 the "Energy efficient refurbishment" programme replaced the " $\mathrm{CO}_{2}$ refurbishment of buildings" programme. The new programme offers preferential loans and grants, which may not be combined. The idea of a set of predefined packages of measures was abandoned. Instead the KfW Efficiency House (KfW-EH) was created as a benchmark. The KfW-EH 100 exactly matches 
the EnEV minimum requirements for new buildings in terms of annual primary energy demand and heat loss (100\%). The $\mathrm{KfW}$ grants and loans are only available for refurbishment that is more ambitious than the minimum requirements of the EnEV (better than KfW-EH 140 for existing buildings). Initially only refurbishments leading the KfW-EH 100 received the incentives.

As the EnEV standard was tightened in October 2009 (see Box 20 above), the loan conditions were relaxed. This meant that refurbishments leading to efficiency levels of KfW EH 115 were eligible and additionally requirements for heat loss were loosened. During a transition period of 8 months even efficiency levels of KfW EH 130 were still accepted. With the new "energy efficient refurbishment" programme, debt relief between $5 \%$ and $15 \%$ of the loan became available for higher efficiency levels reached. It was not a condition anymore to implement specific packages of measures; however for single measures no debt relief was given. The loans cover up to $100 \%$ of costs for energy efficient refurbishment including costs for planning and expert guidance. The maximum value of loans is EUR 75000 per housing unit for refurbishment to KfW efficiency house levels and EUR 50000 per housing unit for single measures (KfW, 2012b). The interest rates applied vary according to prevailing market conditions. They also depend on the size of public funds made available for the programme. Interest rates are lower for short term loans than for longer term loans (source: questionnaire to $\mathrm{KfW}$ ).

Grants are available for the refurbishment of one-family or two-family houses as well as privately owned apartments using KfW Efficiency Houses as references. The size of the grants was restricted in 2010 to $10-20 \%$ of eligible costs for packages of measures depending on the efficiency level reached. For single measures $5 \%$ of eligible costs and maximum EUR 2500 is granted (Clausnitzer, et al., 2010).

The promotion of single measures with high efficiency standards was introduced to enhance accessibility to the programme, allowing a step by step approach to refurbishment. This allowed building owners to get started with the refurbishment, e.g. with the insulation of windows or outer walls, provided that strict efficiency requirements for the component are met.

\section{Box $21 \cdot$ Application procedures}

Applications for participation in the grant schemes are send directly to $\mathrm{KfW}$ without an intermediary. Applications for loans are to be filed at a local bank as the local bank assumes the liability for the credit. They need to be sent and approved before the start of the refurbishment works.

$\mathrm{KfW}$ recommends an expert supervision for all planning and implementation of refurbishment works. For loan application and for expenditure reporting for grants as well as loans a co-signature of an expert is obligatory. This has also been the case in the predecessor programme " $\mathrm{CO}_{2}$ refurbishment of buildings". Full expert supervision is only mandatory since July 2011 and only for refurbishment to a KfW-EH 55 level or better. Related costs are eligible for KfW support (KfW, 2012a, KfW, 2012b).

\section{Data availability}

The KfW, together with the BMVBS, have regularly funded evaluations of the measures. Almost all of the numbers shown in this case study are directly or indirectly based on the yearly evaluations funded by the $\mathrm{KfW}$ and the BMVBS (and carried out by the Bremen Energy Institute and Forschungszentrum Jülich). The evaluations are mainly based on yearly surveys where participants of the programmes answered a detailed questionnaire, which were extrapolated for the overall programmes. ${ }^{118}$ Consistency between the sample and whole programme was verified through

\footnotetext{
${ }^{118}$ The number of responses was around 500 for the years 2005 and 2006 (1-2\% of loans granted) and over 1000 for each year between 2007 and 2010 (1-4\% of loans and grants accepted). Average levels of $\mathrm{m}^{2}$ refurbished, size of loans and grants, and
} 
comparison with the KfW database on measures supported.

\section{Assessment}

\section{Effectiveness}

Impact on the market

Figure 6 gives an overview of the volumes of grants and loans over the period 2001-2010. It combines the numbers from the two programmes. The 2009 value comprises approvals for the " $\mathrm{CO}_{2}$ refurbishment of buildings" programme until March, as well as approvals from the "Energy efficient refurbishment" programme starting in April. The volume of approved grants and loans considerably increased during 2009 and 2010 due to additional funds made available in 2009 as part of the German stimulus package. KfW statistics show that the volume has declined in 2011.

The volume of loans disbursed between 2001 and 2010 amounted to over EUR 23.3 billion. The average size of loans between 2005 and 2010 was approximately EUR 80000 for the refurbishment of on average 4 housing units. The average size of loans rose steadily until 2008 (EUR 97000 ) but fell in 2009 and 2010 to around EUR 87000 and EUR 85000 respectively (calculated from Clausnitzer, et al., 2007-2010 and Diefenbach et al. 2011).

The proportion of overall investments to loan size is has been rising from 1.1 in 2008 to 1.39 in 2010. Much higher proportions can be found for the promotion of new low energy buildings, e.g. 3.91 in 2010 (Kuckshinrichs, et al., 2011).

Grants were introduced in 2007 and between 2007 and 2010 the approved amount rose to about EUR 228 million. Average grant sizes have steadily decreased over the years from EUR 5200 in 2007 to EUR 1700 in 2010 (calculated from Clausnitzer, et al., 2007-2010 and Diefenbach et al. 2011). In terms of volume the grant scheme is dwarfed by the much larger size of loans. 
Figure 6 - Volume of grants and loans 2001-2009

Page | 118

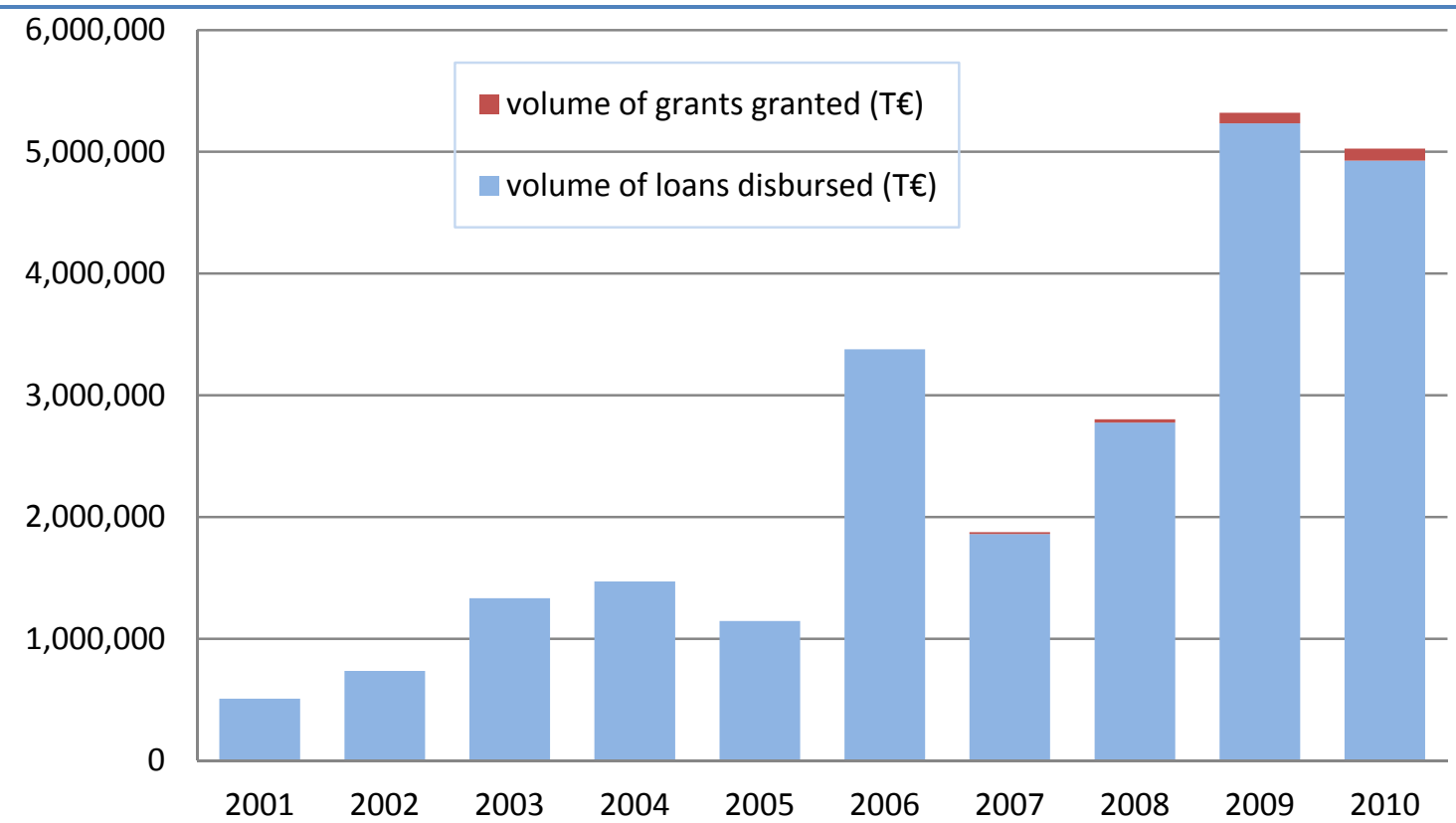

Note: for the programmes " $\mathrm{CO}_{2}$ refurbishment of buildings" (2001-2009) and "Energy efficient refurbishment" (2009-2010) Source: IEA analysis based on Kleemann et al., 2005, Clausnitzer, et al., 2007-2010 and Diefenbach, et al. 2011

Looking at the number of grants and loans approved the picture changes radically. Figure 7 combines the two programmes with a joint value for 2009, as in Figure 6. In terms of the applications approved, the grant programme has been growing rapidly since its introduction and the number of grants almost equaled the number of loans in 2010. Between 2005 and 2010 more than 250000 loans and about 116000 grants were approved. With about 18 million residential buildings in Germany (BBSR, 2011), about $2 \%$ of the residential building stock was refurbished using these $\mathrm{KfW}$ programmes during these years.

Figure 7 - Number of grants and loans 2005-2010

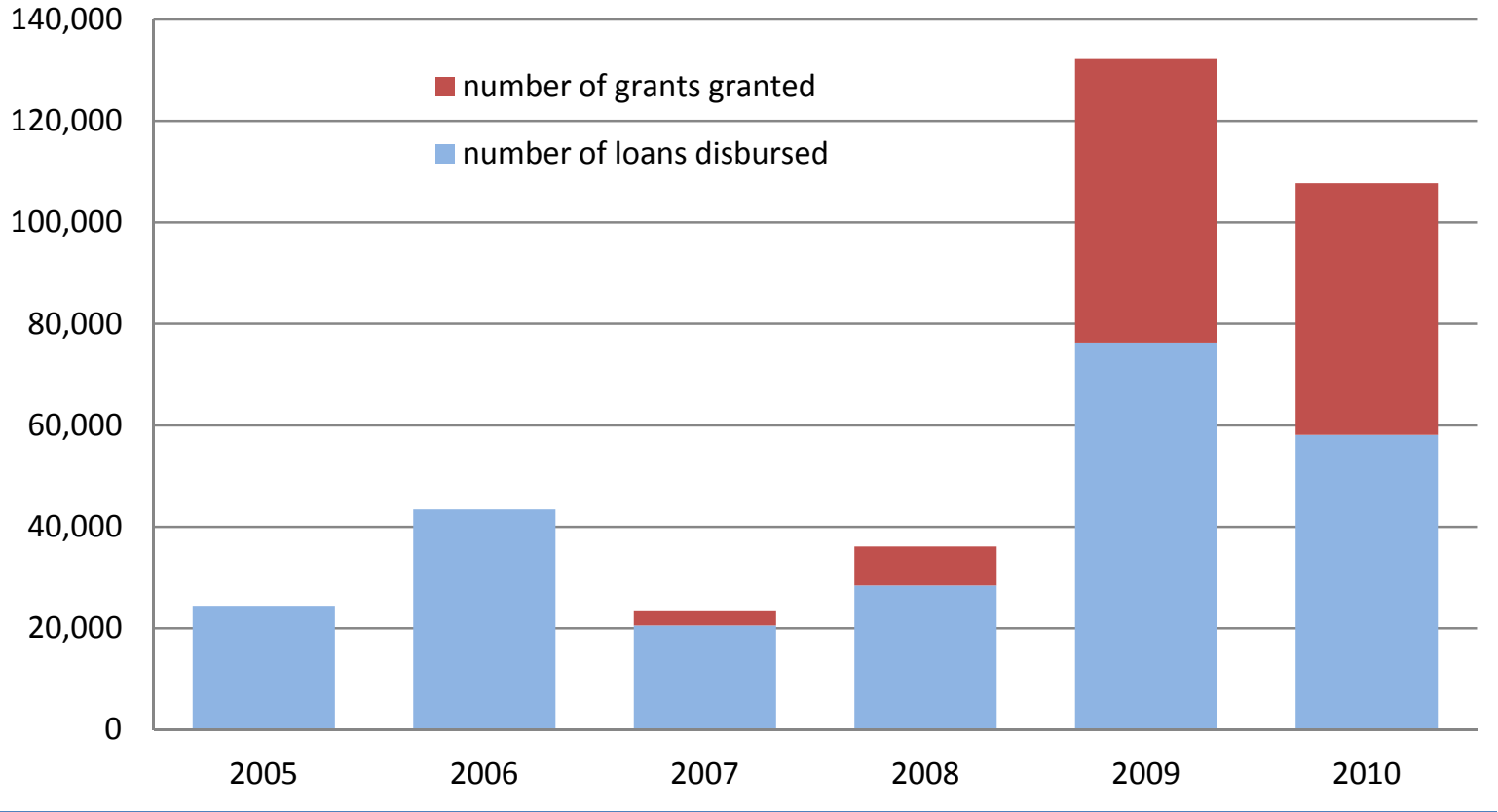

Note: for the programmes " $\mathrm{CO}_{2}$ refurbishment of buildings" (2005-2009) and "Energy efficient refurbishment" (2009-2010) Source: IEA analysis based on Clausnitzer, et al., 2007-2010 and Diefenbach, et al., 2011)

Buildings refurbished were mainly one-family homes: more than $95 \%$ of grants and more than 
75\% of loans were used for one-family homes (calculated from Clausnitzer, et al., 2008-2010).

Table 19 gives an overview of the measures undertaken as part of the two programmes. The numbers for 2009 in this table only reflect the programme "Energy efficient refurbishment". For the exchange of windows and the exchange of heating systems, numbers are not available for all years. The given percentages should only serve as an indication as they are based on survey results and where percentages are very low the risk of error is very high.

It can be seen that from 2009 on, the percentages of measures undertaken per building have declined sharply. From 2009 single measures were financed in order to enlarge the target groupp. This is in line with the new approach to allow refurbishments step by stepp. As has been noted above, the average loan size has been decreasing since 2009, thus also indicating that fewer measures are implemented per loan application. Looking at the sharp rise in the absolute number of grants and loans financed since 2009, this does not necessarily mean that overall less measures have been financed but that more buildings are being refurbished in a less comprehensive way.

Even though this approach thus seems to have achieved its aim of widening the target group, it is possible that some participants deferred undertaking more comprehensive retrofitting because of the availability of grants and the financing of single measures.

Table 19 - Measures undertaken in buildings participating in the programmes 2005-2010

\begin{tabular}{|c|c|c|c|c|c|c|}
\hline Roof/ last floor ceiling insulation & $67 \%$ & $76 \%$ & $88 \%$ & $89 \%$ & $45 \%$ & $45 \%$ \\
\hline Outer walls insulation & $60 \%$ & $66 \%$ & $82 \%$ & $86 \%$ & $35 \%$ & $35 \%$ \\
\hline Floor insulation & $47 \%$ & $49 \%$ & $64 \%$ & $64 \%$ & $16 \%$ & $16 \%$ \\
\hline Installation of ventilation system & $3 \%$ & $5 \%$ & $7 \%$ & $10 \%$ & $3 \%$ & $5 \%$ \\
\hline Exchange of heating systems & $\mathrm{n} / \mathrm{a}$ & $\mathrm{n} / \mathrm{a}$ & $\mathrm{n} / \mathrm{a}$ & $\mathrm{n} / \mathrm{a}$ & $\mathrm{n} / \mathrm{a}$ & $53 \%$ \\
\hline Installation of solar water heating & $29 \%$ & $29 \%$ & $27 \%$ & $34 \%$ & $18 \%$ & $17 \%$ \\
\hline $\begin{array}{l}\text { Absolute number of grants and loans } \\
\text { financed }\end{array}$ & $24.4 \mathrm{~T}$ & $43.5 \mathrm{~T}$ & $23.4 \mathrm{~T}$ & $36.1 \mathrm{~T}$ & $132.2 \mathrm{~T}$ & 107.7T \\
\hline
\end{tabular}

Note: for the programmes " $\mathrm{CO}_{2}$ refurbishment of buildings" (2005-2008) and "Energy efficient refurbishment" (2009-2010)

Source: IEA analysis based on Clausnitzer, et al., 2007-2010 and Diefenbach, et al., 2011)

Neuhoff et al. point out that even though the size of incentives that can be obtained is proportionate to the intensity of the retrofit undertaken, the majority of the participants opted for the lowest possible level of retrofit. In 2010 more than 8000 projects received financial support for measures leading to a KfW-EH 100 level of refurbishment compared to only 112 projects leading to a KfW-EH 55 level of refurbishment (Neuhoff, et al., 2011).

Despite the incentives already offered, the annual rate of EE refurbishments in Germany remains low at around 1\%. In 2010 the German government has affirmed plans to double this rate through a range of measures including a further development of these incentive schemes (BMWi/BMU, 2010).

\section{Energy savings}

The programmes were evaluated in terms of reduction of final energy demand and emission savings in terms of $\mathrm{CO}_{2}$ equivalents. The following numbers are rough estimations based on yearly surveys that describe the difference between before the refurbishment and after. Thus they include all measures implemented and not only those directly funded by the programmes (Clausnitzer, et al., 2010).

The total reduction in final energy demand in buildings participating in the refurbishment 
schemes (loan and grant programmes combined) has been estimated to be around $45 \%$ in 2007 and $48 \%$ in 2008. In 2009 and 2010 the estimated average decreased to $27 \%$ and $31 \%$ respectively, which very likely can also be explained by the introduction of incentives for single measures only. Averages for 2005 and 2006 are not available. (Clausnitzer, et al., 2007-2010 and Diefenbach et al., 2011) However, from Figure 8 it can be seen that total reduction in final energy demand has been rising in 2009 and is only little lower in 2010 reflecting the tendencies of an increase in the absolute number of loans and grants approved for less deep refurbishment.

Figure 8 - Reductions in final energy demand 2005-2010

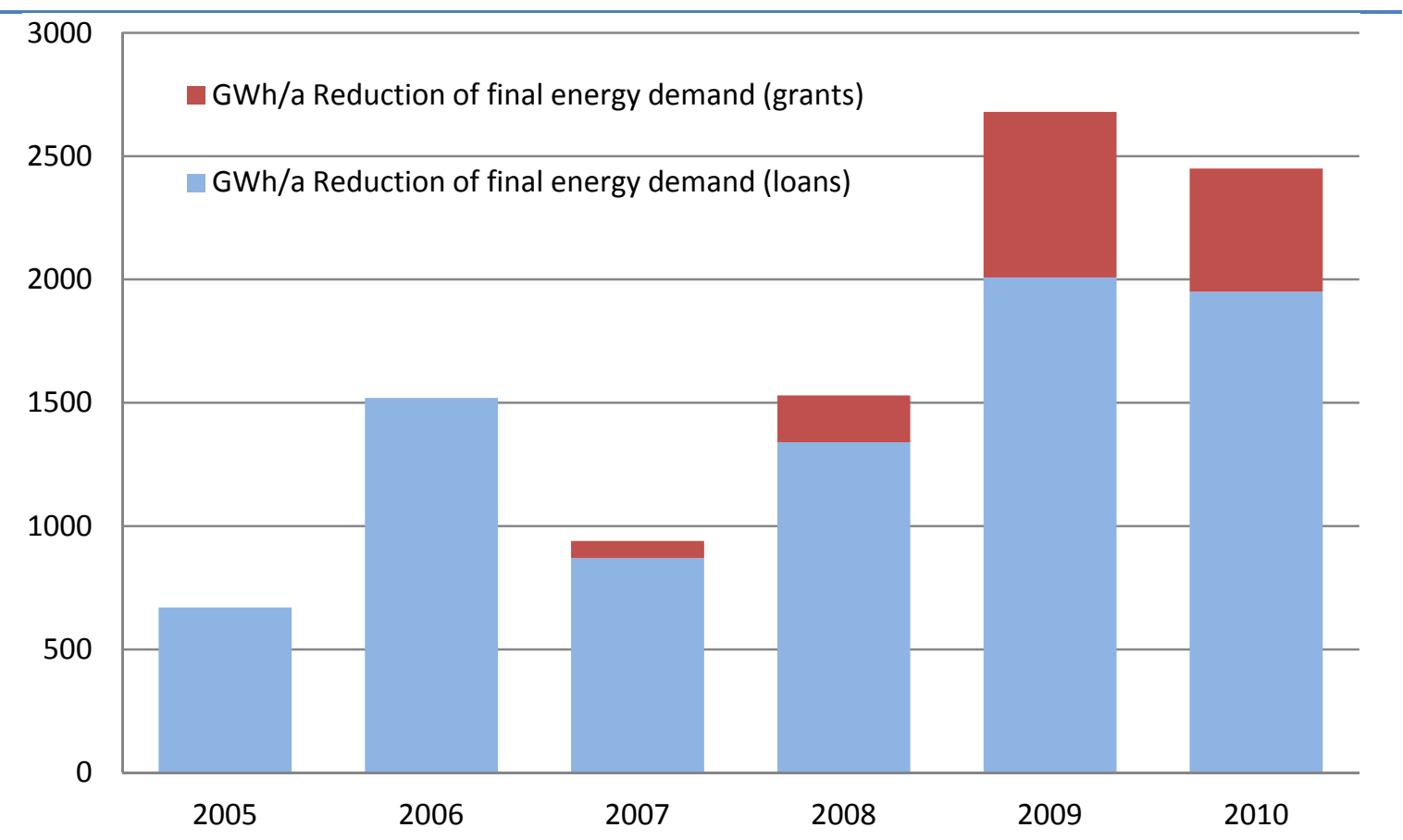

Note: for the programmes "CO2 refurbishment of buildings" and "Energy efficient refurbishment"

Source: IEA analysis based on Clausnitzer, et al., 2007-2010 and Diefenbach, et al., 2011

\section{Gross $\mathrm{CO}_{2} \mathrm{e}$ emission savings}

The estimated reduction in $\mathrm{CO}_{2} \mathrm{e}$ emission is slightly higher than the reduction in energy demand. $\mathrm{CO}_{2} \mathrm{e}$ emission calculations include not only emissions produced within the buildings but also those related to generation, transport and conversion of the energy source (Clausnitzer, et al., 2010). Average emission reductions achieved in participating buildings were $60 \%$ (2005 and 2006), $50 \%$ (2007), 56\% (2008), 33\% (2009), 37\% (2010). Again the sharp decline in $\mathrm{CO}_{2}$ emissions saved per building in the years 2009/2010 can be observed. Overall emission reduction during the years 2005 to 2010 cumulates to around 3.7 million tons of $\mathrm{CO}_{2}$ e (Clausnitzer, et al., 2007-2010 and Diefenbach, et al., 2011). 
Figure 9 • Avoided CO2 equivalent emissions cumulated 2005-2010

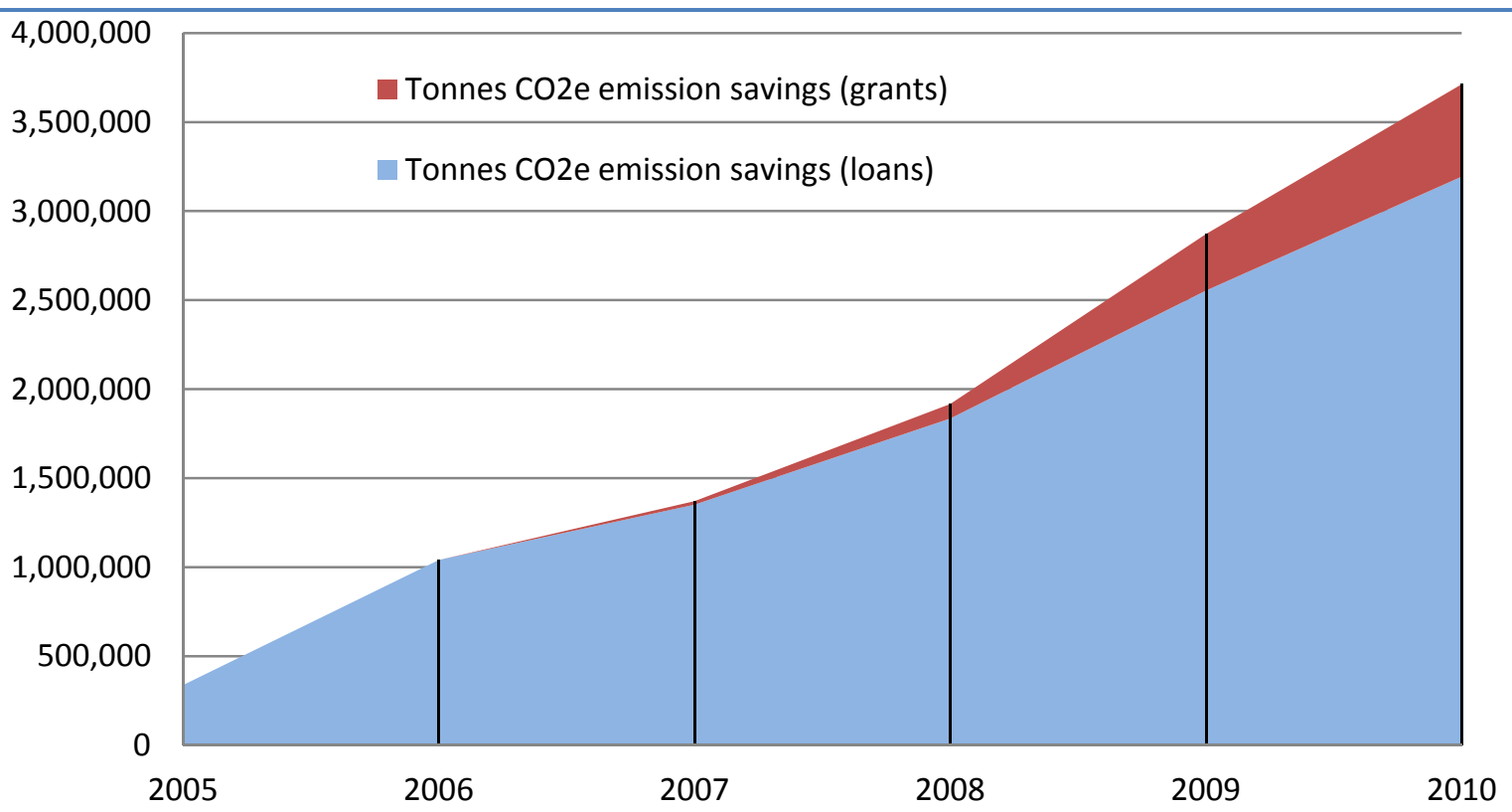

Note: for the programmes "CO2 refurbishment of buildings" and "Energy efficient refurbishment"

Source: IEA based on Clausnitzer, et al., 2007-2010 and Diefenbach, et al., 2011)

\section{Rebound effect}

There is no information available on the rebound effect attached to these programmes. General estimations of the rebound effect for efficiency gains in residential heating in Germany range between $12 \%$ and $49 \%$. The effect seems to be at the lower end of the range for building owners and at the higher end for low income tenants (Madlener and Hauertmann, 2011).

\section{Free-ridership}

No estimations of free-ridership are found in the available assessments of the programmes. However, Kuckshinrichs et al. discuss the issue and argue that as incentives were only given for refurbishment that led to an achievement of the stricter standards for new buildings, it is likely the free-riding was reduced. In support of this argument they cite assessments of refurbishment activities in Germany. These have shown that measures, which were implemented outside the $\mathrm{KfW}$ support schemes did not meet the KfW requirements (Kuckshinrichs, et al., 2011). General recommendations to reduce rebound effects frequently mention that incentives should be specifically given to innovative products and services with a low market share. Thus this argumentation seems valid as houses that do fulfil energy efficiency requirements for new buildings represent only a small market share in Germany. This is even more so as the standards are frequently tightened. Still, it must be assumed that there exists a certain amount of freeridership, even though it might be lower compared to less ambitious programmes.

Another argumentation put forward emphasises, that some of the participants, even though they would have been able to undertake the investment without the incentive, were only made aware of the opportunities of energy efficiency investments through the programme (Kuckshinrichs, et al., 2011) and therefore the awareness-raising and information effects of such programmes should not be underestimated. However, if this were the main barrier addressed by the programme, other policies are likely to be more cost-effective. 


\section{Economic efficiency}

\section{Public costs in relation to environmental impacts}

There are no separate figures available for the administrative costs of the discussed programmes. However, it can be assumed that the transaction costs have risen with the introduction of the grants programme, given the relatively small size of investments and the high number of applications to be treated (compare Figure 6 and Figure 7 above).

Aggregate data is available on overall programme costs and the ratio of total costs for the public budget to energy or emissions savings achieved can be estimated. Calculations assume for simplification purposes a life time of 30 years of investments made. Data includes also the programme costs and achievements in terms of final energy and $\mathrm{CO}_{2}$ emission reduction for the refurbishment of communal and social infrastructure buildings. ${ }^{119}$ Yet their share in the overall budget is very small (less than $2 \%$ ).

Table 20 gives an overview of rough estimations of the public-cost-to-savings relation for the years from 2008 until 2010. Final energy saved cost about EUR 0.02 per kWh of public funds through the programmes, with a slightly decreasing tendency. The public cost per tonne of $\mathrm{CO}_{2} \mathrm{e}$ emissions saved has been decreasing from EUR 57 in 2008 to EUR 41 in 2010. These estimations only analyse the public funds used to incentivise the investments made and not the cost effectiveness of the investments themselves.

Table 20 - Estimated ratio of public costs to energy and emission savings

\begin{tabular}{lccc}
\hline & 2008 & 2009 & 2010 \\
\hline Total cost of the programmes (million $€$ ) & 973 & 1608 & 1155 \\
\hline Total final energy savings achieved (GWh/year) & 1605 & 2789 & 2592 \\
\hline Public costs per kWh saved $(€), 30$ years life time & 0.020 & 0.019 & 946000 \\
\hline $\mathrm{CO}_{2} \mathrm{e}$ emission savings (tonnes/year) & 572000 & 995000 & 41 \\
\hline Public cost per tonne $\mathrm{CO}_{2} \mathrm{e}$ saved $(€), 30$ years life time & 57 & 54 & \\
\hline
\end{tabular}

Note: aggregated numbers for the programmes " $\mathrm{CO}_{2}$ refurbishment of buildings" and "Energy efficient refurbishment" including the "Special promotion energy efficient refurbishment" as well as KfW programmes for communal clients ${ }^{120}$.

Source: IEA calculations based on Kuckshinrichs, et al., 2011 with KfW adjustments; Diefenbach, et al., 2011 and Clausnitzer et al., 2011

The figures presented in Table 20 represent an average of investments in different energy efficiency measures; high costs per achieved savings can also be the result of ambitious savings targets that encourage the use of innovative methods and materials, which are more costly due to their small market shares.

The overall impacts of the programmes on the public budget are discussed below in a section below.

\section{Employment effects}

The construction industry in Germany had suffered from a major downturn for more than a

\footnotetext{
119 Namely the programmes „KfW-Kommunalkredit - Energetische Gebäudesanierung“, „Energieeffizient Sanieren Kommunen“ und "Sozial investieren - Energetische Gebäudesanierung"

${ }^{120}$ Namely: "communal credit EE refurbishments", "energy efficient refurbishment communes" and "Social investments EE refurbishments"
} 
decade. Studies show that the size of the industry was halved in terms of active companies as well as employees between 1995 and 2008. Thus job creation or at least saving jobs became a declared goal of the programme (Kuckshinrichs, et al., 2010). Since 2005 the employment in construction stabilised around 730000 jobs (Kuckshinrichs, et al., 2011).

Figure 10 shows employment effects with regard to the housing refurbishment programmes estimated using an input output analysis. For every million Euros invested the programmes are estimated to have saved/created employment between 13.4 and 18.3 person years or on average 16.4 person years (Clausnitzer, et al., 2007-2010 and Diefenbach, et al., 2011). The funds of the programme were massively increased in 2009 as part of the German economic stimulus package. With 111000 person years of work saved or created at its peak in 2009, it can be considered successful in preserving jobs during the economic crisis. There is no information provided on the duration of the jobs. However, not only the construction sector has benefited from this employment effect - it is estimated that only $55 \%$ of the employment effects from the $\mathrm{KfW}$ refurbishment and construction programmes can be attributed to the construction sector, while the rest benefits other related sectors (Kuckshinrichs, et al., 2011).

Figure 10 - Employment effects 2005-2010

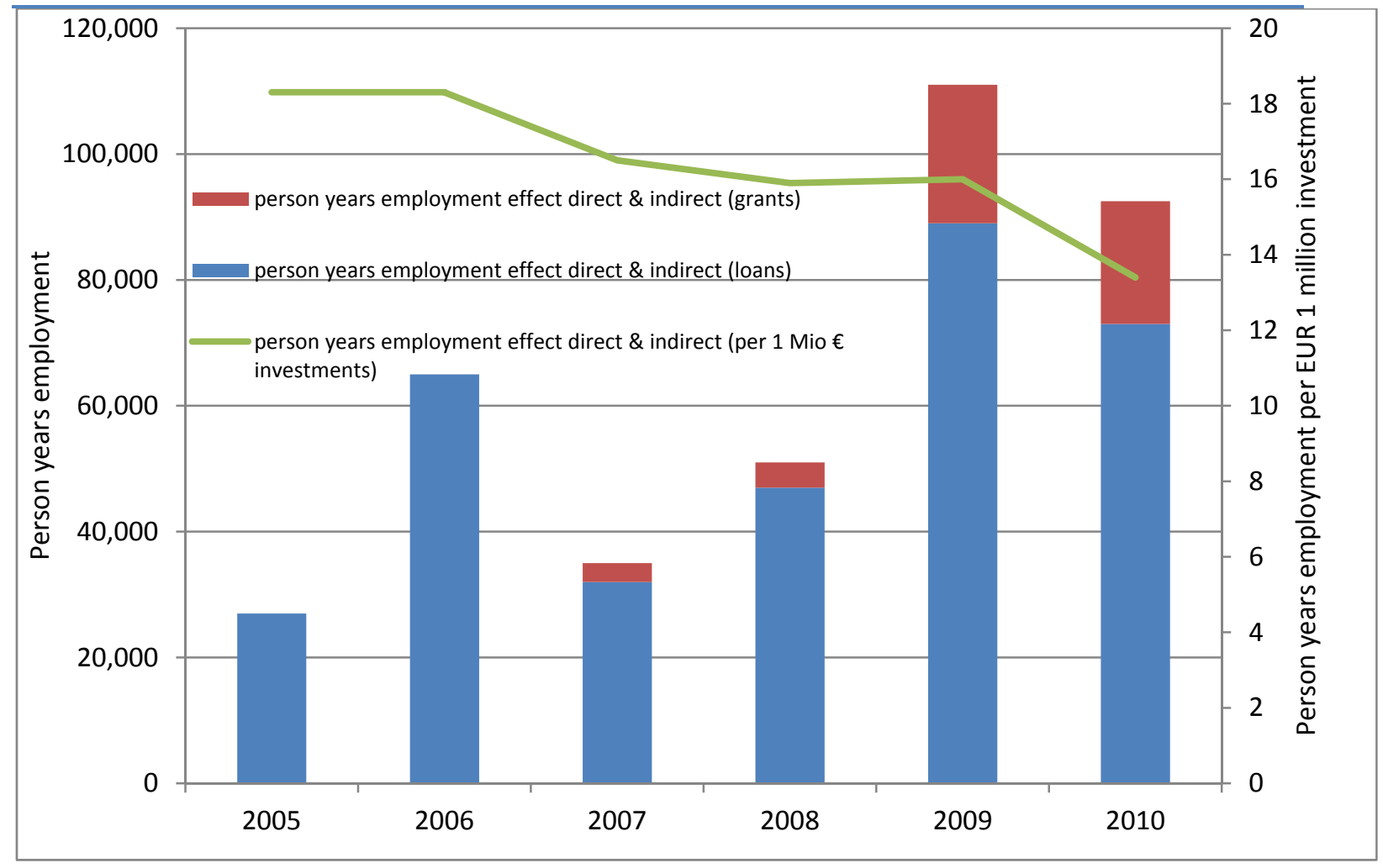

Note: for the programmes " $\mathrm{CO}_{2}$ refurbishment of buildings" and "Energy efficient refurbishment"

Source: IEA analysis based on Clausnitzer, et al., 2007-2010 and Diefenbach, et al., 2011)

\section{Public budget effects}

The public budget impacts of the " $\mathrm{CO}_{2}$ refurbishment of buildings" and the new construction programmes have been evaluated for the years between 2005 to 2010 (Kuckshinrichs et al., 2010, 2011). In both evaluations the incentives available communes and social institutions were analysed together with those for private households. Programme costs are those funds needed to finance grants and preferential loans.

Five types of public revenues that have been positively affected through the programmes were analysed:

- Value added tax (VAT) paid by investors 
- Taxes less subsidies on goods

- Other taxes on production less subsidies

- Wage tax, social security contributions, avoided costs of unemployment

- Taxes on property income or profits of corporations

The highest public incomes are generated via the employment effect. For each study two scenarios were calculated: (i) assuming that all person hours are worked through overtime in existing jobs, and (ii) assuming that they are covered entirely through job creation. The job creation scenario almost doubles the benefits to the public budget.

The second most important public revenue is created through the VAT payments, which are almost of a similar dimension as the employment effects in the overtime scenario. All other positive effects on public income are relatively small.

Results from both scenarios are summarised in Table 21 where it is clear that in both scenarios public revenues as a result of the programme activities are higher than programme costs.

Table 21 Total impact in millions of Euros according to the two employment scenarios

\begin{tabular}{c|c|c|c|c|c|c}
\hline & $\mathbf{2 0 0 5}$ & $\mathbf{2 0 0 6}$ & $\mathbf{2 0 0 7}$ & $\mathbf{2 0 0 8}$ & $\mathbf{2 0 0 9}$ & $\mathbf{2 0 1 0}$ \\
\hline Programme cost & 267 & 1014 & 637 & 1293 & 2035 & 1366 \\
$\begin{array}{c}\text { Net benefit: } \\
\text { scenario overtime }\end{array}$ & 292 & 343 & 222 & 1478 & 3326 & 3987 \\
$\begin{array}{c}\text { Net benefit: } \\
\text { scenario job creation }\end{array}$ & 490 & 838 & 444 & 2335 & 5126 & 5810 \\
\hline
\end{tabular}

Note: numbers for the years 2005-2007 comprise KfW programmes for refurbishment in the residential sector; numbers for the years 2008-2010 comprise KfW programmes for refurbishment and new construction in the residential and communal sector

Source: Kuckshinrichs, et al., 2010, 2011

The funds for the low interest loans and for grants come from the budget of the Federal Ministry of Transport, Buildings and Urban Development. However, a big part of the revenues generated by the programme go to sub-national levels thus generating a form of internal budget redistribution within the different administrative levels (Kuckshinrichs, et al., 2011).

\section{Policy interaction}

An important feature of the programmes is their linkage to EnEV standards for new buildings. Whenever the standards are tightened the requirements of the programmes follow automatically, thus ensuring finance of only the most ambitious measures that outperform the mainstream. Transition periods whenever the standards are tightened ensure smooth adjustment.

Key to the success of the programme is that $\mathrm{KfW}$ accompanies the programmes with a range of activities in the field of information and awareness-raising campaigns as well as technical assistance to the lending banks. Through its information campaigns the KfW Efficiency House has become established as a widely known and accepted brand for energy-efficient housing.

\section{Other interesting features (funding sources)}

The Kreditanstalt für Wiederaufbau (KfW) is a non-profit public bank that offers a number of incentive schemes with the aim of increasing energy efficiency in the housing sector, in small and medium enterprises and in communes and social institutions. The programmes are funded by the German government through federal budget allocations and the Energy and Climate fund, which is resourced through the auctioning of $\mathrm{CO}_{2}$ certificates in the framework of the $\mathrm{CO}_{2}$ cap and trading system. Thus the resources available to the $\mathrm{KfW}$ programmes are dependent on the 
revenues raised through this system and political decisions to top up the available funds with money from the federal budget. The government decision to use part of stimulus funds for these programmes has significantly increased the available budgets in 2009 and 2010. This means however, that the funding is dependent on federal budget decision making. The $\mathrm{KfW}$ adjusts the interest rate of its loans to the amount of funds available. If fewer funds are available, then the interest rates for loans given out rise. Changing interest rates create uncertainty and can be a disincentive to potential investors, who might be tempted to postpone investments hoping for lower interest rates in the future.

\section{Discussion}

The $\mathrm{KfW}$ programmes can be considered successful in terms of public budget spending as, according to the evaluations they have not only achieved significant energy demand and $\mathrm{CO}_{2} \mathrm{e}$ emission reductions but have also led to net benefits to the public budget. With its strict efficiency requirements which are based on the overall energy performance, the programmes promote the uptake of the most efficiency technologies available.

Very positive is also the linkage of the programme requirements to the requirements of the building energy code EnEV. If the building energy code is tightened, these changes automatically affect the programmes eligibility requirements as they are formulated as a percentage improvement relative to the building energy code requirements. Both characteristics allow for stable programme conditions that need little updating and ensure at the same time the promotion of the most efficient technologies and measures available on the market. Also in terms of supporting jobs within the construction sector and beyond, at least in the short term, the programme has had a very positive impact.

Some uncertainties remain with regard to long term savings and rebound effects. Ex post evaluations are important to verify if planned energy and emission savings have been achieved in reality and if they are achieved permanently. Yet, in order to provide reliable conclusions, the collection of the data needed is likely to be time and resource consuming, especially when it has not been planned at the design stage of the programmes.

Refurbishment rates in Germany (1\%) remain far below the necessary level to achieve the energy efficiency goals set by the government. Further action is thus needed to step up the renovation rates. Another critical point is the unstable funding situation of the programme which is highly dependent on yearly budget decisions of the government.

Even though not part of the evaluations, it can be assumed that the programmes do help familiarising local banks with energy efficiency lending. Future potential research questions include an evaluation of whether the programmes high quality requirements have generated sufficient demand for highly efficient materials and construction methods to encourage further research and innovation activities in the sector.

The $\mathrm{KfW}$ represents an example of good practice in terms of regular and publicly available evaluations of its energy efficiency refurbishment programmes. Even though not all aspects are covered and ex post verification is lacking, this is an important step in the right direction to be able to better design economic instruments for deep retrofit of buildings. 


\section{Italy: tax incentives and white certificates}

\section{Context}

Compared to other IEA member countries and major economies, Italy's energy intensity has traditionally been low. Italy's final energy consumption per capita is 2.4 toe/capita compared with the EU average of 2.7 toe/capita (ENEA, 2011a). The consumption trend in the end-use sectors shows a $6.6 \%$ increase in 2001-2005 and a $6.2 \%$ decrease in 2006-2010, with a mean annual decrease rate of $c a .1 .25 \%$, (ENEA, 2011a). Along with the severe consumption contraction in the industrial sector, such decrease stems from the economic crisis and the effects of measures aimed at promoting and incentivising energy efficiency, but also from a slight consumption decrease in transports, which offsets the consumption increase in the residential and tertiary sector.

Final energy use in 2010 was 137.5 Mtoe (3.6\% higher than 2009). The distribution of energy uses among various sectors shows that the residential and tertiary sector is responsible for the largest share of $35 \%$ of energy use (which also demonstrates a strong increase from $30.8 \%$ in 2004), (ENEA, 2011b).

While the potential for energy efficiency improvements is high in the residential and tertiary sector, energy consumption per capita showed only a 2.6\% decrease over the period 2000-2009, well below the corresponding variation for EU27 (-11.7\%) and in comparable EU countries, e.g. almost $15 \%$ in France and $16 \%$ in the United Kingdom (ENEA 2011b).

Italy adopted a strong National Energy Efficiency Action Plan (NEEAP) in 2007, setting an overall energy efficiency target of $9.6 \%$ improvement by 2016 (126,327 GWh/pp. a.). The 2010 NEEAP evaluation found that the intermediary energy-savings target (3\% by 2010) has been surpassed (4.3\%), in part because of policies implemented in the buildings sector (see Table 22). These policies include the implementation of the EPBD Directive (2002/91/EC), a White Certificate scheme, a tax deduction for building renovations that improve the energy performance in residential buildings, and other instruments.

Table 22 - Annual energy savings achieved in 2010 compared to targets for 2010 and 2016

\begin{tabular}{|c|c|c|c|c|c|}
\hline Measures & $\begin{array}{c}\text { Annual } \\
\text { savings } \\
\text { achieved } \\
\text { through } \\
\text { measures } \\
\text { under the } \\
\text { EEAP 2007 } \\
\text { (net of } \\
\text { duplication) }\end{array}$ & $\begin{array}{l}\text { Annual savings } \\
\text { of non-EEAP } \\
2007 \text { measures }\end{array}$ & $\begin{array}{c}\text { Total annual } \\
\text { savings } \\
\text { achieved in } \\
2010\end{array}$ & $\begin{array}{c}\text { Annual } \\
\text { energy } \\
\text { savings } \\
\text { expected for } \\
2010 \\
\text { (EEAP 2007) }\end{array}$ & $\begin{array}{c}\text { Annual } \\
\text { energy } \\
\text { savings } \\
\text { expected for } \\
2016 \\
\text { (EEAP 2007) }\end{array}$ \\
\hline Total residential sector & 25359 & 6068 & 31427 & 16998 & 56830 \\
\hline Total service sector & 653 & 4389 & 5042 & 8130 & 24700 \\
\hline Total industrial sector & 3350 & 4920 & 8270 & 7040 & 21537 \\
\hline Total transport sector & 2972 & - & 2972 & 3490 & 23260 \\
\hline
\end{tabular}

Note: savings in GWh/pp. a.

Source: ENEA, 2011b

Institutional support to oversee and assist with implementation has been provided through the national agency ENEA (see Box 22). Having a designated agency to oversee policy implementation is an important prerequisite for effective implementation and timely evaluation of policy instruments, their update on the ground and effects on energy consumption. 
Pursuant to Legislative Decree no. 115 of 30th May, 2008, ENEA functions as National Agency for Energy Efficiency. Its main tasks are to provide:

- $\quad$ support to the Ministry for Economic Development (MSE) and Regions to ensure that the above Decree is implemented;

- support to MSE to draw up National Action Plans for Energy efficiency and the Annual Report on Energy Efficiency;

- technical and scientific support and consultancy services to the State, regions and local bodies to allow them to provide the necessary measures in order to achieve the national energy saving objectives;

- methods to measure and verify energy saving;

- information to citizens, public administrations, enterprises and economic operators with regard to energy saving instruments and the mechanisms as well as the financial and judicial situation necessary for energy efficiency diffusion and promotion.

\section{Buildings energy efficiency policies}

The reference law for energy efficiency in the building sector is the legislative decree n. 192 of 19 August 2005 that was developed to comply with the EU directive 2002/91/EC. This decree introduced standards, conditions and modalities to improve the energy performance of buildings. It has been further reviewed and improved through the introduction of the legislative decree $n$. 311 of 29th December 2006 that introduced new rules to stimulate the diffusion of renewable energy sources for the building sector (Glorioso et al., 2007).

In addition, an energy performance certificate (EPC) is mandatory when a building or flat is sold. Since 2012, EPCs are also to be provided when a building or flat is rented. The NEEAP is developing policies to promote passive-energy houses (PEH) and zero-energy buildings (ZEB). However, these building performances are not yet specifically required and no target for the market share of construction of these building types has been set, except a goal set by the government for all new public buildings to be of zero energy consumption by 2020 .

The Ministry of Economic development is preparing provisions that would establish, inter alia (ENEA, 2011a):

- definition of "nearly zero energy buildings" for each type of building, in relation to specific parameters (climatic environment, socio-economic context) expressed in $\mathrm{kWh} / \mathrm{m}^{2} \mathrm{pp}$. a.;

- gradual introduction of the minimum requirements through to 2020, 2018 for public buildings, bearing in mind the different types of buildings, with the specification of intermediate energy efficiency limits at least until 2015;

- reinforcement of their guiding role in the public sector through refurbishments in the direction of "nearly zero energy buildings";

- definition of an information framework on the financial measures to support the achieving of the goal of "nearly zero energy buildings", and on measures relating to the use of renewable sources in new constructions and existing buildings (only if undergoing major refurbishment);

- reinforcement of the role of the energy performance certification of buildings.

The Italian government is also in the process of developing a new legislative decree that would target energy efficiency improvements in the public sector as a priority. It is expected to be launched in 2012 and to be implemented mostly with the involvement of ESCOs. Implementation of policies for existing buildings is sometimes hampered by the lack of comprehensive information on the entire building stock, including different type of use, different size of buildings, different 
ages. Systematic information on insulation levels, types of windows, heating, ventilation, and airconditioning (HVAC) systems is also missing.

The following sub-sections focus on the two economic instruments that target energy efficiency improvements in the Italian buildings sector: white certificates and tax deductions.

\section{White certificates}

White certificates have been introduced by the two Law Decrees "20th July 2004" and represent the main tool to promote energy efficiency measures in Italy. Each white certificate (WhC) represents a saving of 1 tonne of oil equivalent (toe) achieved through the implementation of specific projects. WhCs are issued by the Italian Manager of the Electric Market (GME) on the basis of the energy savings certified by the Italian Authority of Gas and Electricity (AEEG). In the third period from 2013 to 2016, the system will be managed by the Manager of Energy Systems (the same body that currently oversees connection and performance of renewable energy sources).

The functioning of this mechanism is based on an energy saving obligation to electricity and gas distributors with more than 50000 clients (according to the amendment of 2007), to achieve annual fixed objectives of energy saving. The obligation is placed on 10 electricity distributors and 20 gas distributors. Further decrees will probably extend the application of the provisions of these Decrees to distributors with less than 50000 clients for the period 2013-2016. The annual energy saving objectives increase year by year and are achieved through the implementation of specific projects with end-users who benefit directly from the resulting reduced energy expenditures.

Eligible projects are:

- rephasing of electric systems;

- electric motors and their applications;

- lighting systems;

- reduction of electricity leaking;

- switching from electricity to other fuels or vice versa when this produces primary energy savings;

- reduction of electricity consumption for heating purposes and air conditioning;

- high efficiency electric appliances and office equipment;

- reduction of primary energy consumption for heating, ventilation and air conditioning systems;

- promotion of end-use technologies fuelled by renewable sources;

- electric and gas-fuelled vehicles;

- information campaigns to raise awareness and promote energy savings.

When a distributor does not satisfy its annual obligation through the implementation of projects, he can buy white certificates generated by interventions implemented by other operators.

The aim of the Law Decrees is to achieve by the end of the five-year 2005-2009 period a total energy saving of 2.9 million toe, representing the energy consumption annual increase registered in the period 1999-2001. Projects have to contribute to the achievement of cumulative targets within 5 years. For some specific projects (buildings thermal envelope, bioclimatic design, reduction of cooling needs, etc.), the time limit for delivering results is raised up to eight years. 
Table 23 - Cumulative Targets for the Italian White Certificate System (Mtoe/year)

\begin{tabular}{lll}
\hline Year & Electricity distributors & Gas distributors \\
\hline 2005 & 0.1 & 0.1 \\
2006 & 0.2 & 0.2 \\
2007 & 0.4 & 0.4 \\
2008 & 1.2 & 1.0 \\
2009 & 1.8 & 1.4 \\
2010 & 2.4 & 1.9 \\
2011 & 3.1 & 2.2 \\
\hline 212 & 3.5 & 2.5 \\
\hline
\end{tabular}

Source: ENEA, 2011

\section{Assessment}

\section{Effectiveness}

In the early stages of the programme, providers installed compact fluorescent light bulbs and paid for the installations themselves as it was an economical way to gain the necessary white certificates. Distributors implemented other energy saving measures through contracting Energy Service Companies (ESCOs). ESCOs usually provide finance and receive compensation equals to the rate of the saved electricity and gas supply. The compensation covers the running cost and the cost of investment given that less energy is consumed. ESCOs also accept long-term pay back periods.

2005 was the first year of application of the White Certificates mechanism. The 2005 energy saving objective was 152000 toe, while the certified achieved result was about 287000 toe. This result is the consequence of projects implemented in the period from 2001 to 2005 . Almost $75 \%$ of these projects were devoted to reducing electrical consumption; $22 \%$ reduced natural gas consumption; $3 \%$ reduced energy consumption from other sources. The total energy saved in 2005 is equivalent to the annual electrical production of a $160 \mathrm{MW}$ power plant. The total $\mathrm{CO}_{2} \mathrm{e}$ avoided emissions were more than 750000 tons. During 2005, 13898 white certificates were traded, representing $9 \%$ of the overall 2005 objective.

By July 2008 further effects were evident: ${ }^{121}$

- Many ESCOs have become active in implementing projects; ${ }^{122}$

- Over 3200 projects had been implemented;

- 2.0 Mtoe of energy saving achieved (with respect to the 2008 cumulative target of 2.2 Mtoe);

- Over 5.5 million tons of carbon dioxide emissions were avoided;

- Benefit for end users significantly outweighed the tariff contribution (in a ratio of roughly 1 to 8 ).

\footnotetext{
${ }^{121}$ According to the presentation on white certificates in Italy by Rino Romani and Walter Cariani in Sofia on October 29, 2008

${ }^{122}$ There are between 100 and 150 ESCOs active in Italy, of which about two thirds are small companies that were established within the last four years; only 9 ESCOs are large companies (ENEA, 2011a).
} 
Table 24 - Energy savings achieved through White Certificates by 30 September 2010

\begin{tabular}{|c|c|c|}
\hline Standard/analytical schedules & EEAP reference & $\begin{array}{c}\text { Energy } \\
\text { saving } \\
\text { (FEC) } \\
\text { [GWh pp. } \\
\text { a.] }\end{array}$ \\
\hline Compact fluorescent bulbs (up to $31 / 07 / 08$ ) excluding purchase vouchers & RES-2 & 7405 \\
\hline Compact fluorescent bulbs (from 01/08/08 to $31 / 01 / 10$ ) & RES-2 & 43 \\
\hline $\begin{array}{l}\text { Residential installation of high quality compact fluorescent bulbs with } \\
\text { incorporated ballast (from 01/02/2010) }\end{array}$ & RES-2 & 39 \\
\hline $\begin{array}{l}\text { Installation of } 4 \text { star efficiency single family natural gas-fired central } \\
\text { heating boilers with a normal thermal power not above } 35 \mathrm{~kW}\end{array}$ & RES-8 & 100 \\
\hline Replacement of single glazing with double glazing & RES-1 & 46 \\
\hline $\begin{array}{l}\text { Use of solar panels for production of domestic hot water (up to } \\
31.01 .2010 \text { ) }\end{array}$ & RES-6 & 428 \\
\hline $\begin{array}{l}\text { Replacement of domestic electrical appliances with similar Class A } \\
\text { products (up to } 31 / 07 / 2008 \text { ) }\end{array}$ & RES 3-4-5 & 105 \\
\hline $\begin{array}{l}\text { Installation of low flow-rate shower heads in residential buildings (up to } \\
31 / 07 / 2008 \text { ) excluding purchase vouchers }\end{array}$ & RES-11 & 4341 \\
\hline Water saving kits in residential buildings (from 01/08/2008 to 31/01/2010) & RES-11 & 73 \\
\hline $\begin{array}{l}\text { Installation of low flow-rate shower heads in hotels and guest houses (up } \\
\text { to } 31 / 011 / 2010 \text { ) }\end{array}$ & TER-5 & 55 \\
\hline $\begin{array}{l}\text { Installation of low flow-rate shower heads in sports facilities (up to } \\
31 / 01 / 2010 \text { ) }\end{array}$ & TER-5 & 330 \\
\hline Installation of aerators for taps in residential buildings (up to $31 / 07 / 2008$ ) & RES-11 & 1464 \\
\hline $\begin{array}{l}\text { Replacement of mercury vapour bulbs with high pressure sodium vapour } \\
\text { bulbs in public lighting installations }\end{array}$ & TER-4 & 141 \\
\hline Replacement of incandescent traffic lights with LED traffic lights & TER-4 & 141 \\
\hline $\begin{array}{l}\text { Installation of centralised HVAC systems in residential and commercial } \\
\text { buildings }\end{array}$ & RES-8 & 46 \\
\hline Other measures & & 124 \\
\hline Total & & 14881 \\
\hline
\end{tabular}

Source: ENEA, 2011a

Table 24 shows that the majority of savings were achieved through installation of compact fluorescent bulbs (around 50\% of all savings achieved by the white certificate scheme in this time period). Another large share of savings is attributed to installation of low flow-rate shower heads in residential buildings. It is interesting to note that the white certificate scheme so far has promoted a very limited action on measures related to the building envelope (only around 60 GWh pp. a. of savings out of $14881 \mathrm{GWh}$ pp. a. could be attributed to actions related to building envelope), which is explained by cost-effectiveness and short payback period of other measures.

\section{Economic efficiency}

Included in the final discussion.

\section{Policy interaction}

The white certificate scheme is considered to be successful in achieving the set targets on energy efficiency improvements. According to the analysis by ENEA of the effectiveness of energy efficiency policies, in 2007-2010 over $82 \%$ of the total savings obtained are as a result of measures in compliance with the two policy instruments - Legislative Decree 192/05 on minimum energy performance standards in buildings, and the white certificates scheme. Both instruments contributed almost equally to the overall energy savings achieved in the period.

The white certificate scheme in Italy is operated simultaneously with a national scheme granting $55 \%$ tax deduction (discussed later in the paper) when energy efficiency refurbishments are 
undertaken and with many regional incentives. The ENEA identifies a potential problem of double counting and suggests compartmentalisation of incentive measures as much as possible. Some assessment studies suggest that most of the measures related to building envelope and replacement of heating systems in the residential sector are implemented due to the incentives provided by the tax credit. ${ }^{123}$

It is also interesting to note that the White certificates scheme as well as the national tax crediting scheme are implemented as supplementary policy measures to the EU ETS that covers power plants and thus any emissions coming from large electricity and heat producers. However, it is known to policy makers that market and non-market barriers and imperfections create obstacles for the carbon price in reaching cost-effective emission reduction opportunities. It is also known that there are many such barriers in the residential and service sectors, and many cost-effective energy efficiency measures are not implemented despite the presence of a carbon price. Thus, the supplemental policies, such as white certificates and tax credits, deliver some of the required abatement under the cap and reduce the abatement needed in response to the price signal.

It may be useful to assess the costs and benefits of these policies and their interactions with the carbon pricing mechanism. However, given the known and documented difficulties in tapping energy efficiency potential in the buildings sector, these policies can be justified due to their ability to improve cost-effectiveness of the whole policy package. If supplementary policies overor under-deliver on their expected level of emissions reduction, the abatement required from the ETS can be significantly higher or lower, leading to added uncertainty in carbon prices (Hood, C, 2011).

\section{Tax support schemes}

\section{Description of policy}

Energy saving in Italy is supported through specific fiscal and administrative measures, generally introduced each year with the Financial Law, such as:

- Tax credits: deduction from income taxes of a certain \% of total cost of the interventions

- Reduced taxation (such as VAT) for clean technology equipments and systems

- Reduction/ rationalization of administrative procedures and costs.

This section examines the $55 \%$ tax credits for energy efficiency improvement measures in the residential sector. In Italy, tax incentives for energy efficiency improvements to existing buildings have been in place since 2007. The income tax credit of $55 \%$ of energy efficiency improvement costs is distributed over ten years (before 2011 - five years). The programme provides tax credits to households for comprehensive or single retrofit measures, such as thermal insulation, installation of solar panels, if they reduce annual energy demand for heating to levels at least 20 $\%$ lower than the current overall building performance standards, also for replacement of heating and air-conditioning systems with certified efficient models, or for comprehensive retrofit work (see the table below). The tax credit covers $55 \%$ of the energy-related cost, but cannot exceed a maximum value that depends on the type of measure taken (see Table 25). In order to apply for a tax credit, building owners must submit an application that contains a description of the work performed, confirmation documents for payments, and performance certificates (online or via post) within 90 days of the work's completion. All applications are collected and managed by ENEA - the national agency responsible for the implementation of the tax incentives program (see Box 22). After approval of retrofit costs by ENEA, building owners can submit their claims for tax credits to the tax authority. The total deductable amount is then distributed over a period of ten years.

\footnotetext{
${ }^{123}$ Personal communication with Paolo Bertoldi (Joint Research Centre of the European Commission) in August 2012.
} 
In order to apply for a tax credit, building owners must submit an application that contains a description of the work performed, confirmation documents for payments, and performance certificates (online or via post) within 90 days of the work's completion. All applications are collected and managed by ENEA - the national agency responsible for the implementation of the tax incentives program (see Box 22). After approval of retrofit costs by ENEA, building owners can submit their claims for tax credits to the tax authority. The total deductable amount is then distributed over a period of ten years.

Table 25 - Measures supported and level of tax credits in Italy

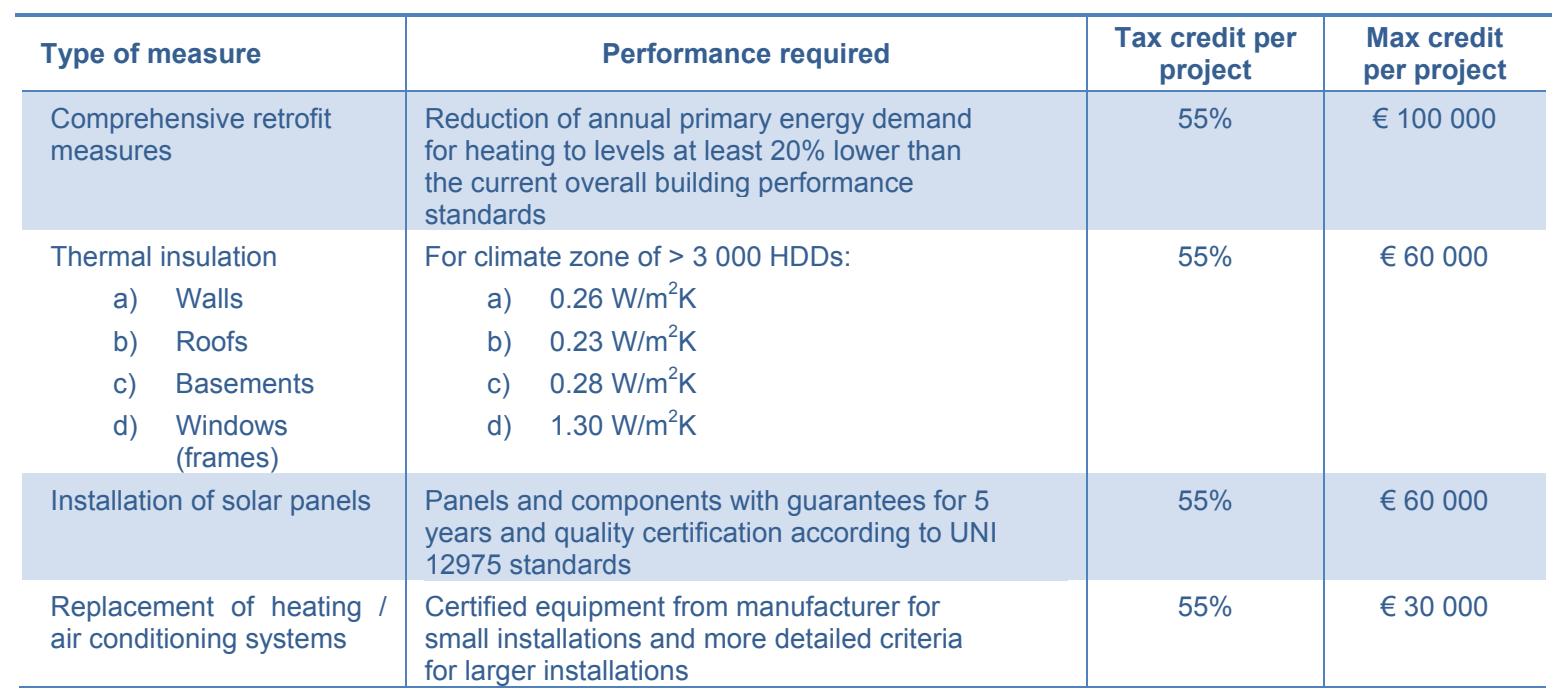

Source: ENEA 2011a

\section{Effectiveness}

In 2009, building owners submitted 240,000 tax credit applications. As the programme was originally expected to be terminated in 2010, the number of applications in 2010 exceeded the previous year by around $70 \%$ (exact figure not yet available). Since then, the programme has been extended annually and it is not clear from year to year whether and at what scale it will continue. Table 26 summarises the main performance indicators of the Italian tax credit programme in 2009.

Table 26 - Claims and investment supported by the Italian tax credits, 2009

\begin{tabular}{|c|c|c|c|c|c|}
\hline \multicolumn{2}{|c|}{ Type of measure } & $\begin{array}{l}\text { Number of } \\
\text { applications } \\
\text { accepted }\end{array}$ & $\begin{array}{l}\text { Average energy } \\
\text { savings (kWh) }\end{array}$ & $\begin{array}{c}\text { Average cost } \\
\text { per kWh saved } \\
(€)\end{array}$ & $\begin{array}{c}\text { Total } \\
\text { investment } \\
\text { (Mio. } €)\end{array}$ \\
\hline \multicolumn{2}{|c|}{$\begin{array}{l}\text { Comprehensive retrofit } \\
\text { measures }\end{array}$} & 5622 & 21538 & 0.04 & $106(3 \%)$ \\
\hline \multicolumn{6}{|c|}{ Thermal insulation } \\
\hline a) & Walls & 5377 & 8025 & 0.14 & $125(3 \%)$ \\
\hline \multirow{2}{*}{ b) } & $\begin{array}{l}\text { Floors } \\
\text { roofs }\end{array}$ & 9838 & 16115 & 0.15 & $360(10 \%)$ \\
\hline & \multicolumn{4}{|c|}{ c) Windows } & $1516(42 \%)$ \\
\hline \multicolumn{2}{|c|}{$\begin{array}{l}\text { Installation } \\
\text { panels }\end{array}$} & 35248 & 6960 & 0.07 & $339(9 \%)$ \\
\hline \multicolumn{2}{|c|}{$\begin{array}{l}\text { Replacement of heating / } \\
\text { air conditioning systems }\end{array}$} & 68056 & 9164 & 0.15 & $1171(32 \%)$ \\
\hline
\end{tabular}

ENEA estimates a lasting energy saving of about $6500 \mathrm{Gwh} /$ year. Table 27 shows details of the $55 \%$ tax deduction programme implementation carried out by 31 December 2010. 
Table 27 - Performance indicators of the $55 \%$ tax deduction programme

\begin{tabular}{|c|c|c|c|}
\hline Type of work & $\begin{array}{l}\text { Current maximum } \\
\text { allowable deduction } \\
\text { expense (Euros) }\end{array}$ & $\begin{array}{l}\text { Estimated number } \\
\text { of works carried out } \\
\text { by } 31.12 .2010\end{array}$ & $\begin{array}{l}\text { Average annual } \\
\text { saving by type of } \\
\text { work } \\
\text { MWh/yr. }\end{array}$ \\
\hline Insulation of walls, floors and roofs & 60000 & 50000 & 12 \\
\hline Replacement of windows & 60000 & 470000 & 2.5 \\
\hline $\begin{array}{l}\text { Replacement of heating plant with } \\
\text { condensing boilers, heat pumps or } \\
\text { geothermal plants }\end{array}$ & 30000 & 300000 & 10 \\
\hline Installation of solar heating panels & 60000 & 160000 & 7 \\
\hline $\begin{array}{l}\text { Comprehensive works carried out on } \\
\text { buildings }\end{array}$ & 100000 & 20000 & 20 \\
\hline
\end{tabular}

Source: ENEA, 2011a

\section{Economic efficiency}

As Table 26 shows, the cost per kWh saved varies widely and ranges between EUR 0.03 (for comprehensive retrofit measures) and EUR 0.25 (for window replacement). These evaluations point out that comprehensive retrofit (i.e. the implementation of a package of several measures) is more cost-efficient than single measures.

In general, the distribution of investments is not uniform across different measures. Despite the high energy saving potentials, higher absolute support values, and lower average cost of comprehensive retrofits compared to many single measures, their share of investments was only $3 \%$ in 2009 . Households instead pursued mainly single measures, such as window retrofits (42\%), the replacement of heating systems (32\%), and the insulation of walls and floors (13\%). The low demand for comprehensive retrofit can be partially explained by the greater complexity of such measures as well as by insufficient incentives. The support for comprehensive and single measures is the same, so there is no additional incentive to pursue higher levels of efficiency. At the same time, comprehensive retrofit performance criteria are more stringent than those of single measures. As a result, these tax incentives as currently designed are unlikely to lead to a significant increase in the comprehensive thermal retrofit rate.

The analysis by ENEA of results of the 55\% tax deduction scheme shows that in 2007-2009 an overall energy saving value of $4250 \mathrm{GWh}$ was achieved at a total cost of EUR 7520 million. In 2009, total investment in buildings retrofit supported by the programme constituted more than EUR 2.6 billion, primarily in the residential sector (96\%). New estimates in 2010 show that between 2007 and 2010 the total number of works carried out was about 100000 and overall investment exceeded EUR 11 billion. The total value of the tax credits was about EUR 6 billion to be spread over the period 2008-2015.

There are no estimates on the free-rider rates for this incentive

\section{Discussion}

The effectiveness of the main national instruments to improve energy efficiency has been assessed by calculating their contribution to the achievement of the 2010 intermediate target (35 $658 \mathrm{GWh} /$ year) laid down in EEAP 2007. The various instruments' effectiveness - expressed as a ratio between the saving value derived from each improvement measure and the value of the 2010 intermediate target - is shown in Figure 11. It shows that White Certificates (EEC) and energy performance standards for new and refurbished buildings set by the EPBD Directive (2002/91/EC) give the highest contribution in terms of saved energy. In 2010, $47711 \mathrm{GWh} /$ year. of energy savings were achieved in total; which considerably exceeds the target (35 658 GWh/year). 
Figure 11 Percentage effectiveness of energy efficiency measures

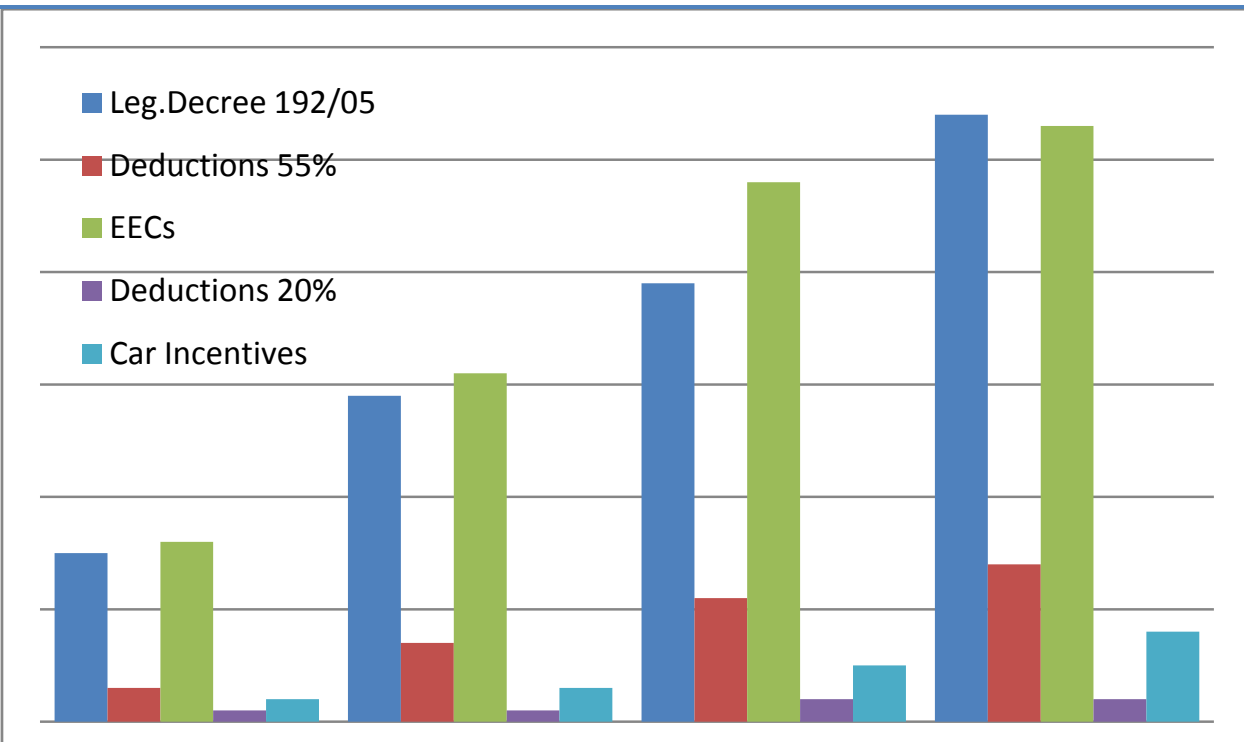

Note: Leg.Decree 192/05: minimum energy performance standards in Buildings; EEC: energy efficiency (or white) certificates Source: ENEA, 2011a

Table 28 shows the economic efficiency of incentive schemes. The economic efficiency assessment is based on the cost paid per unit of saved energy (e.g., $€ / \mathrm{kWh}$ saved) and refers both to the total investment and to the amount of public contribution. The data in the table demonstrate that not only does the mechanism of White Certificates (EEC) give the highest contribution in terms of saved energy, but it is also the most cost-effective. It is also worth mentioning that in Italy the share of rented houses is less than $20 \%$. Therefore, the problem of split incentives between tenants and home owners is relatively small.

Table 28 Economic efficiency of incentives

\begin{tabular}{lll}
\hline Measure & $\begin{array}{c}\text { Cost-effectiveness of total } \\
\text { investment }(\boldsymbol{\epsilon} / \mathbf{k W h})\end{array}$ & $\begin{array}{c}\text { Cost-effectiveness for the } \\
\text { government }(\boldsymbol{\epsilon} / \mathbf{k W h})\end{array}$ \\
\hline Leg. Decree 192/05 & 0.13 & 0.05 \\
\hline $\mathbf{5 5 \%}$ deductions & 0.10 & 0.002 \\
\hline $\mathbf{2 0 \%}$ deductions & 0.013 & 0.0012 \\
\hline EEC (White certificates) & Not available & 0.10 \\
\hline Car incentives & 0.82 & Noble \\
\hline
\end{tabular}

Note: Leg.Decree 192/05: minimum energy performance standards in Buildings; EEC: energy efficiency (or white) certificates Source: ENEA, 2011b

Overall the residential and tertiary sector has contributed significantly to the achievement of the EEAP 2007 targets. This has mainly been possible due to the implementation of Directive 2002/91/EC by updating the reference legislation, adjusting the relevant technical provisions and incentivising any intervention in this sector. In 1990 - 2009, the residential sector recorded the best results in terms of increase in energy efficiency: in 2009 an overall $23.9 \%$ increase in energy efficiency compared to 1990 was achieved, (ENEA 2011b).

The following conclusions can be drawn:

- Italy has a broad set of incentives to promote energy efficiency in buildings. The two most cost effective measures are considered to be the White certificates scheme and the Legislative Decree 192/05 on minimum energy performance of new and refurbished buildings. 
- Current incentives are not designed to promote deep retrofits of existing buildings, they rather focus on single measures, it means that a large potential for energy savings remains locked-in.

- The two economic instruments, the $55 \%$ tax deduction and the white certificate scheme, that have been the focus of this analysis, promote single measures in the buildings sector.

- Availability and quality of data could still pose a challenge for tracking policy implementation. Ideally, the base level data on types of buildings, their age, and energy Page | 135 consumption are needed.

- Italy has been successful in setting long-term and intermediate policy targets and carrying out an intermediate evaluation in 2010 to assess the actual rate of policy implementation and attainment of set targets. 


\section{Ireland: Home Energy Saving Scheme grants}

\section{Context}

Ireland has set a national target of $20 \%$ energy savings in 2020 adopted as part of the government's Energy Policy Framework 2007 to 2020 (DCENR 2007). The energy intensity, adjusted for PPP, of Ireland's economy is among the lowest in the IEA and has been declining steadily since 1990 at an average rate of 3\% per year, compared with an average decline rate in IEA countries of just $1.4 \%$ per year. Ireland's National Energy Efficiency Action Plan (NEEAP) updates and expands the 2007 Action Plan submitted to the European Commission (EC) in the context of the EU Energy Services Directive (DCENR 2009). The second Irish NEEAP was scheduled for submission to the EC in June 2011 and the Department of Communications, Energy, and Natural Resources has commenced work on a revised NEEAP, drawing together a steering group of departments and agencies that are involved in its implementation. There has also been consultation with stakeholders and industry on priorities for inclusion in the NEEAPP.

Between 2000 and 2008 the rate of energy efficiency improvement in Ireland was comparable with the EU with a progression of 9\% compared to an EU improvement of $8 \% .{ }^{124}$ Improvements in Ireland in the late 1990's were mainly due to increased efficiency in the industrial sector whereas the more recent improvements have largely been caused by the household sector. Such improvements are composed of the retrofitting of existing stock and large numbers of new houses which observe stricter building regulations, as well as fuel switching to oil and gas from solid fuels such as coal and wood.

According to NEEAP's Maximising Ireland's Energy Efficiency 2009-2020, the residential sector is the single sector that can make the most significant contribution towards projected energy savings in 2020. Dynamisation of standards for new buildings in Ireland includes improvement in energy performance of existing homes and ongoing revisions of regulations leading to energy use reductions in new homes. Revised regulations for new dwellings in 2008 improved on previous regulations (2002) by reducing theoretical energy demand of the typical new home by $40 \%$. A further $20 \%$ reduction was required in the most recent (2012) update to Regulations. Regulations now also include minimum levels of renewable energy supply per dwelling. Replacement boilers in existing dwellings must be more efficient than the regulated $90 \%$ minimum.

This case study will examine the Home Energy Saving Scheme (HES) and later the Better Energy Homes (BEH) scheme in the residential sector implemented by the Sustainable Energy Authority Ireland (SEAI).

The HES programme was evaluated by SEAI and the results published in September 2011 under the title Economic Analysis of Residential and Small-Business Energy Efficiency Improvements. This has been the basis for this case study with some updating and correspondence with SEAI.

\section{Home Energy Saving (HES) Scheme}

The Home Energy Saving (HES) scheme provided grants to householders for energy efficiency upgrades such as roof insulation, external wall insulation, dry-lining, and various other measures from 2008 until mid- 2011. HES became part of the Better Energy Homes scheme which was reopened on $8^{\text {th }}$ December 2011. This evaluation includes data up to end 2011. A list of measures for which grants could be awarded and the grant amounts are shown in Table 29.

\footnotetext{
${ }^{124}$ Energy Efficiency Profile: Ireland at www.odyssee-indicators.org
} 
Table 29 - Measures and grant amounts effective under the Home Energy Saving (HES) Scheme

\begin{tabular}{|c|c|c|c|c|c|}
\hline Measure & Category & 2009 & 2010 & 2011 & 2012 \\
\hline Roof & Roof Insulation & $€ 250$ & $€ 200$ & $€ 200$ & $€ 200$ \\
\hline \multirow[t]{9}{*}{ Wall } & Cavity wall insulation & $€ 400$ & $€ 400$ & $€ 400$ & $€ 250$ \\
\hline & Internal Wall Dry-Lining & $€ 2500$ & $€ 2500$ & $€ 2000$ & \\
\hline & - Apartment or mid-terrace house & & & & $€ 900$ \\
\hline & - Semi-detached or end of terrace & & & & $€ 1350$ \\
\hline & - Detached house & & & & $€ 1800$ \\
\hline & External wall insulation & $€ 4000$ & $€ 4000$ & $€ 4000$ & \\
\hline & - Apartment or mid-terrace house & & & & $€ 1800$ \\
\hline & - Semi-detached or end of terrace & & & & $€ 2700$ \\
\hline & - Detached house & & & & $€ 3600$ \\
\hline \multirow{4}{*}{$\begin{array}{l}\text { Heating } \\
\text { Controls }\end{array}$} & High Efficiency Gas or Oil fired Boiler with & $€ 700$ & $€ 700$ & $€ 560$ & $€ 560$ \\
\hline & Heating Controls Upgrade & & & & \\
\hline & Heating Controls Upgrade & $€ 500$ & $€ 500$ & $€ 400$ & $€ 400$ \\
\hline & Solar heating & & & $€ 800$ & $€ 800$ \\
\hline BER & A Before works and an After works BER & $€ 200$ & $€ 100$ & $€ 80$ & $€ 50$ \\
\hline Assessment & assessment must be completed & & & & \\
\hline
\end{tabular}

\section{Assessment of data}

The SEAI evaluation of the HES programme estimated the scheme to have delivered benefits to society of between $€ 106 \mathrm{~m}$ and $€ 518 \mathrm{~m}$ (taking into account all energy and $\mathrm{CO}_{2}$ price range scenarios). The SEAl estimates that for every euro invested in the scheme, a net benefit to society of five euros was delivered via energy, $\mathrm{CO}_{2}$, energy and other pollutant savings.

Participating households were expected to save an average of $€ 450$ per annum on energy bills. The payback time for investments on upgrade measures included in the scheme was expected to be around eight years.

\section{Effectiveness}

Impact on the market

One of the major outcomes of Government programmes promoting energy efficiency and renewable energy is to develop new markets for sustainable energy goods and services. In Ireland, the SEAI points to growing evidence of the development of markets for energy efficiency and renewable energy, with more than 4,000 registered service providers associated with the delivery of SEAI programmes to the residential and business sectors. This is a major increase over the past three to four years.

Up to mid-2012, nearly 130,000 homes were upgraded with a combination of these measures which represents 7.6 percent of the total occupied dwelling stock (1.7 million). Of the measures undertaken, roof and cavity wall insulation have been the most widespread, making up nearly $65 \%$ of all measures, particularly in 3 or 4-bedroom detached houses (see Table 30). After these two measures, the upgrade of gas boilers was the next most popular measure, particularly in apartments. 
Table 30 - Installed measures per dwelling type 2009/2010

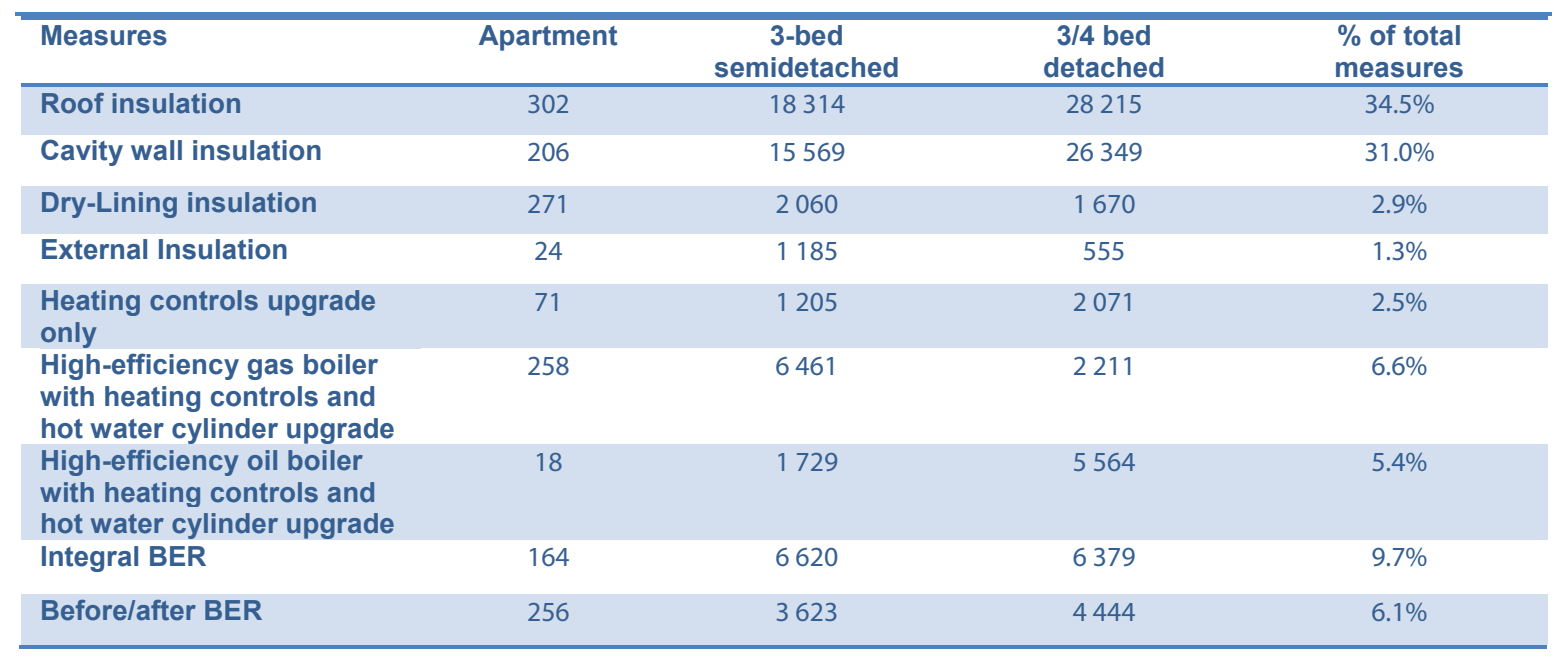

\section{Energy savings}

Energy savings from each measure were based on estimated data from the HES pilot scheme in $\mathrm{kWh} / \mathrm{m}^{2}$ and calculated for the programme annually (Table 31). The average improvement in energy performance per household in the programme is approximately $21 \%$.

Table 31 Estimated savings per year

\begin{tabular}{lccccc}
\hline & 2009 & 2010 & 2011 & Mid- 2012 & Total \\
\hline Energy savings & $90 \mathrm{GWh}$ & $253 \mathrm{GWh}$ & $262 \mathrm{GWh}$ & $100 \mathrm{Gwh}$ & $\mathbf{7 0 5} \mathrm{GWh}$ \\
No. of dwellings & 16344 & 45990 & 47594 & 18241 & 128169 \\
\hline
\end{tabular}

The energy savings are assumed to take into account estimates of "deadweight"125 (called freeridership in other case studies) but not the rebound effect. The total annual energy savings estimated attributable to the programme between the start of the programme in 2009 and the end June 2012 are $705 \mathrm{GWh}$. In 2012, the numbers participating have fallen somewhat, possibly due to the ongoing economic recession in Ireland or the reduction in grant amounts awarded which occurred in December 2011.

Cumulative energy savings after the assumed deadweight from the measures in 2009 and 2012 are 17250 (GWh) over a 30 year lifetime.

\section{Gross $\mathrm{CO}_{2}$ emissions saved}

$\mathrm{CO}_{2}$ emissions reductions of approximately 1.5 tonnes per dwelling per year are estimated due to reduced consumption of fossil fuels in the SEAI analysis (Scheer and Motherway, 2011). If the programme were to stop now, the buildings already renovated would continue to save $\mathrm{CO}_{2}$ emissions the total $\mathrm{CO}_{2}$ emissions saved over 30 years from 9 percent of the housing stock would achieve $4.3 \mathrm{Mt} \mathrm{CO}_{2}$ emissions.

\section{Rebound effect}

Since the start of the programme, a billing analysis of a sample of gas-heated homes in the programme has been carried out. The results show that the true savings are $36 \%$ lower for the sample than the original estimates (Scheer et al., 2012). This value could reflect either the

\footnotetext{
${ }^{125}$ Households which may have taken some measures, such as those listed in Table 2, without the scheme in place.
} 
rebound effect from building dwellers or bad installation practices so that the new equipment does not achieve the energy savings estimated in advance.

More investigation is needed to see whether the same is true for other fuels, particularly heat oil. It is very possible that there are significant differences in energy performance and behaviour in occupants of houses with different fuels, since different fuels may reflect the infrastructure and type of building. For example, it is more likely that a building fuelled by heating oil is a detached house, compared with a gas-fired heating system. It is not appropriate to assume the billing analysis results for gas-heated homes hold for other types of heating systems also. Therefore since a billing analysis has not been carried out on other fuels, the ex-ante engineering estimates of energy savings from the programme are used in these calculations.

\section{Free-ridership}

No free-ridership was documented but an estimate of $18 \%$ was assumed and included in the energy savings calculations.

\section{Economic efficiency}

The economic efficiency of a policy instrument comprises both static and dynamic efficiencies. The static efficiency of an instrument establishes whether the objectives are achieved at least cost compared to other policy instruments and requires a benefit-cost analysis. The dynamic efficiency determines the extent to which the policy promotes innovation and continuous improvements in energy efficiency.

\section{Public budget costs}

The annual cost to the public budget of this programme averaged EUR 39.7 million over 2009 to 2011; $6 \%$ of which was administrative costs (Table 32). The direct cost of subsidies for the three years of the programme to the end of 2011 was EUR 106 million (discounted) or $40 \%$ of the total Exchequer cost of the scheme. Other costs arise from the lost VAT and carbon tax due to the reduction in energy use of scheme participants. Inflows to the Exchequer include the value of $\mathrm{CO}_{2}$ savings on the basis of avoided need to purchase carbon credits ( $37 \%$ of benefits) and eventual inflow of VAT ( $50 \%$ of benefits) based on an estimated $70 \%$ return of participants' financial savings to the economy. VAT on works undertaken (after the deadweight adjustment) makes a further modest contribution to the Exchequer. Other public budget impacts such as reduced unemployment benefit paid out due to an increase in employment in the buildings sector have not been considered here.

Table 32 - Value of awarded tax credits = government revenue foregone (Euros)

\begin{tabular}{ccccc}
\hline Year & $\begin{array}{c}\text { SEAl grant spend } \\
\text { (EUR millions) }\end{array}$ & $\begin{array}{c}\text { Administrative costs } \\
\text { (EUR millions) }\end{array}$ & $\begin{array}{c}\text { Total public spend } \\
\text { (EUR millions) }\end{array}$ & $\begin{array}{c}\text { Private funds leveraged } \\
\text { (EUR millions) }\end{array}$ \\
\hline $\mathbf{2 0 0 9}$ & 16.2 & 1.0 & 17.2 & 31.0 \\
$\mathbf{2 0 1 0}$ & 45.2 & 2.7 & 47.9 & 75.1 \\
$\mathbf{2 0 1 1}$ & 57.7 & 3.5 & 61.2 & 103.8 \\
\hline
\end{tabular}

Table 33 shows the net present value of the cost of the energy savings. This adds the upfront public and private costs of the grant programme to the monetised energy savings over the lifetime of the energy efficiency measure (30 years). The measures subsidised were found to have a payback period of eight years on average and therefore after this period of time, net benefits from the measures begin to accrue. The value of the energy saved ( $€$ per $\mathrm{kWh}$ ) is estimated on the basis of average fuel prices for 2008, 2009, 2010, 2011 for the domestic sector and an assumed fuel mix for savings of $95 \%$ heating fuels ( $45 \%$ gas, $45 \%$ oil and $5 \%$ solid fuel) and $5 \%$ electricity, 
resulting from the technologies supported (i.e. insulation, high efficiency boilers and heating controls), as recorded by the Energy Policy Statistical Support Unit (EPSSU) of SEAI. ${ }^{126}$

Table 33 - Overview of Cost-Benefit Analysis results (including sensitivity analysis)

\begin{tabular}{|c|c|c|c|c|}
\hline \multirow[b]{2}{*}{$\begin{array}{l}\text { Scenario 1: Energy } \\
\text { savings only }\end{array}$} & \multirow{2}{*}{$\begin{array}{c}\text { cost per unit energy } \\
\text { saved }(€ \text { per kWh) } \\
-€ 0.022\end{array}$} & \multicolumn{3}{|c|}{$\begin{array}{c}\text { Societal NPV savings }(€ m) \text { over lifetime of technologies } \\
\text { installed }\end{array}$} \\
\hline & & $€ 370$ & $€ 149$ & $€ 6747$ \\
\hline $\begin{array}{l}\text { Scenario 2: Energy } \\
\text { and } \mathrm{CO}_{2} \text { savings }\end{array}$ & $-€ 0.026$ & $€ 441$ & $€ 213$ & $€ 890$ \\
\hline $\begin{array}{c}\text { Scenario 3: Energy, } \\
\mathrm{CO}_{2} \text { and other } \\
\text { pollutant savings }\end{array}$ & $-€ 0.028$ & $€ 481$ & $€ 253$ & $€ 929$ \\
\hline
\end{tabular}

Source: Scheer and Motherway 2011

The NPV can also be presented in terms of $\mathrm{CO} 2$ emissions saved and it is estimated that there is a net benefit to society of between $€ 85$ and $€ 110$ per tonne $\mathrm{CO} 2$ emissions abated (headline scenario).

\section{Policy interaction}

Benefits from the HES can be linked directly to jobs creation and support in areas such as supply, installation and project management of proposed improvements, householder comfort and areas of health through enhanced household living environment. However, detailed input-output tables are needed to carry you this estimation. SEAl estimates that $60 \%$ of overall expenditure is on labour. For 2010 this was estimated to be an expenditure of more than $€ 72$ million, sufficient to directly support 2000 full-time jobs, based on the average industrial wage. Including indirect jobs, this would equate to over 3000 jobs in 2010.

Other potential policy interactions are minimum energy performance standards and labelling and the requirement to have a building energy certificate at the time of buildings sale or rent. In Ireland, an energy-provider obligation is now in place and the BES could overlap in providing incentives to householders to renovate their buildings. This could effectively amount to subsidising the energy providers.

\section{Discussion}

The BES/HES has made a good start in getting householders to think about energy efficiency and implement energy efficiency measures. However, the improvement in energy performance achieved to date has been limited at around $20 \%$.

The BES/HES schemes have raised awareness of energy efficiency. This has been reinforced by the Buildings Energy Rating requirement for all residential buildings rented or sold in Ireland. It can be expected that capacity has been increased in the construction sector in energy efficiency retrofits as a result of the scheme.

Finance and regulation are needed to deepen the level of retrofit of residential buildings in Ireland. Eligibility for financing of EE retrofit should be tied to the building codes, i.e. comprehensive building energy requirements. Under the current buildings energy rating over 400 000 houses are rated F or $\mathrm{G}$ and another 200000 are rated E. SEAl estimates that at least 100000 houses need to be retrofitted at an average cost of $€ 10000 .^{127}$

\footnotetext{
${ }^{126}$ http://www.seai.ie/Publications/Statistics_Publications/Fuel_Cost_Comparison/

${ }^{127} \mathrm{http}: / /$ www.iiea.com/events/consumer-attitudes-to-retrofit-experiences-in-the-home-energy-saving-scheme
} 
Financing instruments to achieve the ambitious targets set out in the National Energy Efficiency Action Plan are currently under development. There are significant challenges facing policy makers in developing financial mechanisms to mobilise investment in low-energy buildings in Ireland. In the current recession, the construction sector and bank lending are at an all-time low. While EE retrofit provides opportunities to create employment in the construction sector, it is very difficult to obtain traditional debt finance for any purpose, including energy efficiency measures, from the banks. Also, following a crash in property prices, householders are unwilling to take on any debt.

Recent analysis has examined several Pay as You Save (PAYs) schemes and compared their viability with more traditional debt finance and the use of private savings (Maguire and Curtin, 2011). It is found that a well-designed PAYs would be most likely the best option, however it will not be easy to implement.

A good evaluation was published on the BES/HES that has increased transparency in the scheme. 


\section{Acronyms, abbreviations and units of measure}

\section{Acronyms and abbreviations}

ACEEE

ADEME

AEEG

ARRA

BEEP

BMU

BMVBS

BMWi

CDM

CFL

CIDD

$\mathrm{CO}_{2}$

$\mathrm{CO}_{2} \mathrm{e}$

DSIRE

E3G

EBRD

EC

ECEEE

ECO-PTZ

EE

EEEF

EIB

ENEA

EnEV

ESA

ESCO

EPC

EU

EU ETS

FEMP

GIS

GME

HDD

HVAC

IEA

IPEEC

JI

KfW

KfW EH

LED

LFI

MBCPFP
Assigned amount units

American Council for an Energy-Efficient Economy

French Agency for the Environment and Energy Governance

Italian Authority of Gas and Electricity

American Recovery and Reinvestment Act

Buildings Energy Efficiency Policies database

German Federal Ministry for the Environment, Nature Conservation and Nuclear Safety

German Federal Ministry of Transport, Building and Urban Development

German Federal Ministry of Economics and Technology

Clean Development Mechanism (under the Kyoto Protocol)

Compact fluorescent light bulbs

French Sustainable development tax credit (Crédit d'impôt développement durable)

Carbon dioxide

Carbon dioxide equivalents

US Database of State of State Incentives for Renewables and Efficiency

Third Generation Environmentalism

European Bank for Reconstruction and Development

European Commission

European Council for an Energy-Efficient Economy

French Eco-zero interest loan (Eco-Prêt à taux zero)

Energy efficiency

European Energy Efficiency Fund

European Investment Bank

Italian National Agency for New Technologies, Energy and sustainable economic development

German Energy Savings Ordinance

Energy Service Agreement

Energy Service Company

Energy Performance Contracting

European Union

European Union Emission Trading System

US Federal Energy Management Programme

Green investment schemes

Italian Manager of the Electricity Market

Heating Degree Days

Heating, ventilation and air conditioning

International Energy Agency

International Partnership on Energy Efficiency Cooperation

Joint Implementation (under the Kyoto Protocol)

German Kreditanstalt für Wiederaufbau

German KfW efficiency house standard

Light-emitting diode

Local financial institutions

French Ministry for the Budget, Public Accounting, Civil Service and Public Reforms 


$\begin{array}{ll}\text { MEDDTL } & \text { French Ministry for Ecology, Sustainable Development, Transport and Housing } \\ \text { MINEFI } & \text { French Ministry of Economy, Finance and Industry } \\ \text { MUSH } & \text { Municipal governments, universities, schools and hospitals } \\ \text { NEAP } & \text { Italian National Energy Efficiency Action Plan } \\ \text { NREL } & \text { US National Renewable Energy Laboratory } \\ \text { OECD } & \text { Organisation for Economic Cooperation and Development } \\ \text { PACE } & \text { Property Assessed Clean Energy } \\ \text { PEH } & \text { passive-energy houses } \\ \text { PEPDEE } & \text { Policies for Energy Provider Delivery of Energy Efficiency } \\ \text { POA } & \text { Programmes of Activities (under the Kyoto Protocol) } \\ \text { QECB } & \text { US Qualified Energy Conservation Bonds } \\ \text { SGFGAS } & \text { French Société de Gestion du Fonds de Garantie de l'Accession Social à la } \\ & \text { Propriété } \\ \text { SRI } & \text { Socially responsible investment } \\ \text { UNEP } & \text { United Nations Environment Programme } \\ \text { UNFCCC } & \text { United Nations Framework Convention on Climate Change } \\ \text { VAT } & \text { Value added tax } \\ \text { WEF } & \text { World Economic Forum } \\ \text { WhC } & \text { White certificates } \\ \text { ZEB } & \text { Zero energy buildings }\end{array}$

\section{Units of measure}

$\begin{array}{ll}\mathrm{EJ} & \text { exajoule } \\ \mathrm{Gt} & \text { gigatonne } \\ \mathrm{Gtoe} & \text { gigatonnes of oil equivalent } \\ \mathrm{GW} & \text { gigawatt } \\ \mathrm{GWh} & \text { gigawatt hour } \\ \mathrm{kWp} & \text { kilowatt-peak } \\ \mathrm{MtCO} & \text { megatonnes of carbon dioxide } \\ \mathrm{Mtoe} & \text { million tonnes of oil equivalent } \\ \mathrm{tCO}_{2} & \text { tonnes of carbon dioxide } \\ \mathrm{T} € & \text { thousand Euros } \\ \text { toe } & \text { tonnes of oil equivalent } \\ \mathrm{TWh} & \text { terawatt-hour }\end{array}$




\section{References}

ADEME (Agence de l'Environnement et de la Maitrise de l'Energie) (2011), Bâtiment Chiffres clés, ADEME, Valbonne, France, http://www2.ademe.fr/servlet/getDoc?cid=96\&m=3\&id=82617\&p1=30\&ref=12441

AECOM Australia Pty Ltd (2011), Green Loans: Review of householder perspectives, prepared for the Department of Climate Change and Energy Efficiency, Fortitude Valley, Australia, www.climatechange.gov.au/en/government/initiatives/ /media/government/initiatives/Gree nLoans-Review-20111231-PDF.pdf

AGF (Advisory Group on Climate Change Financing) (2010), "Carbon Market Public Revenues", Work Stream Paper 1, United Nations, New York, www.un.org/wcm/content/site/climatechange/pages/financeadvisorygroup/pid/13300

ANAO (Australian National Audit Office) (2010), Green Loans Program, Audit Report No. 9 201011, Commonwealth of Australia, Barton ACT, Australia, www.anao.gov.au/ /media/Uploads/Documents/2010\%2011_audit_report_no_9_.pdf

ASUE (Arbeitsgemeinschaft für sparsamen und umweltfreundlichen Energieverbrauch e.V) (2009), Die EnergieEinsparVerordnung EnEV, ASUE, Berlin

BBSR (Bundesinstitut für Bau-, Stadt- und Raumforschung) (2011), „,Struktur der Bestandsinvestitionen“, BBSR-Berichte Kompakt, Bundesamt für Bauwesen und Raumforschung, Bonn, www.bbsr.bund.de/nn_21272/BBSR/DE/Veroeffentlichungen/BerichteKompakt/2011/DL_12 2011,templateld=raw, property=publicationFile.pdf/DL_12_2011.pdf

Bell, C. J., S.Nadel and S. Hayes (2011), “On-bill financing for energy efficiency improvements: A review of current program challenges, opportunities, and best practices", Report Number E118, American Council for an Energy-Efficient Economy, Washington, D.C., http://aceee.org/research-report/e118

Bertoldi, PP. and S. Rezessy (2005), Energy Service Companies in Europe - Status Report 2005, European Commission Joint Research Centre, Institute for Environment and Sustainability, Luxembourg, http://publications.jrc.ec.europa.eu/repository/bitstream/111111111/15108/1/jrc59863\%20r eal\%20final\%20esco\%20report\%202010.pdf

Bharvirkar, R., C. Goldman, D. Gilligan, T. E. Singer, D. Birr, PP. Donahue, and S. Serota (2008), Performance Contracting and Energy Efficiency in the State Government Market, Ernest Orlando Lawrence Berkeley National Laboratory, Berkeley CA, http://eetd.Ibl.gov/EA/EMP/reports/lbnl-1202e.pdf

Blovenberg, A.L. (1999), "Green Tax Reforms and the Double Dividend: an Updated Reader's Guide", International Tax and Public Finance, 6, 421-443, Springer, Heidelberg.

Blyth, W. and R. Baron (2003), Green investment schemes: options and issues, OECD/IEA, Paris, http://www.oecd.org/dataoecd/48/54/19842798.pdf

BMVBS (Bundesministerium für Verkehr, Bau und Stadtentwicklung) (2011), Wohnen und Bauen in Zahlen 2010/2011, BMVBS, Berlin

BMWi/BMU (Bundesministerium für Wirtschaft und Technologie/ Bundesministerium für Umwelt, Naturschutz und Reaktorsicherheit) (2010), Energy Concept for an Environmentally Sound, Reliable and Affordable Energy Supply, BMWi/BMU, Berlin, www.bmwi.de/English/Navigation/Service/Publications/publications-archive,did=367764.html 
Bovenberg, A.L._(1999), “Green Tax Reforms and the Double Dividend: An Updated Reader's Guide", International Tax and Public Finance 6, 421-443, Springer, Heidelberg.

Brown, M.(2008), "State energy efficiency policies - Options and lessons learned", Funding for energy efficiency brief \#1, Alliance to Save Energy, Washington DC, http://ase.org/sites/default/files/file_Brief_1v3.pdf

Brown, J., B. Buchner, G. Wagner, and K. Sierra (2011), Improving the effectiveness of climate finance: a survey of leveraging methodologies. Available at: http://climatepolicyinitiative.org/wp-content/uploads/2011/11/Effectiveness-of-ClimateFinance-Methodology.pdf

Buchner, B., A. Falconer, M. Hervé-Mignucci, C. Trabacchi and M. Brinkman (2011), The landscape of climate finance, Climate Policy Initiative, Venice, http://climatepolicyinitiative.org/publication/the-landscape-of-climate-finance/

Buonicore, A. (2012), "Emerging Best Practice for Underwriting Commercially-Attractive Energy Efficiency Loans", Paper No 12-002 BEPAnews, April 20.

Burtraw, D. and I. Parry (2011), "Options for Returning the Value of CO2 Emissions Allowances to Households", RFF Discussion Paper 11-03, Resources for the Future, Washington DC. Available at: http://www.rff.org/rff/documents/RFF-DP-11-03.pdf

BPIE (Building Performance Institute Europe) (2010), Financing energy efficiency (EE) in buildings, BPIE, Brussels, http://www.bpie.eu/large_scale.html

Bundesministerium der Finanzen (BMF) (2011), Wirtschaftsplan des Klima- und Energiefonds Bundeshaushalt 2012 Einzelplan 60, BMF, Berlin, www.bundesfinanzministerium.de/bundeshaushalt2012/pdf/epl60/s6092.pdf

Caldecott, B. (2010), Green Infrastructure Bonds: Accessing the scale of low cost capital required to tackle climate change, Climate Change Capital Think Tank, London, www.climatechangecapital.com/media/172622/ccc\%20thinktank\%20\%20green\%20infrastructure\%20bonds\%20\%20accessing\%20the\%20scale\%20of\%20low\%20cost\%20capital\%20required\%20to\%20tackle \%20climate\%20change.pdf

CDP (Carbon Disclosure Project) (2011), CDP Carbon Action Initiative Summary Report, CDP, London, www.cdproject.net/CDPResults/CDP-Carbon-Action-Initiative-Summary-Report2011.pdf

CDC Climate (2012), "Financing the transition to a green economy: Their word is their (green) bond", Climate Brief no. 14, Caisse des Dépôts, Paris, www.cdcclimat.com/IMG/pdf/1205_climate_brief_14_-_financing_the_transition_to_a_green_economy_their_word_is_their_green_bond.pdf

Child R., O. Langniss, J. Klink, D. Gaudioso (2008), "Interactions of white certificates with other policy instruments in Europe", Energy Efficiency, Vol. 1, No. 4, pp. 283-295, Springer Science and Business Media

Clapp, C., Ellis, J., Benn, and J. Corfee-Morlot, J. (2012), Tracking climate finance: what and how? OECD, Paris. Available at: http://www.oecd.org/env/climatechange/50293494.pdf

Clausnitzer, K.-D., J. Gabriel, N. Diefenbach, T. Loga, W. Wosnoik (2007), Effekte des $\mathrm{KfW}-\mathrm{CO}_{2^{-}}$ Gebäudesanierungsprogramms 2005 und 2006, Bremer Energie Institut / Institut Wohnen und Umwelt GmbH / Institut für Statistik, Universität Bremen, Bremen/Darmstadt, www.iwu.de/fileadmin/user_upload/dateien/energie/klima_altbau/Monitoringbericht_2005_ 2006.pdf 
Clausnitzer, K.-D., J. Gabriel, N. Diefenbach, T. Loga, W. Wosnoik (2008), Effekte des $\mathrm{CO}_{2^{-}}$ Gebäudesanierungsprogramms 2007, Bremer Energie Institut / Institut Wohnen und Umwelt $\mathrm{GmbH}$ / Institut für Statistik, Universität Bremen, Bremen/Darmstadt, www.iwu.de/fileadmin/user_upload/dateien/energie/klima_altbau/Studie_Effekte_KfW_CO2_ Sanierungsprogramm2007.pdf

Clausnitzer, K.-D., J. Gabriel, S. Eilmes, N. Diefenbach, T. Loga, W. Wosnoik (2009), Effekte des $\mathrm{CO}_{2}$ Gebäudesanierungsprogramms 2008, Bremer Energie Institut / Institut Wohnen und Umwelt $\mathrm{GmbH}$ / Institut für Statistik, Universität Bremen, Bremen/Darmstadt, www.iwu.de/fileadmin/user_upload/dateien/energie/klima_altbau/Monitoringbericht_KfW_2 008.pdf

Clausnitzer, K.-D., M. Fette, J. Gabriel, N. Diefenbach, T. Loga, W. Wosnoik (2010), Effekte der Förderfälle des Jahres 2009 des $\mathrm{CO}_{2}$-Gebäudesanierungsprogramms und des Programms "Energieeffizient Sanieren", Bremer Energie Institut / Institut Wohnen und Umwelt GmbH / Institut für Statistik, Universität Bremen, Bremen/Darmstadt, www.iwu.de/fileadmin/user_upload/dateien/energie/klima_altbau/Studie_Effekte_KfW_CO2Sanierungsprogamm2009.pdf

Clausnitzer, K.-D., M. Fette, J. Gabriel (2011), Evaluation der KfW-Programme „KfWKommunalkredit - Energetische Gebäudesanierung", "Energieeffizient Sanieren - Kommunen" und "Sozial investieren - Energetische Gebäudesanierung" der Jahre 2007 bis 2010, Bremer Energie Institut, Bremen/Darmstadt, www.kfw.de/kfw/de/l/II/Download_Center/Fachthemen/Research/PDFDokumente_Evaluationen/55017_p_0.pdf

Consortium for Energy Efficiency (CEE) (2012), State of the efficiency program industry: budgets, expenditures, and impacts 2011, CEE, Boston, MA, www.cee1.org/files/2011\%20CEE\%20Annual\%20Industry\%20Report.pdf

Danish Ministry of Taxation (2009), Danish tax reform 2010, paper to the OECD WP2 meeting November 2009, www.skat.dk/getFile.aspx?ld=65278

Della Croce, R., C. Kaminker and F. Stewart (2011), "The role of pension funds in financing green growth initiatives", OECD Working Papers on Finance, Insurance and Private Pensions, No.10, OECD, Paris, http://dx.doi.org/10.1787/5kg58j1/wdjd-en

Department of Communications, Energy, and Natural Resources (DCENR) (2007), Delivering a Sustainable Energy Future for Ireland, Dublin, Ireland. Available at: http://www.dcenr.gov.ie/Energy/Energy+Planning+Division/Energy+White+Paper.htm

DCENR (2009), Maximising Ireland's Energy Efficiency 2009-2020: the National Energy Efficiency Action Plan, Dublin, Ireland. Available at:

http://www.dcenr.gov.ie/Energy/Energy+Efficiency+and+Affordability+Division/National+Ener gy+Efficiency+Action+Plan.htm

Crossley, D. and Swanson (2011), Effective Energy Efficiency Obligations, Presentation at IEA Workshop on Policies for Energy Provider Delivery of Energy Efficiency, December $12^{\text {th }}$, Sydney. http://www.iea.org/media/workshops/2011/aupedee/Crossley_Swanson.pdf

Diefenbach, N., T. Loga, J. Gabriel, M. Fette (2011), Monitoring der KfW-Programme "Energieeffizient Sanieren" 2010 und "Ökologisch / Energieeffizient Bauen" 2006-2010, Institut Wohnen und Umwelt GmbH, Bremer Energie Institut, Bremen/Darmstadt, www.kfw.de/kfw/de/l/II/Download_Center/Fachthemen/Research/PDFDokumente_Evaluationen/55016_p_0.pdf

Di Santo, D., D. Forni, V. Venturini, E. Biele (2011), "The white certificate scheme: the Italian experience and proposals for Improvement", European Council for an Energy Efficient Economy (ECEEE) Summer Study, http://www.eceee.org/conference_proceedings/eceee/ 
EC (European Commission) (2009), Energy saving obligations and tradable white certificates, Joint Research Centre of the European Commission, Ispra, Italy, http://ec.europa.eu/energy/efficiency/studies/doc/2009_12_jrc_white_certificates.pdf

EC (2011a), Scaling up international climate finance after 2012, European Commission, Brussels, http://ec.europa.eu/economy_finance/articles/financial_operations/pdf/sec_2011_487_final_ en.pdf

EC (2011b), Addressing the Rebound Effect, study by Global View Sustainability Services, BIO Intelligence Service and Ecologic Institute, European Commission Directorate General for Environment, Brussels, http://ec.europa.eu/environment/eussd/pdf/rebound_effect_report.pdf

EC (2012a), Financial Support for energy efficiency in buildings, consultation paper, European Commission Directorate General for Energy, Brussels, http://ec.europa.eu/energy/efficiency/consultations/20120518_eeb_financial_support_en.ht $\mathrm{m}$

EC (2012b), CIP Performance Report, EC, Brussels, http://ec.europa.eu/cip/files/docs/cip_performance_report_en.pdf

Eichholtz, PP. , N. Kok, and J. M. Quigley (2011), The Economics of Green Buildings. Working Paper No. W10-003, Program on Housing and Urban Policy, University of Berkeley.

ENEA (Agenzia nazionale per le nuove tecnologie, l'energia e lo sviluppo economico sostenibile) (2011a) Italian Energy Efficiency Action Plan, ENEA, Rome, http://www.buildupp. eu/publications/20812

ENEA (2011b), Energy Efficiency Annual Report 2010, ENEA, Rome, http://old.enea.it/com/ingl/New_ingl/publications/pdf/execRAEEinglese.pdf

Energy Charter (2004), Investing in Energy efficiency - Removing the barriers, Energy Charter Secretariat, Brussels, www.encharter.org/index.php?id $=166 \& \mathrm{~L}=0$

Enting, Katrin and Hendrikje Reich (forthcoming), Auctioning emission allowances to contribute to the USD 100 billion goal - European experiences, paper presented at the 2012 Lund Conference on Earth System Governance, www.lund2012.earthsystemgovernance.org/LC2012-paper165.pdf

EuroACE (European Alliance of Companies for Energy Efficiency in Buildings) (2010), Making money work for buildings - Financial and fiscal instruments for energy efficiency in buildings, EuroACE, Brussels, www.euroace.org/PublicDocumentDownload.aspx?Command=Core_Download\&Entryld=133

Fraunhofer ISI, Ecofys Germany GmbH, Öko-Institut e.V. (2012), Kosten-/Nutzen-Analyse der Einführung marktorientierter Instrumente zur Realisierung von Endenergieenisparungen in Deutschland, Karlsruhe/Berlin/Freiburg, www.bmwi.de/BMWi/Navigation/Service/publikationen, did=486790.html

Galvin, R. (2010), "Thermal upgrades of existing homes in Germany: The building code, subsidies, and economic efficiency", Energy and Buildings, Vol. 42, Elsevier, Amsterdam, pp. 834-844

Geller, H., PP. Harrington, A. H. Rosenfeld, F. Unander (2006), Policies for increasing energy efficiency: Thirty years of experience in OECD countries; Energy Policy 34, pp. 556-573

Giraudet, Louis-Gaëtan, Luc Bodineau and Dominique Finon (2011), "The costs and benefits of white certificate schemes", Energy Efficiency, Vol. 5, No.2, pp. 179-199, Springer Science and Business Media.

Glorioso, C., M. Lionetti, F. Presicce (2007), “Energy efficiency and renewable energy - Italy national study", Mediterranean and national strategies for sustainable development-Priority 
field of action 2: Energy and climate change, UNEP/Italian Ministry for the Environment and the Sea/ Plan Bleu,

http://www.planbleu.org/publications/atelier_energie/IT_National_Study_Final.pdf

Gold, R.and S. Nadel (2011), "Energy Efficiency Tax Incentives 2005-2011: How have they performed?", White Paper, American Council for an Energy-Efficient Economy, Washington, D.C., http://aceee.org/white-paper/energy-efficiency-tax-incentives

Grimes, A., T. Denne, PP. Howden-Chapman, R. Arnold, L. Telfar-Barnard, N. Preval and C. Young (2012), Cost-benefit Analysis of the Warm Up New Zealand: Heat Smart Programme, Ministry of Economic Development, New Zealand, www.med.govt.nz/sectors-industries/energy/pdfdocs-library/energy-and-the-environment/energy-efficiency/nzif-cba-report.pdf/view

Hamilton, B. (2011), "A Vermont Case Study and Roadmap to 2050", The Atlantic Energy Efficiency Policy Briefs, Earth Sciences Institute, Dublin, www.ucd.ie/earth/newsevents/latestnews/aeepolicybriefs

Hayes, S., S. Nadel, C. Granda and K. Hottel (2011) "What have we learned from energy efficiency financing programmes?", Report number U115, American Council for an Energy-Efficient Economy, Washington, D.C., http://aceee.org/research-report/u115

Heffner, G., PP. DuPont, G. Rybka (2012), Energy provider-delivered energy efficiency: An international review, paper submitted to the International Energy Program Evaluation Conference, 12 -14 of June 2012 in Rome

Heffner, G., E. Lees, D. Crossley, J. Migden-Ostrander (2012) ,Evaluating policies for energy provider-delivered energy efficiency, paper submitted to the European Council for an Energy Efficient Economy (ECEEE) Summer Study on Industry, 11.-14. September 2012, Arnhem, Netherlands

Heffner, G. and L. Ryan (2011) "Funding energy efficiency: earmarked environmental taxes versus system public benefit charges", Climate \& electricity annual - data and analysis, OECD/IEA, Paris, www.iea.org/w/bookshop/add.aspx?id=410

Hesser, T. G. (2012) "Is debt financing opening up for energy efficiency?" Research Note, Bloomberg New Energy Finance, 25 April 2012.

Hood, C. (2010), "Reviewing Existing and Proposed Emissions Trading Schemes", International Energy Agency Information Paper, OECD/IEA, Paris. Available at https://www.iea.org/publications/freepublications/publication/ets_paper2010.pdf.

Hood, C. (2011), "Summing up the Parts: combining policy instruments for least-cost climate mitigation strategies", Information Paper, OECD/IEA, Paris.

http://www.iea.org/publications/freepublications/publication/Summing_Upp. pdf

IEA (International Energy Agency) (2010a), Energy Technology Perspectives, OECD/IEA, Paris, www.iea.org/techno/etp/index.asp

IEA (2010b), "Energy performance certification of buildings", Policy Pathway Series, OECD/IEA, Paris, www.iea.org/papers/pathways/buildings_certification.pdf

IEA (2011a), "Joint Public-Private Approaches for Energy Efficiency Finance", Policy Pathway Series, OECD/IEA, Paris, www.iea.org/papers/pathways/finance.pdf

IEA (2011b), 25 Energy efficiency policy recommendations: 2011 Update, OECD/IEA, Paris, www.iea.org/papers/2011/25recom_2011.pdf

IEA (2012a), Energy Technology Perspectives, OECD/IEA, Paris

IEA (2012b), Energy Prices and Taxes: Quarterly Statistics, second quarter 2012, OECD/IEA, Paris 
IEA and AFD (2008), Promoting energy efficiency investments: Case studies in the residential sector, OECD/IEA, Paris, www.iea.org/w/bookshop/add.aspx?id=326

IEA and EBRD (European Bank for Reconstruction and Development) (2010), Energy Efficiency Governance, OECD/IEA, Paris, www.iea.org/publications/freepublications/publication/eeg.pdf

Kaminker C., and F. Stewart (2012), "The role of institutional investors in financing clean energy", OECD Working Papers on Finance, Insurance and Private Pensions, No. 23, OECD, www.oecd.org/finance/privatepensions/WP_23_TheRoleOfInstitutionallnvestorsInFinancingCl eanEnergy.pdf

Kats, G., A. Menkin, J. Dommu and M. DeBold (2011), Energy efficiency financing - Models and strategies, Capital E, Washington D.C., www.cap-e.com/Capital-

E/Energy_Efficiency_Financing.html

KfW (2012a), „Bauen, Wohnen, Energie sparen: Energieeffizient sanieren - Investitionszuschuss“, Merkblatt, Frankfurt am Main, www.kfw.de/kfw/de/I/II/Download_Center/Foerderprogramme/versteckter_Ordner_fuer_PD F/6000002245_M_430.pdf

KfW (2012b), „Bauen, Wohnen, Energie sparen: Energieeffizient sanieren - Kredit“, Merkblatt, Frankfurt am Main, www.kfw.de/kfw/de/I/II/Download_Center/Foerderprogramme/versteckter_Ordner_fuer_PD F/6000002214_M_151_152.pdf

Kleemann, M. and PP. Hansen (2005), Evaluierung der CO2-Minderungsmassnahmen im Gebäudebereich, Forschungszentrum Jülich, Jülich, http://juwel.fzjuelich.de:8080/dspace/bitstream/2128/441/1/Umwelt_60.pdf

Kuckshinrichs, W., PP. Hansen and T. Kronenberg (2009), Gesamtwirtschaftliche CO2Vermeidungskosten der energetischen Gebäudesanierung und Kosten der Förderung für den Bundeshaushalt im Rahmen des CO2-Gebäudesanierungsprogramms, Jülich Foschungszentrum (IEK-STE), Jülich, www.kfw.de/kfw/de/I/II/Download_Center/Fachthemen/Research/PDFDokumente_Evaluationen/33807_p_0.pdf

Kuckhinrichs, W., T. Kronenberg, PP. Hansen (2010), The social return on investment in the energy efficiency of buildings in Germany, Energy Policy 38, pp. 4317-4329.

Kuckshinrichs, W., T. Kronenberg and PP. Hansen (2011), Wirkungen der Förderprogramme im Bereich "Energieeffizientes Bauen und Sanieren" der KfW auf die öffentlichen Haushalte, Forschungszentrum Jülich (IEK-STE), Jülich www.kfw.de/kfw/de/l/II/Download_Center/Fachthemen/Research/PDFDokumente_Evaluationen/53915_p_0.pdf

Larsen, Peter H., Charles A. Goldman and Andrew Satchwell (2012), Evolution of the U.S. Energy Service Company industry: market size and project performance from 1990-2008, Ernest Orlando Lawrence Berkley National Laboratory, Berkeley CA, http://eetd.lbl.gov/ea/emp/reports/lbnl-5447e.pdf

Lawrence Berkeley National Laboratory (LBNL) (2011), "Using Qualified Energy Conservation Bonds (QECBs) to fund a residential energy efficiency loan program: case study on Saint Louis County, MO", Clean Energy Financing Policy Brief, LBNL, Berkeley CA, http://eetd.lbl.gov/ea/emp/reports/ee-policybrief_062011.pdf

Lees, E. (2012), Results to Date from Existing EU Obligations on Energy Providers, Presentation at PEPDEE EU Regional Policy Dialogue, January 18th, Brussels.

http://www.iea.org/media/workshops/2012/pepdeebrussels/LeesSession2Resultsfromexisting EUobligationsonenergyproviders.pdf 
Madlener, R., and M. Hauertmann (2011), Rebound effects in German residential heating: Do ownership and income matter?, Institute for Future Energy Consumer Needs and Behaviour, E.ON Energy Research Centre and RWTH Aachen University, Aachen, www.eonerc.rwthaachen.de/global/show_document.asp?id=aaaaaaaaaacgaxc

Maguire, J. and J. Curtin (2011), Thinking Deeper: Financing options for deeper retrofit, SEAI, Ireland. Available at: http://www.iiea.com/publications/thinking-deeper-financing-options-forhome-retrofit

Marbek and Navigant (2010), Impact Attribution of Industrial, Commercial and Institutional Energy Efficiency Programmes, pp. 35.

http://www.merx.com/English/supplier menu.asp?WCE=Show\&TAB=1\&PORTAL=MERX\&State $=7 \&$ id $=161003 \&$ FED ONLY=0\&hcode=0j0ZFfYh\%2FJFwuefm8Jb2PA\%3D\%3D

Marino, A., PP. Bertoldi, S. Rezessy and B. Boza-Kiss (2010), Energy Service Companies Market in Europe - Status Report 2010, European Commission, Joint Research Centre, Institute for Energy, Ispra, Italy, http://iet.jrc.ec.europa.eu/energyefficiency/sites/energyefficiency/files/escos-market-ineurope_status-report-2010.pdf

MEDDTL (Ministère de l'Ecologie,du Développement Durable, des Transports et du Logement), MINEFI (Ministère de l'Economie, des Finances et de l'Industrie), MBCPFP (Ministère du Budget, des Comptes Publiques, de la Fonction Publique et de la Réforme de l'Etat), ADEME (2011), "Synthese de l'évaluation du credit d'impot développement durable", Rapport du comité d'évaluation des dépenses fiscales et des niches sociales - Annexe $D$, Ministère de I'Economie, des Finances et de l'Industrie, Paris, www.economie.gouv.fr/economie/rapportcomite-d\%E2\%80\%99evaluation-des-depenses-fiscales-et-des-niches-sociales

MINEFI (2011), "Dépense fiscale no. 210321: Eco-prêt à taux zéro", Rapport du comité d'évaluation des dépenses fiscales et des niches sociales - Annexe J-Fiches, 173-DF210321, MINEFI, Paris, www.economie.gouv.fr/economie/rapport-comite-d\%E2\%80\%99evaluationdes-depenses-fiscales-et-des-niches-sociales

Morel, R. and A. Delbosc (2012), Assessing the financial efficiency of the Green Climate Fund: leverage ratios - from theory to practice, Point Climat No. 19, CDC Climate Research, Caisse des Depots Group, France. Available at: http://www.cdcclimat.com/IMG//pdf/12-0910_climate_brief_no19_-_leverage.pdf

Neuhoff, K., H. Amecke, A. Novikova, K. Stelmakh, J. Deason, and A. Hobbs (2011), Using Tax Incentives to Support Thermal Retrofits in Germany, Climate Policy Initiative, Berlin. http://climatepolicyinitiative.org/wp-content/uploads/2011/12/Policies-Supporting-ThermalEfficiency-in-Germanys-Building-Sector.pdf

Neuhoff, K., K.Stelmakh, H.Amecke, A. Novikova, J.Deason, and A.Hobbs (2011), "Financial Incentives for Energy Efficiency retrofits in Buildings", German Institute for Economic research and Climate Policy Initiative http://www.aceee.org/files/proceedings/2012/data/papers/0193000422.pdf

Newell, G., J. McFarlane, N. Kok (2011), Building better returns - A study of the financial performance of green office buildings in Australia, The Australian Property Institute, Sydney and Property Funds Association, Flinders Land, Australia, www.api.org.au/assets/media_library/000/000/219/original.pdf?1315793106

Nishida, Y. and Y. Hua (2011), “Motivating stakeholders to deliver change: Tokyo's cap-and-trade program", Building Research and Information, Vol. 39/5, ppp. 518-533, www.tandfonline.com/doi/abs/10.1080/09613218.2011.596419\#preview

NRCan (Natural Resources Canada) (2010), Evaluation of Energy Efficiency for Industry, Housing and Buildings, http://www.nrcan.gc.ca/evaluation/reports/2010/2827. 
NRCan Office of Energy Efficiency (2012a), Energy Efficiency Trends in Canada 1990 to 2009, http://oee.nrcan.gc.ca/publications/statistics/trends11/index.cfm?attr=0

NRCan Office of Energy Efficiency (2012b), Improving Energy Performance in Canada - Report to Parliament Under the Energy Efficiency Act For the Fiscal Year 2010-2011, http://oee.nrcan.gc.ca/publications/statistics/parliament10-11/index.cfm.

NRCan Office of Energy Efficiency (2012c), Personal communication.

NREL (National Renewable Energy Laboratory) (2011), Economic impacts from the Boulder County, Colorado ClimateSmart loan program: Using property-assessed clean energy (PACE) financing, NREL, Golden Colorado, www.nrel.gov/docs/fy11osti/52231.pdf

O'Donnell, Arthur and Brittany Gibson (2012), The U.S. Energy Service Company market - energy performance contracting and energy efficiency for the MUSH, federal, industrial, commercial, and public building markets, PikeResearch, Boulder, CO, USA, www.pikeresearch.com/research/the-u-s-energy-service-company-market

OECD (Organisation for Economic Cooperation and Development) (2006), The political economy of environmentally related taxes, $\mathrm{OECD}$, Paris.

OECD (2010a), Tax Expenditures in OECD Countries, OECD, Paris.

OECD (2010b), Taxation, Innovation and the Environment, OECD, Paris.

OECD (2011a), Environmental taxation: a guide for policy makers, OECD, Paris, www.oecd.org/dataoecd/17/7/48164926.pdf

OECD (2011b), Inventory of estimated budgetary support and tax expenditures for fossil fuels: preliminary version, OECD, Paris, www.oecd.org/dataoecd/40/35/48805150.pdf

OECD (2011c), "Interactions between emission trading systems and other overlapping policy instruments", General Distribution Document, Environment Directorate, OECD, Paris, www.oecd.org/fr/environnement/outilsetevaluationdespolitiquesdelenvironnement/4818889 9.pdf

OECD (2012), OECD Environmental Outlook to 2050, OECD, Paris, www.oecd.org/document/11/0,3746,en_2649_37465_49036555_1_1_1_37465,00.html

Pasquier, S. and A. Saussay (2012), Progress implementing the IEA 25 energy efficiency policy recommendations: 2011 evaluation, IEA Insights Paper Series, OECD/IEA, Paris, www.iea.org/publications/insights/progress_implementing_25_ee_recommendations.pdf

Pavan, M. (2009), "Distributor obligations and White Certificates in Italy", presentation at the JRC Workshop on White Certificates, Utility and Supplier Obligations, 31 March - 1 April 2009

Plan Bâtiment Grenelle (2011), Pour une meilleure efficacité des aides à la performance énergétique des logements privés, MEDDTL, Paris, www.legrenelleenvironnement.fr/Presentation-officielle-du-rapport.html

Renewable Funding, Clinton Climate Initiative, Lawrence Berkeley National Laboratory (LBNL)(2011), Property Assessed Clean Energy (PACE) Financing: Update on Commercial Programs, LBNL, Berkeley, http://eetd.Ibl.gov/ea/ems/reports/pace-pb-032311.pdf

Rudolph, S. and T. Kawakatsu (2012), "Tokyo's greenhouse gas emission trading scheme - A model for sustainable megacity carbon markets?", Joint Discussion Paper Series in Economics of the universities of Aachen, GieBen, Göttingen, Kassel, Marburg, Siegen, No. 25-2012, Philipps-University, Marburg, Germany, www.unimarburg.de/fb02/makro/forschung/magkspapers/25-2012_rudolph.pdf

Ryan, L., S. Moarif, E. Levina, R. Baron (2011), "Energy efficiency policy and carbon pricing”, IEA Information Paper, OECD/IEA, Paris, www.iea.org/papers/2011/EE_Carbon_Pricing.pdf 
Ryan, L. and N. Campbell (2012), "Spreading the net: the multiple benefits of energy efficiency improvements", IEA Insights Paper Series, OECD/IEA, Paris, www.iea.org/publications/insights/ee_improvements.pdf

Rezessy, S. and P. Bertoldi (2010), Financing energy efficiency: forging the link between financing and project implementation, European Commission Joint Research Centre, Ispra, Italy, http://ec.europa.eu/energy/efficiency/doc/financing_energy_efficiency.pdf

Robins, N. and Z. Knight (2012), Bonds and climate change: the state of the market in 2012, HBSC Global Research, London, www.research.hsbc.com/midas/Res/RDV?ao=20\&key=2za2M1a3ty\&n=330639.PDF

Satchwell, A., C. Goldman, PP. Larsen, D. Gilligan and T. Singer (2010), A survey of the U.S. ESCO industry: market growth and development from 2008-2011, Ernest Orlando Lawrence Berkley National Laboratory, Berkeley CA, http://eetd.Ibl.gov/ea/ems/reports/Ibnl-3479e.pdf

Scheer, J. and B. Motherway (2011), Economic Analysis of Residential and Small-Business Energy Efficiency Improvements, Sustainable Energy Authority of Ireland (SEAI) Report, Dublin, Ireland.

Scheer, J., M. Clancy, and S. Ní Hógáin (2012), Quantification of energy savings from Ireland's Home Energy Saving scheme: an ex post billing analysis", Energy Efficiency, Volume 5 Issue 1, Springer, the Netherlands.

Schimschar, S., K. Blok, T. Boermans, A. Hermelink (2011), "Germany's path towards nearly zeroenergy buildings: Enabling the greenhouse gas mitigation potential in the building stock", Energy Policy, Vol. 39, Elsevier, Amsterdam, ppp. 3346-3360.

Schumpeter, J. A. (1942), Capitalism, Socialism, and Democracy, Harper and Brothers, New York.

Sedano, R. (2011), Who Should Deliver Ratepayer-Funded Energy Efficiency? A 2011 Update, The Regulatory Assistance Project, Vermont, US, http://raponline.org/document/download/id/4707

Seifried, D., E. Richter, R. Schüle (2009), "Improving energy efficiency for low-income families", Summer Study, European Council for an Energy-Efficient Economy, www.eceee.org/conference_proceedings/eceee/2009/

Singh, J., D. R. Limaye, B. Henderson, and X. Shi (2010), Public procurement of energy efficiency services: Lessons from international experience, IBRD/ The World Bank, Washington D.C.

Sustainable Energy Authority of Ireland (2009), Ireland's Low-Carbon Opportunity, Dublin, Ireland.

Sweatman, PP. and K. Managan (2010), Financing Energy Efficiency Building Retrofits: International Policy and Business Model Review and Regulatory Alternatives for Spain, Climate Strategy and Partners, Madrid, Spain. Available at: http://www.climatestrategy.es/index.php?id=19

Thorne, J. (2003), Residential Retrofits: Directions in Market Transformation, ACEEE, ppp. 10-11.

Togeby, M., K. Dyhr-Mikkelsen, A. Larsen, M.J. Hansen, Peter Bach (2009), “Danish energy efficiency policy: revisited and future improvements", Summer Study, Panel 2: policy implementation, European Council for an Energy Efficient Economy (ECEEE), La Colle sur Loup, France, www.eceee.org/conference_proceedings/eceee/2009/Panel_2/2.043/paper

T'Serclaes, P. de (2010), "Money matters: Mitigating risk to spark private investments in energy efficiency", IEA Information Paper, OECD/IEA, Paris, www.iea.org/papers/efficiency/money_matters.pdf

Tuerk, A., M. Sharmina, J. Geiler, L. Qiao (2008), Green Investment Schemes: Maximizing their benefit for climate and society, Joanneum Research, Graz, Austria and Central European 
University, Budapest, Hungary,

www.ceu.hu/sites/default/files/field_attachment/project/node-3349/gisfullreport.pdf

Tuerk, A., D. Frieden, M. Sharmina, H. Schreiber and D. Ürge-Vorsatz (2010), Green investment schemes: first experiences and lessons learned, Joanneum Research, Graz, Austria and Central European University, Budapest, Hungary, http://3csepp. ceu.hu/node/15675

UN-AGF (2010), Workstream 7 Paper: Public intervention to stimulate private investment in adaptation and mitigation. Available at: http://www.un.org/wcm/webdav/site/climatechange/shared/Documents/AGF_reports/Work _Stream_7\%20_Public_Private.pdf

UNEP (United Nations Environment Programme) (2007), Assessment of policy instruments for reducing greenhouse gas emissions from buildings, Report for the UNEP-Sustainable Buildings and Construction Initiative, Budapest, www.unep. org/themes/consumption/pdf/SBCl CEU Policy Tool Report.pdf

UNEP (2012), Cities and Carbon Finance: A feasibility study on an urban CDM, UNEP, www.unepp. org/urban_environment/PDFs/UNEP_UrbanCDMreport.pdf

United States Department of Energy (US DoE) (2010), Clean energy finance guide for residential and commercial building improvements - third edition, US DoE, www4.eere.energy.gov/wip/solutioncenter/finance_guide/content/chapter_documents

WBCSD (World Business Council for Sustainable Development) (2007), Energy Efficiency in Buildings: Business realities and opportunities, WBCSD, Conches-Geneva/Washington, DC, www.wbcsd.org/Pages/EDocument/EDocumentDetails.aspx?ID=13559\&NoSearchContextKey= true

WEC (World Energy Council) (2010), Energy Efficiency: A Recipe for Success, WEC, London, www.worldenergy.org/documents/fdeneff_v2.pdf

WEC (2011), Policies for the future: 2011 assessment of country energy and climate policies, www.worldenergy.org/documents/wec_2011_assessment_of_energy_and_climate_policies.p df

WEF (World Economic Forum) (2011), A profitable and resource efficient future: Catalysing retrofit finance and investing in commercial real estate, WEF, Geneva, www.weforum.org/reports/profitable-and-resource-efficient-future-catalysing-retrofitfinance-and-investing-commercia 


\section{iea}

\section{International Energy Agency}
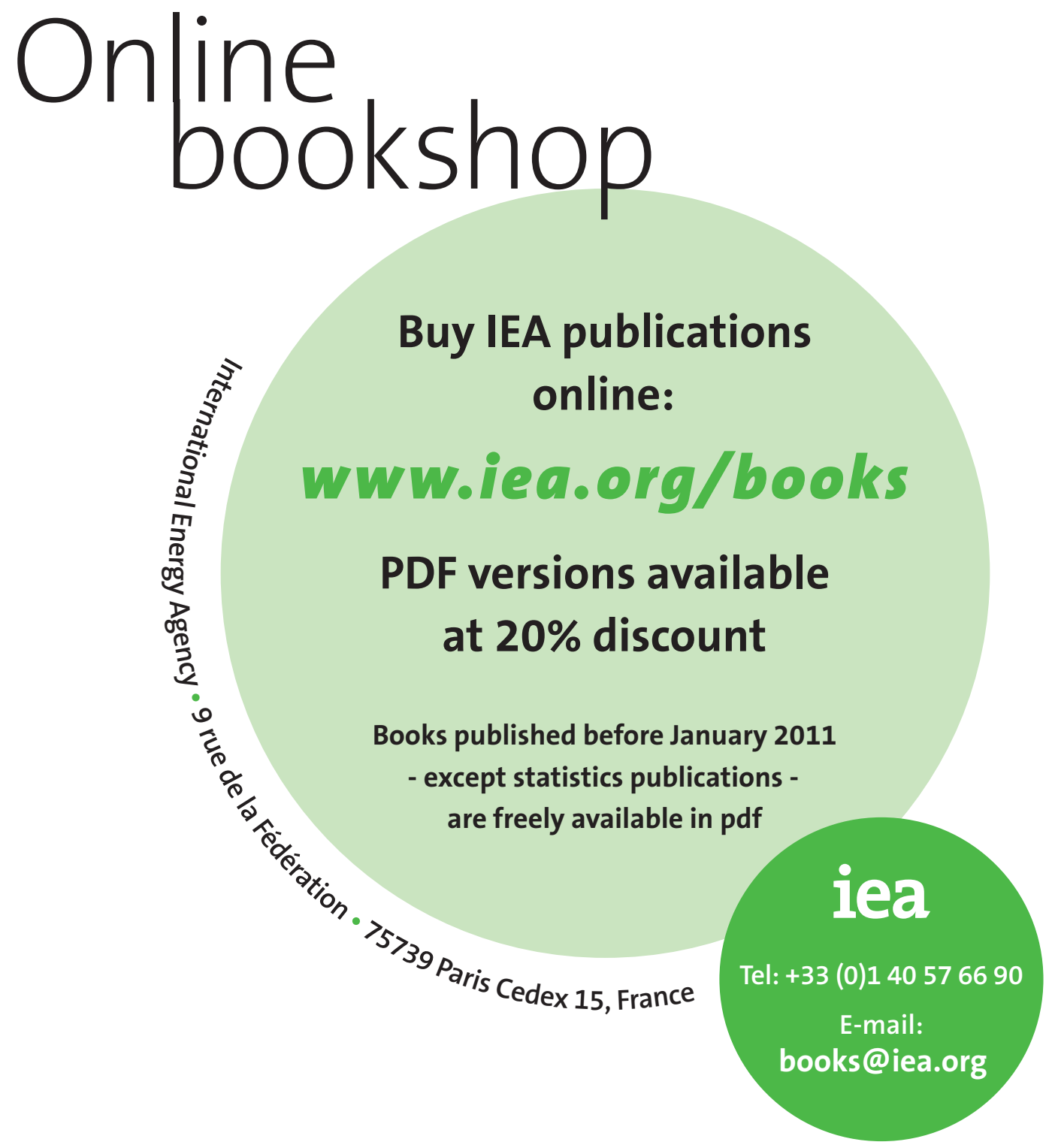